\title{
Drought stress response of tetraploid hybrid aspen \\ (Populus tremula L. x P. tremuloides Michx.) \\ of protoplast fusion experiments
}

\author{
Dissertation \\ zur Erlangung des mathematisch-naturwissenschaftlichen Doktorgrades \\ “Doctor rerum naturalium” \\ der Georg-August-Universität Göttingen \\ im Promotionsprogramm "Molekulare Wissenschaften und \\ Biotechnologie von Nutzpflanzen (BIONUTZ)” \\ der Georg-August University School of Science (GAUSS)
}

Vorgelegt von

Anne Hennig

aus Böblingen

Göttingen, 2015 


\section{Betreuungsausschuss}

Prof. Dr. Andrea Polle, Büsgen-Institut, Abteilung Forstbotanik und Baumphysiologie, Universität Göttingen

Prof. Dr. Reiner Finkeldey, Büsgen-Institut, Abteilung Forstgenetik und Forstpflanzenzüchtung, Universität Göttingen

PD Dr. Thomas Teichmann, Schwann-Schleiden Zentrum, Abteilung Zellbiologie der Pflanze, Universität Göttingen

\section{Mitglieder der Prüfungskommission}

Referentin: Prof. Dr. Andrea Polle, Büsgen-Institut, Abteilung Forstbotanik und Baumphysiologie, Universität Göttingen

Korreferent: Prof. Dr. Reiner Finkeldey, Büsgen-Institut, Abteilung Forstgenetik und Forstpflanzenzüchtung, Universität Göttingen

\section{Weitere Mitglieder der Prüfungskommission}

PD Dr. Matthias Fladung, Thünen-Institut, Institut für Forstgenetik, Arbeitsbereich Genomforschung, Thünen-Institut Braunschweig; Mitglied des Lehrkörpers der Universität Hamburg

Prof. Dr. Petr Karlovsky, Abteilung Molekulare Phytopathologie and Mykotoxinforschung, Universität Göttingen

Prof. Dr. Norbert Lamersdorf, Büsgen-Intitut, Abteilung Ökopedologie der gemäßigten Zonen, Universität Göttingen

PD Dr. Thomas Teichmann, Schwann-Schleiden Zentrum, Abteilung Zellbiologie der Pflanze, Universität Göttingen 


\section{Acknowledgement}

I would like to express my gratitude to a large number of people who supported me during the last years and therefore contributed to the completion of my dissertation. First of all, I thank Prof. Dr. Andrea Polle for giving me scientific advice and guidance and thereby enabling me to create this dissertation.

I would like to thank Prof. Dr. Reiner Finkeldey for examining my thesis as second supervisor and for being a member of my thesis and examination committee.

I am thankful to PD Dr. Thomas Teichmann for giving me scientific support when questions occurred and also for attendance to my thesis and examination committee.

Furthermore, I am very greatful to PD Dr. Matthias Fladung, to Prof. Dr. Norbert Lamersdorf and to Prof. Dr. Petr Karlovsky for attending my examination committee.

I appreciate the financial support by the "Fachagentur Nachwachsende Rohstoffe e.V." within the project "ZÜEND - Züchtung neuer Energiepappeln für Deutschland" (FKZ 22005010).

I am very thankful to Dr. Sonja Löffler for supporting me with the biochemical analyses. Moreover, I thank Dres. Jochen Kruppa, Klaus Jung, Andreas Leha from the Core Facility Medical Biometry and Statistical Bioinformatics (Department of Medical Statistics, University of Göttingen), Dres. Gabriela Salinas-Richter and Claudia Pommerenke from the DNA Microarray and Deep-Sequencing Facility (Göttingen) and Prof. Dr. Konstantin Krutovsky from the Forest Genetics Department for cooperation and helpful discussions and Dr. Nathaniel Street for kindly providing the contigs for the genome analyses.

I am especially greatful to all of my colleagues of the department Forest Genetic Resources of the Northwest German Forest Research Institute, Hann. Münden, for the nice working atmosphere and support whenever needed. I particularly thank Dr. Jörg Kleinschmit for scientific advice, lively discussing questions and support at any time. Furthermore, I especially thank Dagmar Leisten for constantly helping and supporting me throughout the last years. I highly appreciate technical assistance by Silvia Köhler and Tina Wetzel within and also beyond the project ZÜEND. Moreover, I would like to thank Steffen Fehrenz for inspiring discussions, for raising new research questions and realizing them in experiments. I thank Dr. Alwin Janßen for advice and support through the last years. I am especially greatful to Sergej Havel who helped me with the microsatellite analyses, to Christoph Stiehm, Dr. Meik Meißner and Dr. Wilfried Steiner for discussions also apart from work. I am greatful to Irene Wenzlitschke, 
Ngoc Tuan Pham and Dr. Andreas Meier-Dinkel for help in the lab and to all other colleagues who supported me although not mentioned by name.

I would like to thank all colleagues from the Forest Botany department who warmly welcomed me especially Dr. Bettina Otto, PhD Dennis Janz, Kristina Schröter, Mareike Kafka, Michaela Rath, Dr. Anna Müller, Christine Kettner, Shanty Paul, Dr. Nicole Brinkmann, Dr. Henning Wildhagen, Merle Fastenrath, Lisa Kins, Silke Ammerschubert and Edy Nur. Furthermore, I would like to thank PhD Dennis Janz for answering questions in association with the genome analysis and Dr. Bettina Otto for critical review of my thesis. I am also very greatful to Christine Kettner, Merle Fastenrath and Shanty Paul for technical advice with the microscope and porometer.

Finally, I would like to thank all my friends for support beyond the dissertation. I am very thankful to my parents who greately supported me whenever I needed help. Furthermore, I am very greatful to Sebastian for practical assistance with statistics, $\mathrm{R}$ and formatting but especially for encouraging and believing in me. 


\section{List of contents}

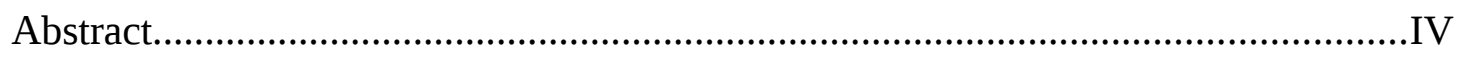

Zusammenfassung..........................................................................................

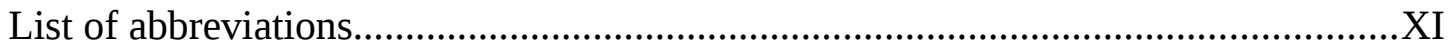

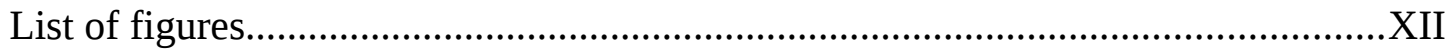

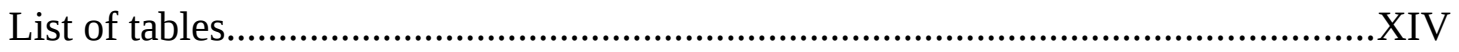

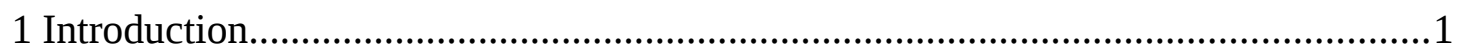

1.1 Drought as an environmental threat for plants....................................................

1.2 Genome duplication and copy number variation in plants....................................

1.3 Polyploidy and its effects on stress tolerance in plants........................................ 4

1.4 Characterization of Populus tremula (L.) x P. tremuloides (Michx.)....................6

1.5 Somatic hybridization of hybrid aspen.............................................................

1.6 Energy demand and biomass production...........................................................

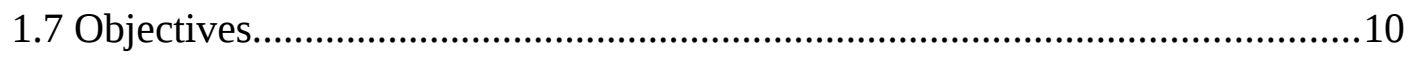

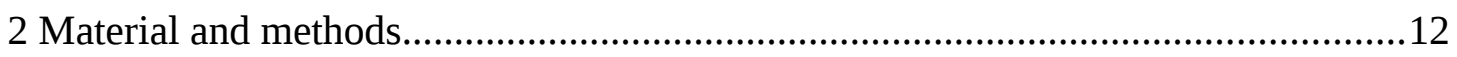

2.1 Plant material............................................................................................

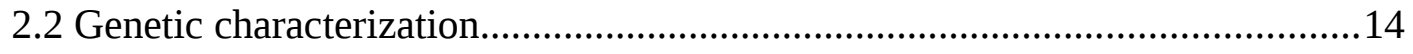

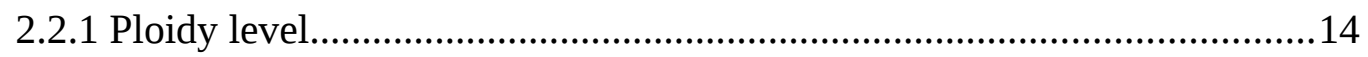

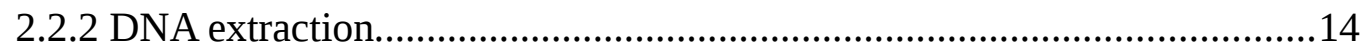

2.2.3 Nuclear simple sequence repeats analysis.................................................15

2.2.4 Whole genome sequencing and annotation................................................15

2.3 Experimental design..................................................................................

2.3.1 Experiment 1........................................................................................

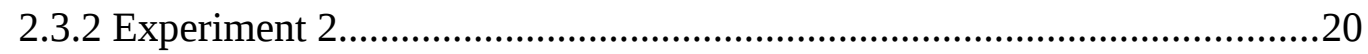

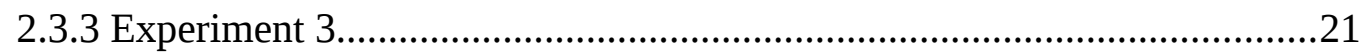

2.4 Investigated parameters....................................................................................23

2.4.1 Leaf and stomata morphology ...................................................................23

2.4.2 Height, stem biomass, relative height and stem biomass increment..........23

2.4.3 Total leaf area and leaf mass per area......................................................24

2.4.4 Relative soil moisture, water consumption and leaf vitality.......................25

2.4.5 Relative leaf water content and stomatal conductance................................26 


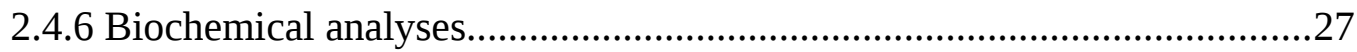

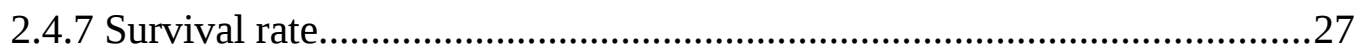

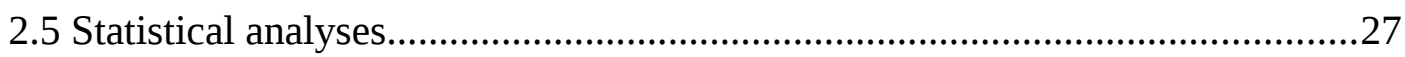

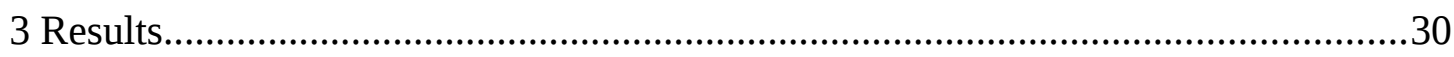

3.1 Morphological and drought stress characterization of the diploid original line and tetraploid fusion lines of hybrid aspen.....................................................30

3.1.1 Morphological characterization of hybrid aspen lines.............................30

3.1.2 Drought stress characterization of hybrid aspen lines.............................34

3.2 Drought performance of 20 hybrid aspen fusion lines and detailed drought responses of selected tetraploid hybrid aspen lines.

3.2.1 Screening of hybrid aspen lines of different ploidy level for drought performance and morphological traits..............................................42

3.2.2 Detailed drought responses of selected tetraploid hybrid aspen lines.......51

3.3 Whole genome sequencing of selected hybrid aspen fusion lines.....................64

3.3.1 Overview of detected copy number variations........................................64

3.3.2 Copy number variations altered with regard to the diploid original line...65

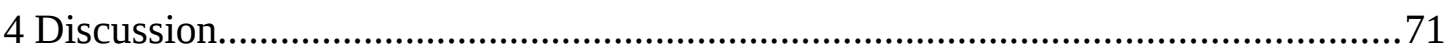

4.1 Morphological and drought stress characterization of the diploid original line and tetraploid fusion lines of hybrid aspen...................................................71

4.1.1 Morphological characterization of hybrid aspen lines..............................71

4.1.2 Drought stress characterization of hybrid aspen lines.............................72

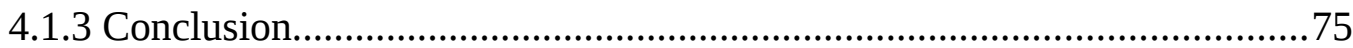

4.2 Drought performance of diploid "fusion” and tetraploid fusion lines and detailed drought responses of selected tetraploid fusion lines..........................76

4.2.1 Morphological characterization of diploid “fusion” and tetraploid fusion

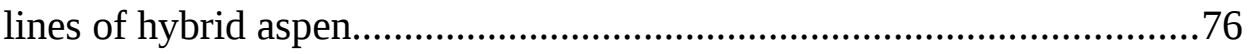

4.2.2 Drought responses of the diploid "fusion" and the tetraploid fusion lines 78

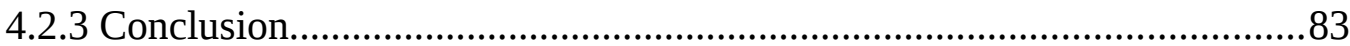

4.3 Whole genome sequencing of selected tetraploid hybrid aspen fusion lines....84

4.3.1 Basic characterization of the detected copy number variations.................84

4.3.2 Possible phenotypic influence due to copy number variations..................85

4.3.3 Limitations of the present copy number variation analysis.......................86 


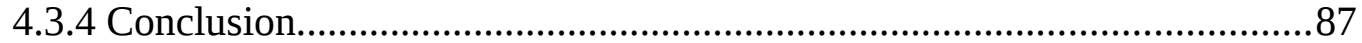

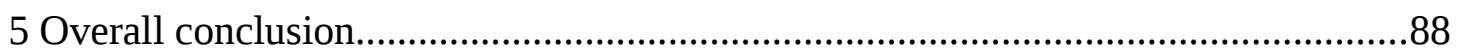

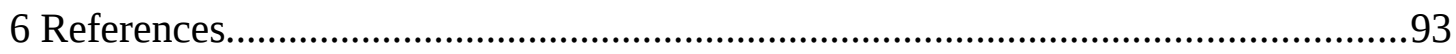

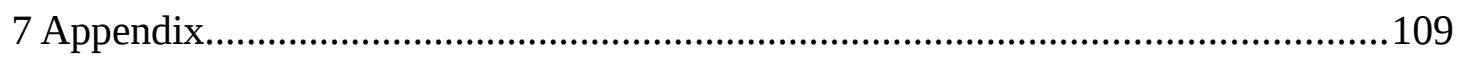

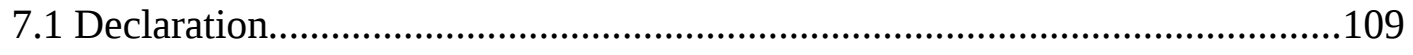

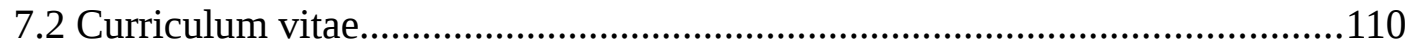

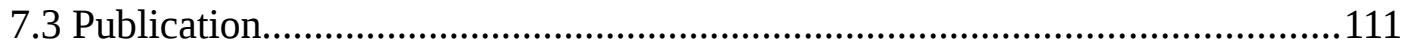




\section{Abstract}

Poplar (Populus) varieties that are planted in short rotation coppice are supposed to show high biomass production, the ability to propagate via stem cuttings but also drought tolerance because drought is a very important abiotic stressor that can negatively influence the plants' growth, vitality and productivity. For polyploid varieties of various species as crop species (Triticum), herbaceous species (Lonicera, Spathiphyllum, Nicotiana) as well as in tree species (Betula) higher tolerance towards stresses as, for example, drought was reported. Hybrid aspen Populus tremula (L.) x P. tremuloides (Michx.) that belong to the section Populus exhibit economically viable increase on soils where other tree species fail but miss the propagation via stem cuttings. Poplar species of the sections Tacamahaca and Aigeiros as, for example, P. nigra (L.) and P. trichocarpa (Torr. \& Gray) x P. deltoides (Bartram ex Marsh) can be propagated via stem cuttings. To overcome crossing incompatibilties somatic hybridization was applied to P. tremula x P. tremuloides ('Münden 2') as one fusion partner and P. x canescens (INRA clone No. 717 1-B4), P. nigra or P. trichocarpa $\mathrm{x}$ P. deltoides (B19) as the second fusion partner. According to the leaf morphology and microsatellite analysis the obtained fusion lines were assigned to the original clone P. tremula x P. tremuloides ('Münden 2') and showed a tetraploid set of chromosomes. In this dissertation, the main aim was to investigate the drought responses of the tetraploid hybrid aspen lines in comparison to the diploid original line P. tremula $\mathrm{x}$ P. tremuloides ('Münden 2'). Therefore, the following questions were addressed. (i) Do the tetraploid hybrid aspen lines perform better under drought than the diploid original line regarding e.g. the water consumption and the leaf vitality? (ii) Do the tetraploid hybrid aspen lines distinguish from the diploid original line in morphological traits as stomatal morphology, height, stem biomass and leaf area? (iii) Is the better drought performance in the tetraploid hybrid aspen lines due to the increased ploidy level, i.e. do the tetraploid hybrid aspen lines show better drought performance as higher survival rates, a delay in leaf wilting and higher relative leaf water content than the diploid "fusion” lines? (iv) Do the tetraploid hybrid aspen show early physiological changes in the relative leaf water content, the carbohydrate concentration and the stomatal conductance? (v) Are there any genetic modifications 
apart from the tetraploidy like duplications or deletions that might influence the drought performance?

In a first experiment, four hybrid aspen lines were obtained. Two of them showed lower water consumption relative to height and three delayed leaf wilting compared to the diploid original line. Furthermore, the tetraploid hybrid aspen lines exhibited lower stomatal density, increased stomatal length, comparable or lower height, stem biomass and total leaf area and enhanced leaf mass per area when compared to the diploid original line. In a second experiment, four diploid "fusion" lines and 16 tetraploid fusion lines were screened for their drought performance. The tetraploid fusion lines showed enhanced survival rates over the diploid lines but exhibited decreased height. With regard to height 11 tetraploid fusion lines exhibited delayed total leaf wilting while none of the four diploid "fusion" lines showed a delay in total leaf wilting with regard to the height when compared to the diploid original line. In a third experiment, two lines were selected from the second experiment that showed a delay in total leaf wilting with regard to height but comparable height growth to the diploid original line. Here, physiological traits like the water consumption and physiological responses like the relative leaf water content, the stomatal conductance and the carbohydrate content were investigated in a time course. A lower water consumption was observed in both tetraploid fusion lines in comparison to the diploid original line resulting in lower drought stress of the tetraploid fusion lines. The finding of lower water consumption in the tetraploid fusion lines was consistent with the increased soil moisture levels compared to the diploid original line. On the other hand, a lower water consumption would be in accordance with a lower stomatal conductance that was not observed in general for the tetraploid fusion lines. The tetraploid fusion lines were able to maintain the stomatal conductance relative to the control at relative soil moisture levels where the diploid original line had already closed their stomata. This finding supports a higher drought tolerance for the tetraploid fusion lines.

Genetic modifications such as duplications and deletions were detected using copy number variation analysis. Whole genome sequencing was applied to three tetraploid fusion lines and the diploid original line. The three tetraploid fusion lines exhibited growth comparable to that of the diploid original line but also delayed total leaf 
wilting with regard to height. The copy number variation analysis revealed only three segments that were altered in all tetraploid fusion lines compared to the diploid line. Genes that were putatively encoded by these segments were not annotated. One tetraploid fusion line showed a high number of 90 segments that were increased in this line but neither in the diploid original nor in the other two sequenced tetraploid fusion lines. Although this line showed better drought performance than the diploid original line the water consumption, the leaf vitality and the stomatal conductance did not differ from the other tested tetraploid fusion line (experiment 3). This finding indicates that the drought response is rather due to the tetraploidy than to other genetic modifications. Nevertheless, a functional characterization of the three segments that were altered in all tetraploid fusion lines in comparison to the diploid line is useful and should be conducted in furture studies as drought-relevant genes might be affected. The relevance to drought of these putative genes could be tested by exposing knock-out mutants to dry conditions.

Finally, it should be noted that the heterofusion frequency was very low with a few hybrids dying already in the in vitro stage. The fusion products originated from a joint project with several hundred fusion lines that were genetically characterized and only a few revealed as heterofusions. The heterofusion frequencies in other species (Cyclamen, Brassicaceae, Fabaceae, Poaceae, Solanaceae) is low as well. Since in this dissertation homofusion lines were investigated only, the propagation via stem cuttings was not investigated but I focused on drought responses of the tetraploid hybrid aspen lines.

In conclusion, morphological changes and higher drought tolerance were observed in the hybrid aspen lines with increased ploidy level. This renders them to be planted on sites where water is a limiting factor and high failure of plants due to drought is expected. 


\section{Zusammenfassung}

Pappelsorten (Populus) für den Anbau in Kurzumtriebsplantagen sollten neben einer hohen Biomasseproduktion und der Vermehrbarkeit über Steckhölzer auch Trockentoleranz aufweisen. Trockenheit stellt einen wichtigen abiotischen Stressor dar, der das Wachstum der Pflanze, ihre Vitalität und ihre Produktivität negativ beeinflussen kann. Polyploide Sorten von Getreidepflanzen (Triticum), krautigen Pflanzen (Lonicera, Spathiphyllum und Nicotiana) aber auch Baumarten (Betula) zeigen eine höhere Toleranz gegenüber Stress, wie z.B. Trockenstress, im Vergleich zu Sorten mit niedrigerem Ploidiegrad. Hybridaspen Populus tremula (L.) x P. tremuloides (Michx.) der Sektion Populus können auch auf Grenzertragsböden ökonomische Zuwächse verzeichnen, auf denen andere Baumarten ausfallen. Den Hybridaspen fehlt allerdings die Vermehrbarkeit über Steckhölzer. Anderen Pappelarten der Sektionen Tacamahaca und Aigeiros wie beispielsweise P. nigra (L.) and P. trichocarpa (Torr. \& Gray) x P. deltoides (Bartram ex Marsh) zeigen diese entscheidende Eigenschaft. Da Kreuzungen zwischen den Sektionen Populus und Tacamahaca oder Aigeiros auf natürlichem Weg schwierig sind, wurde die Methode der somatischen Hybridisierung eingesetzt. Der Klon P. tremula x P. tremuloides ('Münden 2') wurden als ein Fusionspartner und einer der Klone P. x canescens (INRA clone No. 717 1-B4), P. nigra oder P. trichocarpa x P. deltoides (B19) als zweiter Fusionspartner in Hybridisierungsexperimenten verwendet. Blattmorphologisch und durch Mikrosatellitenanalysen konnten die erhaltenen Fusionsprodukte dem Ausgangsklon P. tremula x P. tremuloides ('Münden 2') zugeordnet werden, wiesen dabei aber einen tetraploiden Chromosomensatz auf.

In der vorliegenden Dissertation war das zentrale Ziel, Trockenstressreaktionen tetraploider Hybridaspenlinien (HAL) im Vergleich zur diploiden Ausgangslinie P. tremula x P. tremuloides ('Münden 2') zu untersuchen. Dazu wurden die folgenden Fragen aufgestellt. (i) Sind die tetraploiden HAL dem diploiden Ausgangsklon unter Trockenheit überlegen z.B. hinsichtlich des Wasserverbrauchs und des Verwelkungsund Vertrocknungszeitpunktes der Blätter? (ii) Unterscheiden sich die tetraploiden HAL von dem diploiden Ausgangklon in morphologischen Ausprägungen wie beispielsweise der Stomatamorphologie, der Höhe, der Biomasse und der 
Gesamtblattfläche? (iii) Ist die höhere Trockentoleranz der tetraploiden HAL durch den erhöhten Ploidiegrad verursacht? (iv) Zeigen die tetraploiden HAL unter Trockenstress früh physiologische Veränderungen im Kohlenhydratgehalt, dem relativen Blattwassergehalt und der stomatären Leitfähigkeit? (v) Gibt es genetische Modifikationen abgesehen von der Tetraploidie wie z.B. Duplikationen und Deletionen, die eventuell Einfluss auf das Trockensressverhalten haben könnten?

In einem ersten Experiment wurden vier tetraploide HAL untersucht. Zwei HAL zeigten einen geringeren Wasserverbrauch und drei HAL eine spätere Verwelkung als der diploide Ausgangsklon. Außerdem entwickelten die tetraploiden HAL eine geringere Stomatadichte, größere Stomata und eine vergleichbare oder geringere Höhe, Biomasse und Gesamtblattfläche im Vergleich zum diploiden Ausgangsklon.

Das zweite Experiment wurde mit vier diploiden und 16 weiteren tetraploiden HAL durchgeführt. Auch die diploiden Linien stammten aus Protoplastenfusionsexperimenten. Die tetraploiden HAL wiesen im Mittel eine höhere Überlebensrate als die diploiden HAL auf, entwickelten aber durchdschnittlich ein geringeres Höhenwachstum. Unter Berücksichtigung der Höhe verwelkten 11 tetraploide, aber keine diploide HAL später als der diploide Ausgangsklon.

In einem dritten Experiment wurden zwei Linien aus dem zweiten Experiment ausgewählt, die vergleichbares Höhenwachstum zeigten, aber später verwelkten als der diploide Ausgangklon. Es wurden physiologische Merkmale wie der Wasserverbrauch und der Verwelkungszeitpunkt der Blätter beobachtet und der relative Blattwassergehalt, die stomatäre Leitfähigkeit und der Kohlenhydratgehalt in einer Zeitreihe untersucht. Geringerer Wasserverbrauch im Vergleich zum diploiden Ausgangsklon konnte in beiden tetraploiden HAL gezeigt werden. Diese Beobachtung deckt sich mit dem höheren relativen Bodenwassergehalt der tetraploiden HAL im Vergleich zum diploiden Ausgangsklon. Insgesamt spricht das für geringeren Trockenstress in den tetraploiden HAL. Auf der anderen Seite sollte ein geringerer Wasserverbrauch auch eine geringere stomatäre Leitfähigkeit nach sich ziehen. Dies war in den tetraploiden HAL nicht durchgehend der Fall. Relativ zur Kontrolle konnten die tetraploiden Linien aber eine höhere stomatäre Leitfähigkeit bei Bodenwassergehalten aufrechterhalten, bei denen die diploide Ausgangslinie bereits ihre Stomata geschlossen hatte. Dies weist ebenfalls auf eine höhere Trockentoleranz 
der tetraploiden HAL hin.

Genetische Modifikationen wie beispielsweise Duplikationen und Deletionen wurden mit Hilfe von “copy number variation”(“Kopienzahlvariation”)-Analysen an drei tetraploiden HAL und der diploiden Ausgangslinie durchgeführt. Die drei tetraploiden Linien zeigten vergleichbares Höhenwachstum, aber spätere Verwelkung als die diploide Ausgangslinie. Bei dieser Analyse konnten nur drei Segmente detektiert werden, die bei allen drei tetraploiden HAL im Vergleich zum diploiden Ausgangsklon verändert vorlagen. Die putativen Gene der detektierten Segmente wiesen keine Annotation auf. Eine der drei tetraploiden HAL zeigte eine hohe Anzahl von 90 Segmenten, die hier aber weder in dem diploiden Ausgangsklon noch in den beiden anderen tetraploiden Linien erhöht vorlagen. Diese Linie zeigte zwar eine höhere Trockentoleranz als der diploide Ausgangsklon, aber nicht gegenüber der anderen untersuchten tetraploiden HAL (Experiment 3). Beide tetraploiden HAL waren bezüglich des Wasserverbrauchs, des Verwelkungszeitpunktes und der stomatären Leitfähigkeit ähnlich. Dies lässt vermuten, dass die Trockentoleranz durch die Tetraploidie und nicht durch weitere genetische Modifikationen bedingt ist. Trotzdem ist eine weiterführende funktionelle Untersuchung der drei Segmente, die in allen tetraploiden HAL verändert auftraten, sinnvoll, da auch hier ein trockenrelevantes Gen verändert sein könnte. Um eine Relevanz der putativen Gene bezüglich Trockenheit zu testen, könnte zukünftig das Verhalten von Knock-outMutanten, denen die entsprechende Sequenz fehlt, unter Trockenstress untersucht werden.

Abschließend ist zu bemerken, dass neben den hier untersuchten HAL mehrere hundert Fusionsprodukte in einem Verbundprojekt genetisch charakterisiert wurden. Die Heterofusionsfrequenz war äußerst gering und die Hybriden waren bereits in der in vitro Phase nicht überlebensfähig. Geringe Heterofusionsfrequenz wurde beteits in anderen Arten beobachtet (Cyclamen, Brassicaceae, Fabaceae, Poaceae, Solanaceae). Da in dieser Dissertation nur Homofusionslinien verwendet wurden, wurde die Vermehrbarkeit über Steckhölzer nicht getestet, sondern der Fokus auf das Trockenstressverhalten der tetraploiden Homofusionslinien gelegt.

Zusammenfassend zeigen die Ergebnisse, dass veränderte morphologische Ausprägungen und eine höhere Trockentoleranz in den HAL mit erhöhten Ploidiegrad 
auftraten. Dies prädestiniert die tetraploiden Linien für Standorte, an denen Wasser als limitierender Faktor auftritt und hohe Ausfallraten durch Dürre erwartet werden. 


\section{List of abbreviations}

\begin{tabular}{|c|c|}
\hline $\begin{array}{l}\text { Bartram ex Marsh } \\
\text { b }\end{array}$ & $\begin{array}{l}\text { John Bartram ex Charles Dwight Marsh } \\
\text { base }\end{array}$ \\
\hline bp & base pair \\
\hline BMEL & "Bundesministerium für Ernährung und Landwirtschaft" \\
\hline CNV & copy number variation \\
\hline $\mathrm{CO}_{2}$ & carbon dioxide \\
\hline DAI & day after irrigation \\
\hline dsDNA & double strand DNA \\
\hline $\mathrm{eFP}$ & electronic fluorescent pictographic \\
\hline GC & guanine, cytosine \\
\hline Gray & Samuel Frederick Gray \\
\hline HAL & Hybridaspenlinie (hybrid aspen line) \\
\hline INRA & The National Institute for Agricultural Research \\
\hline $\mathrm{K}$ & potassium \\
\hline $\mathrm{L}$. & Carl Linnaeus \\
\hline LEA & late embryogenesis abundant (protein) \\
\hline $\mathrm{MgO}$ & magnesium oxide \\
\hline Michx. & André Michaux \\
\hline $\mathrm{N}$ & nitrogen \\
\hline nSSR & nuclear simple sequence repeat \\
\hline $\mathrm{P}$ & phosphate \\
\hline $\mathrm{Pa}$ & Pascal \\
\hline PCR & polymerase chain reaction \\
\hline POPTR & Populus trichocarpa (gene identification numbers) \\
\hline ppm & parts per million \\
\hline ROS & reactive oxygen species \\
\hline Rubisco & ribulose-1,5-bisphosphate carboxylase/oxygenase \\
\hline RWC & relative leaf water content \\
\hline SAI & stomatal area index \\
\hline SE & standard error \\
\hline SRC & short rotation coppice \\
\hline $\mathrm{TE}$ & Tris-EDTA (ethylenediaminetetraacetic acid) \\
\hline Torr. & John Torrey \\
\hline VPD & vapor pressure deficit \\
\hline
\end{tabular}




\section{List of figures}

Figure 1.1 Scheme of protoplast fusion possibilities......................................8

Figure 2.1 Scheme of plants distribution in the box, experiment 1......................17

Figure 2.2 Time course of modeled tempreature and relative humidity

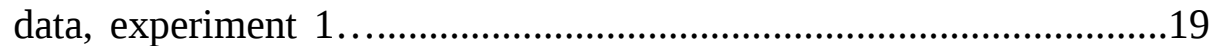

Figure 2.3 Scheme of plants distribution in the box, experiment 2.....................20

Figure 2.4 Scheme of plants distribution in the box, experiment 3.....................21

Figure 2.5 Scheme of stomatal length measurement...........................................23

Figure 3.1 Leaf morphology, experiment 1 ................................................31

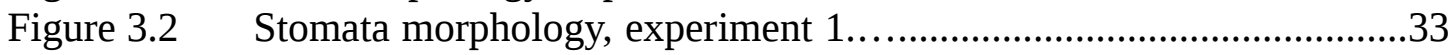

Figure 3.3 Relative soil moisture, experiment 1 .................................................35

Figure 3.4 Scheme of staggered drought periods, cumulative plot of water volume, boxplot vapour pressure deficit, experiment 1 .......................36

Figure $3.5 \quad$ Water consumption per height, experiment 1..................................37

Figure 3.6 Time course of leaf wilting and leaf desiccation, experiment 1...........38

Figure 3.7 Stomatal conductance of watered plants, stomatal conductance drought-exposed plants, carbohydrate concentration, experiment 1....39

Figure 3.8 Relative height and stem increment, experiment 1............................40

Figure 4.1 Initial plant height, experiment 2..................................................44

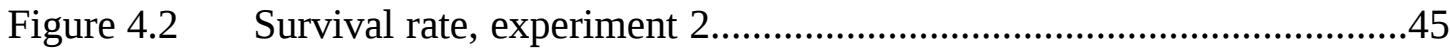

Figure 4.3 Relative leaf water content, experiment 2.........................................46

Figure 4.4 Scatterplot of the plant height and the day after irrigation when total leaf wilting occurred, experiment 2................................47

Figure 4.5 Day after last irrigation when total leaf wilting occurred with regard to height, experiment 2....................................................48

Figure 4.6 Day after last irrigation of total leaf wilting and partly (25\%) and total leaf desiccation, experiment 2.................................................49

Figure 5.1 Initial plant height, experiment 3...............................................52

Figure 5.2 Stomatal morphology, experiment 3................................................53

Figure 5.3 Time course of relative soil moisture, experiment 3............................55

Figure 5.4 Cumulative plot of water volumes and water consumption with regard to height, experiment 3................................................56

Figure 5.5 Time course of leaf wilting and leaf desiccation, experiment 3..........58

Figure 5.6 Relative leaf water content at the soil moisture target levels, experiment 3...............................................................................59

Figure 5.7 Carbohydrate concentration at the soil moisture target levels, experiment 3...........................................................................60

Figure 5.8 Osmolality one week after the 5 vol.-\% soil moisture target level, experiment 3.................................................................................61

Figure 5.9 Stomatal conductance at the soil moisture target levels,

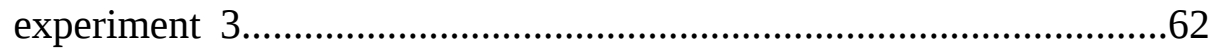

Figure 5.10 Relative height increment, experiment 3........................................63 
Figure 6.1 Pairwise comparison of detected copy number variations...................64

Figure 6.2 Genome distribution of segments with copy number variations in the tetraploid fusion lines compared to the diploid original line..........66

Figure 6.3 Venn diagram of altered segments with copy number variations in the tetraploid fusion lines compared to the diploid original line................67

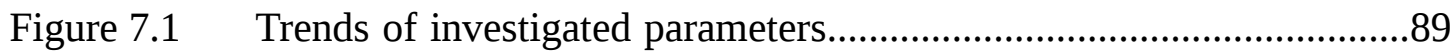




\section{List of tables}

Table 2.1 Fusion partners of the plant material used in the experiments.........13

Table 2.2 Time points when the respective soil moistures were reached and stomatal conductance and relative leaf water content were measured,

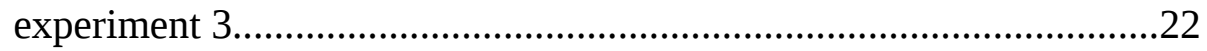

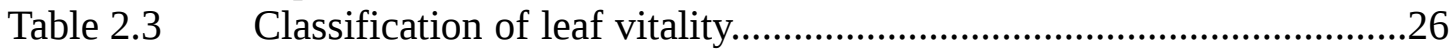

Table 3.1 Genetic characterization of the diploid original line and tetraploid hybrid aspen fusion lines, experiment 1 ...............................................31

Table 3.2 Morphological characterization of the diploid original line and tetraploid hybrid aspen fusion lines under optimal water supply, experiment 1 .....................................................................32

Table 3.3 Significance of the parameters genotype, treatment and light and their interaction effects on the target variables stomatal conductance, carbohydrate concentration, relative height and stem increment,

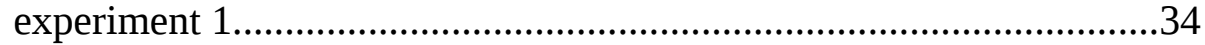

Table 4.1 Morphological and genetic characterization of diploid "fusion" and tetraploid fusion lines of hybrid aspen, experiment 2 .....

Table 4.2 Coefficient of determination of the day after irrigation when total leaf wilting occurred and the relative leaf water content, experiment 2

Table 5.1 Significance of the parameters genotype, treatment and light and their interaction effects on the target variables stomatal conductance, carbohydrate concentration and relative height increment,

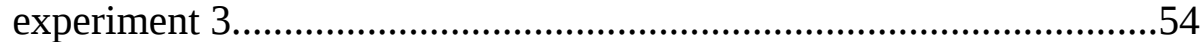

Table 5.2 Day after starting the experiment when the target soil moisture levels

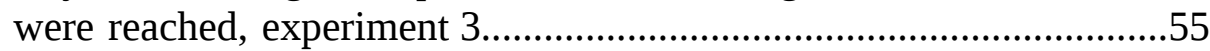

Table $5.3 \quad$ Leaf vitality decline, experiment 3..................................................57

Table 6.1 Segments with copy number variations altered in at least two tetraploid fusion lines compared to the diploid original line.................70

Table 7.1 Ranking of investigated hybrid aspen lines according to their morphological and physiological performance. 


\section{Introduction}

\subsection{Drought as an environmental threat for plants}

Plants in their natural habitat are exposed to variations in environmental conditions. As they are sessile they have to cope with climate. When these conditions are favorable, plants grow well. But when environmental conditions deteriorate it can result in stress. A stressor is defined as any external factor that negatively influences plant growth, productivity, reproductive capacity or survival (Rhodes and NadolskaOrczyk, 2001). Abiotic stressors such as the availability of light, nutrients and water play an important role in the plant development (Baumeister and Ernst, 1978; Fankhauser and Chory, 1997; Orcutt and Nilsen, 2000; Farooq et al., 2009). Drought represents an important abiotic stressor that diminishes the plant's vitality and thus threatens its survival (Araus et al., 2002; Flexas et al., 2004; Farooq et al., 2009; Fischer and Polle, 2010).

Plants can cope with drought either by stress avoidance or stress tolerance. Stress avoidance is referred to as the plants ability to minimize the adverse effect, i.e. a reduction of the water loss and the maintenance of the water uptake (Farooq et al., 2009; Puijalon et al., 2011). A drought avoidance mechanism that occurs early in the response to drought is stomatal closure to diminish transpiration (Pareek et al., 2010). Regulation of stomatal opening can be induced by signaling molecules and stimuli like, for instance, turgor loss and subsequent absisic acid synthesis and low light (Farquhar and Sharkey, 1982; Gilroy et al., 1990). Stomata serve as a gate for uptake of gases like carbon dioxide $\left(\mathrm{CO}_{2}\right)$ that is the central compound for carbohydrate production in photosynthesis but in turn water molecules get lost (Farquhar and Sharkey, 1982; Gilroy et al., 1990). Therefore, stomatal regulation is a key point for controlling water loss and $\mathrm{CO}_{2}$ uptake (Farquhar and Sharkey, 1982). Stomatal closure, the subsequent increased stomatal resistance and resistances inside the leaf as the lower internal mesophyll conductance lead to a low $\mathrm{CO}_{2}$ concentration inside the chloroplast (Flexas et al., 2004; Rennenberg et al., 2006). The decreased ratio between 
$\mathrm{CO}_{2}$ and oxygen in the chloroplast promotes the oxygenation reaction of the ribulose1,5-bisphosphate carboxylase/ oxygenase (Rubisco) at the expense of carboxylation (Rennenberg et al., 2006). The ribulose-1,5-bisphosphate regeneration declines and the Rubisco protein decreases resulting in a reduced photosynthesis rate (Flexas et al., 2004). Heat can cause lower mesophyll conductance as well and it remains difficult to differentiate between heat and drought as a triggering factor for lower mesophyll conductance as they usually occur simultaneously (Rennenberg et al., 2006). When drought proceeds a further drought avoidance mechanism is the shedding of leaves as this reduces the plant's transpiration surface (Gaur et al., 2008; Fischer and Polle, 2010). Leaf shedding in response to drought has for example been investigated in Populus (Fischer and Polle, 2010). Changes in leaf morphology such as smaller leaves and a decreased total leaf area have been supposed as drought avoidance mechanism for Cicer as well (Gaur et al., 2008).

Stress tolerance is defined as the capacity to endure unfavorable conditions (Puijalon et al., 2011). Osmotic adjustment by carbohydrates, organic acids and inorganic ions or changes in tissue elasticity can enhance a plant's drought tolerance (Touchette et al., 2009). For instance, the increase of nonstructural carbohydrates such as glucose, fructose and sucrose have been investigated in Betula, as well as in Populus and these solutes were supposed to function in osmoprotection (Peuke et al., 2002; Shi et al., 2002; Danielsen and Polle, 2014). In Populus, osmotic adjustment was mainly due to malic acid, potassium ions, sucrose and glucose (Tschaplinski and Tuskan, 1994). Apart from the adjustment of osmolytes also a high baseline concentration of solutes was assumed to be favorable for drought tolerance (Tschaplinski and Tuskan, 1994). Cattivelli et al. (2008) reported that osmotic adjustment plays a role in minimizing yield loss when drought occurs. Therefore, analysis of osmotic adjustment under different drought conditions has been suggested as an effective selection criterion for drought tolerant genotypes (Cattivelli et al., 2008).

Apart from the metabolic reactions that occur in response to dry conditions distinct morphological and physiological characteristics have been associated with plants of xeric habitats. These traits are favorable under drought as the water loss is minimized. 
For example, a smaller leaf area, increased leaf thickness and leaf mass per area are related to dry habitat plants (Kubiske and Abrams, 1992; Abrams et al., 1994; Gaur et al., 2008). With an increased leaf mass per area the surface-volume ratio is decreased and this may result in a reduced transpiration. Abrams et al. (1994) studied 17 temperate tree species from sites contrasting in humidity and found that in plants of xeric habitats the stomatal length and the net photosynthesis rate is increased compared to that from wet and wet-mesic sites. The comparison of a drought-tolerant with a drought-susceptible black poplar clone also showed characteristics that are associated to dry conditions like smaller and thicker leaves, enhanced stomatal size, reduced stomatal density and low plant height (Regier et al., 2009). These traits that emerged from evolutionary processes seem to be advantageous under dry conditions probably as a result of minimized transpiration.

\subsection{Genome duplication and copy number variation in plants}

Genome duplication (polyploidization) has naturally occurred in the evolution of several plant species including crops like Gossypium hirsutum, Triticum aestivum, and Oryza sativa but also in tree species such as Populus (Finnegan, 2002; Blanc and Wolfe, 2004; Rausher, 2007). Duplicated genes typically show a diversification in functions or subfunctionalization (Adams and Wendel, 2005). Gene expression silencing of polyploid genes can thereby be organ-specific and was observed to occur even reciprocally in different organs, i.e. leaving one homeolog silenced in some organs and the other silenced in other organs resulting in subfunctionalization (Adams et al., 2003). Several studies revealed that gene doubling can also influence the transcription levels by epigenetic alterations in the cytosine methylation or silencing of the ribosomal RNA leading to variations of morphology and phenotype (Finnegan, 2002; Liu and Wendel, 2003; Adams and Wendel, 2005).

Copy number variations (CNVs) are defined as DNA segments larger than $1 \mathrm{~kb}$ that are present in compared genomes but show variations in the copy number (Freeman et al., 2006; Springer et al., 2009). CNVs can occur in different functional regions of the 
DNA as for instance in stop codons, in exons and promoters, within an intron or in intergenic regions (Conrad et al., 2010). If CNVs appear in regulatory regions such as stop codons or promoters it is assumed that this can have impact on the gene dosage by disrupting coding sequences and long-range gene regulation (Kleinjan and van Heyningen, 2005; Conrad et al., 2010). Increased copy numbers can correlate both positively and negatively with the gene expression; for example if a transcriptional repressor is deleted the gene expression of the target gene might be positively influenced (Lee et al., 2006; McCarroll et al., 2006). But CNVs do not necessarily result in high genomic disorders and can have no apparent influence on the phenotype as well (Clancy, 2008; Freeman, 2006). CNVs can be due to homologous and nonhomologous recombination after double strand breaks and errors during replication (Conrad et al., 2010). Double strand breaks can arise during tissue culturing for example and CNV has been related to stress adaptation (Kaeppler and Phillips, 1993; Svitashev and Somers, 2001; Oh et al., 2012). If CNV occur in drought-relevant genes with a subsequent increase in gene expression this can cause higher drought tolerance (Xu et al., 1996; Kleinjan and van Heyningen, 2005). For example, in Zea, the increased expression of HVA1 a barley group3 LEA (late embryogenesis abundant) protein led to higher drought tolerance (Xu et al., 1996).

\subsection{Polyploidy and its effects on stress tolerance in plants}

Several studies have shown enhanced stress tolerance for polyploid varieties in different species (Xiong et al., 2006; Li et al., 2009; van Laere et al., 2010; Deng et al., 2012). For instance, octaploid tobacco plants showed increased survival times over their tetraploid counterparts when exposed to stresses like cold, shade, water logging, nutrient deficiency and drought (Deng et al., 2012). Decreased susceptibility of polyploid varieties to drought was detected in crop species (Triticum), herbaceous species (Lonicera, Spathiphyllum, Nicotiana) as well as in tree species (Betula) (Li et al., 1996; Xiong et al., 2006; Li et al., 2009; van Laere et al., 2010; Deng et al., 2012). Polyploidy can induce morphological changes in leaf characteristics that are 
associated with drought tolerance like an increased leaf thickness, a smaller total leaf area and an enhanced leaf mass per area (Kubiske and Abrams, 1992; Li et al., 2009). For instance, greater stomatal length and reductions in stomatal density, that are characteristics of plants in xeric habitats, were observed in polyploid Betula and Spathiphyllum (Abrams et al., 1994; Li et al., 1996; Regier et al., 2009; van Laere et al., 2010). Polyploidy can also influence the metabolic performance resulting in an induction of superoxide dismutase and catalase and consequently decreased accumulation of reactive oxygen species (ROS) (Deng et al., 2012). Deng et al. (2012) observed less growth, but increased concentrations of the ROS scavenging metabolites and soluble sugars in the octaploid compared to the tetraploid tobacco varieties. Therefore, they assumed that the octaploid varieties invest more in antioxidants and thus secondary metabolism than the plants with reduced ploidy (Deng et al., 2012). In Lonicera, the soil water potential, the pre-dawn leaf water potential, the transpiration rate and the stomatal conductance were less affected in drought-treated tetraploid variants compared to their diploid relatives (Li et al., 2009). As well, the net photosynthesis rate was less susceptible to drought in the tetraploid plants in comparison to the diploid suggesting higher $\mathrm{CO}_{2}$ assimilation per unit leaf area in the tetraploid plants under dry conditions (Li et al., 2009).

Moreover, endopolyploidization is a response to drought. For example, endoreduplication has been observed in drought-exposed Arabidopsis leaf mesophyll cells resulting in less sensitivity of the final leaf area to drought (Cookson et al., 2006). Furthermore, under drought GTL1, a trihelix transcription factor, is downregulated in Arabidopsis (Kaplan-Levy et al., 2012). This leads to increased endopolyploidy and a subsequent decrease in the stomatal number (Kaplan-Levy et al., 2012). These effects are assumed to maintain the leaf area for photosynthesis while reducing the transpiration due to fewer stomata (Kaplan-Levy et al., 2012). The systematic endoreduplication in drought-adapted species implies an advantage of this mechanism for growth under dry conditions (Scholes and Paige, 2015) and indicates a benefit for polyploid-related morphological traits as increased cell size under drought. 


\subsection{Characterization of Populus tremula (L.) x P. tremuloides (Michx.)}

The species Populus includes six sections, i.e. Abaso, Aigeiros, Leucoides, Populus, Tacamahaca and Turanga (Eckenwalder, 1996). The classification on the section and species level is controversially discussed, but according to Eckenwalder (1996) the genus comprises 29 species. Populus tremula (L.) x P. tremuloides (Michx.) is a hybrid between the quaking aspen that naturally occurs in North America and the European aspen that is distributed over Europe and Asia (Romme et al., 2005; Tamm, 1994). Both species are classified in the section Populus and easily hybridize with each other (Eckenwalder, 1996). P. tremula (L.) and P. tremuloides (Michx.) are regarded as pioneer colonizing tree species both with a wide ecological distribution (Geburek, 1994; Tamm, 1994). The natural occurrence of $P$. tremuloides ranges from atlantic to continental and aspen grow in regions with temperatures down to $-60{ }^{\circ} \mathrm{C}$, an annual precipitation of $180 \mathrm{~mm}$ and a vegetation period of 80 days (Geburek, 1994). P. tremuloides also appear in humid areas with about $1000 \mathrm{~mm}$ annual precipitation (Geburek, 1994) indicating a wide amplitude of this species towards water availability. As well, the occurrences of $P$ tremula ranges from steppes, semideserts to swamps and show no specific demands for the climate, the temperature and precipitation (Tamm, 1994). Both aspen species grow on soils of different fertility even on stony bedrocks and the $\mathrm{pH}$ value of the soil can range between acidic and alkaline (Geburek, 1994; Tamm, 1994). Although the growth is enhanced on fertile sites, aspen show economically viable increase on sites where other tree species fail (Mohrdiek, 1977). Drought tolerance for hybrid aspen is assumed although the literature is limited (Pakull et al., 2009). But the natural distribution of the parental species indicates high tolerance towards different humidity conditions. A decisive characteristic of pioneer species is fast juvenile growth (Dalling and Hubbell, 2002). Both P. tremula and P. tremuloides show this specific trait that is important in short rotation coppice (SRC) for biomass production (Geburek, 1994; Tamm, 1994; Schirmer, 2009). Hybrids of these two species (P. tremula x P. tremuloides) exhibit enhanced growth probably due to a heterosis effect (Yu et al., 2001). A further 
important trait for poplar cultivated in SRC is the propagation via stem cuttings as this considerably reduces the investment costs (Stanturf et al., 2001). Aspen miss this decisive trait as they propagate vegetatively via root suckers (Geburek, 1994; Tamm, 1994).

\subsection{Somatic hybridization of hybrid aspen}

Somatic hybridization or protoplast fusion has been used since the 1970s as a breeding method to combine plants of different species. Somatic hybrids contain the genetic material of both parental species including the cytoplasmatic material with mitochondria and chloroplasts (Landgren and Glimelius, 1990). For the chloroplast genome, uniparental inheritance is mainly observed, but co-existence was also found in some lines (Liu et al., 2005). Instead, for the mitochondrial genome recombination and rearrangements appeared (Liu et al., 2005). In conventional breeding the mitochondria and chloroplasts are primarily of uniparental inheritance (Birky, 1995). Besides, polyploidy can occur in the offspring when the chromosome sets of two protoplasts merge (Grosser et al., 2000). As the protoplast fusion suspension contains a variable number of cells of both parental species and the somatic hybridization is not directed, heterofusion but also homofusion can occur (Fig. 1.1). Apart from the addition of two complete diploid chromosome sets also aneuploid fusion products can be generated (Fig. 1.1). It has been observed in fusion hybrids that one nucleus or chromosomes of one fusion partner were predominant while only a few chromosomes of the second fusion partner occurred that were eliminated over time (Binding and Nehls, 1978; Prange et al., 2012).

Hybrid aspen show enhanced growth compared to the parental species and economically reasonable increase in biomass on poor soils (Mohrdiek, 1977; Yu et al., 2001) but they propagate vegetatively via root suckers. Poplar species of the sections Tacamahaca and Aigeros, as for example, P. nigra (L.) and P. trichocarpa (Torr. \& Gray) x P. deltoides (Bartram ex Marsh) can be propagated via stem cuttings (Stanturf et al., 2001). But the hybridization of P. tremula x P. tremuloides with P. nigra and 
P. trichocarpa x P. deltoides is difficult under natural conditions (Willing and Pryor, 1976; Liesebach et al., 2010). To combine the traits of both the hybrid aspen on the one hand and the black poplar (P. nigra) and the balsam poplar (P. trichocarpa $\mathrm{x}$ P. deltoides) on the other hand the method of somatic hybridization was used. This can be an auspicious approach as favorable traits can be joined in one plant.
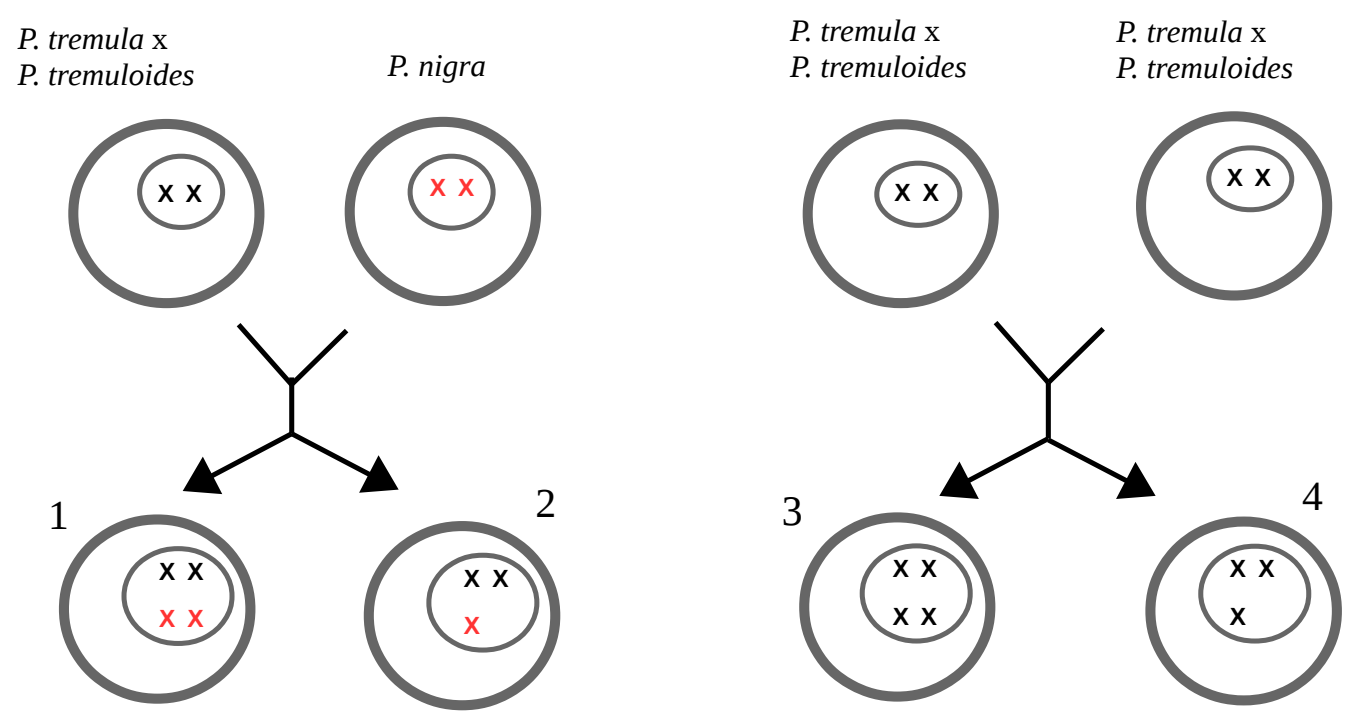

Figure 1.1: Scheme of protoplast fusion possibilities (x symbolizes the chromosome set, $2 \mathrm{x}$ : diploid; $4 \mathrm{x}$ : tetraploid, 1: tetraploid heterofusion, 2: aneuploid heterofusion missing chromosomes of one fusion partner, 3: tetraploid homofusion, 4: aneuploid homofusion).

\subsection{Energy demand and biomass production}

The world primary energy demand is increasing (Berndes et al., 2003; Asif and Muneer, 2007; Doman et al., 2014). In 2008, about $11 \%$ of this demand was met by renewable sources such as hydropower, biomass, biofuels, wind, geothermal and solar energy (IPCC, 2011). Biomass from bioenergy plants is expected to have a good potential to meet the increasing demand for global primary energy (Weih, 2004; Karp and Shield, 2008; Weih et al., 2014). Compared to fossil fuels, biomass contributes only marginally to the emission of greenhouse gases (Weih, 2004). The greenhouse gases reached their highest levels in history during the past decade and are the main 
drivers of climate change (IPCC, 2014). Biomass is therefore considered to contribute substantially to the alleviation of climate change challenge (Weih, 2004; Karp and Shield, 2008). The establishment of SRC is one possibility of generating biomass for energy purposes. SRC refers to plantations of fast growing trees and shrubs for biomass production with high initial growth and a rotation time of 3 to 5 years (Karp and Shield, 2008). The plantations of SRC show high biomass production and carbon dioxide fixation; the subsequent use of wood chips has low carbon abatement costs (BMEL, 2007). In 2012, SRC covered an area of 5000 to 6000 ha in Germany, i.e. only $0.0003 \%$ of the managed agricultural land (von Wühlisch, 2012; BMEL, 2014). It has been suggested that conflicts in land use for food or biomass production can be diminished by establishing SRC on marginal sites, that are affected by pollution, salinization or low water and mineral supply (Kuzovkina and Quigley, 2005; Karp and Shield, 2008; Polle et al., 2013). Therefore, species and varieties with high stress tolerance are required (Karp and Shield, 2008; Weih et al., 2014). However, biomass yield highly depends on the availability of water and drought tolerance can also be achieved at the expense of biomass (Araus et al., 2002; Bogeat-Triboulot et al., 2006; Cattivelli et al., 2008). Poplars are needed that combine enhanced drought tolerance and good biomass production. As drought periods are likely to increase with climate change (Regier et al., 2009) drought tolerance and the maintenance of growth are important breeding objectives (McKendry, 2002; Cattivelli et al., 2008).

Protoplast fusion of poplar species that exhibit good growth on soils with poor water and nutrient supply as P. tremula x P. tremuloides with poplar species that can be propagated via stem cuttings as $P$. nigra or P. trichocarpa $\times$ P. deltoides seems to be a promising approach. The enhanced ploidy level that can occur in the protoplast fusion products may also positively influence the performance of the plants exposed to stress, e.g. drought (Li et al., 2009; van Laere et al., 2010; Deng et al., 2012). 


\subsection{Objectives}

In this dissertation the objective was to investigate the drought response of tetraploid hybrid aspen that were generated by protoplast fusion between P. tremula $\mathrm{x}$ P. tremuloides ('Münden 2') as one fusion partner and either P. x canescens (INRA clone No. 717 1-B4), P. nigra or P. trichocarpa x P. deltoides (B19) as the second fusion partner.

The following questions were addressed:

i. Do the tetraploid hybrid aspen lines perform better under drought than the diploid original line, e.g. concerning the water consumption and the leaf vitality?

ii. Do the tetraploid hybrid aspen lines distinguish from the diploid original line in morphological traits like stomatal morphology, height, stem biomass and leaf area?

iii. Is the better drought performance in the tetraploid hybrid aspen lines due to the increased ploidy level, i.e. do the tetraploid hybrid aspen lines show better drought performance such as higher survival rates, a delay in leaf wilting and higher relative leaf water content than the diploid "fusion" lines?

iv. Do the tetraploid hybrid aspen show early physiological changes in the relative leaf water content, the carbohydrate concentration and the stomatal conductance?

v. Are there any genetic modifications apart from the tetraploidy like duplications or deletions that might influence the drought performance?

For this purpose greenhouse experiments were conducted. In experiment 1, four hybrid aspen lines of protoplast fusion experiments between P. tremula $\mathrm{x}$ P. tremuloides ('Münden 2') and P. nigra and P. trichocarpa x P. deltoides (B19) were characterized for morphological traits and their drought performance. The results of this experiment that are reported in this thesis have been published (Hennig et al., 2015, appendix 7.3). 
A screening of 20 hybrid aspen lines from protoplast fusion experiments between P. tremula x P. tremuloides ('Münden 2') and P. x canescens (INRA clone No. 717 1-B4) and P. nigra for drought tolerance was conducted in experiment 2. Four "fusion" lines that originated from protoplast fusion experiments but showed a diploid set of chromosomes were included to investigate the influence of the ploidy level on the drought performance. In experiment 3, two tetraploid hybrid aspen lines were selected that showed a significant delay in total leaf wilting with respect to height compared to the diploid original line. The analysis of drought performance was extended and detailed time courses of particular physiological traits were investigated. A copy number variation analysis was conducted to detect genetic modifications such as duplications or deletions that might play a role in the enhanced drought performance of the tetraploid hybrid aspen lines. For this purpose, the whole genome of the tetraploid hybrid aspen lines of experiment 3 and one further hybrid aspen line were sequenced along with the diploid original line. The selected lines showed a delayed leaf wilting with respect to height compared to the diploid original line. 


\section{Material and methods}

\subsection{Plant material}

Five-year-old trees of $P$. tremula x $P$. tremuloides ('Münden 2'), twenty-year-old trees of P. nigra and twenty five-year-old trees of P. trichocarpa x P. deltoides (B19) were used for establishing in vitro cultures. Terminal and axillary winter buds of one-yearold shoots were harvested and processed after a protocol modified according to Ahuja (1984). Buds were washed in tap water and sterilized in $70 \%$ ethanol (Carl Roth GmbH \& Co. KG, Karlsruhe, Germany) with 0.1 \% L-ascorbic acid (Sigma Aldrich Laborchemikalien GmbH, Hannover, Germany) for 20 seconds and in sodium hypochlorite (Carl Roth GmbH \& Co. KG, Karlsruhe, Germany) (supplemented with 2 drops of Tween 20 (Carl Roth GmbH \& Co. KG, Karlsruhe, Germany) for 20 minutes. Material was then washed three times for five minutes in sterilized tap water. After shoot development plantlets were subcultured every four weeks on MSMedium (Murashige and Skoog, 1962) supplemented with 0.2 ppm 6-benzylaminopurine (Fluka Chemie GmbH, Steinheim, Germany), 2 \% sucrose (Carl Roth GmbH \& Co. KG, Karlsruhe, Germany) and 2.9 g/l Gelrite (Duchefa Biochemie, Haarlem, Netherlands). In vitro culture of $P$. x canescens (INRA clone No. 717 1-B4) was not obtained via buds but provided as in vitro cultures by the Company Phytowelt GreenTechnologies GmbH, Cologne, Germany. Protoplast fusion of the in vitro poplar clones was established according to modified protocols of Guo and Deng (1998), Sasamoto et al. (2006) by the company Phytowelt GreenTechnologies GmbH as described previously (Lührs et al., 2010; Efremova et al., 2013). Protoplast fusion experiments were conducted between P. tremula $\mathrm{x}$ P. tremuloides ('Münden 2') as one fusion partner and P. $x$ canescens (INRA clone No. 717 1-B4), P. nigra or P. trichocarpax P. deltoides (B19) as second fusion partner. Shoot cultures from fusion products were regenerated as separate lines. The lines were micropropagated and rooted ex vitro by directly transferring them to substrate (nursery substrate ( $\mathrm{N}: 250 \mathrm{mg} / \mathrm{l}$ P: $140 \mathrm{mg} / \mathrm{l}, \mathrm{K}: 250 \mathrm{mg} / \mathrm{l}$ ), Kleeschulte 
Erden GmbH, Rüthen, Germany) under a foil tunnel equipped with a fog system. Plantlets were hardened by reducing air humidity gradually during four weeks. Rooted plans were transferred into 1.3-liter pots (substrate composition as above blended with one gram long-term fertilizer Osmocote Exact lo start 8-9 M (1 g/l, $\mathrm{N}: \mathrm{P}: \mathrm{K}=15: 8: 10+3 \mathrm{MgO})$, The Scotts Company LLC, Heerlen, Netherlands per liter soil) and cultured in the greenhouse. For hibernation temperature was decreased according to ambient conditions but did not drop below $5{ }^{\circ} \mathrm{C}$. Plants of all tested fusion lines (Tab. 2.1) were watered to field capacity until the experiments started. All experiments were carried out in a greenhouse.

Table 2.1: Fusion partners of the plant material used for the experiments (P1: P. x canescens (INRA clone No. 717 1-B4), P3: P. tremula x P. tremuloides ('Münden 2'), P7: P. nigra, P9: P. trichocarpa $\mathrm{x}$ P. deltoides (B19)).

\begin{tabular}{|c|c|c|}
\hline Line & Fusion partner 1 & Fusion partner 2 \\
\hline \multicolumn{3}{|c|}{ Experiment 1} \\
\hline 27-01 & \multicolumn{2}{|c|}{ Diploid original clone P3 } \\
\hline 27-09 & \multirow{3}{*}{ P3 } & \multirow{3}{*}{ P9 } \\
\hline $27-10$ & & \\
\hline $27-11$ & & \\
\hline $27-12$ & P3 & P7 \\
\hline \multicolumn{3}{|c|}{ Experiment 2} \\
\hline $18-03$ & \multicolumn{2}{|c|}{ Diploid original clone P3 } \\
\hline $14-01$ & \multirow{7}{*}{ P3 } & \multirow{7}{*}{ P7 } \\
\hline $14-02$ & & \\
\hline $14-03$ & & \\
\hline $14-04$ & & \\
\hline $14-05$ & & \\
\hline $14-06$ & & \\
\hline $14-07$ & & \\
\hline $14-08$ & \multirow{3}{*}{$\mathrm{P} 1$} & \multirow{3}{*}{ P3 } \\
\hline 14-09 & & \\
\hline $14-10$ & & \\
\hline $18-04$ & P3 & P7 \\
\hline
\end{tabular}




\begin{tabular}{|c|c|c|}
\hline Line & Fusion partner 1 & Fusion partner 2 \\
\hline $18-05$ & \multirow{6}{*}{ P3 } & \multirow{6}{*}{ P7 } \\
\hline $18-06$ & & \\
\hline $18-07$ & & \\
\hline $18-08$ & & \\
\hline 18-09 & & \\
\hline $18-10$ & & \\
\hline $18-11$ & \multirow{2}{*}{$\mathrm{P} 1$} & \multirow{2}{*}{ P3 } \\
\hline $18-12$ & & \\
\hline $18-13$ & P3 & P7 \\
\hline \multicolumn{3}{|l|}{ Experiment 3} \\
\hline $18-03$ & \multicolumn{2}{|c|}{ Diploid original clone P3 } \\
\hline $14-04$ & \multirow{2}{*}{ P3 } & \multirow{2}{*}{ P7 } \\
\hline $14-07$ & & \\
\hline \multicolumn{3}{|l|}{$\begin{array}{l}\text { Whole genome } \\
\text { sequencing }\end{array}$} \\
\hline $18-03$ & \multicolumn{2}{|c|}{ Diploid original clone P3 } \\
\hline $14-03$ & \multirow{3}{*}{ P3 } & \multirow{3}{*}{ P7 } \\
\hline $14-04$ & & \\
\hline $14-07$ & & \\
\hline
\end{tabular}

\subsection{Genetic characterization}

\subsubsection{Ploidy level}

The relative DNA content was analyzed for all tested lines by flow cytometry from leaves of in vitro cultures (Plant Cytometry Services, Netherlands).

\subsubsection{DNA extraction}

The protocol of Dumolin et al. (1995) was used for total DNA isolation from leaves of in vitro cultures. Differing from the protocol the pellet was dissolved in $75 \mu \mathrm{l}$ 1 x TE RNase A (100 mg/ml, Quiagen, Hilden, Germany). 


\subsubsection{Nuclear simple sequence repeats analysis}

Nuclear simple sequence repeats (nSSR) analyses were conducted for all tested lines. Additionally, the other diploid original lines that were used for protoplast fusion analyes were included as references in the nSSR analyses, i.e. P. nigra (P7) and P. trichocarpa x P. deltoides (clone B19; P9). Eleven primers (ORPM0023, ORPM1031, ORPM1249, ORPM1261, PMGC0433, PMGC2163, WPMS05, WPMS09, WPMS12, WPMS14, GCPM2768) were selected that were located on nine linkage groups (http://web.ornl.gov/sci/ipgc/ssr_resource. htm; van der Schoot et al., 2000; Smulders et al., 2001; Tuskan et al., 2004). Polymerase chain reaction was performed as described by Eusemann et al. (2009), van der Schoot et al. (2000) and Smulders et al. (2001). nSSR fragment length analysis was carried out using a LICOR sequencer (4300 DNA analyzer, LI-COR Biosciences, Bad Homburg, Germany). For genotype analysis the software Saga v3.0 (LI-COR Biosciences, Bad Homburg, Germany) was used.

\subsubsection{Whole genome sequencing and annotation}

\section{Sequencing}

Whole genome sequencing was applied to three fusion lines and the diploid original clone (Tab. 2.1) by the DNA Microarray and Deep-Sequencing Facility Göttingen. Genomic DNA was sonicated by using the DNA Shearing for Bioruptor®NGS to 350 bp fragments. Library preparation for DNA-Seq was performed using the TruSeq DNA Sample Prepv2 Kit renamed TruSeq DNA LT SamplePrep Kit (Illumina, Catalog IDs:**FC-121-2001, FC-121-2002) starting from 1000 ng of genomic DNA. The barcodes used for sample preparation were index 5, 6, 15 and 7 according to the indications given by the protocol. Accurate library quantitation of DNA libraries was performed by using the QuantiFluor ${ }^{\mathrm{TM}} \mathrm{dsDNA}$ System (Promega). The size range of final cDNA libraries was determined applying the DNA 1000 chip on the Bioanalyzer 2100 from Agilent (470 bp). DNA libraries were amplified and sequenced by using 
the cBot and HiSeq 2000 from Illumina (PE, 2×100 bp, 20 Gb/sample ca. 100 million reads per sample). Sequence images were transformed with Illumina software BaseCaller to bcl files, which were demultiplexed to fastq files with CASAVA (version 1.8.2). Quality check was done via FastQC (version 0.10.1, Babraham Bioinformatics).

\section{Mapping, detecting copy number variation and annotation}

The mapping, the detection of copy number variations and the annotation was conducted by the Core Facility Medical Biometry and Statistical Bioinformatics (Department of Medical Statistics, University of Göttingen). Minimal read length was set at 25 bp and low quality bases with a phred score lower 20 were removed to ensure a sufficient quality of the sequences with high precision in mapping. Reads were aligned to the reference sequence of P. tremula $\times$ P. tremuloides consisting of 290142 contigs of 200 to 128000 bp length allowing a mismatch rate of $3 \%$. The contigs were provided by Nathaniel Street (Umeå Plant Science Centre, Umeå, Sweden). The rate of uniquely mapped reads was between $67 \%$ and $69 \%$. To avoid redundancies, reads that mapped in more than one contig were removed. The number of contigs was reduced to 110000 by filtering for a number of at least 50 reads on a given contig in all samples. Coverage was summarized over a sliding window of $650 \mathrm{bp}$, having 100 reads in median in each window. GC bias was corrected using the rectification of loess fit depending on the copy number ratio to the GC content and data were normalized for library size. To identify segments with copy number variations (CNVs) a pairwise comparison of four samples was performed. After filtering for a minimum sum of 30 reads for both samples per window, the coverage of reads was summed up per each sliding window. Results were filtered for contigs with a $\log$ ratio more than $|\log 2(1.5)|$, that is a minimum 1.5-fold difference in coverage between the analyzed samples. For enabling functional analysis the sequences were mapped to the reference genome of $P$. trichocarpa (Nisqually-1) for genome genome alignment using the program MuSIC (Tsai et al., 2004). Thereby, the POPTR identifications numbers were obtained. In the following functional analysis 
the POPTR numbers were used for input in the "Keyword search" tool of Phytozome (http://phytozome.jgi.doe.gov; Goodstein et al., 2012). To gain further information whether the identified genes were related to drought and growth, in silico expression analysis was conducted in POPGENIE (“exImage” tool; http://popgenie.org/eximage; Sjödin et al., 2009). Here, the expression in P. tremula tissue, in young expanding leaves that were sampled in the field and in leaves after three days drought exposure in the greenhouse were chosen. The electronic fluorescent pictographic (eFP) browser displayed the expression in the specific tissue in relation to the expression over all analyzed tissues.

\subsection{Experimental design}

\subsubsection{Experiment 1}

Four lines from protoplast fusion and the original diploid hybrid aspen ('Münden 2') were used in a greenhouse experiment (Tab. 2.1). Ten plants of each clone were randomly chosen as control and ten as treatment plants. Two plants each of four lines, still planted in three-liter pots, were placed into one box (eight plants) according to a scheme applying maximal space to the plants of one line (Fig. 2.1). The plants' positions were changed in each box in order to let all lines pass all positions of the boxes (four different distributions, one was repeated).

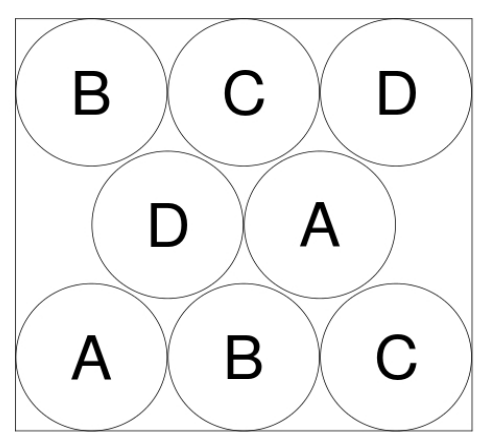

Figure 2.1: Scheme of the plants distribution in the box for experiment 1 (eight plants per box planted in three-liter pots, two plants of one line (symbolized by the same letter) were placed at maximal space). 
During the experiment the boxes were rotated daily to avoid positional effects. No artificial light was supplemented. Temperature and relative air humidity during experimental time ranged from $16{ }^{\circ} \mathrm{C}$ to $37^{\circ} \mathrm{C} / 37 \%$ to $60 \%$ (day) and from $11^{\circ} \mathrm{C}$ to $15{ }^{\circ} \mathrm{C} / 80 \%$ to $99 \%$ (night), respectively. Because of data logger failure inside the greenhouse during eight days (day 11 to day 19), hourly data of existing data pairs for inner and outer temperature were used to generate a linear regression model (Equation 1) with the outer temperature $\left(x_{1}\right)$ as predictor variable.

$$
y=\beta_{0}+x_{1} \beta_{1}+\varepsilon \quad \text { Equation } 1
$$

The modeled and measured temperatures showed a quite high correlation $\left(\mathrm{R}^{2}=0.92\right.$, Fig. 2.2 A). The relative humidity was modeled using a generalized linear regression approach as the target variable ranged between 0 and $100 \%$. Therefore, a logit function was applied (Equation 2) with the predicted temperature inside the greenhouse $\left(x_{1}\right)$ and the hour of the day $\left(x_{2}\right)$ as predictor variables.

$$
\hat{y}=\frac{\exp \left(\beta_{0}+\beta_{1} x_{1}+\beta_{2} x_{2}\right)}{1+\exp \left(\beta_{0}+\beta_{1} x_{1}+\beta_{2} x_{2}\right)} \quad \text { Equation } 2
$$

For more flexibility of the model Equation 2 was extended by flexible splines according to Wood (2011). The predicted values of the relative humidity were highly correlated with the measured values $\left(\mathrm{R}^{2}=0.79\right.$, Fig. $\left.2.2 \mathrm{~B}\right)$. The vapor pressure deficit (vpd) was determined using the predicted temperature and relative humidity data with the Clausius-Clapeyron relationship according to Hartmann (1994).

All plants were watered twice up to saturation before starting the experiment. Then, control plants were watered daily to field capacity and treatment plants were gradually dried to the respective soil moisture target levels. After culturing the plants at this level for one week, treatment plants were not watered anymore but still investigated. The experiment ended at day 56, when all plants were harvested for 
biomass analysis.

The leaf morphology of in vitro plants was investigated (2.4.1). The stomatal length, density and the stomatal area index were analyzed before starting the drought treatments (2.4.1). During the whole experiment the relative soil moisture and the leaf vitality were investigated for control and treatment plants (2.4.4). Water consumption was measured within one week during the 10 vol.-\% period (2.4.4). The relative height increment, the stomatal conductance and the carbohydrate concentration were investigated for control and treatment plants after the 10 vol.-\% soil moisture period (2.4.2, 2.4.5, 2.4.6). At the end of the experiment the stem biomass, the leaf mass per area and the total leaf area per plant were analyzed using control plants (2.4.2, 2.4.3). The relative stem increment was investigated for control and treatment plants after the experiment (2.4.2).

A

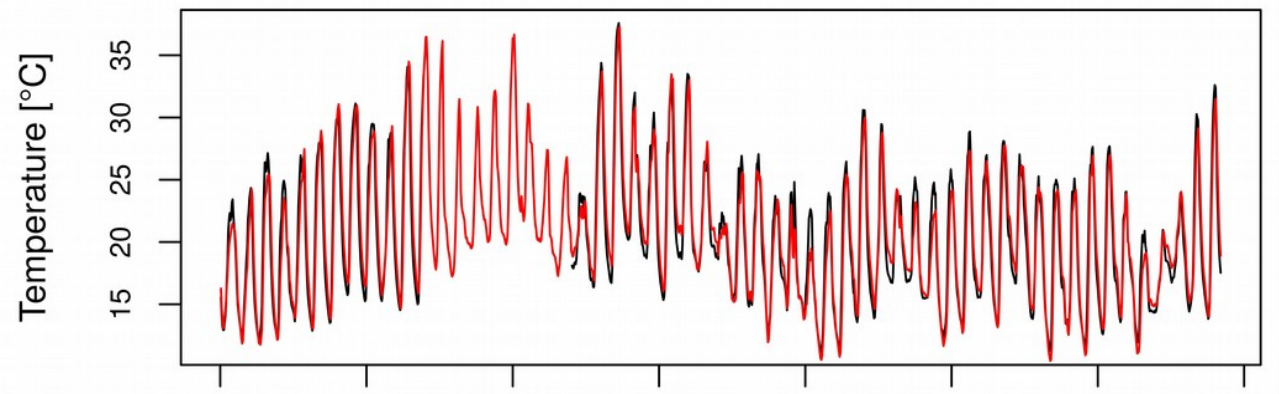

B

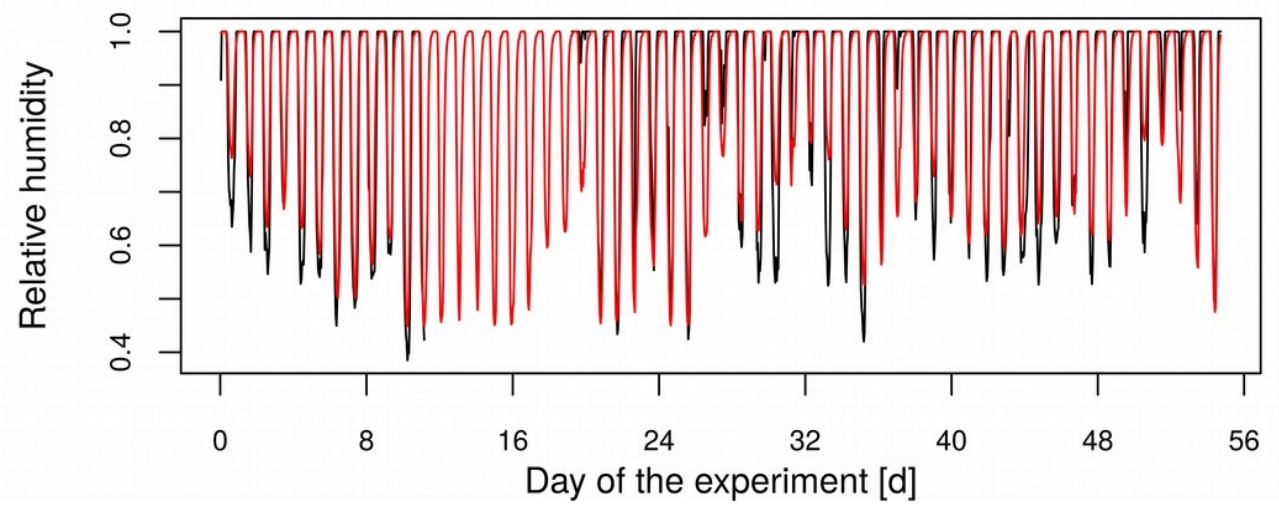

Figure 2.2: Time courses of (A) temperature and (B) relative humidity of experiment 1 (black: measured data, red: modeled data). 


\subsubsection{Experiment 2}

Twenty hybrid aspen fusion lines and the original clone P. tremula $\times$ P. tremuloides ('Münden 2') were investigated in this experiment (Tab. 2.1). Plants were transferred to soil in April 2012, planted into 1.3-liter pots in May 2012 (substrate composition as mentioned in section 1 with long-term fertilizer $(1 \mathrm{~g} / \mathrm{l}$, Osmocote Exact Standard 5-6 M (1 g/l, N:P:K = 15:9:12 + 2 MgO), The Scotts Company LLC, Heerlen, Netherlands) and cultured in the greenhouse until the experiment started. Four plants were randomly chosen as control and 12 as treatment plants with the exception of line 18-05, 18-08, 18-09 and 18-12. For these lines the following numbers were used: 18-05: 3 control, 8 treatment plants, 18-08: 2 control, 5 treatment plants, 18-09: 3 control, 9 treatment and 18-12: 2 control, 8 treatment plants. Three plants of each line (5 lines), still planted in 1.3-liter pots, were placed into one box (15 plants) according to a scheme applying maximal space to the plants of one line (Fig. 2.3). The positions of the plants were changed in every box that way that all lines passed all positions of the box (five different distributions).

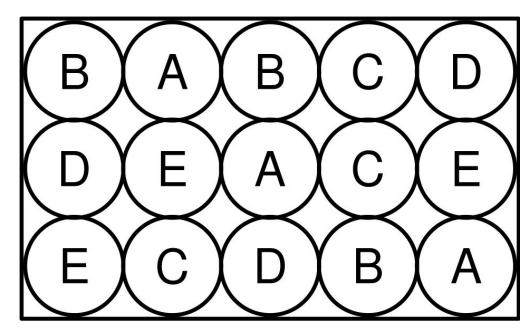

Figure 2.3: Scheme of the plants distribution in the box for experiment 2 (15 plants per box planted in 1.3-liter pots, three plants of one line (symbolized by the same letter) were placed at maximal space).

The plants were watered daily until the experiment started. Additionally, the plants were watered twice to saturation right before starting the experiment. Subsequently, the control plants were watered daily to field capacity, for the treatment plants the water was withheld. No artificial light was supplied. To avoid positional effects all boxes were rotated daily. The experiment started on June, $28^{\text {th }} 2012$ and lasted for 35 days. Initial height was measured for control and treatment plants (2.4.2). Leaf 
vitality was investigated daily for treatment plants and once every week for control plants (2.4.4). At day 7, 19 and 26 the relative water content of the leaves were determined (2.4.5). The survival rate was investigated following the experiment (2.4.7).

\subsubsection{Experiment 3}

Two hybrid aspen fusion lines and the diploid clone P. tremula x P. tremuloides ('Münden 2') were analyzed in this drought stress experiment (Tab. 2.1). Plants of in vitro cultures were planted into soil in April 2013 and transferred to 1.3-liter pots (substrate and long-term fertilizer see section 2.1). On July $17^{\text {th }} 2013$, the plants were re-potted in three-liter pots (substrate composition see section 2.1) with long-term fertilizer (1 g/l, Osmocote Exact Standard 5-6 M (1 g/l, N:P:K = 15:9:12 + 2 MgO), The Scotts Company LLC, Heerlen, Netherlands). Until the start of the experiment on September $16^{\text {th }} 2013$, the plants were watered to pot capacity and cultivated in the greenhouse.

Twenty plants of each line were randomly chosen as control and twenty as treatment plants. Two plants of each line, still planted in three-liter pots, were placed into one box (six plants) applying maximal space between the plants of one line (Fig. 2.4). The positions of the plants were changed in every box that way all lines passed all positions of the box (three different distributions, one was repeated four times, two were repeated three times).

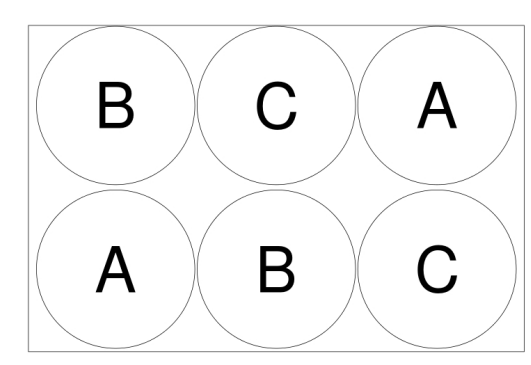

Figure 2.4: Scheme of the plants distribution in the box for experiment 3 (six plants per box planted in three-liter pots, two plants of one line (symbolized by the same letter) were placed at maximal space). 
No artificial light was supplied. All plants were watered twice up to saturation before the experiment started. The control plants were subsequently watered daily to field capacity. The treatment plants were gradually dried to 25, 18, 12 and 5 vol.-\% relative soil moisture and kept at the respective soil moistures for three days until stomatal conductance and relative leaf water content were measured. Uniform drying of the plants of one line was ensured by the procedure described in section 2.4.4. When the target levels were reached, the stomatal conductances of all control and treatment plants were measured (Tab. 2.2, 2.4.5). Afterwards, plant material was harvested for analysis of the relative water content and the carbohydrate concentration (Tab. 2.2, sections 2.4.5, 2.4.6). The time points when the soil target levels were reached were staggered (Tab. 2.2). Initial height was measured for all plants (2.4.2). Relative soil moisture was recorded daily from the beginning of the experiment to day 29. Leaf vitality was investigated daily for treatment plants from the start of the experiment until day 38, then every fourth day (2.4.4). For control plants leaf vitality was investigated weekly (2.4.4). Water consumption were analyzed over the whole experiment (2.4.4). At the end of the experiment the osmolality was analyzed for control and treatment plants (2.4.6).

Table 2.2: Time points when the respective soil moistures were reached and stomatal conductance and relative leaf water content were measured for experiment 3 (d: day after the beginning of the experiment, start: beginning of the respective soil moisture level, meas: measurement of stomatal conductance and harvest for relative leaf water content and biochemical analyses).

\begin{tabular}{|c|c|c|c|c|}
\hline \multirow[t]{2}{*}{ Line } & \multicolumn{4}{|c|}{ Relative soil moisture [vol.-\%] } \\
\hline & 25 & 18 & 12 & 5 \\
\hline & Start / meas & Start / meas & Start / meas & Start / meas \\
\hline $18-03$ & d5 / d8 & d9 / d12 & $\mathrm{d} 13$ / d16 & $\mathrm{d} 17 / \mathrm{d} 20$ \\
\hline $14-04$ & d9 / d12 & $\mathrm{d} 13$ / d17 & $\mathrm{d} 17 / \mathrm{d} 20$ & $\mathrm{~d} 25$ / d28 \\
\hline $14-07$ & d8 / d11 & $\mathrm{d} 12$ / d16 & d16 / d19 & $\mathrm{d} 25 / \mathrm{d} 28$ \\
\hline
\end{tabular}




\subsection{Investigated parameters}

\subsubsection{Leaf and stomata morphology}

Leaf morphology of in vitro plants of the fusion lines were compared to the original diploid clones phenotypically.

The stomatal density and stomatal size were analyzed by leaf impressions from abaxial and adaxial leaf surfaces that were taken near the middle vein and near the bases of the leaves. Impressions were taken on the fifth fully expanded leaf of five plants per line before starting the experiment using clear nail polish. The stomatal density was determined by counting the stomata on three randomly chosen sections $(0.303 \mathrm{~mm}$ x $0.303 \mathrm{~mm})$ of every preparation using a microscope (400 X magnification, Zeiss Axio Observer Z1, Zeiss, Oberkochen, Germany). Subsequently, the number of stomata per square millimeter was calculated. For determining the stomatal size, the length of three guard cells was measured in each section (Fig. 2.5). The stomatal area index (SAI) was calculated as a mean of stomatal size of three stomata of each leaf section on abaxial surface and multiplied with the stomatal density of this section (Ashton and Berlyn, 1994).

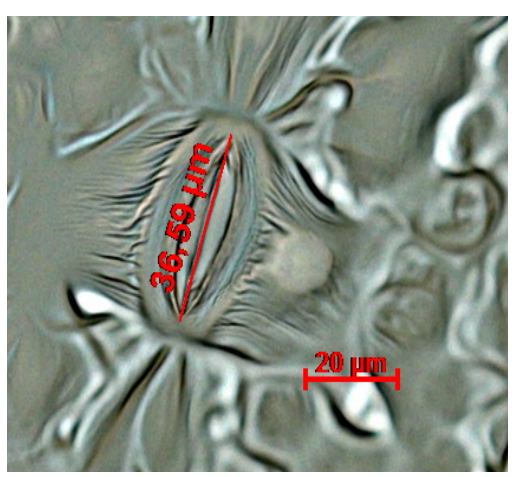

Figure 2.5: Microscopy image of a stomata to illustrate the measurement of the stomatal length (measurements were taken of the inner part of the guard cell).

\subsubsection{Height, stem biomass, relative height and stem biomass increment}

The height of all plants was measured for control and treatment plants at the beginning of all experiments (H_0). To determine the relative height in experiment 1 
and 3, all control and treatment plants were additionally measured (H_1). In experiment 1 the plants were measured after culturing at 10 vol.-\% soil moisture for seven days and in experiment 3 at the end of the 5 vol.-\% period. The relative height increment was calculated by dividing the increment (H_1 - H_0) by the initial height (H_0). As the period until the target soil moisture levels were reached differed among the tested lines, the height increment was divided by the number of cultured days, i.e. for the lines 27-01, 27-09. 27-10, 27-11 and 27-12 as follows: 13, 54, 18, 22, 15 (experiment 1) and for 18-03, 14-04, 14-07 following: 21, 29, 29 (experiment 3).

At the end of experiment 1 , all plants were separated into stem and root segments and dried at $103^{\circ} \mathrm{C}$ for five days for stem biomass analysis. Dry weight of the stems (DW_end) was measured without the roots and leaves for control and treatment plants. Relative stem increment was calculated as follows: First, a model between the final stem dry mass (DW_end) and the final height (H_end) was calculated using a logarithmic function $\left(\log \left(\mathrm{DW} \_\right.\right.$end $)=$H_end $\left.+(\text {H_end })^{2}\right)$ Then, the model was applied to the initial height (H_0) estimating initial stem biomass (DW_0). Finally, the stem increment was calculated (DW_end - DW_0), divided by the initial stem biomass (DW_0) and then normalized to the number of days between the start of the experiment and the end of the 10 vol.-\% period.

\subsubsection{Total leaf area and leaf mass per area}

For determining the total leaf area and the leaf mass per area all leaves of six control plants from each line were harvested, weighed (Sartorius Basic BA 210, Sartorius Weighing Technology GmbH, Göttingen, Germany) and scanned with a standard scanner at the end of the experiment. Leaf area was calculated from the scans using the program Histo Version 1.0.1.2. (Datinf, Tübingen, Germany) 


\subsubsection{Relative soil moisture, water consumption and leaf vitality}

The relative soil moisture was measured daily for the treatment plants and once a week for control plants using a soil moisture sensor (TRIME PICO32; Imko GmbH, Ettlingen, Germany). For experiment 1 the plants were dried until the 10 vol.-\% soil moisture was reached and kept at the 10 vol.-\%-level for one week. To enable uniform drying of the plants within one line the volumetric soil water content was measured daily. Two measurements were performed per each pot and the mean soil moisture per line was calculated for all plants per line. Plants, whose soil moisture dropped below the average level of their line were watered according to a standard curve to reach the mean volumetric soil moisture level. This procedure ensured that all plants of one line reached the 10 vol.-\% soil moisture target level at the same time point. The 10 vol.-\% periods for the different lines were staggered and first occurred in the diploid line at day six after starting the experiment and appeared last for fusion line 27-09 at day 47. The recorded water volumes were summed up per plant over the one-week period at the 10 vol.-\% level.

For experiment 3 the water volume was determined using the same procedure as in experiment 1.The plants were watered until the final target level of 5 vol.- $\%$ and afterwards the irrigation was stopped. To determine the water consumption the water volumes that were applied until the 5 vol.-\% target level was reached were used. A mean water consumption per plant was calculated as the number of irrigation days differed for the analyzed lines.

The wilting and the desiccation of the leaves were determined as indicators of plant vitality daily for treatment plants daily and weekly for control plants. A leaf was regarded as wilted, when its blade was in a parallel position to the shoot, i.e. the angle between the shoot and the leaf blade was $0^{\circ}-10^{\circ}$. Leaves that showed an angle of more than $10^{\circ}$ were considered as not wilted. Both parameters were classified into five categories (0 \%, $25 \%, 50 \%, 75 \%, 100 \%$ ) according to Table 2.3 .

For experiment 2, the day of total leaf wilting and partly and total drying of the 
leaves were determined as the day after the last irrigation event (DAI) when the thresholds $100 \%$ leaf wilting and $25 \%$ / $100 \%$ leaf desiccation occurred.

Table 2.3: Classification of leaf vitality.

\begin{tabular}{c|c}
\hline Scale & $\begin{array}{l}\text { Leaf wilting / desiccation } \\
\text { Percentage of wilted / desiccated leaves [\%] }\end{array}$ \\
\hline \hline $\mathbf{0}$ & 0 \\
\hline $\mathbf{1}$ & 25 \\
\hline $\mathbf{2}$ & 50 \\
\hline $\mathbf{3}$ & 75 \\
\hline $\mathbf{4}$ & 100 \\
\hline
\end{tabular}

\subsubsection{Relative leaf water content and stomatal conductance}

Relative leaf water content (RWC) was analyzed according to Smart and Bingham (1974) on six plants of each line. Six leaves of the upper third of the shoot of six plants were used for analysis paying attention to harvest leaves of the same order for each line and harvest. In experiment 1, the leaves were harvested at the days 7, 19 and 26 and in experiment 3 at the relative target soil moistures when 25, 18, 12 and 5 vol.-\% were reached and furthermore one week after the 5 vol.-\% level. Leaves were directly weighed (Sartorius Basic BA 210, Sartorius Weighing Technology GmbH, Göttingen, Germany). Material was harvested at midday (12 h - $13 \mathrm{~h}$ ). Stomatal conductance was measured between $8.30 \mathrm{~h}$ and $11.30 \mathrm{~h}$ on the eighth fully expanded leaf of all treatment and control plants with a porometer (AP4, Delta-T Devices, Cambridge, UK) at the respective soil water contents, i.e. the 10 vol.-\% level for experiment 1, and for experiment 3 the 25, 18, 12 and 5 vol.-\% levels and additionally at the beginning of the experiment when the relative soil moisture was 30 vol.- $\%$. 


\subsubsection{Biochemical analyses}

For analysis of the carbohydrate concentration leaf samples were taken from the upper fourth fully expanded leaf of five plants of the control and treatment group. For experiment 1 , leaves were harvested at the end of the 10 vol.-\% soil moisture period and for experiment 3 at the relative soil moistures of $25,18,12$ and 5 vol.-\% and additionally one week after the 5 vol.-\% soil moisture target level was reached. Sampling was conducted during the morning (10 h to $12 \mathrm{~h})$. The material was immediately stored at $-20^{\circ} \mathrm{C}$ until further preparation. For total soluble carbohydrates the protocol of Yemm and Willis (1954) was modified as follows: Samples were extracted in $50 \%$ ethanol, incubated with anthrone for 10 minutes at $98{ }^{\circ} \mathrm{C}$ and afterwards immediately cooled down in iced water. Absorbance was then measured at $620 \mathrm{~nm}$ against a blank that included pure methanol instead of the methanol-extracted sample. Osmolality was analyzed at six control and six treatment plants per line using the seventh fully expanded leaf according to the protocol of Wild et al. (1996).

\subsubsection{Survival rate}

The survival rate was investigated in experiment 2 . The water was withheld from the treatment plants during the whole experiment. Afte the experiment the treatment plants were irrigated daily and observed for six month. Plants that re-sprouted were considered as plants that survived. The survival rate per line was calculated as: Survival rate $=$ number of plants that survived $/$ number of treatment plants.

\subsection{Statistical analyses}

All data were analyzed using the statistical software R (R Core Team, 2013). The parameters height, stem biomass, total leaf area, leaf mass per area, stomatal length and density and the stomatal area index were analyzed by an one-way analysis of variance (ANOVA). A post hoc test (TukeyHSD) was used for determining significant differences between the genotypes. The hypothesis $\mathrm{H}_{0}$ describing that no differences 
between the genotypes exist was rejected if $p<0.05$. For the survival rate the differences between the ploidy levels were analyzed using an exact F-Test. Two-way ANOVA with independent factors genotype and treatment was conducted to test genotype, treatment and interaction effects on carbohydrate concentration, osmolality, relative height increment and relative stem increment. For stomatal conductance the factor light was tested in addition. Here, also a TukeyHSD test was used to determine differences between the lines and treatments. The dataset of control and treatment plants were analyzed together when shown in one graph otherwise they were analyzed separately. Relative soil moisture and leaf vitality were analyzed using a Wilcoxon signed-rank test. A pairwise comparison was conducted for the genotypes. Differences between the genotypes for all applied tests were considered to be significant when $\mathrm{p}<0.05$. For the water consumption and the day when total leaf wilting and partly / total drying of the leaves occurred the linear models according to Equation 3 and 4 were tested.

$$
\begin{array}{cr}
y=\beta_{0}+x_{1} \beta_{1}+\varepsilon & \text { Equation } 3 \\
y=\beta_{0}+x_{1} \beta_{1}+x_{2} \beta_{2}+\varepsilon & \text { Equation } 4
\end{array}
$$

where $x_{1}$ indicates the genotype and $x_{2}$ the stem height. When significant differences between the models were found the one with the lowest residual sums of squares were applied. For testing if a model with enhanced parameters is equal to a model with reduced parameters $\left(H_{0}\right)$ the test statistic was calculated by Equation 5 .

$$
F=\frac{\frac{1}{p-k}\left(S S_{\text {reduced }}-S S_{\text {full }}\right)}{\frac{1}{n-p-1} S S_{\text {full }}}
$$

with p number of parameter of the full model, k numbers of parameters of the reduced model and n number of observations. Equation 4 fitted the data better than Equation 3. Differences among the genotypes were detected using Equation 4 by estimating the 
shift of the intercepts from a reference. Afterwards, this shift was tested for being equal to zero $\left(H_{0}\right)$ using the exact F-Test. $H_{0}$ was rejected if $\mathrm{p}<0.05$. Each genotype served as reference using the function "Im". Thereby, all treatments were tested against each other.t 


\section{Results}

\subsection{Morphological and drought stress characterization of the diploid original line and tetraploid fusion lines of hybrid aspen}

\subsubsection{Morphological characterization of hybrid aspen lines}

Four hybrid aspen lines that were obtained after three protoplast fusion experiments between P. tremula $\times$ P. tremuloides and P. trichocarpa $\times$ P. deltoides and one protoplast fusion experiment between $P$. tremula $\times$ P. tremuloides and P. nigra were investigated in comparison to the original diploid clone of P. tremula x P. tremuloides.

In the tested putative heterofusion lines no DNA from P. nigra or P. trichocarpa $\mathrm{x}$ $P$. deltoides was detected by nSSR analysis using $11 \mathrm{nSSR}$ markers that were located on nine linkage groups (Tab. 3.1). This result suggested that only DNA of P. tremula $\mathrm{x}$ P. tremuloides was present. To get further insight into the genetic composition of the hybrid aspen lines flow cytometry was conducted. According to this analysis, the hybrid aspen lines showed a tetraploid set of chromosomes (Tab. 3.1). These analyses, therefore, support that homofusion lines of hybrid aspen (P. tremula x P. tremuloides) were obtained, but no heterofusion lines with other poplar genotypes. This finding was also supported by the leaf morphology of the fusion lines that exhibited a P. tremula $\mathrm{x}$ P. tremuloides phenotype that could be assigned to the original hybrid aspen (Fig. 3.1). In the following text, the putative hybrid aspen clones that originated from the protoplast fusion experiments are therefore named fusion lines. The original diploid P. tremula x P. tremuloides clone is referred to as the diploid line. 
3.1 Morphological and drought stress characterization of the diploid original line and tetraploid fusion lines of hybrid aspen

Table 3.1: Genetic characterization of the diploid original plants (P3: P. tremula $\mathrm{x}$ P. tremuloides ('Münden 2'), P7: P.nigra, P9: P. trichocarpa x P. deltoides (B19)) and tetraploid hybrid aspen lines. In vitro leaves of four-week-old plantlets were used for ploidy and nSSR analyses. Ploidy analyses were not performed for P7 and P9. For homocygote alleles only one fragment length is listed, if heterocygosity occurred all detected fragment lengths are shown (0: microsatellite does not exist in this organism, -1: failure).

\begin{tabular}{|c|c|c|c|c|c|c|c|}
\hline & 27-01 & P7 & P9 & 27-09 & 27-10 & $27-11$ & $27-12$ \\
\hline Plant material & $\begin{array}{l}\text { Original } \\
\text { line P3 }\end{array}$ & $\begin{array}{l}\text { Original } \\
\text { line P7 }\end{array}$ & $\begin{array}{l}\text { Original } \\
\text { line P9 }\end{array}$ & $\begin{array}{l}\text { Fusion line } \\
\text { P3 x P9 }\end{array}$ & $\begin{array}{l}\text { Fusion line } \\
\text { P3 x P9 }\end{array}$ & \begin{tabular}{|l} 
Fusion line \\
P3 x P9
\end{tabular} & $\begin{array}{l}\text { Fusion line } \\
\text { P3 x P7 }\end{array}$ \\
\hline Ploidy level & $2 n$ & - & - & $4 n$ & $4 n$ & $4 n$ & $4 n$ \\
\hline \multicolumn{8}{|l|}{ nSSR marker } \\
\hline GCPM2768 & 189 & 181 & 181,195 & 189 & 189 & 189 & 189 \\
\hline ORPM0023 & 167,177 & 173 & 189,199 & 167,177 & 167,177 & 167,177 & 167,177 \\
\hline ORPM1031 & -1 & -1 & 132 & 116,132 & 116,132 & 116,132 & 116,132 \\
\hline ORPM1249 & 95 & 103 & 105 & 95 & 95 & 95 & 95 \\
\hline ORPM1261 & 134,138 & 122 & 110,132 & 134,138 & 134,138 & 134,138 & 134,138 \\
\hline PMGC0433 & 182,190 & 196 & 208,216 & 182,190 & 182,190 & 182,190 & 182,190 \\
\hline PMGC2163 & 191,203 & 223 & 187,205 & 191,203 & 191,203 & 191,203 & 191,203 \\
\hline WPMS05 & 272,302 & 280,300 & 278 & 272,302 & 272,302 & 272,302 & 272,302 \\
\hline WPMS09 & 0 & 257,263 & 233,283 & 0 & 0 & 0 & 0 \\
\hline WPMS12 & 159,165 & 161 & 153,167 & 159,165 & 159,165 & 159,165 & 159,165 \\
\hline WPMS14 & 208,229 & -1 & 238253 & 208,229 & 208,229 & 208,229 & 208,229 \\
\hline
\end{tabular}

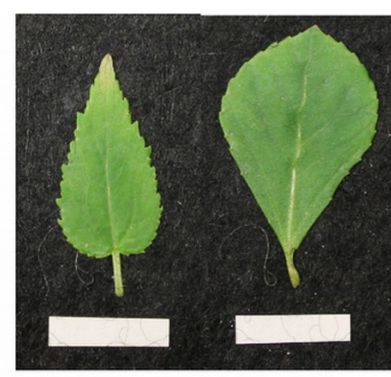

(A)

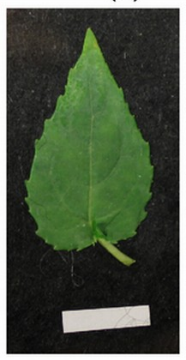

(D)

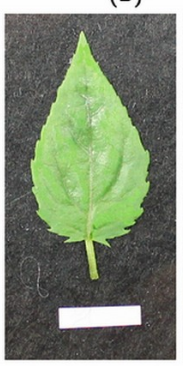

(E)

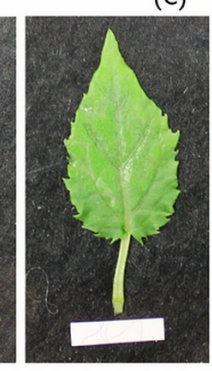

(F)

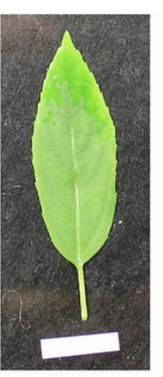

(C)

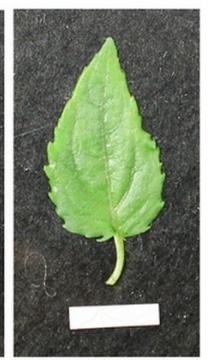

(G)

Figure 3.1: Leaf morphology of in vitro leaves of the diploid original clones (A) P3: P. tremula x P. tremuloides ('Münden 2'), (B) P7: P. nigra, (C) P9: P. trichocarpa x P. deltoides (B19) and the fusion lines (D) 27-09, (E) 27-10, (F) 27-11, (G) 27-12. The white scale bar at the bottom of the pictures measures $1 \mathrm{~cm}$ in length. Plantlets were subcultured for four weeks. 
Table 3.2: Morphological characterization of diploid and tetraploid hybrid aspen lines under optimal water supply. Stem height was measured at the beginning of the experiment and after nine month in soil, other parameters were measured at the end of the experiment. Data are means ( \pm SE, $n=10$ plants (stem height and stem biomass), $n=6$ plants (total leaf area and leaf mass per area), superscripted letters indicate differences between the lines (Tukey HSD test, $\mathrm{p}<0.05)$, P3: P. tremula x P. tremuloides, P7: P.nigra, P9: P. trichocarpa x P. deltoides).

\begin{tabular}{|c|c|c|c|c|c|c|}
\hline Line & $\begin{array}{l}\text { Fusion } \\
\text { partner }\end{array}$ & $\begin{array}{l}\text { Leaf } \\
\text { morphology }\end{array}$ & $\begin{array}{l}\text { Stem height } \\
{\left[\mathrm{m} * 10^{-2}\right]}\end{array}$ & $\begin{array}{l}\text { Stem biomass } \\
\left.\text { [g plant }^{-1}\right]\end{array}$ & $\begin{array}{l}\text { Total leaf area } \\
{\left[\mathbf{m}^{2} * \mathbf{1 0}^{-2} \text { plant }^{-1}\right]}\end{array}$ & $\begin{array}{l}\text { Leaf mass per area } \\
{\left[\mathrm{g} \mathrm{m}^{-2} * 10\right]}\end{array}$ \\
\hline 27-01 & - & P3 & $105.1 \pm 17.6$ & $17.5 \pm 8.3^{b}$ & $30.4 \pm 7.7^{\text {вс }}$ & $1.38 \pm 0.15^{\mathrm{a}}$ \\
\hline $27-09$ & P3 x P9 & P3 & $39.6 \pm 17.3$ & $1.9 \pm 1.2^{2}$ & $6.5 \pm 1.7^{2}$ & $2.26 \pm 1.98^{c}$ \\
\hline 27-10 & P3 x P9 & P3 & $80.3 \pm 16.7^{7}$ & $16.3 \pm 10.0^{\circ}$ & $23.9 \pm 12.7^{b c}$ & $1.59 \pm 0.23^{b}$ \\
\hline $27-11$ & P3 x P9 & P3 & $49.8 \pm 11.8$ & $4.9 \pm 3.5^{\circ}$ & $15.4 \pm 7.8$ ab & $1.53 \pm 0.26^{\mathrm{ab}}$ \\
\hline $27-12$ & P3 x P7 & P3 & $92.8 \pm 18.4^{\mathrm{b}}$ & $22.1 \pm 7.3^{b}$ & $34.2 \pm 6.0$ & $1.69 \pm 0.21^{b}$ \\
\hline
\end{tabular}

For basic characterization of the fusion lines height at the beginning of the experiment after nine month of soil culture and total leaf area, leaf mass per area and stem biomass production at the end of the experiment were compared to the diploid line under optimal water supply (Tab. 3.2). Plants heights were lower for the fusion lines 27-09, 27-10 and 27-11 than for the diploid line. Stem biomass of the fusion lines 27-09 and 27-11 was reduced. Furthermore, for the fusion line 27-09 the total leaf area was decreased compared to the diploid line. The leaf mass per area was increased in the fusion lines except for 27-11 suggesting enhanced leaf thickness for the fusion lines.

Microscopy of the leaf impressions that were taken of the abaxial leaf surface before starting the experiment revealed that the stomatal lengths were higher but the stomatal densities were reduced for all fusion lines in comparison to the diploid line (Fig. 3.2 A, B, D). Among the fusion lines stomatal lengths and densities differed. Fusion line 27-11, which showed the lowest stomatal density on lower leaf surface, exhibited stomata on the leaf adaxial surface. But the stomatal density on the adaxial leaf surface was only 10 stomata $\mathrm{mm}^{-2}$ compared to 75 stomata $\mathrm{mm}^{-2}$ on the abaxial leaf side, thus was significantly lower. None of the other lines, including the diploid line, developed stomata on the adaxial leaf surface. The stomatal area index was reduced for the fusion lines 27-11 and 27-12 compared to the diploid line (Fig. 3.2 C). 
A

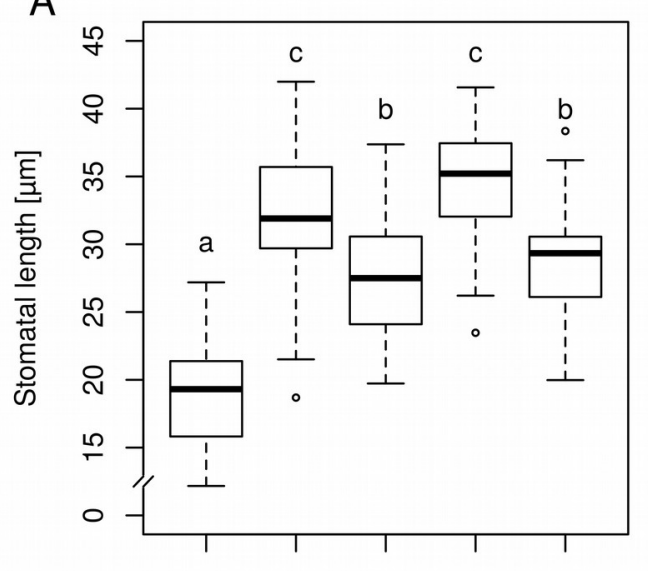

B

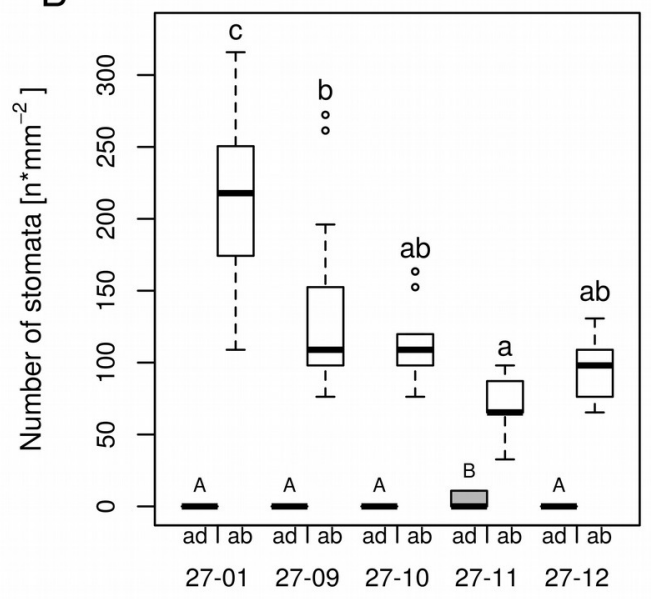

D

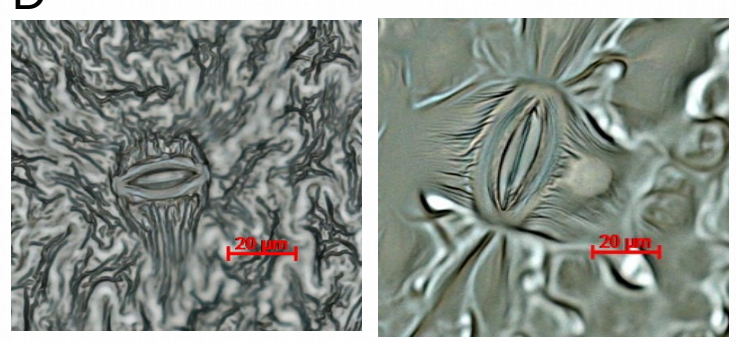

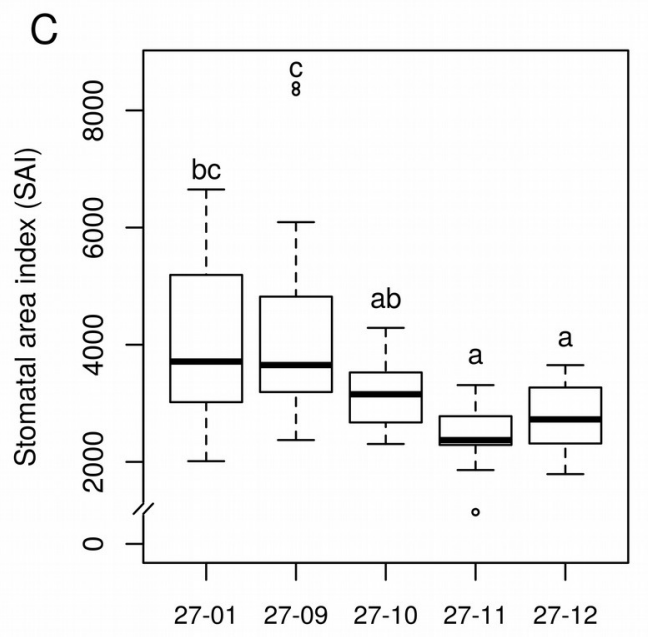

Figure 3.2: (A) Stomatal length ( $\mathrm{n}=45$ stomata per line), (B) stomatal density ( $\mathrm{n}=15$ leaf sections per line and leaf side, grey box: adaxial side (ad), white boxes: abaxial site (ab)) and (C) stomatal area index (SAI, mean stomatal length of three stomata of one leaf section multiplied by the stomatal density of this leaf section, $n=15$ leaf sections per line on abaxial leaf surface), (D) microscopy images of the stomata (left: diploid line 27-01, right: tetraploid fusion line 27-11, $400 \mathrm{x}$ magnification. Boxplot definition: Outer transversal bars of the boxplots include $95 \%$ of the data, $50 \%$ of the data are defined by the boxes themselves, the median is shown by the highlighted line within the box. Outliers are represented by open circles. Different letters at the top of the boxes indicate significant differences between the lines (Tukey HSD test, $\mathrm{p}<0.05$ ), adaxial leaf side is specified by capitals, abaxial site by lowercase letters). 


\subsubsection{Drought stress characterization of hybrid aspen lines}

Interactions between the genotype and the drought treatment occurred in the relative height and stem increment only (Tab. 3.3). All other parameters showed no interaction effects. The parameter light, that was additionally tested for interaction on stomatal conductance had no effect on the target variable (Tab. 3.3).

Table 3.3: Significance of the parameters genotype (G), treatment (T) and light (L) and their interaction effects on the target variables stomatal conductance, carbohydrate concentration, relative height and stem increment $\left(\mathrm{p}<0.05:{ }^{*}, \mathrm{p}<0.01\right.$ : $^{* *}, \mathrm{p}<0.001$ : $* * *$, ns: not significant, - : not analyzed).

\begin{tabular}{l|c|c|c|c|c|c}
\hline Parameter & G & T & L & G:T & G:L & L:T \\
\hline \hline $\begin{array}{l}\text { Stomatal } \\
\text { conductance }\end{array}$ & $\mathrm{ns}$ & $* *$ & $\mathrm{~ns}$ & $\mathrm{~ns}$ & $\mathrm{~ns}$ & $\mathrm{~ns}$ \\
\hline $\begin{array}{l}\text { Carbohydrate } \\
\text { concentration }\end{array}$ & $* * *$ & $* * *$ & - & $\mathrm{ns}$ & - & - \\
\hline $\begin{array}{l}\text { Relative height } \\
\text { increment }\end{array}$ & $* * *$ & $* * *$ & - & $* * *$ & - & - \\
\hline $\begin{array}{l}\text { Relative stem } \\
\text { increment }\end{array}$ & $* * *$ & $* * *$ & - & $*$ & - & - \\
\hline
\end{tabular}

\section{Relative soil moisture}

After stopping irrigation the mean relative soil moisture of the diploid line decreased significantly lower to a value of 0.5 vol.-\% whereas the mean soil moisture of the fusion lines did not drop below 2 vol.-\% (Fig. $3.3 \mathrm{~F}$ ). Instead, at the beginning of the experiment the relative soil moisture of the diploid line was about $30 \mathrm{vol.- \%}$ and thus much lower than that of all fusion lines that started at a relative soil moisture of about 40 vol.-\% (Fig. $3.3 \mathrm{~A}$ - F). 

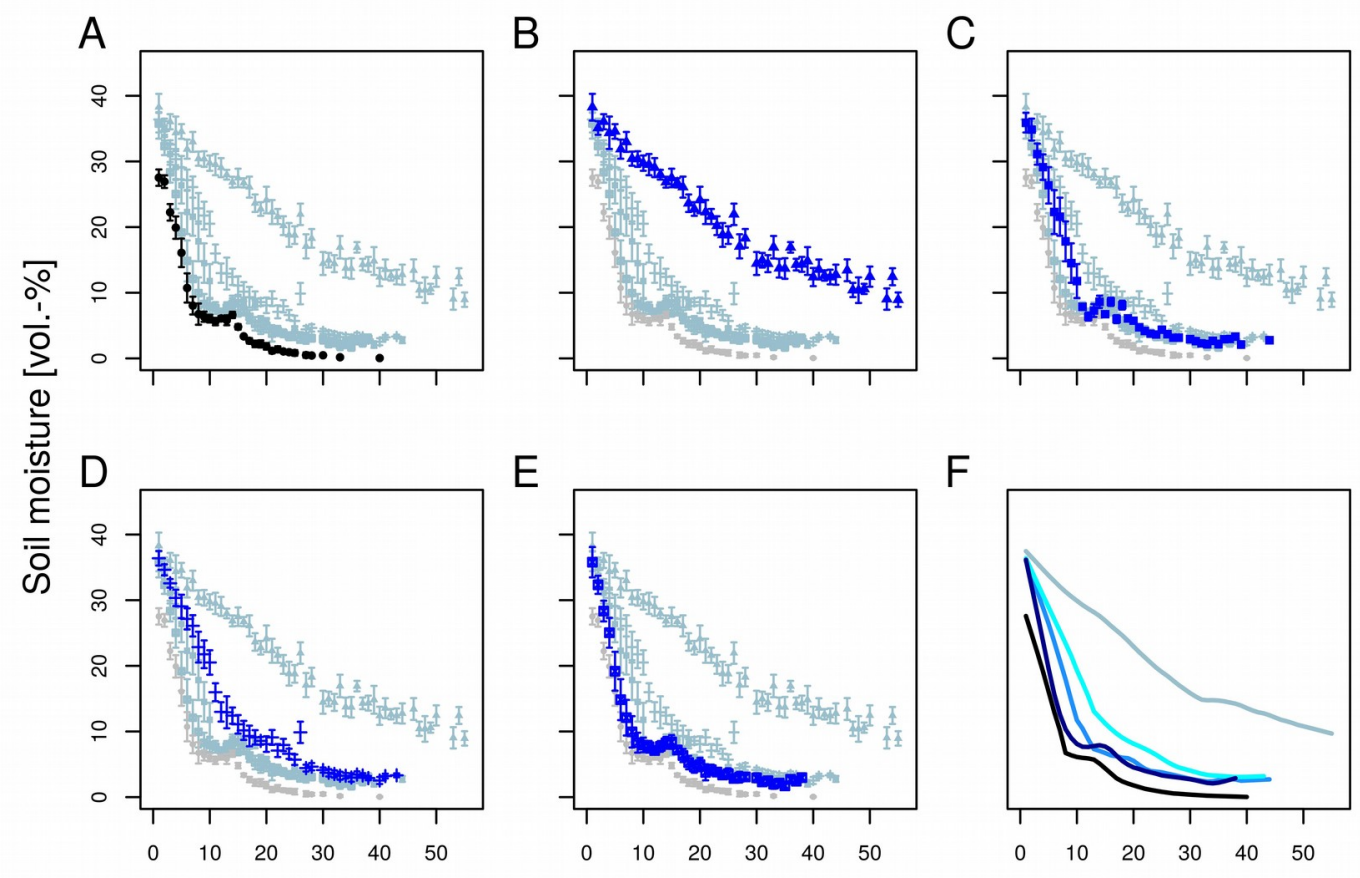

Time [d]

Figure 3.3: Time curves of the relative soil moistures of (A) 27-01, (B) 27-09, (C) 27-10, (D) 27-11, (E) 27-12, (F) plot of the means of all lines (A - E: plot of the means \pm SE, F: means; $\mathrm{n}=10$ plants, data of the respective plot are in bolder colors, others are visualized in light colors, black / grey: diploid line, blue: fusion lines. Different letters indicate significant differences between the lines: 27-01 2 , 27-09 $, 27-10^{\mathrm{c}}, 27-11^{\mathrm{d}}, 27-12^{\mathrm{b}}$ (Wilcoxon signed-rank test, $\mathrm{p}<0.05$ ); plot of the means: $\mathrm{n}=10$ plants, black: $27-01$, light blue: $27-09$, blue: $27-10$, cyan: 27-11, dark blue: 27-12).

\section{Water consumption}

The plants were exposed to drought by gradually drying until the soil moisture levels of 10 vol.-\% were reached (Fig. 3.4 A). Each line attained the target soil moisture at a different time point and was kept at this level for a period of seven days (Fig. 3.4 A). Subsequently, the lines were not watered anymore. The water consumption was determined during the seven-day period at the 10 vol.-\% soil moisture level. The diploid consumed more water than the fusion lines (Fig. 3.4 B). This was not only observed for fusion lines that were smaller than the diploid line, but was also detected for the fusion lines 27-10 and 27-12 when height was respected (Tab. 3.2, Fig. 3.4 B, Fig. 3.5). 

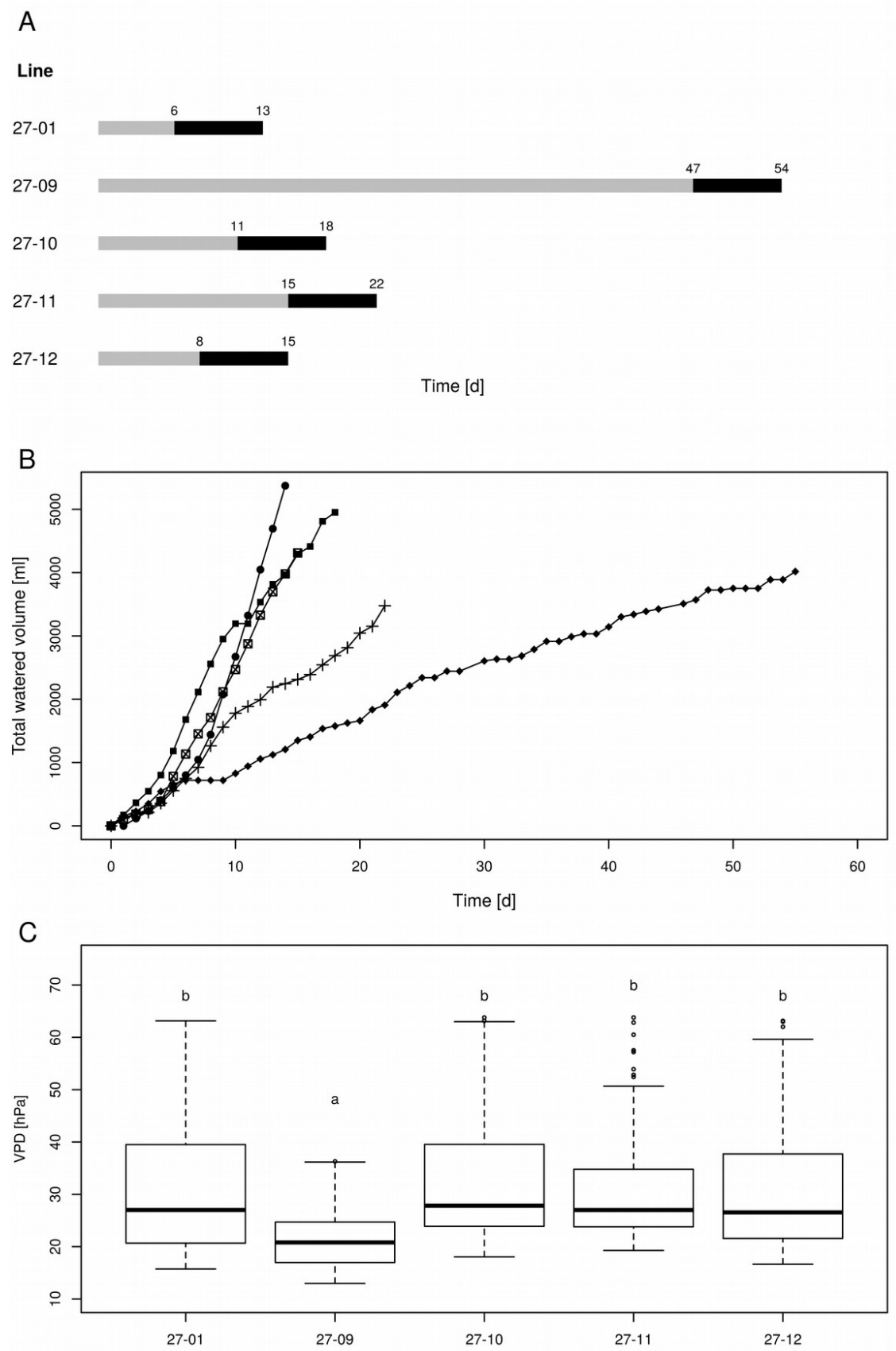

Figure 3.4: (A), Scheme of the drought periods, (B) cumulative water volumes applied to each line, $(\mathbf{C})$ vapor pressure deficit (vpd) over the 10 vol.-\% relative soil moisture period (grey bar: drying period until the 10 vol.-\% soil moisture level was reached for all plants of one line, black bar: 10 vol.-\% soil moisture period; 27-01: circles, 27-10: squares, 27-11: crosses, 27-12: crossed squares. Boxplots are defined as explained in Fig. 1.2, different letters at the top of the boxes indicate significant differences between the lines (TukeyHSD test, $\mathrm{p}<0.05)$ ). 
A further factor that may influence the water consumption is a variation in the vpd. Although the periods when the plants experienced 10 vol.-\% soil moisture occurred at different time points, vpd levels did not differ except for the fusion line 27-09 (Fig. $3.4 \mathrm{C}$ ). Here, the vpd was lower compared to all other lines. Relative to the height this line consumed as much water as the diploid line and even more than the fusion lines 27-10 and 27-12 (Fig. 3.5) that experienced higher vpd. Therefore, variation in vpd among the lines was not the reason for differences in the water consumption. The linear regression analysis showed that the fusion lines 27-10 and 27-12 consumed significantly less water with regard to height than the diploid line (Fig. 3.5).

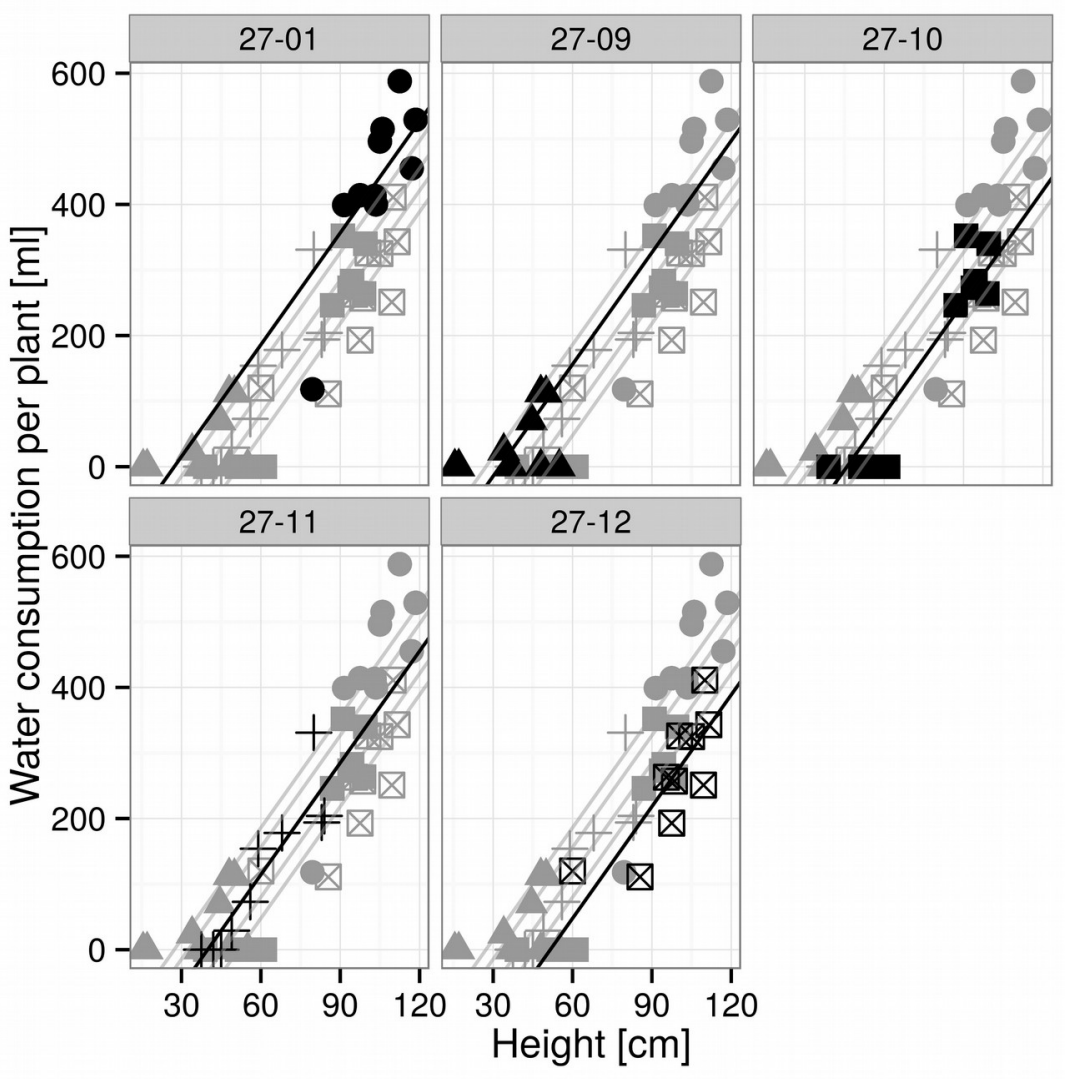

Figure 3.5: Water consumption per plant for seven days at the 10 vol.-\% soil moisture level dependent on their height (27-01: circles, 27-10: squares, 27-11: crosses, 27-12: crossed squares, $\mathrm{n}=10$ plants, data and the regression line of the respective plot are in black, others are visualized in grey; groups with different letters indicate significant differences between the lines (exact F-Test, $\mathrm{p}<0.05$ ): 27-01 ${ }^{\mathrm{a}}, 27-09^{\mathrm{a}}, 27-10^{\mathrm{b}}, 27-11^{\mathrm{ab}}, 27-12^{\mathrm{b}}$ ). 


\section{Leaf vitality}

Leaf wilting and desiccation were determined as indicators for plant vitality (Fig. 3.6 A, B). The wilting process of the diploid plants occurred more rapidly with a steeper increment than in the fusion lines. Average leaf wilting of about $85 \%$ already appeared at the third day after the final irrigation of the diploid line. Similarly strong wilting occurred in the fusion line 27-12 at day nine after the last watering, whereas this threshold was not observed for the fusion lines 27-10 and 27-11 during the whole experiment. Instead, desiccation of leaves was first visible in two fusion lines. The lines 27-10 and 27-12 showed a proportional leaf wilting of about $25 \%$ and $50 \%$, respectively, already at the end of the 10 vol.-\% soil moisture phase. Early leaf desiccation might have had an influence on leaf wilting because leaf desiccation reduces the transpiration surface.

A

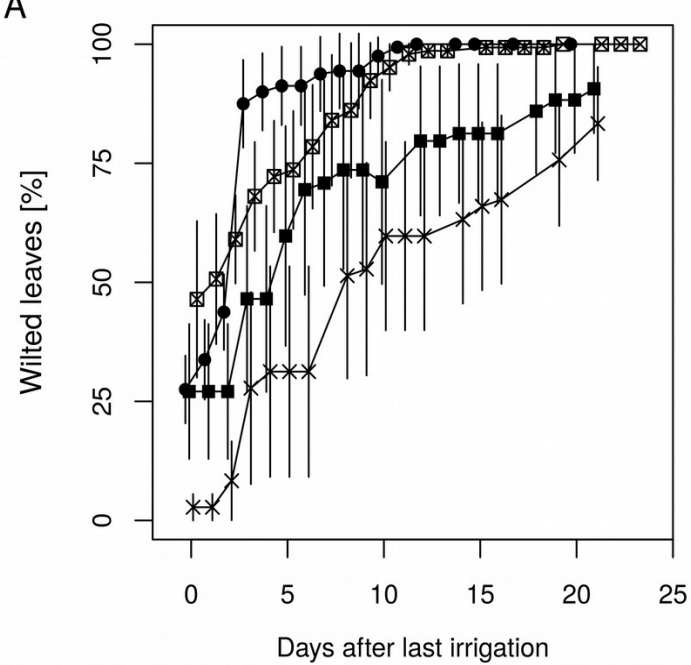

B

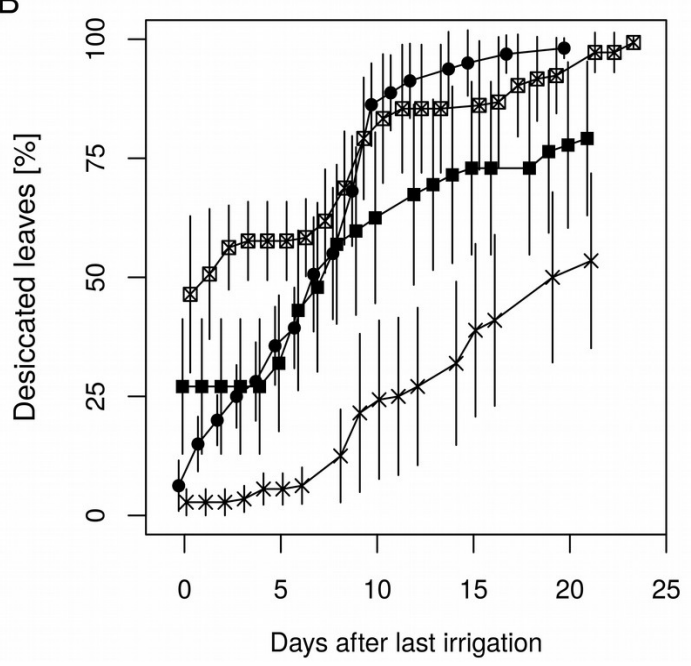

Figure 3.6: Time course of (A) leaf wilting, $\mathbf{( B )}$ desiccation of leaves (data are normalized to the last irrigation event and are means \pm SE, $n=10$ plants. 27-01: circles, 27-10: squares, 27-11: crosses, 27-12: crossed squares. Different letters indicate significant differences between the lines: wilting: $27-01^{\mathrm{a}}, 27-10^{\mathrm{c}}, 27-11^{\mathrm{d}}, 27-12^{\mathrm{b}}$, desiccation: $27-01^{\mathrm{a}}, 27-10^{\mathrm{a}}, 27-11^{\mathrm{c}}$, 27-12 (Wilcoxon signed-rank test, $\mathrm{p}<0.05$ )).

Maximum desiccation of $100 \%$ was reached for the diploid and the fusion line 27-12 twenty days after last irrigation whereas this event did not occur for the fusion lines 27-10 and 27-11. This analysis could not be conducted for the fusion line 27-09, 
3.1 Morphological and drought stress characterization of the diploid original line and tetraploid fusion lines of hybrid aspen

which was the smallest line with the lowest leaf area (Tab. 3.2) and consequently consumed little water. Therefore, this line reached the target date for stopping irrigation (i.e. after seven days at 10 vol.-\% soil moisture) only two days before the end of the whole experimental time period, when leaves of other lines were already wilted.

\section{Stomatal conductance and carbohydrate concentrations}

Under well-watered conditions, no differences were observed among the stomatal conductance of the diploid line and the fusion lines (Fig. 3.7 A).

A

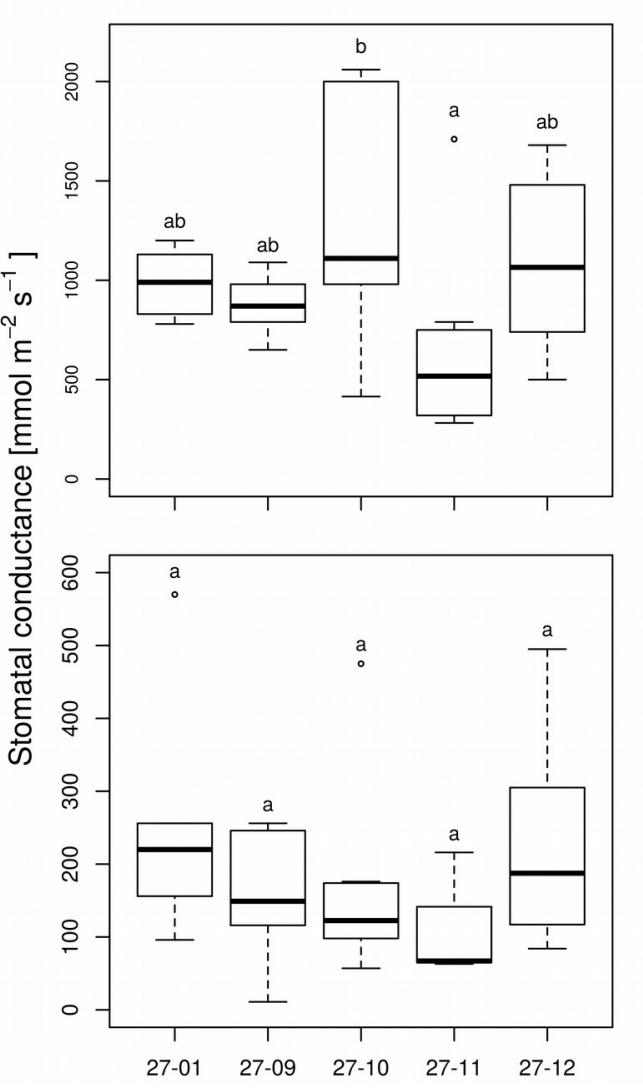

$\mathrm{C}$

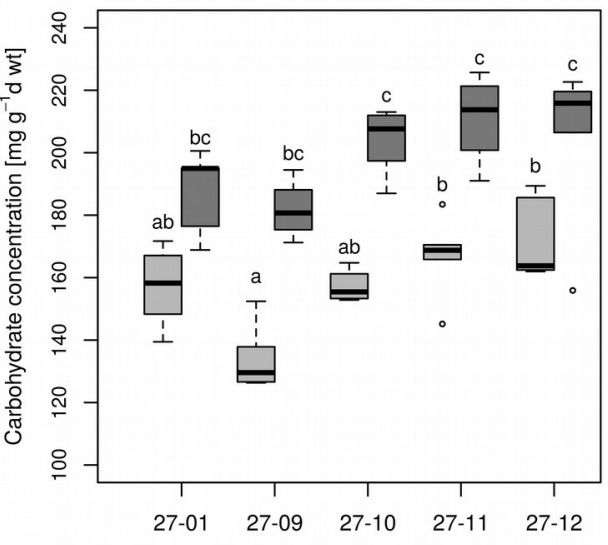

Figure 3.7: Stomatal conductance (A) watered plants, (B) drought-exposed plants and (C) carbohydrate concentration at the end of the 10 vol.-\% soil moisture level (stomatal conductance: $n=10$ plants, carbohydrate concentration: $n=6$ plants, light grey: control plants, dark grey: drought-exposed plants, boxplots are defined as explained in Fig. 3.2, different letters at the top of the boxes indicate significant differences between the lines (TukeyHSD test, $\mathrm{p}<0.05$ ), adaxial leaf side is specified by capitals, abaxial site by lowercase letters). 
All tested lines responded to dry conditions with a reduction in the stomatal conductance (Fig. 3.7 A, B) whereas this did not differ among the drought-exposed lines (Fig. 3.7 B). Here, stomatal conductance was not correlated with stomatal density (Fig. 3.2 B, Fig.3.7 A, B). All fusion lines increased their foliar carbohydrate concentrations in response to drought (Fig. 3.7 C). In the diploid line, the increase was not significant (Fig. 3.7 C). Overall, the carbohydrate concentrations of the fusion lines were similar to that of the diploid line (Fig. 3.7 C).

\section{Biomass production}

Among the fusion lines the relative height increment was reduced under drought in the lines 27-10, 27-11 and 27-12, but not in the line 27-09. This line probably suffered only from mild drought because this fusion line was smaller than the other lines (Fig. 3.8 A). Instead, the diploid line experienced severe drought stress but showed no reduction in relative height increment (Fig. 3.8 A).
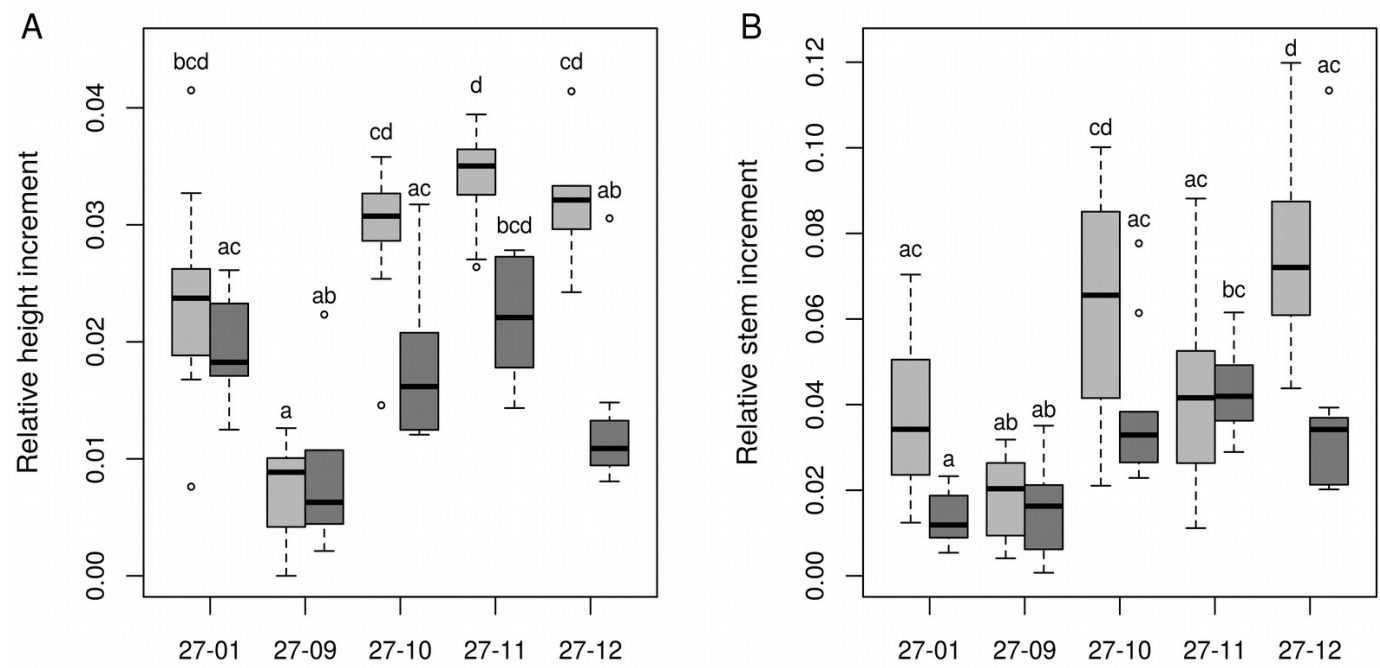

Figure 3.8: (A) Relative height increment (data are normalized to the number of cultured ( $\equiv$ irrigated) days), (B) Relative stem increment (stem without the leaves, data are normalized to the number of irrigated days; watered plants: light grey, drought-exposed plants: dark grey, $\mathrm{n}=10$ plants. Boxplots are defined as explained in Fig. 3.2, different letters at the top of the boxes indicate significant differences between the lines (TukeyHSD test, $\mathrm{p}<0.05$ )). 
Under optimally watered conditions the relative height growth of the fusion lines 27-10, 27-11 and 27-12 was equivalent to that of the diploid line, while that of the fusion line 27-09 was significantly lower (Fig. 3.8 A).

Dry matter of the stem is an important parameter for biomass production in short rotation coppice. The shoot dry matter was analyzed without the leaves. The relative stem increment was not decreased in the fusion lines but enhanced for the fusion line 27-12 compared to the diploid line under optimally watered conditions (Fig. 3.8 B). Under the drought treatment, relative shoot increment was equivalent to the diploid line in all fusion lines except for the fusion line 27-11 that showed an increased relative shoot increment (Fig. $3.8 \mathrm{~B}$ ). 


\subsection{Drought performance of 20 hybrid aspen fusion lines and detailed drought responses of selected tetraploid hybrid aspen lines}

\subsubsection{Screening of hybrid aspen lines of different ploidy level for drought performance and morphological traits}

\section{Morphological characterization of 20 hybrid aspen fusion lines}

Twenty protoplast fusion lines were tested including fourteen fusion lines that were obtained by protoplast fusion experiments between $P$. tremula $\mathrm{x} P$. tremuloides and P. nigra and six fusion lines between $P$. tremula $\mathrm{x} P$. tremuloides and $P$. $\mathrm{x}$ canescens (Tab. 4.1).

For the basic characterization of the fusion lines the leaf morphology was analyzed phenotypically and for genetic characterization flow cytometry and microsatellite analysis using $11 \mathrm{nSSR}$ primers were conducted. The leaf morphology of all fusion lines showed a P. tremula $\times$ P. tremuloides phenotype and was assigned to the original hybrid aspen (Tab.4.1). According to the nSSR markers only DNA of the hybrid aspen and no DNA of the other fusion partners was detected (Tab. 4.1). Four fusion lines $(14-08,18-04,18-07,18-11)$ of 20 revealed a diploid set of chromosomes according to the flow cytometry analysis (Tab. 4.1). Two of these fusion lines were out of protoplast fusion experiments between $P . \mathrm{x}$ canescens and P. tremula $\mathrm{x}$ P. tremuloides and two of a fusion experiment between P. tremula x P. tremuloides and P. nigra (Tab. 4.1). All other fusion lines were tetraploid (Tab. 4.1). As the diploid "fusion" lines probably did not experience protoplast fusion they are named diploid "fusion" lines in the following text. The protoplast fusion lines with a tetraploid set of chromosomes are called tetraploid fusion lines and the original diploid clone 18-03 is referred to as diploid original line. In the following graphics the diploid original and the diploid "fusion" lines are visualized in grey colors and the tetraploid fusion lines in blue. 
Table 4.1: Morphological and genetic characterization of diploid "fusion" and tetraploid fusion lines of hybrid aspen (for all analyses in vitro material was used, plants were subcultured for four weeks, when leaf morphology was determined; diploid original line: 18-03, diploid "fusion" lines: 14-08, 18-04, 18-07, 18-11, other fusion lines are tetraploid, “-”: ploidy analysis not performed. For homocygote alleles only one fragment length is listed, if heterocygosity occurred all detected fragment lengths are shown (0: microsatellite does not exist in this organism, -1: failure). P1: P. x canescens (INRA clone No. 717 1-B4), P3: P. tremula x P. tremuloides ('Münden2'), P7: P.nigra, P9: P. trichocarpa x P. deltoides (B19)).

\begin{tabular}{|c|c|c|c|c|c|c|c|c|c|c|c|c|c|c|}
\hline Line & Fusion partners & $\begin{array}{c}\text { Leaf } \\
\text { morphology }\end{array}$ & $\begin{array}{c}\text { Ploidy } \\
\text { level }\end{array}$ & $\begin{array}{c}\text { nSSR marker } \\
\text { GCPM2768 }\end{array}$ & ORPM0023 & ORPM1031 & ORPM1249 & ORPM1261 & PMGC0433 & PMGC2163 & WPMS05 & WPMS09 & WPMS12 & WPMS14 \\
\hline $18-03$ & Original line P3 & P3 & $2 n$ & 189 & 167,177 & -1 & 95 & 134,138 & 182,190 & 191, 203 & 272,302 & 0 & 159,165 & 208,229 \\
\hline P7 & Original line P7 & P7 & - & 181 & 173 & -1 & 103 & 122 & 196 & 223 & 280,300 & 257,263 & 161 & -1 \\
\hline P9 & Original line P9 & P9 & - & 181,195 & 189, 199 & 132 & 105 & 110,132 & 208,216 & 187, 205 & 278 & 233,283 & 153,167 & 238,253 \\
\hline 14-01 & P3 x P7 & P3 & $4 n$ & 189 & 167,177 & 116,130 & 95 & 134,138 & 182,190 & 191, 203 & 272,302 & 0 & 159, 165 & 208,229 \\
\hline $14-02$ & P3 x P7 & P3 & $4 n$ & 189 & 167,177 & -1 & 95 & 134,138 & 182,190 & 191, 203 & 272,302 & 0 & 159, 165 & 208,229 \\
\hline $14-03$ & P3 x P7 & P3 & $4 n$ & 189 & 167,177 & 116,130 & 95 & 134,138 & 182, 190 & 191, 203 & 272,302 & 0 & 159,165 & 208,229 \\
\hline $14-04$ & P3 x P7 & P3 & $4 n$ & 189 & 167,177 & 116,130 & 95 & 134, 138 & 182,190 & 191, 203 & 272,302 & 0 & 159, 165 & 208, 229 \\
\hline $14-05$ & P3 x P7 & P3 & $4 n$ & 189 & 167,177 & 116,130 & 95 & 134,138 & 182, 190 & 191, 203 & 272,302 & 0 & 159,165 & 208, 229 \\
\hline $14-06$ & P3 x P7 & P3 & $4 n$ & 189 & 167,177 & -1 & 95 & 134,138 & 182, 190 & 191, 203 & 272,302 & 0 & 159, 165 & 208,229 \\
\hline $14-07$ & P3 x P7 & P3 & $4 n$ & 189 & 167,177 & 116,130 & 95 & 134,138 & 182, 190 & 191, 203 & 272,302 & 0 & 159, 165 & 208, 229 \\
\hline $14-08$ & P1 x P3 & P3 & $2 n$ & 189 & 167,177 & 116,132 & 95 & 134,138 & 182, 190 & 191, 203 & 272,302 & 0 & 159,165 & 208,229 \\
\hline 14-09 & P1 x P3 & P3 & $4 n$ & 189 & 167,177 & 116, 132 & 95 & 134, 138 & 182, 190 & 191, 203 & 272,302 & 0 & 159,165 & 208, 229 \\
\hline $14-10$ & P1 x P3 & P3 & $4 n$ & 189 & 167,177 & -1 & 95 & 134,138 & 182,190 & 191, 203 & 272, 302 & 0 & 159, 165 & 208, 229 \\
\hline 18-04 & P3 x P7 & P3 & $2 n$ & 189 & 167,177 & 116,130 & 95 & 134, 138 & 182,190 & 191, 203 & 272, 302 & 0 & 159,165 & 208,229 \\
\hline 18-05 & P3 x P7 & P3 & $4 n$ & 189 & 167,177 & 116,130 & 95 & 134,138 & 182,190 & 191, 203 & 272,302 & 0 & 159, 165 & 208,229 \\
\hline 18-06 & P3 x P7 & P3 & $4 n$ & 189 & 167,177 & 116,130 & 95 & 134, 138 & 182,190 & 191, 203 & 272,302 & 0 & 159, 165 & 208,229 \\
\hline $18-07$ & P3 x P7 & P3 & $2 n$ & 189 & 167,177 & 116, 130 & 95 & 134, 138 & 182,190 & 191, 203 & 272, 302 & 0 & 159, 165 & 208,229 \\
\hline 18-08 & P3 x P7 & P3 & $4 n$ & 189 & 167,177 & 116, 130 & 95 & 134, 138 & 182,190 & 191, 203 & 272, 302 & 0 & 159, 165 & 208, 229 \\
\hline 18-09 & P3 x P7 & P3 & $4 n$ & 189 & 167,177 & 116, 130 & 95 & 134, 138 & 182,190 & 191, 203 & 272, 302 & 0 & 159,165 & 208,229 \\
\hline 18-10 & P3 x P7 & P3 & $4 n$ & 189 & 167,177 & 116,130 & 95 & 134, 138 & 182,190 & 191, 203 & 272, 302 & 0 & 159,165 & 208,229 \\
\hline 18-11 & P1 x P3 & P3 & $2 n$ & 189 & 167,177 & 116,130 & 95 & 134, 138 & 182, 190 & 191, 203 & 272, 302 & 0 & 159,165 & 208,229 \\
\hline $18-12$ & P1 x P3 & P3 & $4 n$ & 189 & 167,177 & 116,130 & 95 & 134, 138 & 182, 190 & 191, 203 & 272,302 & 0 & 159, 165 & 208,229 \\
\hline 18-13 & P1 x P3 & P3 & $4 n$ & 189 & 167,177 & 116,132 & 95 & 134, 138 & 182,190 & 191, 203 & 272, 302 & 0 & 159,165 & 208,229 \\
\hline
\end{tabular}


The height was measured after the plants were cultivated for 12 weeks in soil. The mean height was calculated for the diploid "fusion" lines and the tetraploid fusion lines (Fig. 4.1). The tetraploid fusion lines exhibited reduced height growth $(43 \mathrm{~cm})$ while the diploid "fusion" lines showed increased height $(58 \mathrm{~cm})$ compared to the diploid original line (49 cm) (Fig. 4.1). But significant height reduction in comparison to the diploid original line 18-03 was only detected in two tetraploid fusion lines (18-10, 18-13) (Fig. 4.1). Instead, in the diploid “fusion” lines height growth was increased compared to the diploid original clone 18-03 but significant higher only in the fusion line 14-08 (Fig. 4.1).

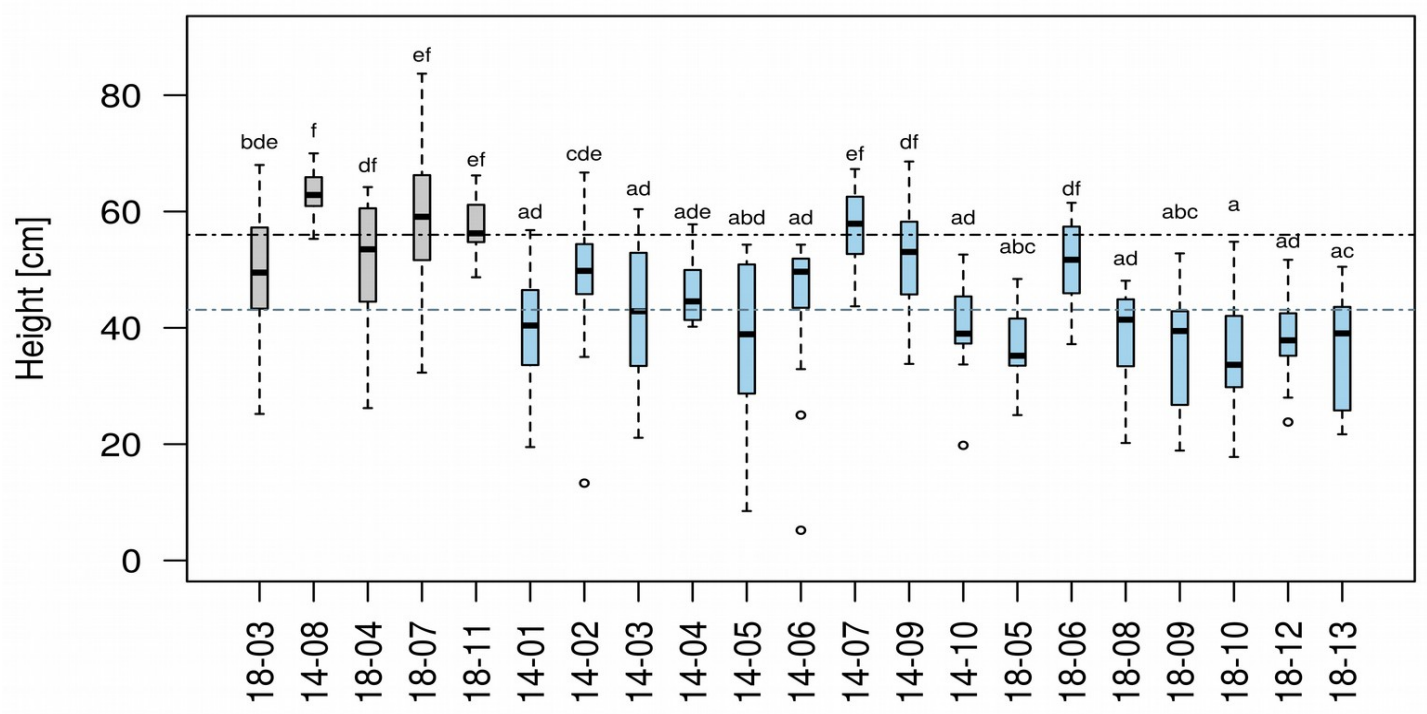

Figure 4.1: Height and overall mean height for the diploid and tetraploid fusion lines (plants were measured at the beginning of the experiment after 12 weeks in soil; diploid lines: grey boxes (18-03: diploid original line, 14-08, 18-04, 18-07, 18-11: diploid "fusion" lines), blue boxes: tetraploid fusion lines, $\mathrm{n}=20$ plants; dotted lines: median of the lines (black: diploid, blue: tetraploid, $n=20$ plants). Boxplots are defined as explained in Fig. 3.2. Different letters at the top of the boxes indicate significant differences between the lines (Tukey-Test, $\mathrm{p}<0.05)$ ). 


\section{Drought performance of 20 hybrid aspen fusion lines}

\section{Survival rate}

After the water had been withheld for 35 days the survival rate was investigated as plants that sprouted after re-irrigation. The survival rate of the tetraploid fusion lines was higher compared to the diploid lines (Fig. 4.2).

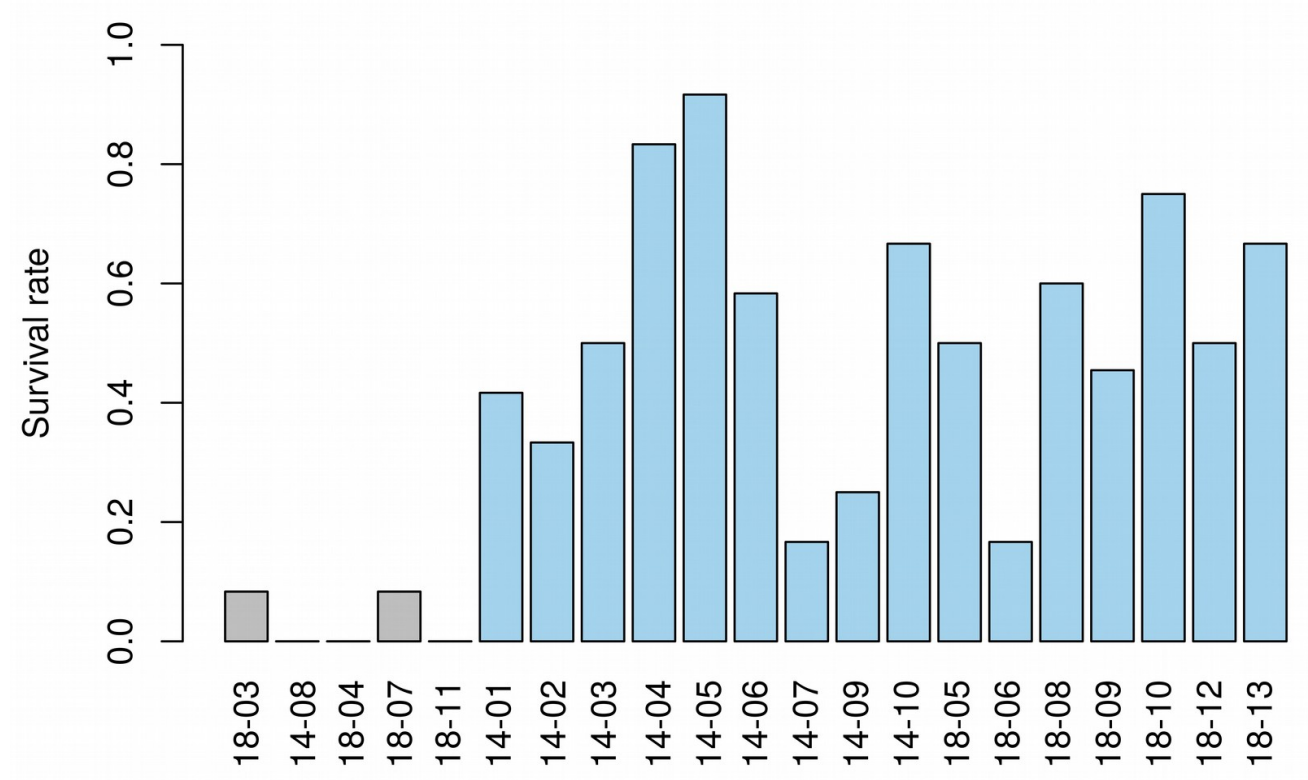

Figure 4.2: Survival rate after re-irrigation when water was withheld for 35 days (observed after six month, 18-03: diploid original line, 14-08, 18-04, 18-07, 18-11: diploid "fusion" lines; others are tetraploid fusion lines, $\mathrm{n}=12$ plants except for the lines 18-05: 8, 18-08: 5, 18-09: 9, 18-12: 8 plants. Different letters indicate significant differences between the ploidy levels: diploid original line ${ }^{\mathrm{a}}$, diploid "fusion" lines ${ }^{\mathrm{a}}$, tetraploid fusion lines ${ }^{\mathrm{b}}$ (exact F-Test, $\mathrm{p}<0.05)$ ).

\section{Relative leaf water content (RWC)}

For analysis of the drought performance the leaf RWC was measured at the days 7, 19 and 26. Here, a decrease was detected for the diploid "fusion" lines and the diploid original line at DAI (day after irrigation) 19 (Fig. $4.3 \mathrm{~A}, \mathrm{~B}$ ). At this time point only one tetraploid fusion line (14-09) showed a lower RWC than the diploid original line 
(Fig. 4.3 A). At day 26 without irrigation the RWC of the tetraploid fusion lines 14-01, 14-07, 14-09 and 18-06 was more decreased than that of the diploid original line 18-03 (Fig. 4.3 A, B). The remaining tetraploid fusion lines in contrast to the diploid original line, showed a higher RWC (Fig. 4.3 A, B). All diploid "fusion" lines had a decreased RWC in comparison to the diploid original line at DAI 26 (Fig. 4.3 A, B). Overall, the lower RWCs of the diploid lines indicate a higher drought stress for the diploid plants compared to the tetraploid fusion lines.

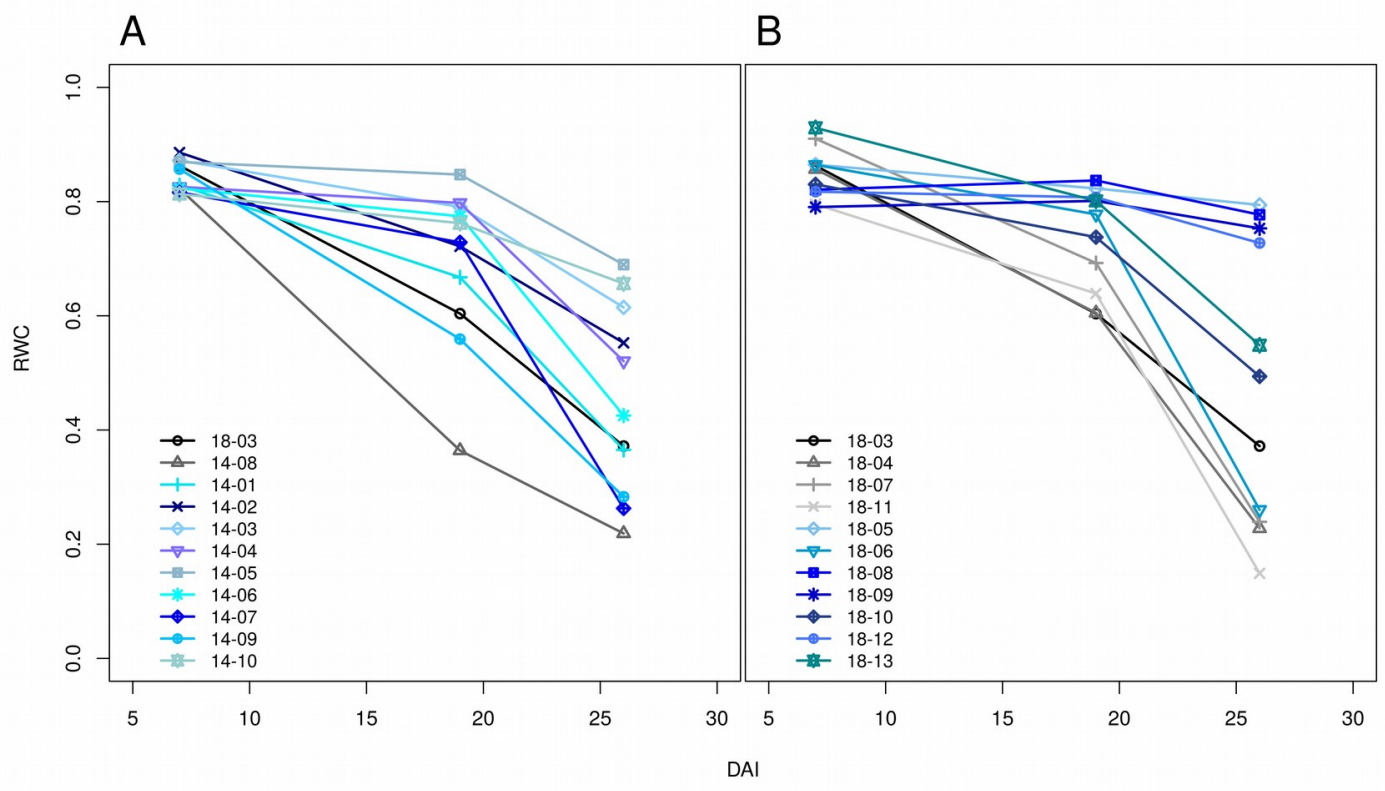

Figure 4.3: Relative water content at day 7, 19 and 26 after irrigation (A) line numbers 14, (B) line numbers 18 (black: diploid original line: 18-03, gray: diploid "fusion" lines: 14-08, 18-04, 18-07, 18-11; blue: tetraploid fusion lines; DAI = day after irrigation; to obtain a better overview of the data they were separated into two graphs according to their line identification numbers). 


\section{Leaf wilting with regard to height}

The DAI when total leaf wilting was observed highly correlated with the plants' height $\left(\mathrm{R}^{2}=0.69\right.$, Fig. 4.4). Therefore, a linear regression model was applied to analyze the mean DAI when $100 \%$ of the leaves were wilted with respect to height and compared to the diploid original line (Fig. 4.5).

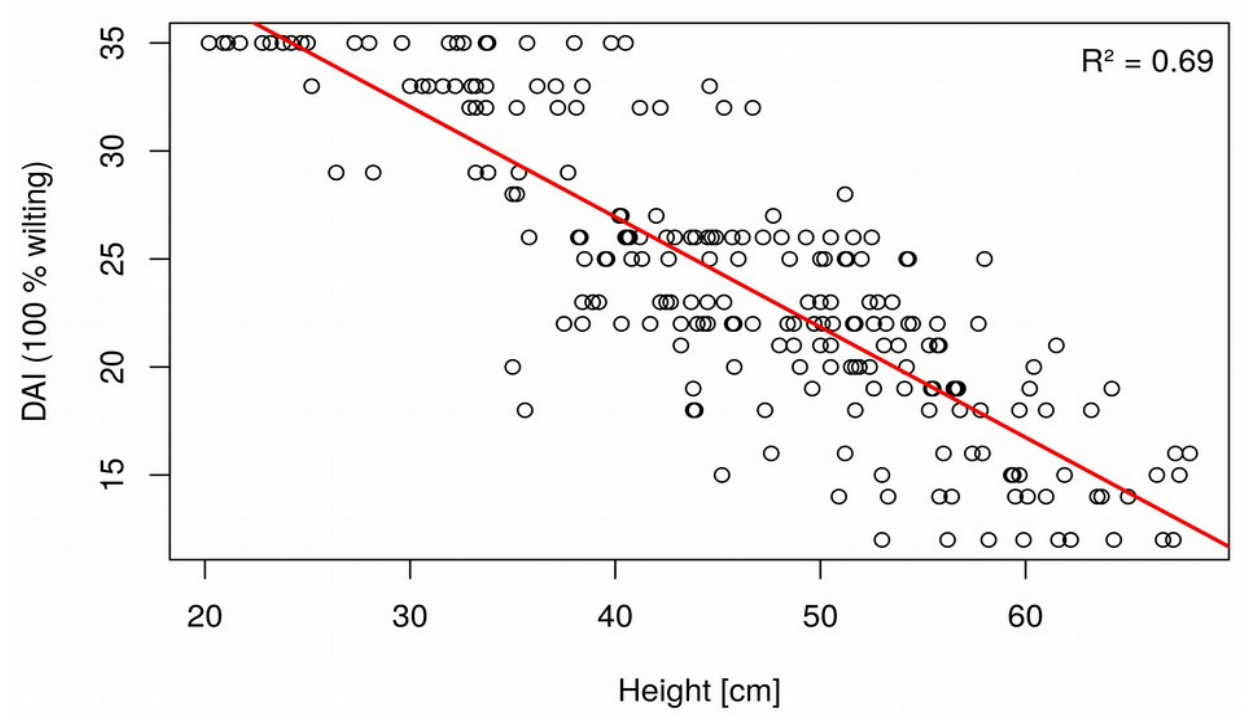

Figure 4.4: Scatterplot of the height at the beginning of the experiment and the DAI (day after last irrigation) when $100 \%$ leaf wilting occurred ( $\mathrm{n}=221$ plants, $\left.\mathrm{R}^{2}=0.69\right)$.

Neither the diploid nor the tetraploid fusion lines wilted earlier with regard to height than the diploid original line (Fig. 4.5). For the tetraploid fusion lines only and not for the diploid "fusion" lines leaf wilting was significantly delayed (Fig. 4.5). Here, the tetraploid fusion lines 14-03, 14-04, 14-05, 14-06, 14-07, 14-10, 18-05, 18-08, 18-10, 18-12 and 18-13 wilted later considering the height than the diploid original line (Fig. 4.5). As the diploid "fusion" lines showed no delay of the DAI when total leaf wilting appeared, this might be influenced by the tetraploidy. The tetraploid fusion lines 14-03, 14-04 and 14-07 showed both comparable height growth to the diploid original line and a delay in total leaf wilting with regard to the diploid original line (Fig. 4.1, Fig. 4.5). 


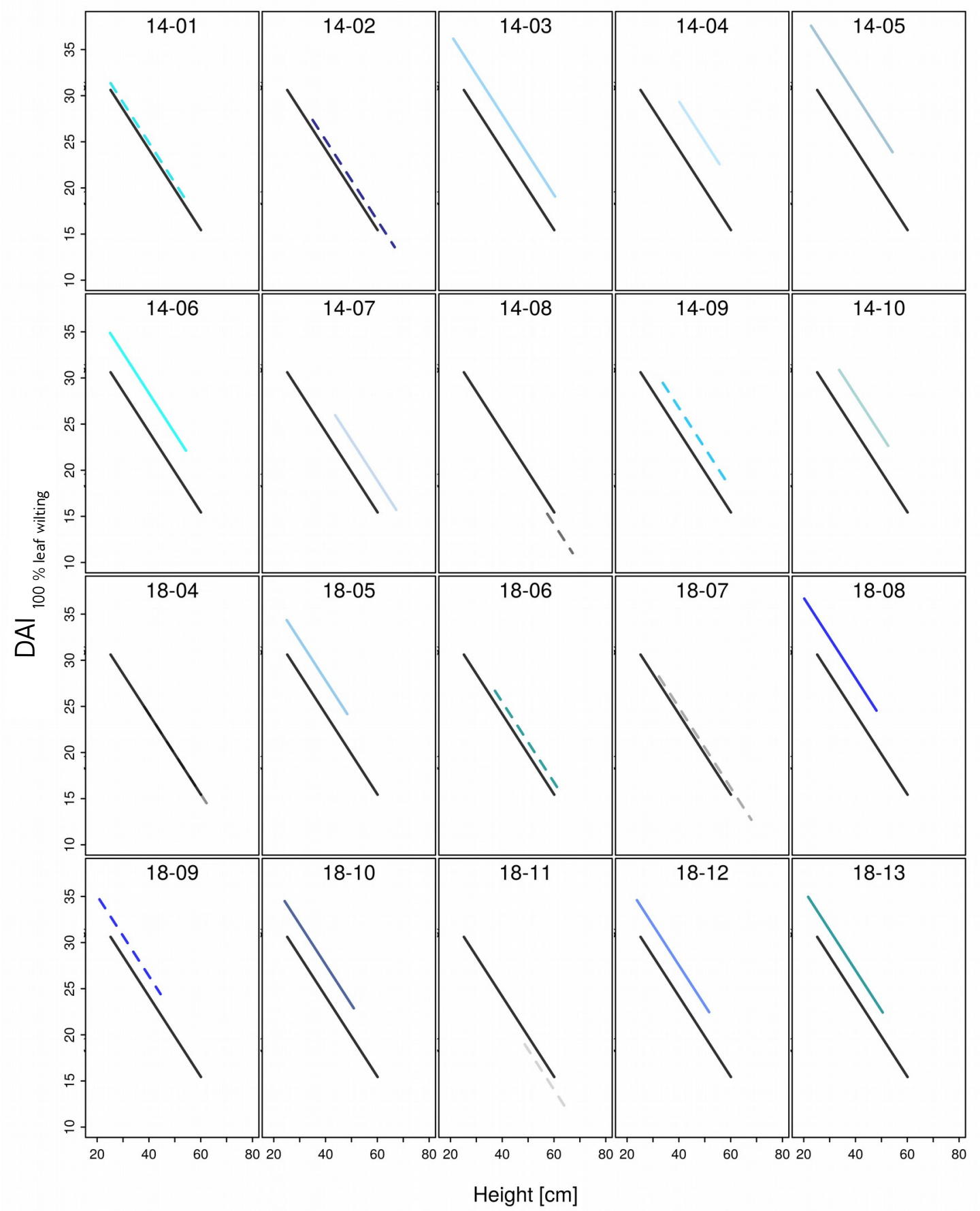

Figure 4.5: Linear regression model of the day after irrigation (DAI) when total leaf wilting occurred and the height of the plants (lines were drawn in the data range only where "height" and "DAI" data were available; the number of the respective hybrid aspen line is written at the top of each sub-plot, each line is plotted together with the diploid original line 18-03 (black line) as reference, diploid "fusion" lines: 14-08, 18-04, 18-07, 18-11 (grey lines); other lines: tetraploid fusion lines (blue lines); lines that differed significantly (exact F-Test, $\mathrm{p}<0.05$ ) from 18-03 are visualized in lines, others are in dashed lines). 


\section{Leaf vitality loss}

The leaf vitality loss was analyzed as the DAI when $100 \%$ of the leaves were wilted as well as $25 \%$ and $100 \%$ of the leaves were desiccated. The mean DAI was analyzed over all plants per line. These analyses revealed that some lines first showed a leaf wilting of $100 \%$ and afterwards the foliage began to dry (Fig. 4.6).

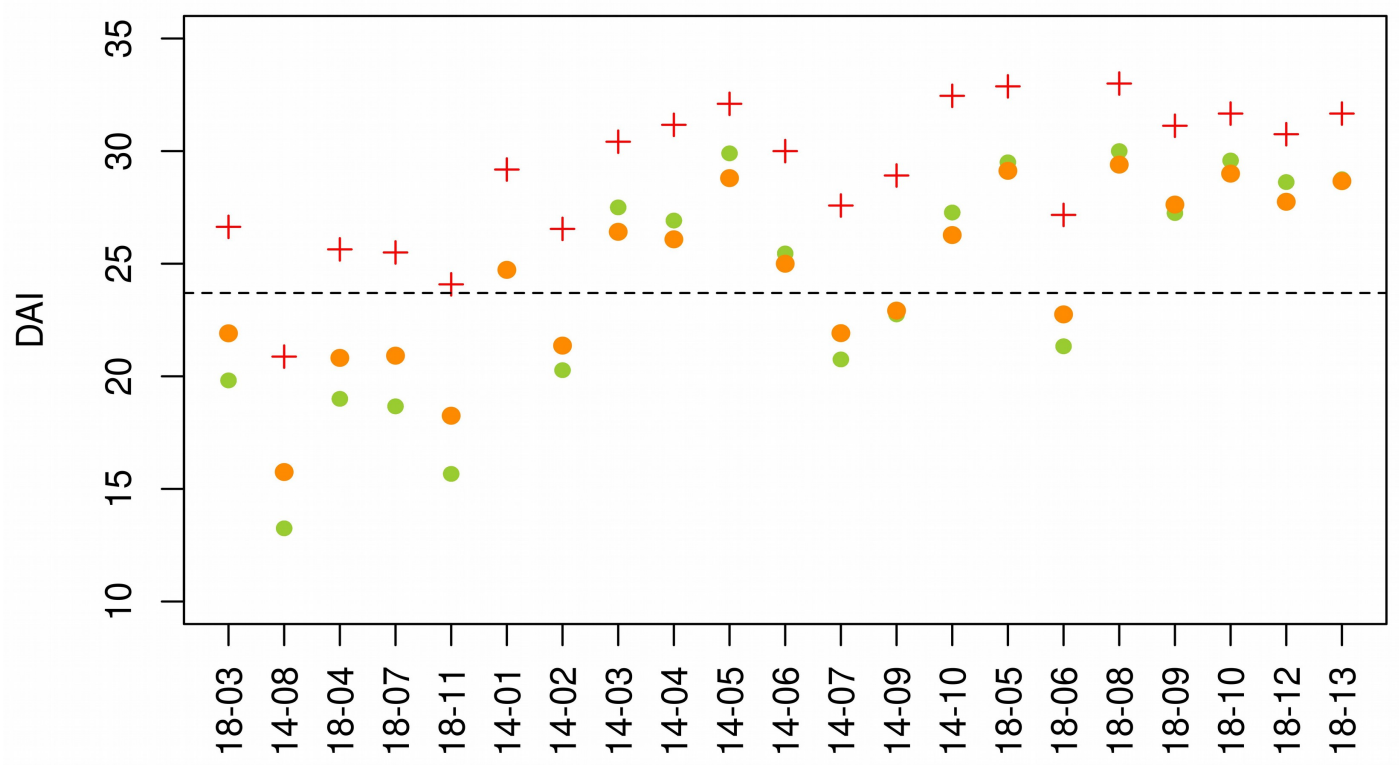

Figure 4.6: DAI (day after irrigation) when $100 \%$ leaf wilting (green dot), $25 \%$ leaf desiccation (orange dot) and $100 \%$ leaf desiccation (red cross) occurred (diploid original line: 18-03, diploid "fusion" lines: 14-08, 18-04, 18-07, 18-11; other lines are tetraploid fusion lines; dotted line: lines above this line first reached the $25 \%$ leaf desiccation and then the $100 \%$ leaf wilting point, lines below: first the $100 \%$ leaf wilting point and afterwards the $25 \%$ leaf desiccation occurred).

For example, in the diploid original line 18-03 and in all diploid "fusion" lines the $100 \%$ leaf wilting occurred before the $25 \%$ leaf desiccation (Fig 4.6). Also for the tetraploid fusion lines 14-02, 14-07, 14-09, 18-06 and 18-09 total leaf wilting was investigated before partly drying of the leaves (Fig. 4.6). These lines and also the diploid "fusion" lines showed no significant delay in the DAI when total leaf wilting occurred with respect to height except for 14-07 (Fig 4.5) and all showed low survival rates (Fig. 4.2). The tetraploid fusion lines 14-01, 14-03, 14-04, 14-05, 14-06, 14-10, 
18-05, 18-08, 18-10, 18-12 and 18-13 first dried only a part of their leaves and afterwards the $100 \%$ leaf wilting occurred (Fig 4.6). These lines showed high survival rates (Fig. 4.2) and a delayed total leaf wilting with respect to height except for the tetraploid fusion line 14-01 (Fig. 4.5). These results suggest that drying of a part of the foliage delays total leaf wilting and enhances the survival rate.

The observed leaf vitality data were underpinned by the analyses of the leaf RWC that were measured at the days 7, 19 and 26. The correlation analysis of the leaf vitality data and the RWC data was conducted as follows. First, the mean DAI when $100 \%$ of the leaves were wilted as well as $25 \%$ and $100 \%$ were desiccated were calculated for each line. Then, the correlation between the DAI and the respective RWC were determined for the days 7, 19 and 26 using pearson's correlation. Afterwards, the coefficients of determination were calculated (Tab. 4.2). The DAI for the analyzed leaf vitality parameters showed high coefficients of determinations values with the leaf RWC values at the days 19 and 26 and not at day 7 (Tab 4.2). These results strengthen the leaf vitality analysis.

Table 4.2: Coefficient of determination between the DAI (day after irrigation) when leaf vitality loss occurred (100\% leaf wilting and $25 \%$ and $100 \%$ leaf desiccation) and the relative leaf water content (RWC) at the days 7, 19 and 26 (means of leaf RWC at the respective day and means of the day when the respective event occurred were calculated per line, then the data were calculated for pearson's correlation and subsequently the data were squared).

\begin{tabular}{l|c|c|c}
\hline Leaf vitality & RWC (d7) & RWC (d19) & RWC (d26) \\
\hline \hline DAI 100 \% leaf wilting & 0.008 & 0.819 & 0.672 \\
\hline $\begin{array}{l}\text { DAI 25 \% of the leaves } \\
\text { desiccated }\end{array}$ & 0.012 & 0.817 & 0.687 \\
\hline $\begin{array}{l}\text { DAI 100 \% of the leaves } \\
\text { desiccated }\end{array}$ & 0.002 & 0.729 & 0.694 \\
\hline
\end{tabular}




\subsubsection{Detailed drought responses of selected tetraploid hybrid aspen lines}

The tetraploid fusion lines 14-04 and 14-07 showed a significant delay of the DAI when total leaf wilting occurred with respect to height in the previous greenhouse experiment (Fig. 4.5). Furthermore, they exhibited comparable height growth to the diploid original line (Fig. 4.1, Fig. 4.5). Therefore, these lines were selected for detailed characterization of their drought response and analyzed in comparison to the diploid original line 18-03. The plants were gradually dried to the target soil moistures of 25, 18, 12 and 5 vol.-\% and following the irrigation was terminated. The stomatal conductance, the relative leaf water content and the carbohydrate concentrations were investigated at the target soil moisture levels to gain insight into early physiological drought responses.

\section{Morphological characterization of selected tetraploid hybrid aspen fusion lines}

\section{Height}

For a basic characterization the height of the plants was measured after the plants were grown 22 weeks in soil. The well-watered control plants and the plants selected for the drought treatment did not differ in height growth at the start of the experiment (Fig. 5.1). Furthermore, the different tested lines did not differ in their height before the start of the experiment (Fig. 5.1). 


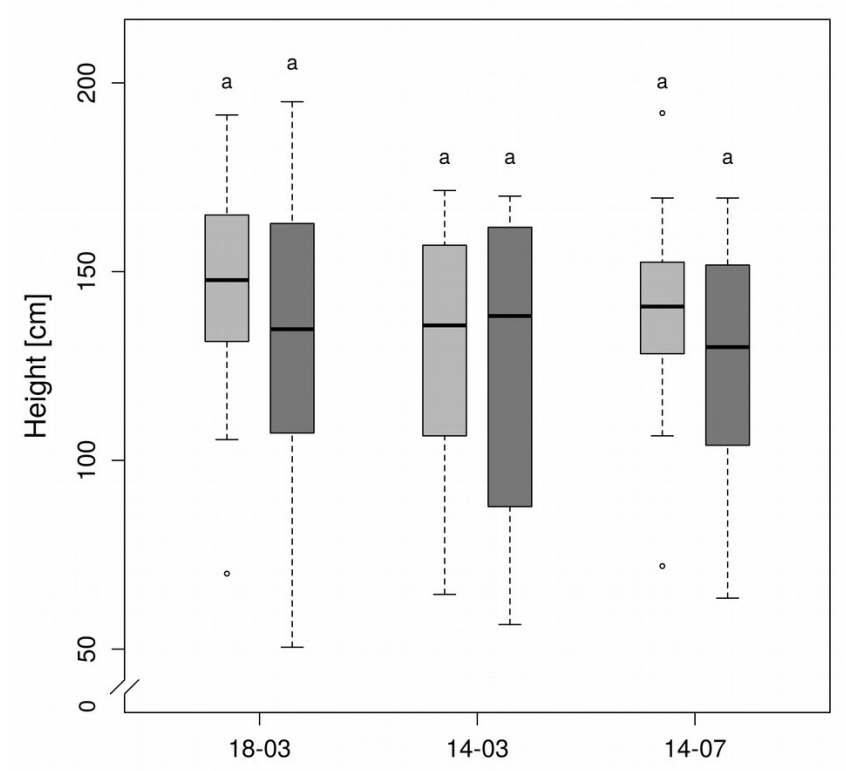

Figure 5.1: Initial height before starting the experiment after 22 weeks in soil (diploid original line: 18-03, tetraploid fusion lines: 14-04 and 14-07:, light grey: plants for the control group, dark grey: plants for the drought treatment; $\mathrm{n}=20$ plants. Boxplots are defined as explained in Fig. 3.2. Different letters at the top of the boxes indicate significant differences between the lines (Tukey-Test, $\mathrm{p}<0.05$ )).

\section{Stomata morphology}

The stomatal length and density were measured before drought was applied. No stomatas were detected on the adaxial side neither in the diploid original line nor in the tetraploid fusion lines (Fig. 5.2 B). Increased stomatal length and decreased stomatal density were detected for the tetraploid fusion lines in comparison to the diploid original line 18-03 (Fig. 5.2 A, B). The tetraploid fusion line 14-07 showed an increased stomatal length compared to the fusion line 14-04 while the stomatal density was decreased but not significantly (Fig. 5.2 A). Larger stomata and lower stomatal density has also been observed in other tetraploid hybrid aspen (Hennig et al, 2015). The stomatal area index was not significantly altered in the tetraploid fusion lines compared to the diploid original line (Fig. 5.2 C). 

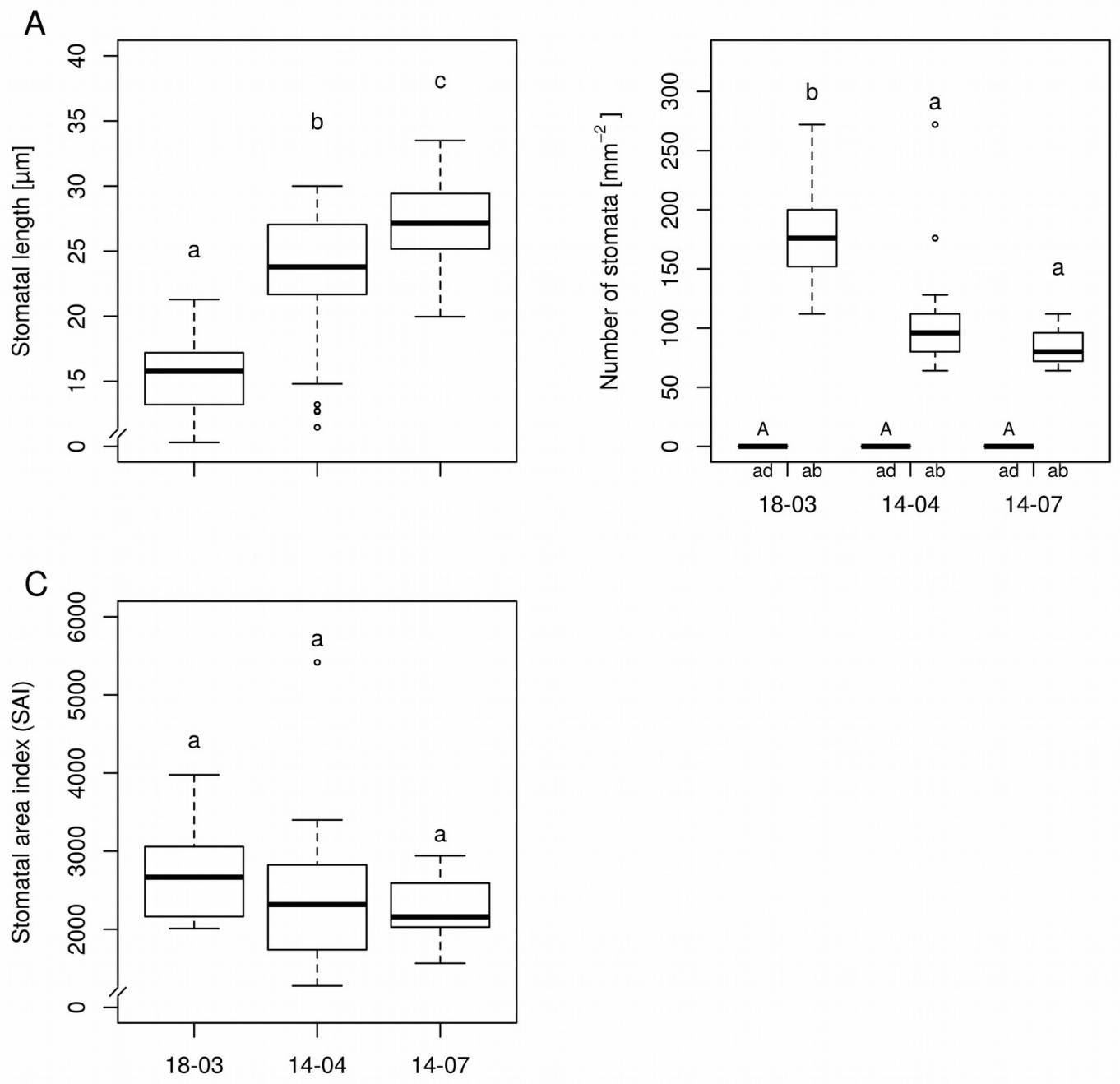

Figure 5.2: (A) Stomatal length on the abaxial leaf side $(n=45$ stomata per line), (B) stomatal density on adaxial and abaxial leaf side $(\mathrm{n}=15$ leaf sections per line and leaf side) and (C) stomatal area index (SAI, mean stomatal length of three stomata of one leaf section multiplied by the stomatal density of this leaf section, $n=15$ leaf sections per line on abaxial leaf surface, ad: adaxial leaf site, ab: abaxial leaf side, diploid original line: 18-03, other lines are tetraploid fusion lines). Boxplot definition: Boxes are defined as explained in Fig. 3.2. Different letters at the top of the boxes indicate significant differences between the lines (Tukey HSD test, $\mathrm{p}<0.05$ ), adaxial leaf side is specified by capitals, abaxial site by lowercase letters). 


\section{Drought responses of selected tetraploid hybrid aspen fusion lines}

Interaction effects between the genotype and the treatment were observed for the parameters relative height increment and stomatal conductance in this experiment (Tab. 5.1). No additional interactions were investigated.

Table 5.1: Significance of the parameters genotype (G), treatment (T), light (L) and their interaction effects on the target variables stomatal conductance, carbohydrate concentration, relative height and stem increment $\left(\mathrm{p}<0.05\right.$ : ${ }^{*}, \mathrm{p}<0.01$ : ${ }^{* *}, \mathrm{p}<0.001$ : ${ }^{* * *}$, ns: not significant, - : not analyzed).

\begin{tabular}{l|c|c|c|c|c|c}
\hline Parameter & G & T & L & G:T & G:L & L:T \\
\hline \hline $\begin{array}{l}\text { Relative leaf water } \\
\text { content }\end{array}$ & $\mathrm{ns}$ & $\mathrm{ns}$ & - & $\mathrm{ns}$ & - & - \\
\hline $\begin{array}{l}\text { Carbohydrate } \\
\text { concentration }\end{array}$ & $* * *$ & $* * *$ & - & $\mathrm{ns}$ & - & - \\
\hline $\begin{array}{l}\text { Stomatal } \\
\text { conductance }\end{array}$ & $* * *$ & $* * *$ & $*$ & $* * *$ & $\mathrm{~ns}$ & $\mathrm{~ns}$ \\
\hline $\begin{array}{l}\text { Osmolality } \\
\text { Relative height } \\
\text { increment }\end{array}$ & $*$ & $*$ & - & $*$ & - & - \\
\hline
\end{tabular}

\section{Relative soil moisture}

For investigating the gradually drying of the soil and thus the stress level applied to the plants the relative soil moisture was measured regularly. Within the experiment the relative soil moisture declined and thus the drought stress increased in all tested lines (Fig. 5.3). But the relative soil moistures over the whole experiment were higher in the tetraploid fusion lines compared to the diploid original line (Fig. 5.3). The soil moisture target level of 25, 18, 12 and 5 vol.-\% occurred later in the tetraploid fusion lines compared to the diploid original line (Tab. 5.2). 

tetraploid hybrid aspen lines

Table 5.2: Day after starting the experiment when the target soil moisture levels were reached (d: day, diploid original line: 18-03, other lines are tetraploid).

\begin{tabular}{l|c|c|c|c}
\hline \multirow{2}{*}{ Line } & \multicolumn{5}{|c}{ Relative soil moisture [vol.-\%] } \\
& $\mathbf{2 5}$ & $\mathbf{1 8}$ & $\mathbf{1 2}$ & $\mathbf{5}$ \\
\hline $18-03$ & $\mathrm{~d} 5$ & $\mathrm{~d} 9$ & $\mathrm{~d} 13$ & $\mathrm{~d} 17$ \\
\hline $14-04$ & $\mathrm{~d} 9$ & $\mathrm{~d} 13$ & $\mathrm{~d} 17$ & $\mathrm{~d} 25$ \\
\hline $14-07$ & $\mathrm{~d} 8$ & $\mathrm{~d} 12$ & $\mathrm{~d} 16$ & $\mathrm{~d} 25$ \\
\hline
\end{tabular}

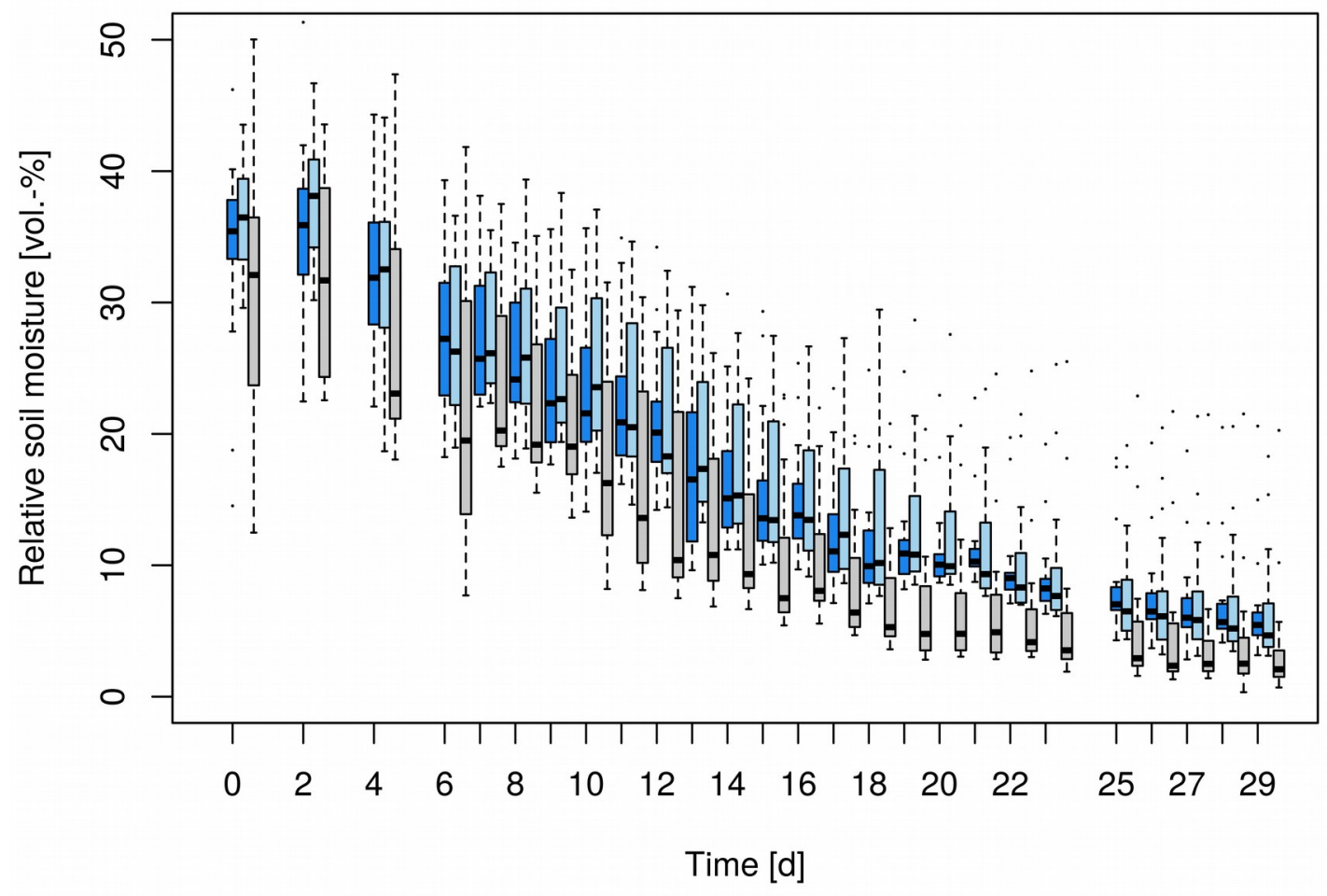

Figure 5.3: Time course of the relative soil moisture (measurements were taken daily except for days 1, 3, 5 and 24; grey boxes: diploid original line 18-03, blue boxes: tetraploid fusion lines: light-blue: 14-04, blue: 14-07, $\mathrm{n}=20$ plants). Boxplots are defined as explained in Fig. 3.2. Significant differences between the lines: $18-03^{\mathrm{a}}, 14-04^{\mathrm{b}}, 14-07^{\mathrm{b}}$ (Wilcoxon signed-rank test, $\mathrm{p}<0.05)$ ). 


\section{Water consumption}

A

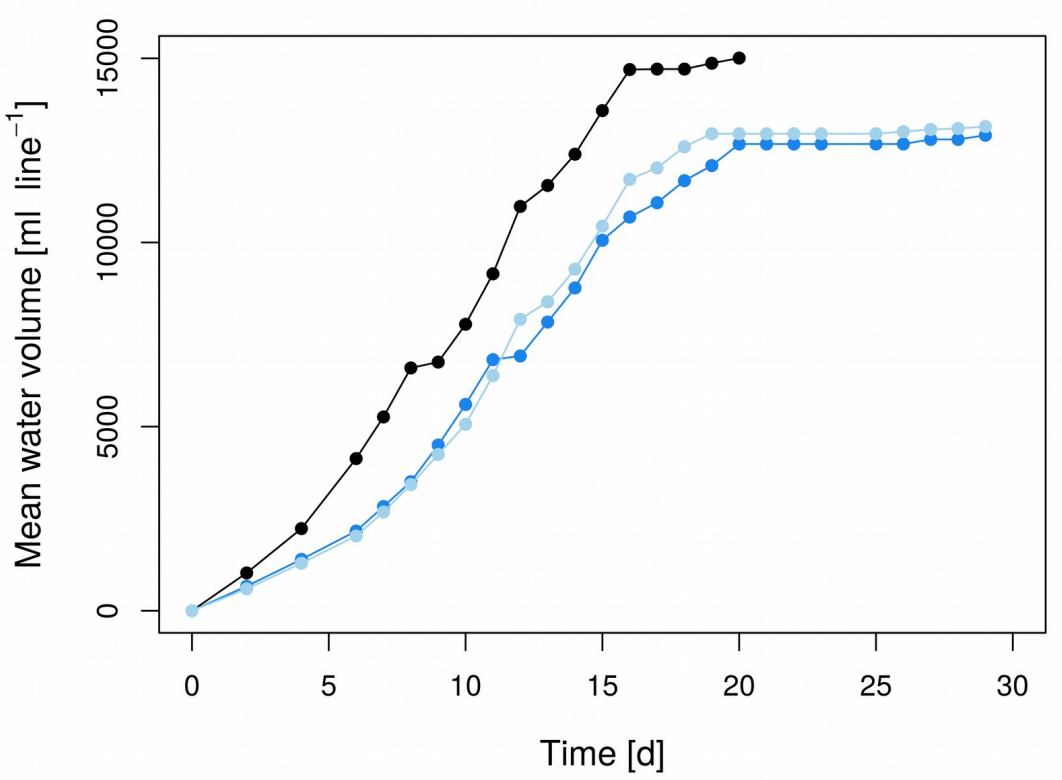

B

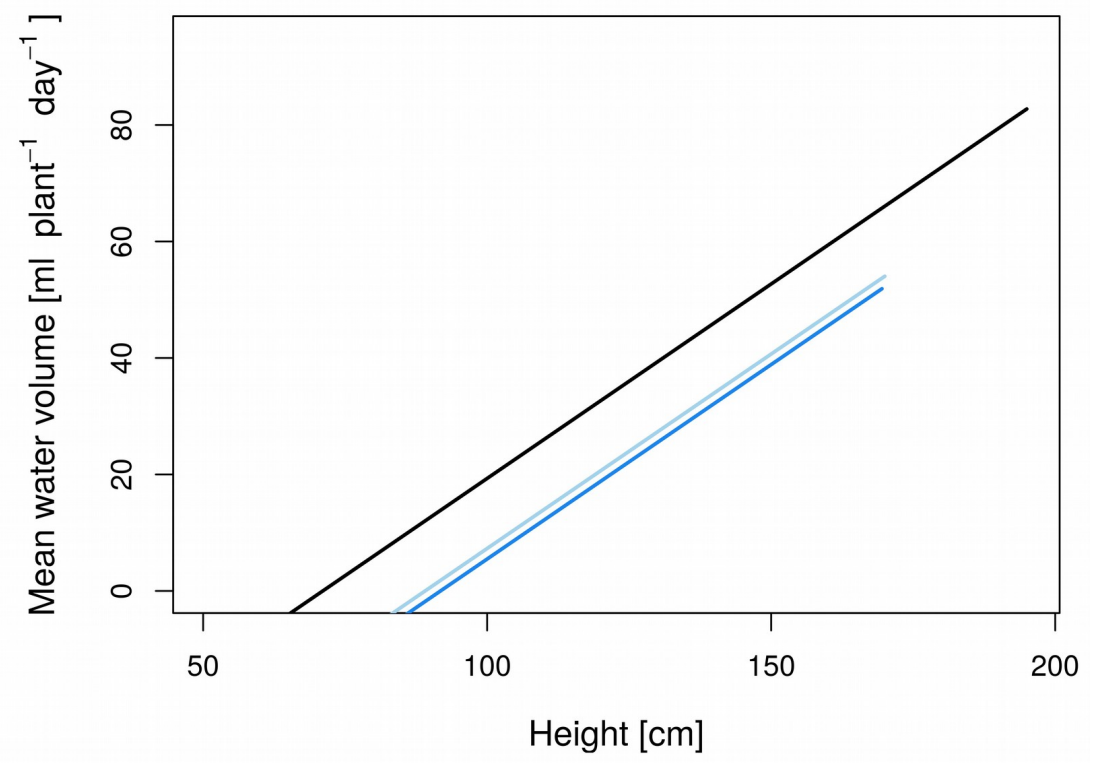

Figure 5.4: (A) Cumulative plot of added water volume during the whole experiment $(\mathrm{n}=$ 20 plants; black: diploid line, blue: tetraploid fusion lines, light-blue: 14-04, blue: 14-07. Different letters indicate significant differences between the lines (Wilcoxon signed-rank test, $\mathrm{p}<0.05)$ : $\left.18-03^{\mathrm{a}}, 14-04^{\mathrm{b}}, 14-07^{\mathrm{b}}\right),(\mathbf{B})$ water consumption over the whole experiment relative to the initial height $(n=20$ plants, data are means of all listed water volumes; regression lines are drawn in the respective area, where data were available; black: diploid line; blue: fusion lines, light-blue: 14-04, blue: 14-07. Different letters indicate significant differences between the lines (exact F-Test, $\mathrm{p}<0.05$ ): $18-03^{\mathrm{b}}, 14-03^{\mathrm{a}}, 14-07^{\mathrm{a}}$ ). 
The water consumption was analyzed as mean water consumption per plant and day during the whole experiment. The tetraploid fusion lines consumed significantly less water in comparison to the diploid original line (Fig. 5.4 A). This was observed both with regard to the whole experiment and to the height of the plants for both tetraploid fusion lines (Fig. 5.4 A, B). A lower water consumption has been observed for two other tetraploid hybrid aspen in comparison to the diploid original line and was also reported in section 3.1.2 (as published in Hennig et al., 2015).

\section{Leaf vitality loss}

The leaf vitality was determined as percentage of wilted and desiccated leaves. Total leaf wilting occurred in $70 \%$ of the plants in the diploid line and in about $40 \%$ of the plants in the tetraploid fusion line 14-04 (Tab. 5.3). In the tetraploid fusion line 14-07 only $17 \%$ showed total leaf wilting at the end of the experiment (Tab. 5.3).

Table 5.3: Leaf vitality decline (day (d) when the respective observation occurred in $50 \%$ of the plants; data are normalized to the last irrigation event; W 25: $25 \%$ leaf wilting, W 100: $100 \%$ leaf wilting, D 25: $25 \%$ leaf desiccation, D 100: $100 \%$ leaf desiccation; diploid original line: 18-03, other lines are tetraploid fusion lines).

\begin{tabular}{l|c|c|c|c|c}
\hline \multirow{2}{*}{ Line } & W 25 & W 100 & \multirow{2}{*}{ D 25 } & \multicolumn{2}{|l}{ Percentage at day 53 } \\
\cline { 3 - 5 } & & & W 100 & D 100 \\
\hline $\mathbf{1 8 - 0 3}$ & d 5 & d 10 & d 13 & $77 \%$ & $70 \%$ \\
\hline $\mathbf{1 4 - 0 3}$ & d 7 & - & d 12 & $43 \%$ & $43 \%$ \\
\hline $\mathbf{1 4 - 0 7}$ & d 9 & - & d 13 & $17 \%$ & $8 \%$ \\
\hline
\end{tabular}

The time points when leaf wilting started was similar between the diploid original line and the tetraploid fusion lines (Tab. 5.3, Fig. 5.5 A). But the rise of the leaf wilting was much steeper in the diploid original line with $50 \%$ of the plants showing total leaf wilting 10 days after the last watering (Fig. 5.5 A). Total leaf wilting in $50 \%$ of the plants was not observed in the tetraploid fusion lines indicating that most of the 
tetraploid fusion lines maintained some of their leaves turgescent over the whole experiment. Furthermore, in the diploid original line all leaves were wilted before $25 \%$ of leaves were dried (Tab. 5.3). In contrast, in the tetraploid fusion lines $25 \%$ leaf drying occurred before total wilting (Tab. 5.3, Fig 5.5 A, B). This was also observed in other tetraploid fusion lines studied in section 3.1.2 (Fig. 3.6).

A

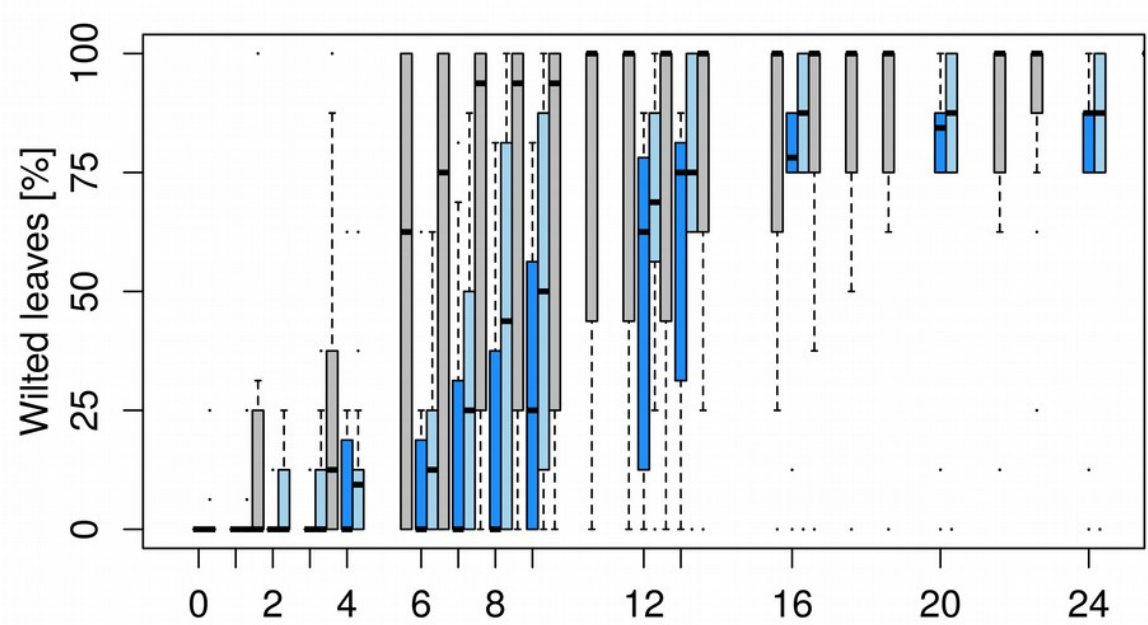

B

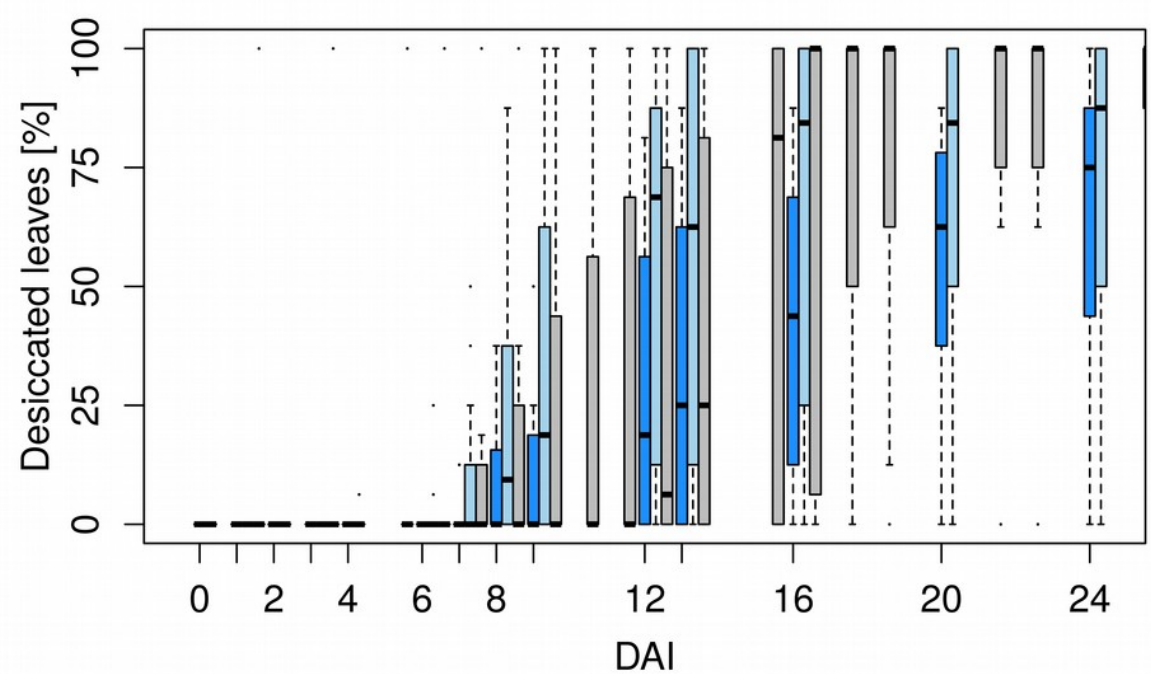

Figure 5.5: Time curves of (A) leaf wilting and (B) leaf desiccation (data are normalized to the day of last irrigation (DAI: day after irrigation); grey boxes: diploid original line, blue boxes: tetraploid fusion lines, light-blue: 14-04, blue: 14-07; number of plants as follows: 18-03: 13, 14-04: 14, 14-07:12 plants. Boxplots are defined as explained in Fig. 3.2. Different letters indicate significant differences between the lines (Wilcoxon signed-rank test $(\mathrm{p}<0.05)$ ): leaf wilting: $18-03^{\mathrm{c}}, 14-04^{\mathrm{b}}, 14-07^{\mathrm{a}}$, leaf desiccation: $\left.18-03^{\mathrm{c}}, 14-04^{\mathrm{b}}, 14-07^{\mathrm{a}}\right)$. 

tetraploid hybrid aspen lines

Moreover, total drying was not reached in $50 \%$ of the plants at DAI 24 in both tetraploid fusion lines whereas this occurred at DAI 16 in the diploid original line (Fig. $5.5 \mathrm{~B}$ ). The fact that both total leaf wilting and total leaf desiccation did not occur in the tetraploid fusion lines implies lower drought stress for theses lines.

\section{Relative leaf water content (RWC)}

To detect early changes in the physiological response the relative leaf water content (RWC), the leaf carbohydrate concentrations and the stomatal conductance were measured at the target soil moisture levels of 25, 18, 12, and 5 vol.-\% and one week after the 5 vol.-\% level was reached. Significant decreases in leaf RWC between control and drought-exposed plants were observed for all lines in the 5 vol.-\% level and one week after this target level occurred (Fig. 5.6 D, E).

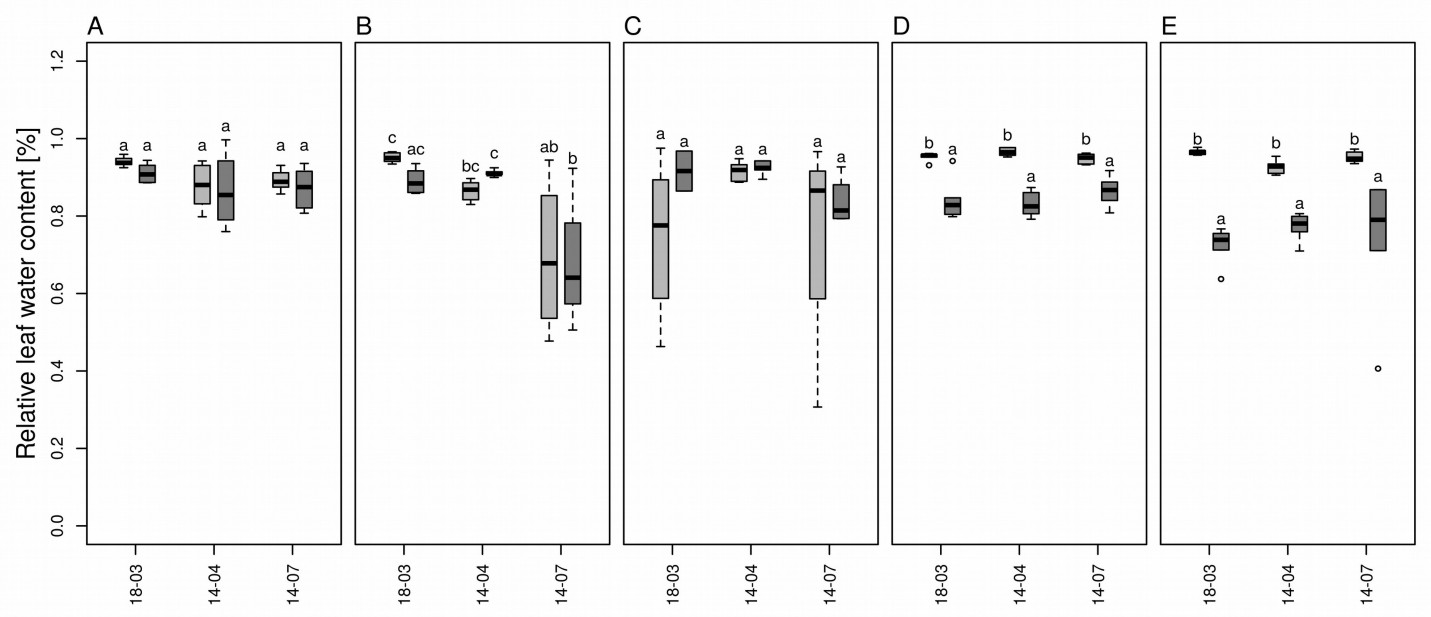

Figure 5.6: Time course of the relative leaf water content (RWC) at the relative soil moisture target levels of the treatment group (A) 25 vol.-\%, (B) 18 vol.- $\%$, (C) 12 vol.- $\%$, (D) 5 vol.-\%, (E) one week after the 5 vol.- $\%$ was reached (the measurements were taken simultaneously for the control and treatment plants when the target levels were reached for the treatment plants, the relative soil moisture of the control plants was stable over the whole experiment at about $30 \%$; light grey: control plants, dark grey: drought-exposed plants, diploid original line 18-03, other lines are tetraploid fusion lines, $n=20$ plants). Boxplots are defined as explained in Fig. 3.2. Different letters at the top of the boxes indicate significant differences between the lines (Tukey-Test, $\mathrm{p}<0.05$ )). 
The leaf RWC of both tetraploid fusion lines were similar to the diploid line (Fig. 5.6 A-E). No line showed a reduction in RWC at relative soil moistures of 12 vol.-\% or higher indicating that effects on RWC occur in an advanced stage of the drought treatment when stress is severe.

\section{Carbohydrate concentration and osmolality}

The carbohydrate concentrations both in the control and treatment plants were significantly higher in the tetraploid fusion lines compared to the diploid line except for the 18 vol.-\% soil moisture level (Fig. 5.7 A-E). The carbohydrate concentration increased relative to the control in the tetraploid fusion line 14-04 under severe drought stress when the soil moisture level was 5 vol.\% and one week after this level was reached (Fig. 5.7 D, E).

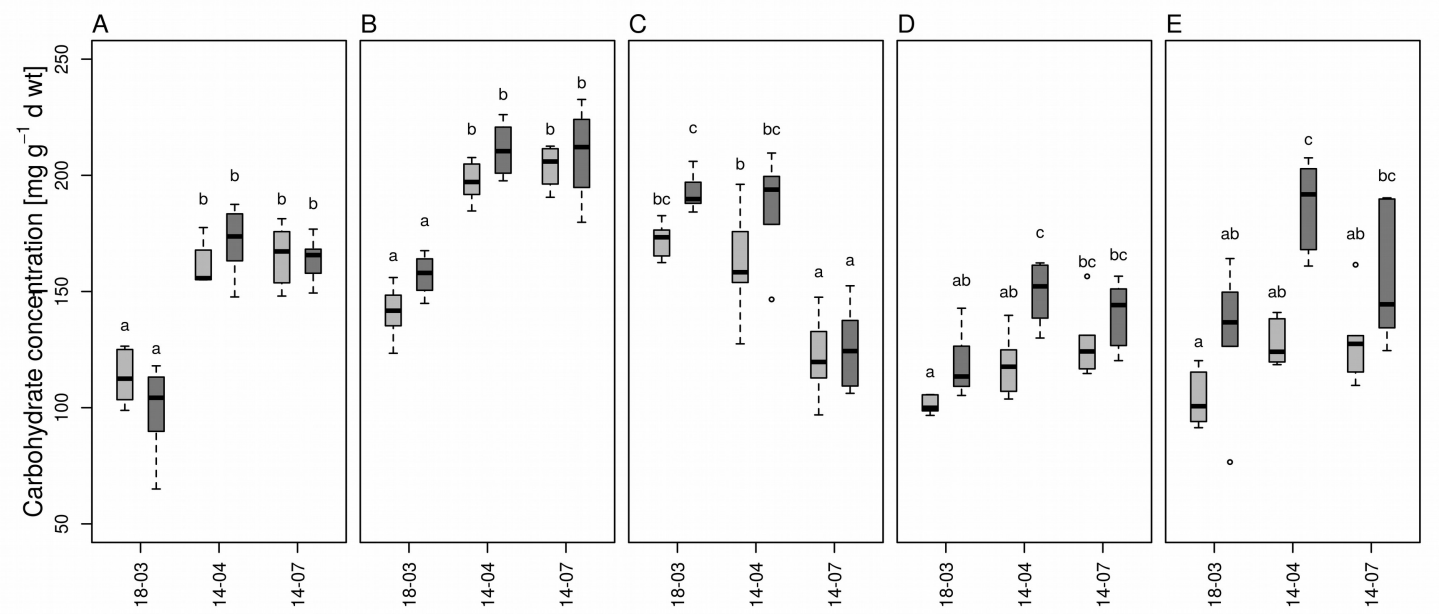

Figure 5.7: Time course of the carbohydrate concentration at the relative soil moisture target levels of the treatment group (A) 25 vol.-\%, (B) 18 vol.-\%, (C) 12 vol.-\%, (D) 5 vol.-\%, (E) one week after the 5 vol.-\% was reached (the measurements were taken simultaneously for the control and treatment plants when the target levels were reached for the treatment plants, the relative soil moisture of the control plants was stable over the whole experiment at about 30 \%; light grey: control plants, dark grey: drought-exposed plants, diploid original line 18-03, other lines are tetraploid fusion lines, $n=20$ plants). Boxplots are defined as explained in Fig. 3.2. Different letters at the top of the boxes indicate significant differences between the lines (Tukey-Test, $\mathrm{p}<0.05$ )). 
In contrast to line 14-04, the carbohydrate concentrations of the diploid original line and the tetraploid fusion line 14-07 were not significantly enhanced compared to the control at the 5 vol.-\% and one week after this target level was reached (Fig. 5.7 D, E).

The osmolality was investigated one week after the 5 vol.-\% soil moisture level was reached. In the treatment plants of the tetraploid fusion line 14-07 the osmolality was increased compared to the diploid original line and the tetraploid fusion line 14-04 (Fig. 5.8). In the control plants the osmolality was similar in all tested lines (Fig5.8).

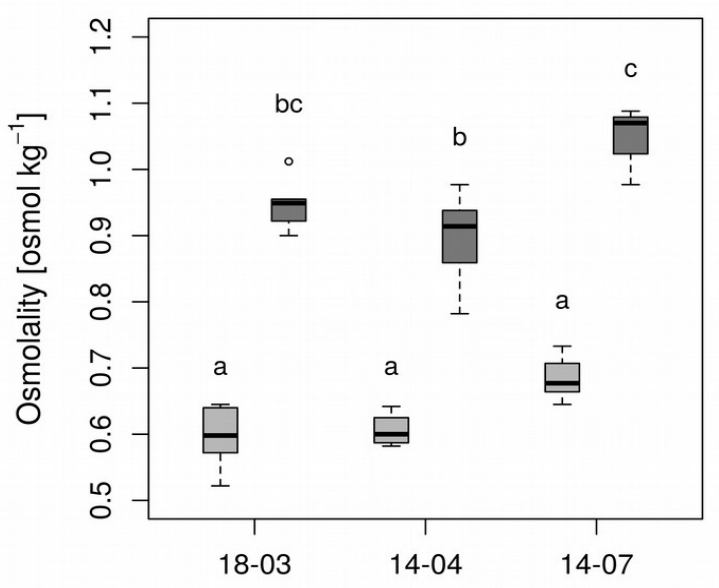

Figure 5.8: Osmolality observed one week after the 5 vol.-\% level was reached (diploid original line 18-03, other lines are tetraploid fusion lines, $n=6$ plants, light grey boxes: watered plants, dark grey boxes: drought-treated plants. Boxplots are defined as explained in Fig. 3.2. Different letters at the top of the boxes indicate significant differences between the lines (Tukey-Test, $\mathrm{p}<0.05$ )).

\section{Stomatal conductance}

Early stomatal closure occurred in the diploid original line but not in the tetraploid fusion lines (Fig. 5.9 D). Relative to the control the stomatal conductance was reduced in the diploid line at 12 vol.-\% relative soil moisture level (Fig. $5.9 \mathrm{D}$ ). In the tetraploid fusion lines the stomatal conductance relative to the control group was not reduced at a relative soil moisture level of $12 \mathrm{vol.-} \%$ indicating higher drought 
tolerance of the tetraploid fusion lines. The stomatal conductance of the tetraploid plants both in the control and treatment was lower compared to the diploid original line in the 18 vol.-\%, 12 vol.-\% and 5 vol.-\% soil moisture levels (Fig. 5.9 C-E).

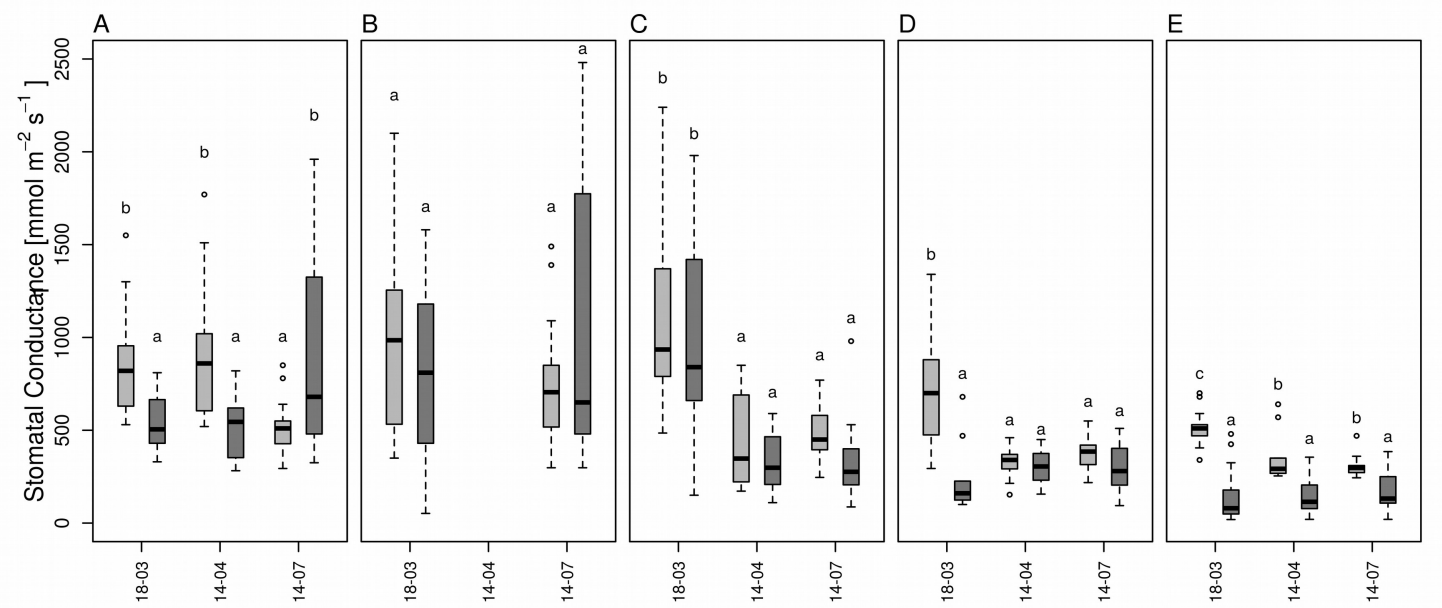

Figure 5.9: Time course of the stomatal conductance at the relative soil moisture target levels of the treatment group (A) 30 vol.-\%, (B) 25 vol.-\%, (C) 18 vol.-\%, (D) 12 vol.- $\%$, (E) 5 vol.-\% (the measurements were taken simultaneously for the control and treatment plants when the target levels were reached for the treatment plants, the relative soil moisture of the control plants was stable over the whole experiment at about $30 \%$; light grey: control plants, dark grey: drought-exposed plants, diploid original line 18-03, other lines are tetraploid fusion lines, $\mathrm{n}=20$ plants). Boxplots are defined as explained in Fig. 3.2. Different letters at the top of the boxes indicate significant differences between the lines (Tukey-Test, $\mathrm{p}<0.05)$ ). 

tetraploid hybrid aspen lines

\section{Relative height increment}

The tetraploid fusion line 14-07 exhibited an increased height increment under control conditions while the diploid original line and the tetraploid fusion line 14-04 did not significantly distinguish from the drought treatment in the relative height increment (Fig. 5.10).

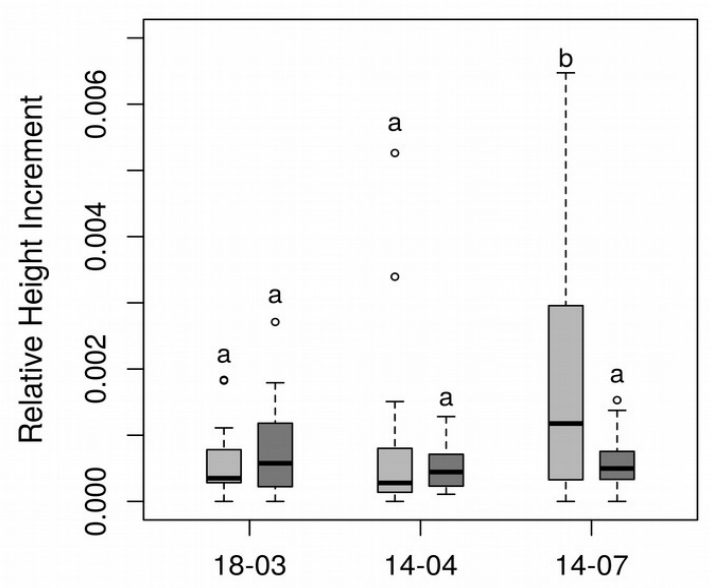

Figure 5.10: Relative height increment measured at the end of the experiment (diploid original line: 18-03, tetraploid fusion lines: 14-04 and 14-07, $n=20$ plants, light grey boxes: watered plants, dark grey boxes: drought-treated plants; the relative height increment is normalized to the number of cultivated days. Boxplots are defined as explained in Fig. 3.2. Different letters at the top of the boxes indicate significant differences between the lines (Tukey-Test, $\mathrm{p}<0.05)$ ). 


\subsection{Whole genome sequencing of selected hybrid aspen fusion lines}

To gain insight into the genetic composition of the tetraploid fusion lines differing in plant performance whole genome sequencing of the diploid original line 18-03 and the tetraploid fusion lines 14-03, 14-04 and 14-07 was conducted. Copy number variations (CNVs) were used to detect chromosome modifications such as deletions and duplication of sequences. CNVs are DNA segments of one kilobase or larger that occur in a variable copy number in comparative groups (Freeman, 2006). These structural sequence variations can be caused by homologous and non-homologous repair after double-strand breaks or errors during replication (Conrad et al., 2010).

\subsubsection{Overview of detected copy number variations}

DNA segments were detected as CNVs at a threshold of 1.5-fold change in one line. In all pairwise comparisons of the tetraploid fusion lines among each other and with the diploid original line line 14-07 had the highest number of segments with CNVs (Fig. 6.1).

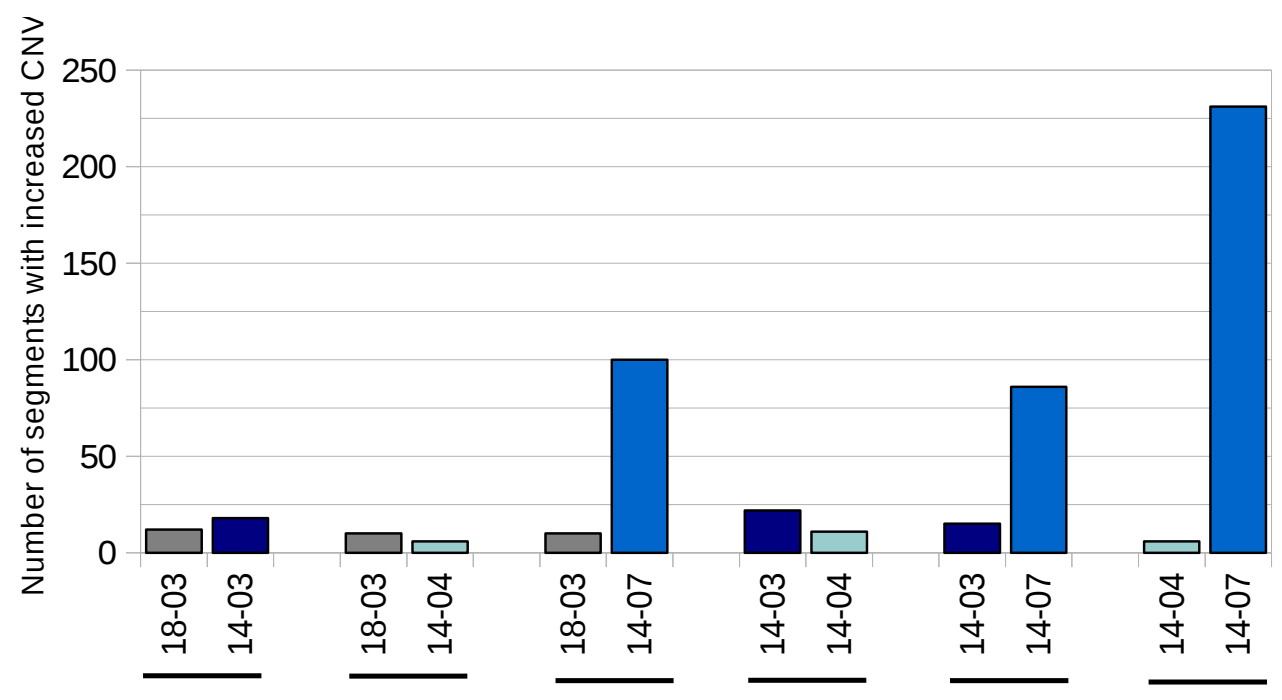

Figure 6.1: Pairwise comparison of the segments with increased copy number variations (threshold: 1.5-fold increase; pairs that were compared with each other are marked with a black line below the line identification numbers; grey: diploid original line 18-03, other lines are tetraploid fusion lines: dark blue: 14-03, light-blue: 14-04, blue: 14-07). 
In comparison to the diploid original line 100 segments were increased and compared to the other tetraploid fusion lines 14-03 and 14-04 86 and 231 segments were increased in 14-07, respectively (Fig. 6.1). For the tetraploid fusion lines 14-03 and 14-04 only small numbers of segments with CNVs were detected indicating only slight modifications in their genome (Fig. 6.1).

\subsubsection{Copy number variations altered with regard to the diploid original line}

In the following analyses the segments that revealed CNVs were separated into increased and decreased segments in the tetraploid fusion lines in comparison to the diploid original line.

\section{Distribution of the altered segments with copy number variation over the genome}

The increased segments were evenly distributed over the genome (Fig. 6.2 A-C). Instead, the decreased segments in the tetraploid fusion line 14-03 were clustered at one end of chromosome 11 (Fig. 6.2 D). The decreased segments in the tetraploid fusion lines 14-04 and 14-07 were evenly distributed over the genome as well (Fig. 6.2 E, F). 
A

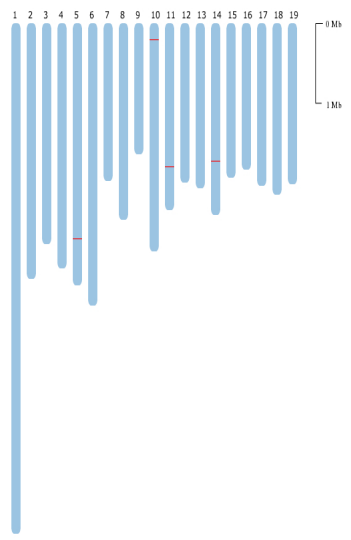

D

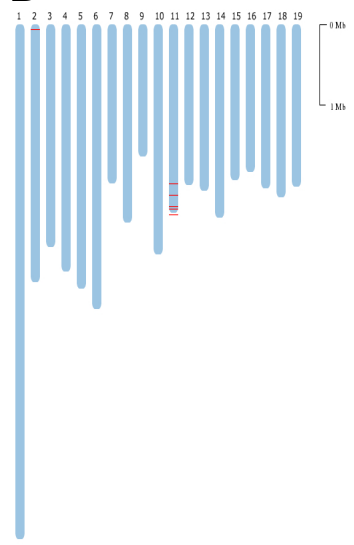

B

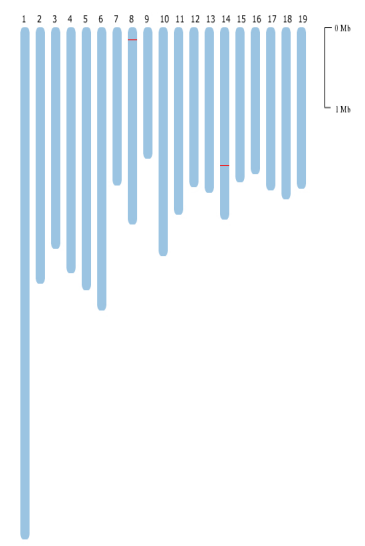

E

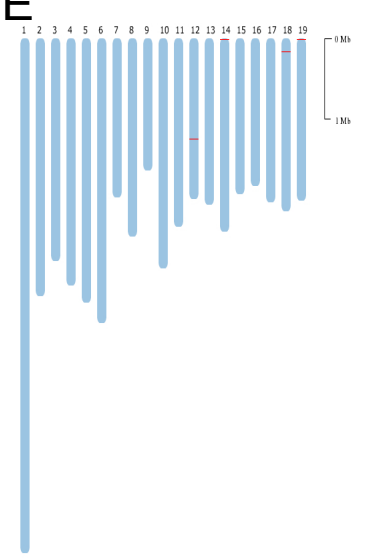

C

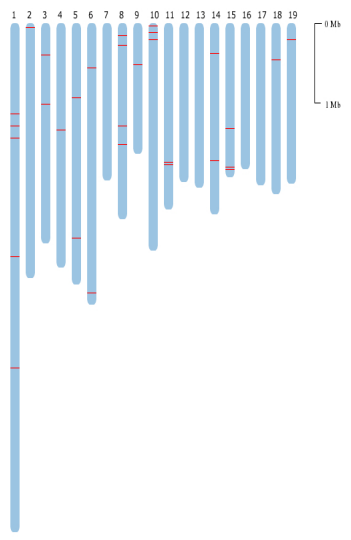

$\mathrm{F}$

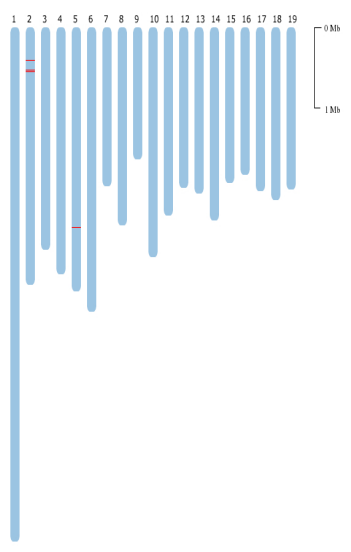

Figure 6.2: Chromosome diagrams of altered segments with copy number variations (CNVs) compared to the diploid original line 18-03, A-C: increased segments with CNVs in the tetraploid fusion lines: (A) 14-03, (B) 14-04, (C) 14-07, D-E: decreased segments with CNVs in the tetraploid fusion lines: (D) 14-03, (E) 14-04, (F) 14-07 (segments with CNVs are marked as red lines, chromosome numbers are written above the schematic chromosomes; "chromosome diagram" tool of POPGENIE, http://popgenie.org/chromosome-diagram). 
Overlap of the altered segments with copy number variations in the tetraploid fusion lines

Two DNA segments with CNVs were increased in all tetraploid fusion lines (Fig. 6.3 A). The tetraploid fusion lines 14-03 and 14-07 revealed the highest overlap of seven further increased segments with CNVs (Fig. 6.3 A). The tetraploid fusion line 14-07 had the highest number with 90 segments that were uniquely increased compared to the diploid original line (Fig. 6.3). In the tetraploid fusion lines 14-03 and 14-04 the number of segments with uniquely enhanced CNVs was low with nine and three detected CNVs (Fig. 6.3). One segment with CNV was decreased in all tetraploid fusion lines compared to the diploid original line (Fig. 6.3 B). One further segment was decreased in the tetraploid fusion lines 14-03 and 14-04 (Fig. 6.3 B). The number of segments that were reduced in one of the tetraploid fusion lines uniquely compared to the diploid original line was between 8 in line 14-04 and ten in line 14-03 (Fig. 6.3 B). In contrast to the 90 detected segments that were increased in line 14-07 compared to the diploid original line, the number of reduced segments compared to the diploid original line was similar the other tetraploid fusion lines (Fig. 6.3 B).

A

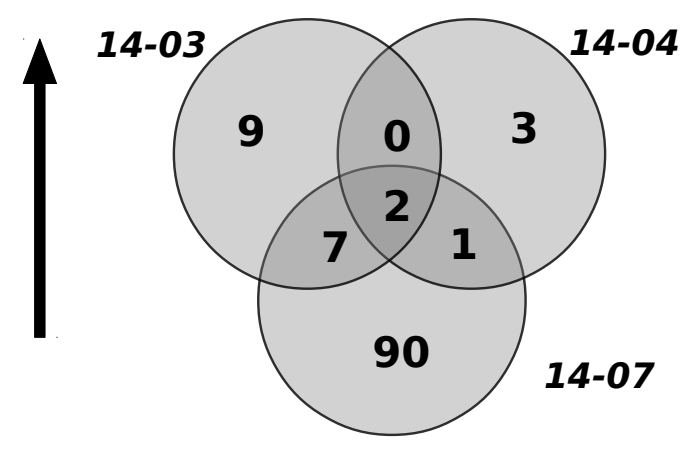

B

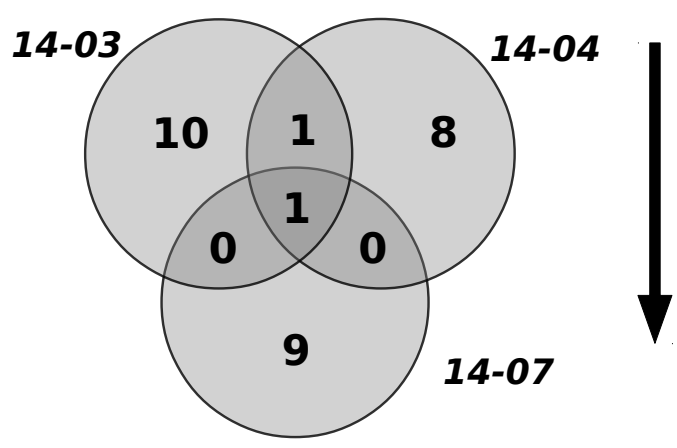

Figure 6.3: Venn diagram of segments with copy number variations (CNVs) that were changed in comparison to the diploid original line 18-03, (A) increased segments with CNVs, (B) decreased segments with CNVs in the tetraploid fusion lines (threshold: 1.5-fold change). 


\section{Functional analysis of the segments showing copy number variations}

Functional information on the segments showing CNVs was obtained via Phytozome using the POPTR numbers (http://phytozome.jgi.doe.gov, Goodstein et al., 2012). To find out whether the genes were related to drought or growth in silico expression analysis in young expanding leaves and in leaves after three days drought exposure was conducted in POPGENIE ("exImage” tool; http://popgenie.org/eximage, Sjödin et al., 2009). The putative function and the expression of the genes encoded by the segments that were altered in at least two tetraploid fusion lines are listed in Table 6.1.

Out of the segments with increased CNVs 10 showed a minimal 1.5-fold change compared to the diploid original clone in at least two tetraploid fusion lines (Tab. 6.1). For two of them an annotation of the genes encoded by these DNA segments was available. POPTR_0008s02410 contains ankyrin repeats that mediate protein-protein interactions (Tab. 6.1, Goodstein et al., 2012). This gene sequence was increased twice and 1.7-fold in the tetraploid fusion lines 14-03 and 14-07, respectively (Tab. 6.1). The expression of POPTR_0008s02410 is highly increased in young expanding leaves and enhanced in leaves after three days drought exposure (Tab. 6.1, Sjödin et al., 2009). A further gene, POPTR_0010s01460, was enhanced 1.7-fold in the tetraploid fusion lines 14-03 and 14-07 compared to the diploid line 18-03. The expression of this gene is highly increased under drought but not enhanced in young expanding leaves (Tab. 6.1, Sjödin et al., 2009). The gene was annotated as being involved in starch and sucrose metabolism by pectate degradation fueling the ascorbate metabolism (Tab. 6.1, Goodstein et al., 2012; Kanehisa et al., 2014). Another gene located in a region with CNV was POPTR_0014s17450. Its expression is strongly decreased under drought, but in young expanding leaves this gene is upregulated (Tab. 6.1, Sjödin et al., 2009). This segment was enhanced in all tetraploid fusion lines (Tab. 6.1). The increase was approximately 1.7-fold in 14-04 and 14-07 and almost 2.8-fold in 14-03 (Tab. 6.1). No annotation was available for this gene. One further segment with increased CNVs in all tetraploid fusion lines was located on contig 36108 (Tab. 6.1). This segment was increased 1.6-fold in the tetraploid fusion 
lines 14-03 and 14-07 and 1.8-fold in the tetraploid fusion line 14-04. For the putative gene no annotation was available as well.

For the decreased segments with CNVs no annotation was obtained as well (Tab. 6.1). One segment showed a CNV in all tetraploid fusion lines and was located on contig 57081 (Tab. 6.1). It occurred 2.7-fold less frequently in line 14-03 and was 1.8-fold decreased in the lines 14-04 and 14-07 compared with the diploid original line (Tab. 6.1). 
Table 6.1: Segments with copy number variations with (at least 1.5-fold change) in at least two tetraploid fusion lines compared to the diploid line 18 -03 (Chr = Chromosome, description was accessed using the data bases of Phytozome (http://phytozome.jgi.doe.gov, Goodstein et al., 2012), the Kyoto Encyclopedia of Genes and Genomes (KEGG, www.genome.jp/kegg/, Kanehisa et al., 2014), gene expression was accessed via the "exImage" tool of POPGENIE (http://popgenie.org/eximage, Sjödin et al., 2009). The electronic fluorescent pictographic (eFP) browser displayed the expression in the specific tissue in relation to the expression over all analyzed P. tremula tissues: “+ +” very high expression (red), “+” high expression (orange), “=” average expression (yellow), light blue:“-” low expression, deep blue: “- -” very low expression, “.” no information available).

\begin{tabular}{|c|c|c|c|c|c|c|c|c|c|}
\hline \multirow[t]{2}{*}{ POPTR-Number } & \multirow[t]{2}{*}{ Contig } & \multirow[t]{2}{*}{$\begin{array}{l}\text { Length } \\
\text { [bp] }\end{array}$} & \multicolumn{3}{|c|}{$\begin{array}{l}\text { Fold change }(\log 2) \text { compared to } \\
\text { the diploid line 18-03 }\end{array}$} & \multirow[t]{2}{*}{ Chr } & \multirow[t]{2}{*}{ Description } & \multicolumn{2}{|l|}{ Expression } \\
\hline & & & 14-03 & 14-04 & 14-07 & & & $\begin{array}{l}\text { Young expanding } \\
\text { leaves }\end{array}$ & $\begin{array}{l}\text { Leaves exposed } \\
\text { to drought } \\
\text { (3 days) }\end{array}$ \\
\hline \multicolumn{10}{|c|}{ Increased DNA segments in the tetraploid fusion lines } \\
\hline POPTR_0003s00760 & 20999 & 11050 & 0.8109 & -0.2537 & 1.0602 & 3 & . & . & . \\
\hline POPTR_0005s22360 & 330 & 5200 & 0.9593 & 0.0919 & 1.1816 & 5 & . & . & . \\
\hline POPTR_0006s00220 & 48082 & 7150 & 0.9296 & 0.4150 & 0.8382 & 6 & . & . & . \\
\hline POPTR_0008s02410 & 21901 & 5200 & 0.0298 & 1.0785 & 0.7827 & 8 & Ankyrin repeat, protein-protein interaction & ++ & + \\
\hline POPTR_0010s01460 & 22926 & 4550 & 0.8568 & 0.0335 & 0.7946 & 10 & $\begin{array}{l}\text { Starch and sucrose metabolism, galacturan 1,4-alpha- } \\
\text { galacturonidase [EC:3.2.1.67], carbohydrate metabolic } \\
\text { process, pentose and glucuronate interconversions }\end{array}$ & $=$ & ++ \\
\hline POPTR_0014s17450 & 58031 & 11050 & 1.4703 & 0.7413 & 0.7742 & 14 & . & + & - \\
\hline POPTR_0017s07180 & 83568 & 7800 & 1.2976 & NA & 0.9737 & 17 & . & . & . \\
\hline . & 36108 & 5200 & 0.6813 & 0.8744 & 0.6515 & . & . & . & . \\
\hline- & 47265 & 4550 & 0.9288 & NA & 0.6108 & . & . & . & . \\
\hline & 66163 & 5200 & 0.7226 & NA & 1.2252 &. & . & . & . \\
\hline \multicolumn{10}{|c|}{ Decreased DNA segments in the tetraploid fusion lines } \\
\hline 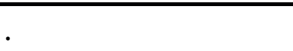 & 57081 & 5200 & -1.4332 & -0.8961 & -0.8311 &. & . & . & . \\
\hline 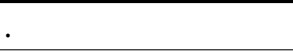 & 91256 & 5850 & -0.7924 & -0.9735 & -0.1846 &. & . & . & . \\
\hline
\end{tabular}




\section{Discussion}

\subsection{Morphological and drought stress characterization of the diploid original line and tetraploid fusion lines of hybrid aspen}

\subsubsection{Morphological characterization of hybrid aspen lines}

nSSR analysis did not reveal the presence of DNA of P. nigra or P. trichocarpa $\mathrm{x}$ P. deltoides in any fusion line. Because all fusion lines were tetraploid, my results suggest that homofusions of two P. tremula x P. tremuloides protoplasts occurred.

Polyploidy often induces morphological and phenotypic variation (Liu and Wendel, 2003). A reduction in height growth, as observed here for some fusion lines, has been reported in other polyploid plants before (Weiss and Porter, 1948; Sharma and Datta, 1957; Riddle and Birchler, 2008; Deng et al., 2012). Because poplars of dry habitats were smaller than those of wet habitats (Regier et al., 2009; Yang and Miao, 2010), the observed height reduction with lower total leaf area in the tetraploid than in the diploid line might be advantageous for drought threatened habitats. It was shown here that these fusion lines also consumed less water than the diploid line.

The stomatal density is correlated with the maximum stomatal conductance in Mediterranean herbs, shrubs and woody species (Galmés et al., 2007). Decreased stomata density as observed in the fusion lines might therefore lead to enhanced drought tolerance as the stomatal conductance is reduced. However, in the fusion lines stomata lengths were enhanced. This modification of the stomatal apparatus has also been observed in other tetraploid species like Spathiphyllum, Platanus or Betula (Li et al., 1996; Liu et al., 2007; van Laere et al., 2010). Hodgson et al. (2010) detected that stomatal length is positively correlated with genome size within the eudicots, 
Poaceae and other monocots without providing a causal link. The correlation of stomatal length with habitat humidity is discussed controversially (Abrams et al., 1994; Hodgson et al., 2010). For example, Hodgson et al. (2010) stated that stomatal length is correlated with habitats of high humidity. Abrams et al. (1994), in contrast, reported increasing stomatal size from wet-mesic to mesic and xeric sites in deciduous tree species. Regier et al. (2009) observed that the stomatal length was increased in one P. nigra genotype under water limited conditions while abaxial stomatal density was reduced. In drought tolerant tomato cultivars stomatal density was decreased, but stomatal size increased compared to drought sensitive genotypes (Kulkarni and Deshpande, 2006). These stomatal traits that have also occurred in the fusion lines and might be the reason for lower water consumption as observed here. Furthermore, Ashton and Berlyn (1994) observed a reduction in the SAI from wet to xeric habitats in Quercus species and suggested this parameter to predict drought tolerance. More, recently QTLs for this trait have been identified and were also linked with drought tolerance (Gailing et al., 2008). Here, SAI was reduced in two fusion lines (Fig. 3.2 C) only one out of these lines consumed significantly less water related to height indicating that SAI might be a relevant parameter associated with water consumption. However, the links between this trait and DNA dosage remain obscure.

\subsubsection{Drought stress characterization of hybrid aspen lines}

\section{Water consumption and leaf vitality}

Polyploid plants often possess superior characteristics in comparison to their diploid counterparts with regard to morphological and physiological changes and their tolerance to environmental stresses (Xiong et al., 2006). In this study, all fusion lines consumed less water relative to height than the diploid line. Reduced water consumption was significant for the fusion lines 27-10 and 27-12, which both showed a total leaf area similar to the diploid line. Furthermore, there were other cases where 
severe height and leaf area reductions decreased the water consumption of the fusion lines. The altered stomatal morphology (decreased stomatal density and increased stomatal size) and the increased leaf mass per area (a low surface to volume ratio) that is linked to dry habitats (Poorter et al., 2009) in the fusion lines 27-10 and 27-12 might have reduced the transpiration and thereby enabled the plants to use water more efficiently.

The leaf wilting was more severe for the diploid line than for the fusion lines, but two of the fusion lines showed early leaf desiccation which increased to about $50 \%$ at the end of the drought. In the genus Populus, leaf shedding occurs to avoid desiccation of the remaining tissue (Fischer and Polle, 2010). Blake and Tschaplinski (1992) noted that leaf shedding and the related reduction of the transpiration surface led to an increase of the water potential in the remaining tissue. In analogy to this, our finding suggests that the early-wilting fusion lines were better adapted to drought than the diploid line because they reduced the transpiration surface rapidly by desiccating a part of the leaves and thereby might have been able to delay wilting of the remaining foliage.

\section{Stomatal conductance and carbohydrate concentration}

The positive correlation between stomatal density and stomatal conductance as described for herbs and trees in literature (Abrams et al., 1994; Galmés et al., 2007) was not found here. Despite the variation in stomatal morphology, significant differences in the stomatal conductance between the different ploidy levels were not discovered under well-watered conditions. In polyploid Betula and Lonicera plants, stomatal conductance was less affected by drought compared to the diploid variants (Li et al., 1996, 2009), whereas the poplar fusion lines in our study exhibited the same response to drought as the diploid line.

Carbohydrates play important roles for osmotic adjustment of poplar tissues to drought stress (Danielsen and Polle, 2014). Notably, in the fusion lines the carbohydrate concentrations were more strongly increased under drought conditions than in the diploid line (Fig. 3.7 C). For instance, Deng et al. (2012) also observed 
enhanced carbohydrate levels and increased survival of octaploid tobacco compared to its tetraploid variant under stress conditions. Accumulation of carbohydrates leads to osmotic adjustment by decreasing the osmotic potential in the cell and contributes to the stress tolerance (Touchette et al., 2009). Carbohydrates also function in osmoprotection by stabilizing proteins and membranes (Crowe et al., 1992). The stronger increase in carbohydrate concentration in the fusion lines might have enabled them to cope with dry conditions better than the diploid line because of improved osmotic adjustment and cellular protection.

\section{Biomass production}

Although the initial height was reduced for the fusion lines 27-09, 27-10 and 27-11 the relative height increment of the fusion lines 27-10, 27-11 and 27-12 was equivalent to that of the diploid line under well-watered conditions indicating no growth constraints (Fig. 3.8 A). Height growth of Populus is sensitive to drought at an early stage (Bogeat-Triboulot et al., 2006). McDowell et al. (2008) suggested that plants under drought conditions suffer mainly from carbon starvation because of stomatal closure. Consequently, growth is reduced. In the context of the present study, this theory implies that the fusion lines 27-10, 27-11 and 27-12 closed their stomata to reduce water loss, as a consequence their height increment decreased. Additionally, they avoided further increase in stress because they reduced the area of growing tissue that had to be supplied with water. This can also be a part of the stress avoidance response. Eventually, these measures may have led to reduced water demand, apparent as the lower water consumption of the fusion lines. In contrast, the diploid line did not respond to drought by early diminishment of height growth and thus, did not save resources. These suggestions are in line with the resource requirement hypothesis pertaining that polyploid plants grow slower and therefore, have a decreased resource demand compared to their diploid counterparts (Deng et al., 2012). In practical terms, it is obvious that in plantations for woody biomass production, genotypes are needed that represent a compromise of biomass production and drought tolerance. In SRC stem biomass production is the most important parameter to be 
optimized because the woody parts are used for energy production (Karp and Shield, 2008; Polle et al., 2013). In our study, an enhancement in the relative shoot increment was detected for the fusion line 27-11 under drought and for 27-12 under control conditions, respectively compared to the diploid line. Because two of these fusion lines also showed total biomass production similar to that of the diploid line, the new genotypes appear to be reasonable alternatives for plantation in dry areas.

\subsubsection{Conclusion}

Overall, the tetraploid lines that were generated by protoplast fusion varied significantly in morphological characteristics such as height, total leaf area and stomatal characteristics as well as in physiological traits such as carbohydrate production under drought and water consumption. The phenotypic diversity might be due to mutations in the chromosomes caused during the protoplast fusion process (Prange et al., 2012). This diversity renders the fusion lines predestined for breeding. Moreover, it was shown that the fusion lines 27-10 and 27-12 desiccated a part of their foliage at an early stage of drought and were more water saving than the diploid line. All fusion lines showed a higher increase in carbohydrate concentration and a decrease in relative height increment when suffered from severe drought suggesting better drought adaptation by stress tolerance and avoidance mechanisms. Adaptability to low water supply is favorable for the SRC plantation, because it is expected that biomass plantations will be established on marginal sites with low water and mineral supply to avoid competition with agricultural land (von Wühlisch, 2012). Furthermore, a decrease in soil moisture of $5 \%$ up to $12 \%$ in the upper $10 \mathrm{~cm}$ deep soil is predicted for large parts of Europe in the long term (year 2080-2099) (Dai, 2012). Thus, it is likely that even production on currently moist sites will have to cope with water limitations in the future. Eventually, a sufficient supply of water is a decisive factor that determines the success of establishing SRC plantations (Helbig and Müller, 2009). Therefore, the fusion lines represent interesting candidates for the cultivation on SRC. 


\subsection{Drought performance of diploid "fusion" and tetraploid fusion lines and detailed drought responses of selected tetraploid fusion lines}

\subsubsection{Morphological characterization of diploid "fusion" and tetraploid fusion lines of hybrid aspen}

\section{Genetic composition of the hybrid aspen lines}

Because our initial study revealed only homofusion lines (Hennig et al., 2015), further 20 protoplast fusion lines were created. The finding that 16 of them were again homofusion lines and 4 diploid lines suggests that heterofusion plants were less vigorous than homofusion plants. The protoplast fusion lines originated from a joint project with several hundred fusion lines that were generated between different poplar species. The number of successful interspecific hybridization was low and none of the hybrids were viable because all died already in the in vitro culture stage. In interspecific hybrids chromosome and also mitochondrial DNA rearrangements were observed (Kao, 1977; Binding and Nehls, 1978; Kemble et al., 1986; Prange et al., 2012). This can be due to abnormalities during mitosis such as, for instance, adhering of chromosomes, fragmented or deformed chromosomes or elimination of alleles (Binding and Nehls, 1978; Prange et al., 2012). It has been observed in fusion hybrids that one nucleus or chromosomes of one fusion partner was predominant while only a few chromosomes of the second fusion partner occurred that were eliminated over time (Binding and Nehls, 1978; Prange et al., 2012). Chromosome rearrangement and elimination may have resulted in slower cell division and thus less growth or even death in the heterofusion lines.

Heterofusion frequencies vary widely between 1 to $20 \%$ in other plant species depending on the species combination, cell types and fusion conditions (Waara and Glimelius, 1995). For example, in cyclamen the highest frequency of interspecific 
hybrids was about 5 \% (Prange et al., 2012) and in Brassicaceae, Fabaceae, Poaceae, and Solanaceae the percentage of hybrids obtained by protoplast fusion was referred to be usually less than $10 \%$ (Waara and Glimelius, 1995). Brewer et al. (1999) stated that somatic hybridization of species with divergent genetic background that show incompatibilities in sexual reproduction may result in low viability of the obtained hybrids. The poplar species used in this study were also associated to different sections of the genus Populus and the success of sexual hybridization between theses sections were low (Willing and Pryor, 1976; Liesebach et al., 2010). However, these incompatibilities might be only one reason for a low heterofusion frequency as also between hybrid aspen and grey poplar that belong to the same section any heterofusions were obtained.

\section{Height of the hybrid aspen lines}

Lower height growth in the tetraploid fusion lines compared to both the diploid original and fusion lines indicate a negative effect of tetraploidy on height growth. Growth reduction was also observed in other tetraploid hybrid aspen from protoplast fusion experiments (Hennig et al., 2015) as well as in other polyploid plants (Weiss and Porter, 1948; Sharma and Datta, 1957; Riddle and Birchler, 2008; Deng et al., 2012). Scholes and Paige (2015) reported that the genome size is positively correlated with the duration of the mitotic cell cycle that leads to effects in the cellular growth and development. A decreased cell division rate can explain the overall lower heights observed in the tetraploid plants.

Increased height growth as observed in the diploid "fusion" lines compared to the diploid original line (Fig. 4.1) might be caused by rejuvenations effects that occurred during the protoplast stage. The diploid "fusion" lines that originated from protoplast fusion were exposed to the protoplast stage whereas the diploid original line did not experience this phase. The protoplast step is accompanied by dedifferentiation of specialized cells and can lead to epigenetic modifications as, for instance, a reduction in heterochromatin that is supposed to contribute to rejuvenation of the plant cell (Tessadori et al., 2007). 


\subsubsection{Drought responses of the diploid "fusion" and the tetraploid fusion lines}

\section{Survival rate of the hybrid aspen lines}

The tetraploid fusion lines were generally smaller than the diploid lines and the survival rates were increased compared to the diploid original line and the diploid “fusion” lines (Fig. 4.2). This may have been expected because irrigation was stopped and therefore the small plants were exposed to mild stress. Here, the dilemma between yield and drought tolerance is evident. Growth depends on the availability of water and drought tolerance can also be achieved at the expense of biomass (Araus et al., 2002; Bogeat-Triboulot et al., 2006; Cattivelli et al., 2008). It seems more sensible from the economical point of view to plant varieties that exhibit decreased growth but instead survive dry periods because, in total, this will result in a higher biomass production. However, genotypes showing both reasonable height growth and drought tolerance are required for SRC plantations that are supposed to be on marginal sites with low water. Comparable height growth to the diploid original line but delayed leaf wilting with regard to height and therefore higher drought tolerance was observed in the tetraploid fusion lines 14-03, 14-04 and 14-07 (Fig. 4.5). These lines were analyzed for genetic modifications apart from tetraploidy as discussed in section 4.3.

The delay of total leaf wilting observed in 11 tetraploid fusion lines while this was not observed in the diploid "fusion" lines suggests higher drought tolerance for the tetraploid plants. In many species, polyploidization has been assumed to be advantageous under stress conditions and was associated to plants in extreme habitats (Ehrendorfer, 1980; Tal, 1980; Li et al., 2009; Deng et al., 2012). Polyploidization can change the gene expression by increased variation in dosage-regulation, altered regulatory interactions and rapid epigenetic effect (Osborn et al., 2003). Guo et al. (1996) reported an increased gene expression per cell in varieties with increasing ploidy level in Zea. For genes showing allele-dosage effects like, for example, 
quantitative traits polyploidy can enhance the variation in intermediate expression (Osborn et al., 2003). Apart from the gene modifications as an altered gene expression or epigenetic gene silencing one substantial effect of polyploidizaiton was the altered stomatal apparatus that might have contributed to the delay in total leaf wilting.

\section{Stomatal morphology and water consumption}

The tetraploid fusion lines 14-04 and 14-07 showed a decreased stomatal density and an increased stomatal length (Fig. 5.2). This modification has also been observed in tetraploid hybrid aspen lines (see section 4.1, as published in Hennig et al., 2015) and furthermore in other tetraploid species like Spathiphyllum, Platanus or Betula (Li et al., 1996; Liu et al., 2007, van Laere et al., 2010) and lead to decreases in the transpiration surface. In Quercus, a reduction of the SAI was found from wet to xeric habitats (Ashton and Berlyn, 1994). Therefore, Ashton and Berlyn (1994) stated that this parameter might predict drought tolerance. In the tetraploid fusion lines this parameter was not decreased compared to the diploid line (Fig. $5.2 \mathrm{C}$ ). In other tetraploid hybrid aspen lines this parameter was only significantly decreased in one fusion line that consumed less water (Hennig et al., 2015). Therefore, SAI is unsuitable to predict drought tolerance in tetraploid hybrid aspen plants.

The link between stomatal length and density and habitat humidity is discussed controversially. Hodgson et al. (2010) suggested that large stomata are found in plants of high humidity habitats. In contrast, Abrams et al. (1994) detected in deciduous tree species an increasing stomatal size from wet-mesic to mesic and xeric sites. In one P. nigra genotype the stomatal length was increased when water was limited whereas abaxial stomatal density was reduced (Regier et al., 2009) indicating an advantage of less but increased stomata under drought exposure. Furthermore, in tomato cultivars low stomatal density and increased size was related to drought tolerant genotypes (Kulkarni and Deshpande, 2006). According to the literature (Abrams et al., 1994; Kulkarni and Deshpande, 2006; Regier et al., 2009) higher stomatal length and lower stomatal density that were found in the tetraploid lines are advantageous in xeric habitats. 
The duplication of the chromosome set also led to a decreased water consumption in the tetraploid fusion lines (Fig. 5.4). This was observed for two out of four other hybrid aspen lines as described in section 3.1.2 as well (also published in Hennig et al., 2015). Therefore, tetraploidy itself did not lead to decreased water consumption with regard to height in general. But in total, four out of six tested lines had a decreased water consumption relative to the height when compared to the diploid original line indicating that tetraploid fusion lines are more water saving. The lower water consumption might be due to the altered stomatal apparatus in the tetraploid fusion lines (Fig. 5.2) that was also observed in the other tetraploid hybrid aspen (section 3.1.2, published in Hennig et al., 2015). In Arabidopsis, transgenic expression activation of a homoedomain-START transcription factor resulted in lower stomatal density and increased size, lower water loss rates, increased photosynthetic rate, lower transpiration and thus higher water use efficiencies (Yu et al., 2008)

\section{Leaf wilting and desiccation}

During drought exposure the leaves of the diploid original line first wilted all and then started to desiccate. Instead, in most of the tetraploid fusion lines, first a part of the leaves was dried while total leaf wilting was delayed (Fig. 4.6, Tab. 5.3, Fig 5.5 A, B). It has been described for two tetraploid hybrid aspen lines as well that drying of a part of the leaves occurred earlier than in the diploid original line resulting in delayed leaf wilting (section 3.1.2, published in Hennig et al., 2015). This mechanism decreases the transpiration surface by reducing the leaf area and is a way of drought avoidance (Gaur et al., 2008). In analogy to this, leaf shedding and subsequent delayed desiccation has been detected in poplar (Fischer and Polle, 2010). By maintaining the turgor in the remaining leaves and the functionality of the leaves, i.e. the photosynthesis can be kept up. This is in accordance with the stomatal conductance that was maintained even under high drought stress in the tetraploid fusion line. Additionally, the photosynthesis can be resumed immediately when drought disappears. It seems unlikely that a simple duplication of the chromosome set results in a different leaf wilting strategy. It is more likely that the tetraploid hybrid aspen 
suffered from milder drought stress that was due to lower water consumption and partly due to lower height. Therefore, the tetraploid fusion lines had time to adapt physiologically to the drought stress by desiccating leaves and thereby reducing the transpiration surface and further decreasing the stress.

\section{Stomatal conductance and biochemical analyses}

The stomatal conductance under control conditions was not decreased in the tetraploid fusion lines (Fig. 5.9). A decrease of the stomatal conductance was also not found in other tetraploid hybrid aspen lines (section 3.1.2, published in Hennig et al., 2015). But we have shown that the tetraploid fusion lines maintained the stomatal conductance under water limiting conditions while the diploid original line showed already strong decreases (Fig. 5.9). In tetraploid plants of Lonicera, the stomatal conductance was also less reduced under drought exposure in comparison to the diploid plants (Li et al., 2009). These findings suggest higher drought tolerance for the tetraploid varieties.

In the control plants of the tetraploid fusion line 14-07 an increase in the relative height increment was observed while the stomatal conductance decreased (Fig. 5.9, Fig. 5.10). This seems to be contrary as higher photosynthetic rates are usually linked with higher stomatal conductance (Ainsworth and Rogers, 2007; Hull-Sanders et al., 2009). Farquhar and Sharkey (1982) found out that the stomatal limitation only slightly influences the photosynthetic rate. They reported that the photosynthetic rate more strongly depends on the regeneration capacity of ribulose-1,5- bisphosphate (Farquhar and Sharkey, 1982).

High concentrations of carbohydrates along with an active adjustment under drought stress determine the drought tolerance of a plant (Tschaplinski and Tuskan, 1994). Carbohydrates play a role in osmotic adjustment by increasing the cell's osmotic potential but also as osmoprotectors by preventing proteins and membranes from damage by stabilization (Crowe et al., 1992; Deng et al., 2012; Danielsen and Polle, 
2014). Therefore, the increased carbohydrate concentration in the tetraploid plants might have increased their drought tolerance.

The concentration of carbohydrates can only partly explain the increased osmolality in the tetraploid fusion line 14-07 as the carbohydrate concentration was not significantly higher under drought (Fig. 5.7, Fig. 5.8). Except for carbohydrates also ions, amino acids, polyols and polyamines and their derivates act as osmolytes (Yancey, 2005; Danielsen and Polle, 2014). In P. tremula for example, the polyamine spermine was increased under high salt concentrations (Jouve et al., 2004). Ha et al. (1998) supposed spermine to protect DNA from damage by scavenging free radicals. The increased osmolality in the tetraploid fusion line 14-07 under drought exposure might have led to enhanced drought tolerance. This line exhibited serious leaf desiccation later than the diploid line and slightly later than the tetraploid fusion line 14-04 (Fig. 5.5 B).

\section{Relative height increment}

The high carbohydrate concentrations might also indicate higher photosynthetic rate of the tetraploid fusion lines. Actually, high carbohydrate rates are assumed to decrease the photosynthesis by feedback regulation (Ewart, 1896; Paul and Pellny, 2003). The crucial link dissolving this discrepancy might be the phloem. About $50 \%$ to $80 \%$ of the assimilates are exported form the leaves for example in maize (KaltTorres et al., 1987). The phloem is thought to play a key role for "managing" the export of the assimilates from photosynthetic active leaves (source) and the import into non-photosynthetic tissues (sink) (Ainsworth and Bush, 2011). RansomHodgkins et al. (2003) described that the capacity of phloem loading was directly proportional to the number of sucrose symporters at the plasma membrane of the sieve elements in Beta. Thereby, the activity of these sucrose symporters is highly dynamically regulated by transcriptional and posttranslational processes (Vaughn et al., 2002). The increased relative height increment that was observed in the tetraploid fusion line 14-07 might be due to genome modifications (section 4.3). 


\subsubsection{Conclusion}

The tetraploid fusion lines showed lower water consumption compared to the diploid original line and were able to maintain the stomatal conductance relative to the control at lower relative soil moistures. This suggests higher drought tolerance for the tetraploid fusion lines in comparison to the diploid original line. Therefore, somatic hybridization for generating drought-tolerant poplar varieties for dry sites is a promising approach. Especially, as higher stress tolerance of polyploid varieties is not only limited to drought. In octaploid tobacco plants increased survival times compared to the tetraploid relatives were reported when the plants were exposed to cold and particularly increased under nutrient deficiency (Deng et al., 2012). Since the plantation of SRC on marginal sites also refers to soils that are affected by pollution, salinization or low nutrient supply (Kuzovkina and Quigley, 2005; Karp and Shield, 2008; Polle et al., 2013) the tetraploid fusion lines represent interesting poplar varieties that may cope with these stress conditions but show economical viable growth. This seems to be of increasing relevance to avoid land use conflicts between biomass and food production as the energy and food demand continues to rise (Karp and Richter, 2011). 


\subsection{Whole genome sequencing of selected tetraploid hybrid aspen fusion lines}

Whole genome sequencing was conducted with the tetraploid fusion lines 14-03, 14-04 and 14-07 along with the diploid original line 18-03 to reveal genome modifications apart from the tetraploidy in the protoplast fusion lines. CNVs can be used to detect genome modifications as duplications or deletions.

\subsubsection{Basic characterization of the detected copy number variations}

Altered DNA segments with CNVs were detected in the tetraploid fusion lines compared to the diploid original line (Fig. 6.1). The number of identified DNA segments showing CNVs varied among the tetraploid fusion lines (Fig. 6.1). While in the tetraploid fusion line 14-07 100 segments were increased when compared to the diploid line, in the tetraploid fusion lines 14-03 and 14-04 only 18 and 6 DNA segments were duplicated, respectively, compared to the diploid original line (Fig. $6.3 \mathrm{~A}$ ). This suggests that genetic variation among the tetraploid fusion lines appeared. But for more reliability of the data set technical and biological replicates are necessary. CNVs are supposed to occur due to double strand breaks in the DNA and subsequent homologous and non-homologous recombination or by errors during replication as well (Conrad et al., 2010). Double strand breaks were associated to tissue culturing apart from genome modifications as single-gene mutation, transposable element activation and a distinct DNA methylation pattern (Kaeppler and Phillips, 1993; Svitashev and Somers, 2001). The passing of tissue culture with several subcultures including many replication cycles might be one reason for the differing numbers of altered DNA segments among the tetraploid fusion lines.

In most of the cases the segments with altered CNVs compared to the diploid line 18-03 were evenly spread over the genome of the tetraploid fusion lines indicating a random distribution (Fig. 6.2). Freeman et al. (2006) described in a review that CNVs 
occur more frequently than expected by chance in regions that already show segmental duplications. Furthermore, CNVs are often related to repeat-rich regions as for example telomeres, centromeres and heterochromatin (Giglio et al. ,2001). In contrast to the altered segments in the other tetraploid fusion lines, the decreased segments in line 14-03 were clustered. They accumulated at the end of chromosome 11 (Fig. 6.2 D) suggesting a deletion of a large DNA segment.

\subsubsection{Possible phenotypic influence due to copy number variations}

Only for two out of the 12 altered segments the encoded gene annotation was available. In the in silico analysis the association to "growth" and "drought" was limited to three altered segments (Tab. 6.1). Therefore, the functional analysis remained unspecific. For further functional characterization of the detected segments knock-out mutants missing the respective DNA segments could be generated in future studies. Subsequently exposing the mutants to drought could reveal the relevance of the DNA segments under drought. This could be enlarged by quantitative expression analysis under dry conditions.

CNVs can occur in different functional regions of the DNA as for example in stop codons, in exons and promoters, within an intron or in intergenic regions (Conrad et al., 2010). When CNVs appear in regulatory regions as stop codons or promoters it is assumed that this can have impact on the gene dosage by disrupting coding sequences and long-range gene regulation (Kleinjan and van Heyningen, 2005; Conrad et al., 2010). Increased copy numbers can correlate both positively and negatively with the gene expression. For example, if a transcriptional repressor is deleted the gene expression of the target gene might be positively influenced (Lee et al., 2006; McCarroll et al., 2006). Stranger et al. (2007) described that about $50 \%$ of the CNV effects are due to disruption of coding sequences or alteration of regulatory and other functional regions that play a role in gene expression (Stranger et al., 2007). But apart from changes in the gene sequence that might cause loss of gene function or altered gene dosage also posttranslational modifications can have impact on the phenotypic 
variation. For further characterization of the altered DNA segments expression analysis could be conducted to detect if the segments are located in a coding sequence or not. The response of knock out mutants under drought could be investigated to determine the drought relevance of the putatively encoded genes.

Apart from the putative function the overlap of segments with CNVs that were changed in all tetraploid fusion lines was low (Fig. 6.3 A, B). This reduces the possibility that many important genes were altered together in all tetraploid fusion lines and leads to the assumption that the enhanced drought performance (significant delay in total leaf wilting with regard to height compared to the diploid line 18-03, Fig. 4.5) is due to the polyploidy but not caused by the altered segments with CNVs. This is underpinned by two facts. (i) The tetraploid fusion line 14-07 exhibited a high number of 90 uniquely increased segments with CNVs (Fig. $6.3 \mathrm{~A}$ ) showed higher drought tolerance compared to the diploid original line but similar drought tolerance as the other tested tetraploid fusion line 14-04. The water consumption, the leaf wilting and desiccation and the stomatal conductance relative to the control in the tetraploid fusion line 14-07 was nearly the same as in the tetraploid fusion line 14-04 (Fig. 5.4 B, 5.5 A, 5.9). And, (ii) none of the four diploid "fusion" lines in section 3.2.1 exhibited a delayed leaf wilting with regard to height in comparison to the diploid original line 18-03. Both findings imply that the tetraploidy is the reason for the enhanced drought tolerance. Nevertheless, functionally caracterizing the three segments that were altered in all tetraploid fusion lines in comparison to the diploid line is useful as drought-relevant genes might be affected. The relevance to drought of these putative genes could be tested using knock-out mutants that are exposed to dry conditions.

\subsubsection{Limitations of the present copy number variation analysis}

For the presented CNV analysis it should be noted that due to a missing reference genome for P. tremula x P. tremuloides or closely related species about 300000 contigs with 200 to 128000 bp length were used. The problems and limitations using 
these contigs were (i) no order, (ii) different length and therefore small contigs were removed as a minimum of 50 reads had to map within a contig, (iii) no alignment resulting in sequence overlaps that represented redundancies (iv) window approach (counting of reads within a frame of $650 \mathrm{bp}$ ) neglected segments at the end of a contig reducing the sequence length that could be investigated (v) no genome-wide CNV analysis but restriction to one contig (vi) the window approach neglected intron-exon regions of the putative encoding genes.

\subsubsection{Conclusion}

Several segments showing CNVs could be detected by whole genome sequencing in the tetraploid fusion lines. For a more reliable data set technical and biological replications should be conducted. Only three segments were altered in all tetraploid fusion lines in comparison to the diploid line. The low number of CNVs reduces the probability that many important drought-relevant genes were altered by CNVs in all tetraploid fusion lines. This indicates that the tetraploidy rather than the CNVs were the reason of enhanced drought performance in the tetraploid fusion lines. This assumption is underpinned by the investigations that the tetraploid fusion line 14-07 revealed the highest number of uniquely increased segments but showed only slight physiological effect in comparison to the tetraploid fusion line 14-04, e.g. a low increase in height, a similar water consumption. Moreover, none of the diploid "fusion" lines in section 3.2.1 exhibited a delayed leaf wilting with respect to height in comparison to the diploid original line. Nevertheless, to investigate if droughtrelevant were affected by the copy number variations the response of knock-out mutants under drought could be investigated. 


\section{Overall conclusion}

In this dissertation, the drought performance of poplar protoplast fusion lines was characterized. The poplar lines that were obtained by somatic hybridization between P. tremula x P. tremuloides as one fusion partner and either P. nigra, P. trichocarpa $\mathrm{x}$ P. deltoides or P. x. canescens as second fusion partner were homofusion lines of P. tremula x $P$. tremuloides.

All tested protoplast fusion lines could be assigned to the hybrid aspen according to their leaf morphology and most of them were tetraploid homofusion lines. Therefore, they were characterized in comparison to the diploid original line P.tremula $\mathrm{x}$ P. tremuloides ('Münden 2'). In the tetraploid fusion lines the relative soil moisture was significantly higher than in the diploid original line throughout all experiments (Fig. 7.1). The higher relative soil moistures suggest that the tetraploid plants absorbed less water from the soil than the diploid plants. This assumption is supported by the decreased water consumption (Fig. 7.1) that was observed for most of the tetraploid fusion lines. The altered stomatal apparatus in the tetraploid lines exhibiting lower stomatal density while increasing length of the stomata (Fig. 7.1) might be one reason for the lower water consumption. Lower stomatal density and increased stomatal length has been observed in poplars of dry habitats (Regier et al., 2009). Furthermore, the higher leaf mass per area and smaller total leaf areas (Fig. 7.1) might also have contributed to the lower water consumption of the tetraploid fusion lines. A higher leaf mass per area was associated to plants of xeric habitats (Abrams et al., 1994). With a decreased total leaf area and an increased leaf mass per area (Fig, 7.1) the transpiration might be lower because the surface-to-volume ratio is reduced. Thicker leaves are typical for xeric habitat plants and were also observed in a droughttolerant $P$. nigra clone indicating to be advantageous under dry conditions because of lower transpiration (Regier et al., 2009). Reduced transpiration would be in accordance with a low stomatal conductance. In general, a lower stomatal conductance was not observed in the tetraploid fusion lines compared to the diploid original line (Fig. 7.1). The tetraploid plants were able to maintain the stomatal 
conductance relative to the control group at lower relative soil moisture levels compared to the diploid original line indicating higher drought tolerance.
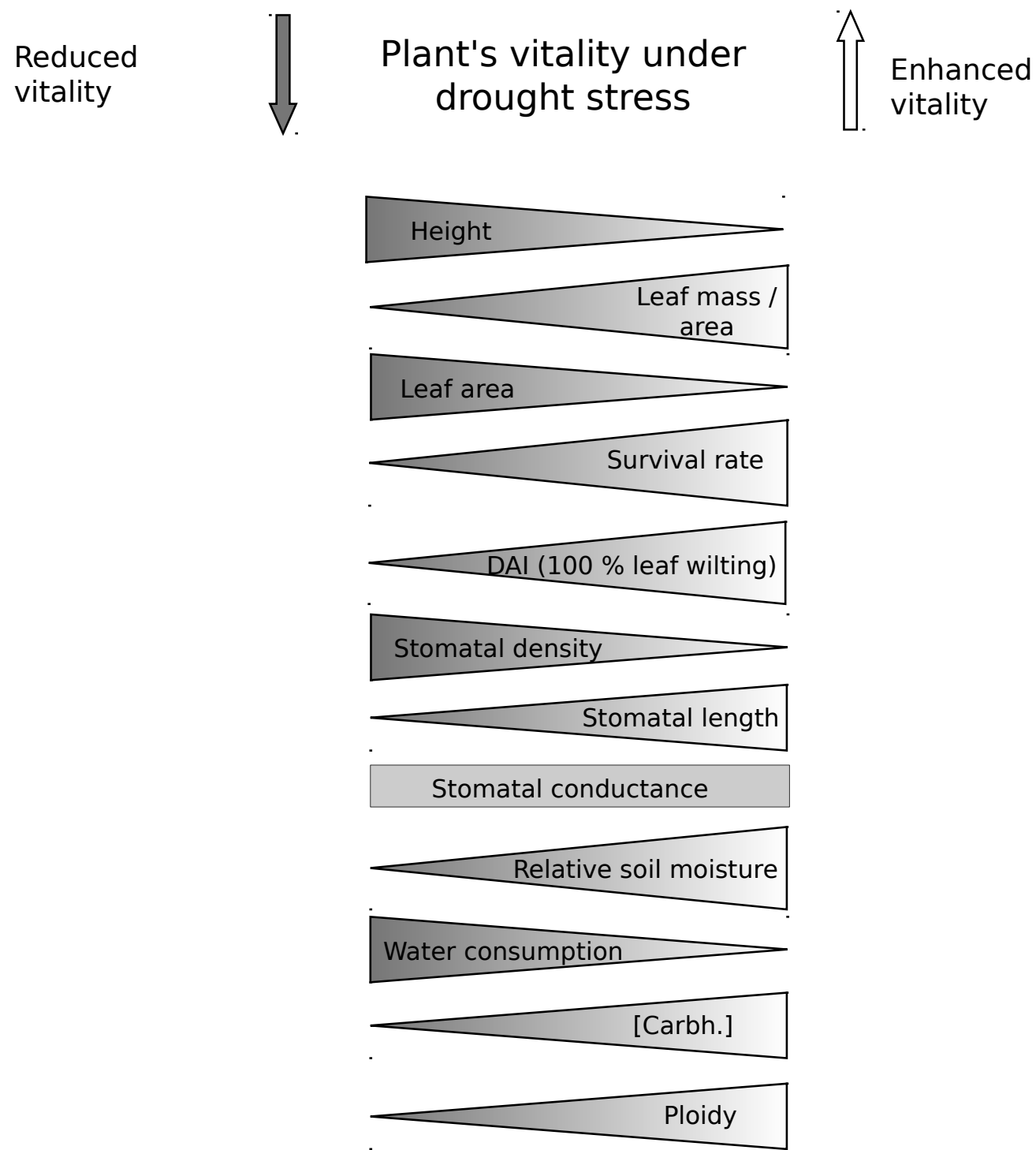

Figure 7.1: Trends of investigated parameters ([Carbh.]:Carbohydrate concentration. Lower height, leaf area, stomatal density and water consumption were observed along with increased leaf mass per area, survival rate, DAI (day after irrigation) when total leaf wilting occurred, stomatal length, relative soil moisture, carbohydrate concentration and ploidy. The tetraploid plants that exhibited these traits showed enhanced vitality under drought stress while in the diploid plants a trend to opposite morphological and physiological characteristics was observed that resulted in lower vitality under dry conditions). 
The higher carbohydrate concentration that were found in the tetraploid fusion lines (Fig. 7.1) under control conditions may also have been advantageous when drought occurred as carbohydrates can function as osmolytes and osmoprotectors (Teixeira and Pereira, 2007; Danielsen and Polle, 2014).

Additionally, the height that tended to be lower in the tetraploid fusion lines than in the diploid line (Fig. 7.1) might have contributed to a lower stress level in the tetraploid fusion lines. Lower height has been observed in polyploid varieties of many species (Weiss and Porter, 1948; Sharma and Datta, 1957; Riddle and Birchler, 2008; Deng et al., 2012) and might be caused by lower cell division rates that occurred in several polyploid plant species (Scholes and Paige, 2015).

To give an overview of morphological traits and the drought performance of the investigated fusion lines they are ranked in Table 7.1 together with the diploid original line. Within the first experiment, the tetraploid fusion line $27-12$ is the line with the highest biomass production and lowest water consumption per height (Tab. 7.1) and is therefore an interesting candidate for SRC on dry sites. Within the screening experiment, the most drought-tolerant fusion lines were the tetraploid fusion lines 14-05, 14-04 and 18-10 that showed the highest survival rates. Here, 14-04 exhibited average height growth in addtition whereas the lines 14-05 and 18-10 were very low (Tab. 7.1). The highest biomass production in experiment 2 was found in the diploid "fusion" lines 14-08, 18-07 and 18-11 but these lines showed low survival rates (Tab. 7.1). Furthermore, in the tetraploid fusion line 14-06 a high survival was observed along with average height growth (Tab. 7.1). Thus, the tetraploid fusion lines 14-04 and 14-06 seem to be reasonable lines for planting in biomass production on dry sites.

In summary, a majority of the tetraploid hybrid aspen lines exhibited higher drought tolerance in the greenhouse experiments. These findings suggest that the tetraploid hybrid aspen are superior on dry sites where failures are expected due to extreme weather conditions as droughts. The viability of these findings should be tested in field trials on dry sites. The better drought performance of the tetraploid fusion lines may be at the expense of growth in some lines. Of course, high biomass production is 
one of the most important traits in short rotation coppice. Therefore, the plantation of drought-tolerant lines with decreased biomass productions should be recommended on soils where water is a limiting factor. Producing tetraploid varieties using somatic hybridization is a promising approach as polyploid varieties might be more stress tolerant, not only with regard to drought but also considering nutrient deficiency and cold hardiness (Deng et al., 2012). 
Table 7.1: Ranking of the hybrid aspen lines with regard to the investigated parameters (27-01 and 18-03: diploid original clone P. tremula $\mathrm{x}$ P. tremuloides ('Münden 2'), diploid “fusion” lines: 14-08, 18-04, 18-07, 18-11, other lines are tetraploid fusion lines. The hybrid aspen lines are ranked separated by the different experiments: 27-lines: experiment 1; 14-lines and 18-lines: experiment 2; 18-03, 14-04, 14-07: experiment 3. The lines are ranked according to their median, NA: no data available, - : not analyzed. RWC: relative leaf water content, DAI: Day after irrigation, rel. sm: relative soil moisture.)

$\stackrel{\varphi}{\sim}$

\begin{tabular}{|c|c|c|c|c|c|c|c|c|c|c|c|c|c|c|c|c|c|c|c|c|}
\hline 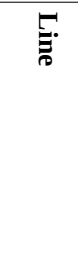 & $\begin{array}{l}\frac{T}{2} \\
\frac{2}{20} \\
\frac{00}{7}\end{array}$ & 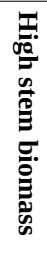 & 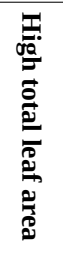 & 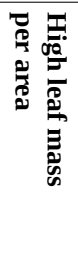 & 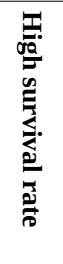 & 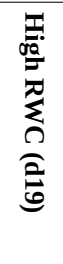 & 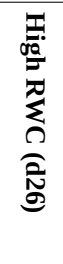 & 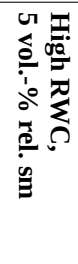 & 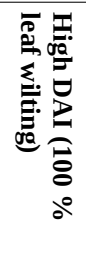 & 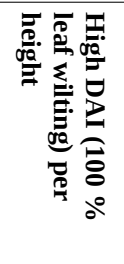 & 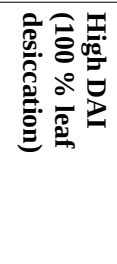 & 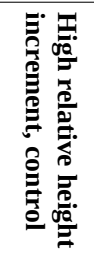 & 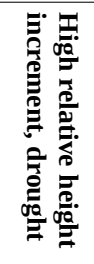 & 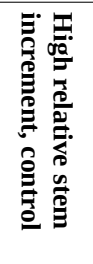 & 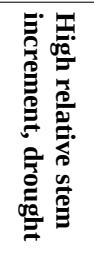 & 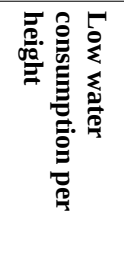 & 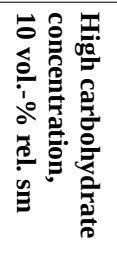 & 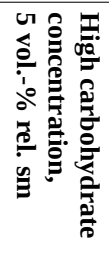 & 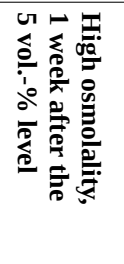 & 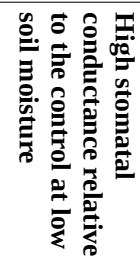 \\
\hline $27-01$ & 1 & 2 & 2 & 5 & - & - & - & - & 4 & - & 4 & 4 & 2 & 4 & 5 & 5 & 4 & - & - & - \\
\hline $\begin{array}{l}27-09 \\
\end{array}$ & 5 & 5 & 5 & 1 & - & - & - & - & $\mathrm{NA}$ & - & NA & 5 & 5 & 5 & 4 & 4 & 5 & - & - & - \\
\hline 27-10 & 3 & 3 & 3 & 3 & - & - & - & - & 2 & - & 2 & 3 & 3 & 2 & 3 & 2 & 3 & - & - & - \\
\hline 27-11 & 4 & 4 & 4 & 4 & - & - & - & - & 1 & - & 1 & 1 & 2 & 3 & 1 & 3 & 2 & - & - & - \\
\hline $27-12$ & 2 & 1 & 1 & 2 & - & - & - & - & 3 & - & 3 & 2 & 1 & 1 & 2 & 1 & 1 & - & - & - \\
\hline 14-01 & 14 & - & - & - & 12 & 16 & 14 & - & 12 & 16 & 12 & - & - & - & - & - & - & - & - & - \\
\hline $14-02$ & 9 & - & - & - & 13 & 14 & 8 & - & 16 & 15 & 17 & - & - & - & - & - & - & - & - & - \\
\hline $14-03$ & 12 & - & - & - & 8 & 8 & 7 & - & 7 & 6 & 10 & - & - & - & - & - & - & - & - & - \\
\hline $14-04$ & 10 & - & - & - & 2 & 7 & 10 & 3 & 10 & 2 & 7 & 3 & 3 & - & - & 2 & - & 1 & 3 & 1 \\
\hline $14-05$ & 17 & - & - & - & 1 & 1 & 5 & - & 2 & 1 & 4 & - & - & - & - & - & - & - & - & - \\
\hline $14-06$ & 11 & - & - & - & 7 & 10 & 12 & - & 11 & 3 & 11 & - & - & - & - & - & - & - & - & - \\
\hline $14-07$ & 4 & - & - & - & 15 & 13 & 16 & 1 & 15 & 9 & 14 & 1 & 2 & - & - & 1 & - & 2 & 1 & 2 \\
\hline $14-08$ & 1 & - & - & - & 19 & 21 & 20 & - & 21 & 20 & 21 & - & - & - & - & - & - & - & - & - \\
\hline $14-09$ & 5 & - & - & - & 14 & 20 & 15 & - & 13 & 12 & 13 & - & - & - & - & - & - & - & - & - \\
\hline $14-10$ & 13 & - & - & - & 4 & 11 & 6 & - & 8 & 4 & 3 & - & - & - & - & - & - & - & - & - \\
\hline $18-03$ & 8 & - & - & - & 17 & 19 & 13 & 2 & 17 & 19 & 16 & 2 & 1 & - & - & 3 & - & 3 & 2 & 3 \\
\hline $18-04$ & 6 & - & - & - & 19 & 18 & 19 & - & 18 & 18 & 18 & - & - & - & - & - & - & - & - & - \\
\hline $18-05$ & 18 & - & - & - & 8 & 3 & 1 & - & 4 & 7 & 2 & - & - & - & - & - & - & - & - & - \\
\hline $18-06$ & 7 & - & - & - & 15 & 9 & 17 & - & 14 & 14 & 15 & - & - & - & - & - & - & - & - & - \\
\hline $18-07$ & 2 & - & - & - & 17 & 15 & 18 & - & 19 & 17 & 19 & - & - & - & - & - & - & - & - & - \\
\hline $18-08$ & 15 & - & - & - & 6 & 2 & 2 & - & 1 & 5 & 1 & - & - & - & - & - & - & - & - & - \\
\hline $18-09$ & 20 & - & - & - & 11 & 5 & 3 & - & 9 & 13 & 8 & - & - & - & - & - & - & - & - & - \\
\hline $18-10$ & 21 & - & - & - & 3 & 12 & 11 & - & 3 & 8 & 5 & - & - & - & - & - & - & - & - & - \\
\hline $\begin{array}{l}18-11 \\
\end{array}$ & 3 & - & - & - & 18 & 17 & 21 & - & 20 & 21 & 20 & - & - & - & - & - & - & - & - & - \\
\hline 18-12 & 16 & - & - & - & 8 & 4 & 4 & - & 6 & 10 & 9 & - & - & - & - & - & - & - & - & - \\
\hline $18-13$ & 19 & - & - & - & 4 & 6 & 9 & - & 5 & 11 & 6 & - & - & - & - & - & - & - & - & - \\
\hline
\end{tabular}




\section{References}

Abrams, M.D., Kubiske, M.E., and Mostoller, S.A. (1994). Relating wet and dry year ecophysiology to leaf structure temperate tree species. Ecology 75, 123133.

Adams, K.L., and Wendel, J.F. (2005). Polyploidy and genome evolution in plants. Curr. Opin. Plant Biol. 8, 135-141.

Adams, K.L., Cronn, R., Percifield, R., and Wendel, J.F. (2003). Genes duplicated by polyploidy show unequal contributions to the transcriptome and organspecific reciprocal silencing. Proc. Natl. Acad. Sci. 100, 4649-4654.

Ahuja, M.R. (1984). A commercially feasible micropropagation method for aspen. Silvae Genet. 33, 174-176.

Ainsworth, E.A., and Bush, D.R. (2011). Carbohydrate export from the leaf: a highly regulated process and target to enhance photosynthesis and productivity. Plant Physiol. 155, 64-69.

Ainsworth, E.A., and Rogers, A. (2007). The response of photosynthesis and stomatal conductance to rising $\left[\mathrm{CO}_{2}\right]$ : mechanisms and environmental interactions: photosynthesis and stomatal conductance responses to rising [CO ${ }_{2}$. Plant Cell Environ. 30, 258-270.

Araus, J.L., Slafer, G.A., Reynolds, M.P., and Royo, C. (2002). Plant breeding and drought in C3 cereals: what should we breed for? Ann. Bot. 89, 925-940.

Ashton, P.M.S., and Berlyn, G.P. (1994). A comparison of leaf physiology and anatomy of Quercus (Section Erythrobalanus-Fagaceae) species in different light environments. Am. J. Bot. 81, 589-597.

Asif, M., and Muneer, T. (2007). Energy supply, its demand and security issues for developed and emerging economies. Renew. Sustain. Energy Rev. 11, 13881413.

Baumeister, W., and Ernst, W. (1978). Mineralstoffe und Pflanzenwachstum, Gustav Fischer Verlag, Stuttgart-New York, 416 S. 
Berndes, G., Hoogwijk, M., and van den Broek, R. (2003). The contribution of biomass in the future global energy supply: a review of 17 studies. Biomass Bioenergy 25, 1-28.

Binding, H., and Nehls, R. (1978). Somatic cell hybridization of Vicia faba+Petunia hybrida. Mol. Gen. Genet. 164, 137-143.

Birky, C.W. j. (1995). Uniparental inheritance of mitochondrial and chloroplast genes: mechanisms and evolution. Proc Natl Acad Sci USA 92, 1133111338.

Blake, T.J., and Tschaplinski, T.J. (1992). Water relations. In: Ecophysiology of short rotation forest crops, Mitchell, C.P., Ford-Robertson, J.B., Hinckley, T., Sennerby-Forsse, L. (eds.), Elsevier, London, pp. 66-94.

Blanc, G., and Wolfe, K.H. (2004). Widespread paleopolyploidy in model plant species inferred from age distributions of duplicate genes. Plant Cell Online $16,1667-1678$.

BMEL (2007). Nutzung von Biomasse zur Energiegewinnung - Empfehlung an die Politik. Wissenschaftlicher Beirat beim Bundesministerium für Ernährung, Landwirtschaft und Verbraucherschutz, 242 S. Available online at: www.bmelv.de/cae/servlet/contentblob/382594/publicationFile/23017/ GutachtenWBA.pdf

BMEL (2014). Starke Landwirtschaft. Available online at: http://www.bmel.de/DE/ Landwirtschaft/landwirtschaft_node.html [Accessed October 29, 2014].

Bogeat-Triboulot, M.-B., Brosche, M., Renaut, J., Jouve, L., Le Thiec, D., Fayyaz, P., Vinocur, B., Witters, E., Laukens, K., Teichmann, T., Altmann, A., Hausman, J.-F, Polle, A., Kangasjarvi, J., and Dreyer, E. (2006). Gradual soil water depletion results in reversible changes of gene expression, protein profiles, ecophysiology, and growth performance in Populus euphratica, a poplar growing in arid regions. Plant Physiol. 143, 876-892.

Brewer, E.P., Saunders, J.A., Angle, J.S., Chaney, R.L., and McIntosh, M.S. (1999). Somatic hybridization between the zinc accumulator Thlaspi caerulens and Brassica napus . Theor. Appl. Genet. 99, 761-771. 
Cattivelli, L., Rizza, F., Badeck, F.-W., Mazzucotelli, E., Mastrangelo, A.M., Francia, E., Marè, C., Tondelli, A., and Stanca, A.M. (2008). Drought tolerance improvement in crop plants: an integrated view from breeding to genomics. Field Crops Res. 105, 1-14.

Clancy, S. (2008). Copy Number Variation. Nat. Educ. 1, 95.

Conrad, D.F., Pinto, D., Redon, R., Feuk, L., Gokcumen, O., Zhang, Y., Aerts, J., Andrews, T.D., Barnes, C., Campbell, P., Fitzgerald, T., Hu, M., Ihm, C.H., Kritiansson, K., MacArthur, D.G., MacDonald, J.R., Onyiah, I., Wing Chun Pang, A., Robson, S., Stirrups, K., Valsesia, A., Walter, K., Wei, J., Wellcome Trust Case Control Consortium, Tyler-Smith, C., Lee, C., Scherer, S.W., and Hurles, M.E. (2010). Origins and functional impact of copy number variation in the human genome. Nature 464, 704-712.

Cookson, S.J., Radziejwoski, A., and Granier, C. (2006). Cell and leaf size plasticity in Arabidopsis: what is the role of endoreduplication? Plant Cell Environ. 29, 1273-1283.

Crowe, J.H., Hoekstra, F.A., and Crowe, L.M. (1992). Anhydrobiosis. Annu. Rev. Physiol. 54, 579-599.

Dai, A. (2012). Increasing drought under global warming in observations and models. Nat. Clim. Change 3, 52-58.

Dalling, J.W., and Hubbell, S.P. (2002). Seed size, growth rate and gap microsite conditions as determinants of recruitment success for pioneer species. J. Ecol. 90, 557-568.

Danielsen, L., and Polle, A. (2014). Poplar nutrition under drought as affected by ectomycorrhizal colonization. Environ. Exp. Bot. 108, 89-98.

Deng, B., Du, W., Liu, C., Sun, W., Tian, S., and Dong, H. (2012). Antioxidant response to drought, cold and nutrient stress in two ploidy levels of tobacco plants: low resource requirement confers polytolerance in polyploids? Plant Growth Regul. 66, 37-47. 
Doman, L., Singer, L., and Arora, V. (2014). International Energy Outlook 2014. U.S. Energy Information Administration (EIA). Available online at: http://www.eia.gov/forecasts/ieo/pdf/0484(2014).pdf [Accessed October 23, 2014].

Dumolin, S., Demesure, B., and Petit, R.J. (1995). Inheritance of chloroplast and mitochondrial genomes in pedunculate oak investigated with an efficient PCR method. Theor. Appl. Genet. 91, 1253-1256.

Eckenwalder, J.E. (1996). Systematics and evolution of Populus. In: Biology of Populus and its implications for management and conservation, R.F. Stettler, H.D. Bradshaw, Jr., P.E. Heilman, and T.M. Hinckley, (eds.) Ottawa, ON, Canada: NRC Research Press, pp. 7-32.

Efremova, N., Lührs, R., Welters, P., Voß, M., Fladung, M., Hennig, A., MeierDinkel, A., Janßen, A. (2013). Züchtung neuer Energiepappeln. KonferenzArtikel, “Agrarholz 2013”, Internationale Konferenz 19.-20.02.2013 in Berlin.

Ehrendorfer, F. (1980). Polyploidy and distribution. In: Polyploidy, Lewis, W.H. (ed.), Springer US, pp. 45-60.

Eusemann, P., Fehrenz, S., and Schnittler, M. (2009). Development of two microsatellite multiplex PCR systems for high throughput genotyping in Populus euphratica. J. For. Res. 20, 195-198.

Ewart, A.J. (1896). On assimilatory inhibition in plants. J. Linn. Soc. Lond. Bot. 31, 364-461.

Fankhauser, C., and Chory, J. (1997). Light control of plant development. Annu. Rev. Cell Dev. Biol. 13, 203-229.

Farooq, M., Wahid, A., Kobayashi, N., Fujita, D., and Basra, S.M.A. (2009). Plant drought stress: effects, mechanisms and management. Agron. Sustain. Dev. 29, 185-212.

Farquhar, G.D., and Sharkey, T.D. (1982). Stomatal conductance and photosynthesis. Annu. Rev. Plant Physiol. 33, 317-345. 
Finnegan, E.J. (2002). Epialleles - a source of random variation in times of stress. Curr. Opin. Plant Biol. 5, 101-106.

Fischer, U., and Polle, A. (2010). Populus responses to abiotic stress. In: Genetics and genomics of Populus, Jansson, S., Bhalerao, R., and Groover, A. (eds.), Springer Verlag Berlin, pp. 225-247.

Flexas, J., Bota, J., Cornic, G., and Sharkey, T.D. (2004). Diffusive and metabolic limitations to photosynthesis under drought and salinity in C3 plants. Plant Biol. 6, 269-279.

Freeman, J.L., Perry, G.H., Feuk, L., Redon, R., McCarroll, S.A., Altshuler, D.M., Aburatani, H., Jones, K.W., Tyler-Smith, C., Hurles, M.E., Carter, N.P., Scherer, S.W., and Lee, C. (2006). Copy number variation: new insights in genome diversity. Genome Res. 16, 949-961.

Gailing, O., Langenfeld-Heyser, R., Polle, A., and Finkeldey, R. (2008). Quantitative trait loci affecting stomatal density and growth in a Quercus robur progeny: implications for the adaptation to changing environments. Glob. Change Biol. 14, 1934-1946.

Galmés, J., Flexas, J., Savé, R., and Medrano, H. (2007). Water relations and stomatal characteristics of mediterranean plants with different growth forms and leaf habits: responses to water stress and recovery. Plant Soil 290, 139155.

Gaur, P.M., Krihsnamurthy, L., and Kashiwagi, J. (2008). Improving droughtavoidance root traits in chickpea (Cicer arietinum L.) - current status of research at ICRISAT. Plant Prod Sci 11, 3-11.

Geburek, T. (1994). Populus tremuloides. In: Enzyklopädie der Holzgewächse: Handbuch und Atlas der Dendrologie, Roloff, A., Weisgerber, H., Lang, U.M., Stimm, B, (Hrsg.) Wiley-VCH Weinheim. 
Giglio, S., Broman, K.W., Matsumoto, N., Calvari, V., Gimelli, G., Neumann, T., Ohashi, H., Voullaire, L., Larizza, D., Giorda, R., Weber, J.L., Ledbetter, D.H., Zuffardi, O. (2001). Olfactory receptor-gene clusters, genomicinversion polymorphisms, and common chromosome rearrangements. Am. J. Hum. Genet. 68, 874-883.

Gilroy, S., Read, N.D., and Trewavas, A.J. (1990). Elevation of cytoplasmic calcium by caged calcium or caged inositol trisphosphate initiates stomatal closure. Nature 346, 769-771.

Goodstein, D.M., Shu, S., Howson, R., Neupane, R., Hayes, R.D., Fazo, J., Mitros, T., Dirks, W., Hellsten, U., Putnam, N., Rokhsar, D.S. (2012). Phytozome: a comparative platform for green plant genomics. Nucleic Acids Res. 40, 1178-1186.

Grosser, J.W., Ollitrault, P., and Olivares-Fuster, O. (2000). Somatic hybridization in citrus: an effective tool to facilitate variety improvement. Vitro Cell. Dev. Biol. - Plant 36, 434-449.

Guo, W.W., and Deng, X.X. (1998). Somatic hybrid plantlets regeneration between citrus and its wild relative, Murraya paniculata via protoplast electrofusion. Plant Cell Rep. 18, 297-300.

Guo, M., Davis, D., and Birchler, J.A. (1996). Dosage effects on gene expression in a maize ploidy series. Genet. Soc. Am. 142, 1349-1355.

Ha, H.C., Sirisoma, N.S., Kuppusamy, P., Zweier, J.L., Woster, P.M., and Casero, R.A. (1998). The natural polyamine spermine functions directly as a free radical scavenger. Proc. Natl. Acad. Sci. 95, 11140-11145.

Hartmann, D.L. (1994). Global physical climatology, Academic Press London, 425pp.

Helbig, C., and Müller, M. (2009). Abiotische und biotische Schadfaktoren in Kurzumtriebsplantagen. In: Anbau und Nutzung von Bäumen auf landwirtschafltichen Flächen, Reeg, T., Bemmann, A., Konold, W., Murach, D., Spiecker, H. (Hrsg.) Wiley-VCH, Weinheim, S. 83-97. 
Hennig, A., Kleinschmit, J.R.G., Schoneberg, S., Löffler, S., Janßen, A., and Polle, A. (2015). Water consumption and biomass production of protoplast fusion lines of poplar hybrids under drought stress. Plant Biotechnol. 6, 330, doi: 10.3389/fpls.2015.00330.

Hodgson, J.G., Sharafi, M., Jalili, A., Diaz, S., Montserrat-Marti, G., Palmer, C., Cerabolini, B., Pierce, S., Hamzehee, B., Asri, Y., Jamzad, Z., Wilson, P., Raven, J.A., Band, S.R. Basconcelo, S., Bogard, A., Carter, G., Charles, M., Castro-Díez, P., Cornelissen, J.H.C., Funes, G., Jones, G., Khoshnevis, M., Pérez-Harguindeguy, N., Pérez-Rontomé, M.C., Shirvany, F.A., Hynd, A., Kowsary, E., Kazemi-Saeed, F., Siavash, B., Villar-Salvador, P., Craigie, R., Naqinezhad, A., Romo-Díez, A., de Torres Espuny, L., and Simmons, E. (2010). Stomatal vs. genome size in angiosperms: the somatic tail wagging the genomic dog? Ann. Bot. 105, 573-584.

Hull-Sanders, H.M., Johnson, R.H., Owen, H.A., and Meyer, G.A. (2009). Effects of polyploidy on secondary chemistry, physiology, and performance of native and invasive genotypes of Solidago gigantea (Asteraceae). Am. J. Bot. 96, $762-770$.

IPCC (2011). Summary for policymakers. In: IPCC Special report on renewable energy sources and climate change mitigation, Edenhofer, O., PichsMadruga, P., Sokona, Y., Seyboth, K., Matschoss, P., Kadner, S., Zwickel, T., Eickemeier, P., Hansen, G., Schlömer, S., von Stechow, C. (eds.), Cambridge University Press, Cambridge, United Kingdom and New York, NY, USA, 26p.

IPCC (2014). Climate change 2014: mitigation of climate change. In: Contribution of working group III to the fifth assessment report of the intergovernmental panel on climate change, Edenhofer, O., Pichs-Madruga, R., Sokona, Y., Farahani, E., Kadner, S., Seyboth, K., Matschoss, P., Kadner, S., Zwickel, T., Eickemeier, P., Hansen, G., Schlömer, S., von Stechow, C. (eds.), Cambridge; New York, NY, Cambridge University Press, p. 1-139. 
Jouve, L., Hoffmann, L., and Hausman, J.-F. (2004). Polyamine, carbohydrate, and proline content canges during salt stress exposure of sspen (Populus tremula L.): involvement of oxidation and osmoregulation metabolism. Plant Biol. 6, 74-80.

Kaeppler, S.M., and Phillips, R.L. (1993). DNA methylation and tissue cultureinduced variation in plants. Vitro Cell. Dev. Biol. - Plant 29, 125-130.

Kalt-Torres, W., Kerr, P.S., Usuda, H., and Huber, S.C. (1987). Diurnal changes in maize leaf photosynthesis. I. Carbon exchange rate, assimilate export rate, and enzyme activities. Plant Physiol. 83, 283-288.

Kanehisa, M., Goto, S., Sato, Y., Kawashima, M., Furumichi, M., and Tanabe, M. (2014). Data, information, knowledge and principle: back to metabolism in KEGG. Nucleic Acids Res. 42, 199-205.

Kao, K.N. (1977). Chromosomal behaviour in somatic hybrids of soybean-Nicotiana glauca. Mol. Gen. Genet. MGG 150, 225-230.

Kaplan-Levy, R.N., Brewer, P.B., Quon, T., and Smyth, D.R. (2012). The trihelix family of transcription factors - light, stress and development. Trends Plant Sci. $17,163-171$.

Karp, A., and Richter, G.M. (2011). Meeting the challenge of food and energy security. J. Exp. Bot. 62, 3263-3271.

Karp, A., and Shield, I. (2008). Bioenergy from plants and the sustainable yield challenge. New Phytol. 179, 15-32.

Kemble, R.J., Barsby, T.L., Wong, R.S.C., and Shepard, J.F. (1986). Mitochondrial DNA rearrangements in somatic hybrids of Solanum tuberosum and Solanum brevidens. Theor. Appl. Genet. 72, 787-793.

Kleinjan, D.A., and van Heyningen, V. (2005). Long-range control of gene expression: emerging mechanisms and disruption in disease. Am. J. Hum. Genet. 76, 8-32.

Kubiske, M.E., and Abrams, M.D. (1992). Photosynthesis, water relations, and leaf morphology of xeric versus mesic Quercus rubra ecotypes in central Pennsylvania in relation to moisture stress. Can. J. For. Res. 22, 1402-1407. 
Kulkarni, M., and Deshpande, U. (2006). Anatomical breeding for altered leaf parameters in tomato genotypes imparting drought resistance using leaf strength index. Asian J. Plant Sci. 5, 414-420.

Kuzovkina, Y.A., and Quigley, M.F. (2005). Willows beyond wetlands: uses of Salix L. species for environmental projects. Water. Air. Soil Pollut. 162, 183-204.

van Laere, K., França, S.C., Vansteenkiste, H., Huylenbroeck, J., Steppe, K., and Labeke, M.-C. (2010). Influence of ploidy level on morphology, growth and drought susceptibility in Spathiphyllum wallisii. Acta Physiol. Plant. 33, 1149-1156.

Landgren, M., and Glimelius, K. (1990). Analysis of chloroplast and mitochondrial segregation in three different combinations of somatic hybrids produced within Brassicaceae. Theor. Appl. Genet. 80, 776-784.

Lee, J.A., Madrid, R.E., Sperle, K., Ritterson, C.M., Hobson, G.M., Garbern, J., Lupski, J.R., and Inoue, K. (2006). Spastic paraplegia type 2 associated with axonal neuropathy and apparent PLP1 position effect. Ann. Neurol. 59, 398403.

Li, W.-D., Biswas, D.K., Xu, H., Xu, C.-Q., Wang, X.-Z., Liu, J.-K., and Jiang, G.-M. (2009). Photosynthetic responses to chromosome doubling in relation to leaf anatomy in Lonicera japonica subjected to water stress. Funct. Plant Biol. 36, 783-792.

Li, W.-L., Berlyn, G.P., and Ashton, P.M.S. (1996). Polyploids and their structural and physiological characteristics relative to water deficit in Betula papyrifera (Betulaceae). Am. J. Bot. 83, 15-20.

Liesebach, H., Naujoks, G., and Ewald, D. (2010). Successful hybridisation of normally incompatible hybrid aspen (Populus tremula $\times$ P. tremuloides) and eastern cottonwood (P. deltoides). Sex. Plant Reprod. 24, 189-198.

Liu, B., and Wendel, J.F. (2003). Epigenetic phenomena and the evolution of plant allopolyploids. Mol. Phylogenet. Evol. 29, 365-379. 
Liu, G., Li, Z., and Bao, M. (2007). Colchicine-induced chromosome doubling in Platanus acerifolia and its effect on plant morphology. Euphytica 157, 145154.

Liu, J., Xu, X., and Deng, X. (2005). Intergeneric somatic hybridization and its application to crop genetic improvement. Plant Cell Tissue Organ Cult. 82, $19-44$.

Lührs, R., Efremova, N., Krull, A., Löfke, C., Ning, D., Müller, A., Polle, A., and Teichmann, T. (2010). Innovative Hybridpappeln - Schnelles Wachstum für Deutschland. Konferenz-Artikel, “Agrarholz 2010”, Internationale Konferenz 18.-19.05.2010 in Berlin.

McCarroll, S.A., Hadnott, T.N., Perry, G.H., Sabeti, P.C., Zody, M.C., Barrett, J.C., Dallaire, S., Gabriel, S.B., Lee, C., Daly, M.J., Altshuler, D.M. (2006). Common deletion polymorphisms in the human genome. Nat. Genet. 38, 8692.

McDowell, N., Pockman, W.T., Allen, C.D., Breshears, D.D., Cobb, N., Kolb, T., Plaut, J., Sperry, J., West, A., Williams, D.G., Yepez, E.A. (2008). Mechanisms of plant survival and mortality during drought: why do some plants survive while others succumb to drought? New Phytol. 178, 719-739.

McKendry, P. (2002). Energy production from biomass (part 1): overview of biomass. Bioresour. Technol. 83, 37-46.

Mohrdiek, O. (1977). Hybridaspen auf Grenzertragsböden. Forstarchiv 48, 158-163.

Murashige, T., and Skoog, F. (1962). A revised medium for rapid growth and bio assays with tobacco tissue cultures. Physiol. Plant. 15, 473-497.

Oh, D.-H., Dassanayake, M., Bohnert, H.J., and Cheeseman, J.M. (2012). Life at the extreme: lessons from the genome. Genome Biol 13, 241.

Orcutt, D.M., and Nilsen, E.T. (2000). The physiology of plants under stress: soil and biotic factors, John Wiley \& Sons, Hoboken, NJ, USA, pp. 696. 
Osborn, T.C., Chris Pires, J., Birchler, J.A., Auger, D.L., Jeffery Chen, Z., Lee, H.-S., Comai, L., Madlung, A., Doerge, R.W., Colot, V., Martienssen, R.A. (2003). Understanding mechanisms of novel gene expression in polyploids. Trends Genet. 19, 141-147.

Pakull, B., Groppe, K., Meyer, M., Markussen, T., and Fladung, M. (2009). Genetic linkage mapping in aspen (Populus tremula L. and Populus tremuloides Michx.). Tree Genet. Genomes 5, 505-515.

Pareek, A., Sopory, S.K., Bohnert, H.J., Govidjee (2010). Abiotic stress adaptation in plants. Springer Science \& Business Media, Dordrecht, Netherlands, 526 pp.

Paul, M.J., and Pellny, T.K. (2003). Carbon metabolite feedback regulation of leaf photosynthesis and development. J. Exp. Bot. 54, 539-547.

Peuke, A.D., Schraml, C., Hartung, W., and Rennenberg, H. (2002). Identification of drought-sensitive beech ecotypes by physiological parameters. New Phytol. 154, 373-387.

Polle, A., Janz, D., Teichmann, T., and Lipka, V. (2013). Poplar genetic engineering: promoting desirable wood characteristics and pest resistance. Appl. Microbiol. Biotechnol. 97, 5669-5679.

Poorter, H., Niinemets, Ü., Poorter, L., Wright, I.J., and Villar, R. (2009). Causes and consequences of variation in leaf mass per area (LMA): a meta-analysis. New Phytol. 182, 565-588.

Prange, A.N.S., Bartsch, M., Meiners, J., Serek, M., and Winkelmann, T. (2012). Interspecific somatic hybrids between Cyclamen persicum and C. coum, two sexually incompatible species. Plant Cell Rep. 31, 723-735.

Puijalon, S., Bouma, T.J., Douady, C.J., van Groenendael, J., Anten, N.P.R., Martel, E., and Bornette, G. (2011). Plant resistance to mechanical stress: evidence of an avoidance-tolerance trade-off. New Phytol. 191, 1141-1149.

Ransom-Hodgkins, W.D., Vaughn, M.W., and Bush, D.R. (2003). Protein phosphorylation plays a key role in sucrose-mediated transcriptional regulation of a phloem-specific proton-sucrose symporter. Planta 217, 483-489. 
Rausher, M.D. (2007). New Phytologist on plant evolution. New Phytol. 174, 705707.

R Core Team (2013). R: A language and environment for statistical computing. R Foundation for statistical Computing, Vienna. Available online at: http:// www.R-project.org.

Regier, N., Streb, S., Cocozza, C., Schaub, M., Cherubini, P., Zeeman, S.C., and Frey, B. (2009). Drought tolerance of two black poplar (Populus nigra L.) clones: contribution of carbohydrates and oxidative stress defence. Plant Cell Environ. 32, 1724-1736.

Rennenberg, H., Loreto, F., Polle, A., Brilli, F., Fares, S., Beniwal, R.S., and Gessler, A. (2006). Physiological responses of forest trees to heat and drought. Plant Biol. 8, 556-571.

Rhodes, D., and Nadolska-Orczyk, A. (2001). Plant stress physiology. Encyclopedia of Life Sciences, pp. 1-7.

Riddle, N.C., and Birchler, J.A. (2008). Comparative analysis of inbred and hybrid maize at the diploid and tetraploid levels. Theor. Appl. Genet. 116, 563-576.

Romme, W.H., Turner, M.G., Tuskan, G.A., and Reed, R.A. (2005). Establishment, persistence, and growth of aspen (Populus tremuloides) seedlings in Yellowstone National Park. Ecology 86, 404-418.

Sasamoto, H., Wakita, Y., Yokota, S., Yoshizawa, N., Katsuki, T., Nishiyama, Y., Yokoyama, T., and Fukui, M. (2006). Effects of electric cell fusion treatment among leaf protoplasts of Populus alba and Alnus firma on growth, leaf morphology, and rapd pattern of eleven acclimatized plants. Vitro Cell. Dev. Biol. - Plant 42, 174-178.

Schirmer, R. (2009). Sortenprüfung von Pappelklonen - Voraussetzung für einen erfolgreichen Energieholzanbau. 28. Internationale Tagung der Arbeitsgemeinschaft (ARGE) für Forstgenetik und Forstpflanzenzüchtung, 4.-6.11.2009 in Treis-Karden, p.123-129.

Scholes, D.R., and Paige, K.N. (2015). Plasticity in ploidy: a generalized response to stress. Trends Plant Sci. 20, 165-175. 
van der Schoot, J., Pospíšková, M., Vosman, B., and Smulders, M.J.M. (2000). Development and characterization of microsatellite markers in black poplar (Populus nigra L.). Theor. Appl. Genet. 101, 317-322.

Sharma, A.K., and Datta, P.C. (1957). Artificial polyploidy in coriander (Coriandrum Sativum L.). Caryologia 10, 152-158.

Shi, L., Guttenberger, M., Kottke, I., and Hampp, R. (2002). The effect of drought on mycorrhizas of beech (Fagus sylvatica L.): changes in community structure, and the content of carbohydrates and nitrogen storage bodies of the fungi. Mycorrhiza 12, 303-311.

Sjödin, A., Street, N.R., Sandberg, G., Gustafsson, P., and Jansson, S. (2009). The Populus genome integrative explorer (PopGenIE): a new resource for exploring the Populus genome: Methods. New Phytol. 182, 1013-1025.

Smart, R.E., and Bingham, G.E. (1974). Rapid estimates of relative water content. Plant Physiol. 53, 258-260.

Smulders, M.J.M., Van Der Schoot, J., Arens, P., and Vosman, B. (2001). Trinucleotide repeat microsatellite markers for black poplar (Populus nigra L.). Mol. Ecol. Notes 1, 188-190.

Springer, N.M., Ying, K., Fu, Y., Ji, T., Yeh, C.-T., Jia, Y., Wu, W., Richmond, T., Kitzman, J., Rosenbaum, H., Kitzman, J., and Rosenbaum, H. (2009). Maize inbreds exhibit high levels of copy number variation (CNV) and presence/absence variation (PAV) in genome content. PLoS Genet 5, e1000734.

Stanturf, J.A., Van Oosten, C., Netzer, D.A., Coleman, M.D., and Portwood, C.J., (2001). Ecology and silviculture of poplar plantations. Poplar Cult. N. Am. 153-206.

Svitashev, S.K., and Somers, D.A. (2001). Genomic interspersions determine the size and complexity of transgene loci in transgenic plants produced by microprojectile bombardment. Genome 44, 691-697.

Tal, M. (1980). Physiology of polyploids. In: Polyploidy, Lewis, W.H. (ed.), Springer NY, USA, pp. 61-75. 
Tamm, Ü. (1994). Populus tremula (L.). In: Enzyklopädie der Holzgewächse: Handbuch und Atlas der Dendrologie, Roloff, A., Weisgerber, H., Lang, U.M., Stimm, B, (Hrsg.) Wiley-VCH Weinheim.

Teixeira, J., and Pereira, S. (2007). High salinity and drought act on an organdependent manner on potato glutamine synthetase expression and accumulation. Environ. Exp. Bot. 60, 121-126.

Tessadori, F., Chupeau, M.-C., Chupeau, Y., Knip, M., Germann, S., Driel, R. van, Fransz, P., and Gaudin, V. (2007). Large-scale dissociation and sequential reassembly of pericentric heterochromatin in dedifferentiated Arabidopsis cells. J. Cell Sci. 120, 1200-1208.

Touchette, B.W., Smith, G.A., Rhodes, K.L., and Poole, M. (2009). Tolerance and avoidance: two contrasting physiological responses to salt stress in mature marsh halophytes Juncus roemerianus Scheele and Spartina alterniflora Loisel. J. Exp. Mar. Biol. Ecol. 380, 106-112.

Tsai, Y.T., Huang, Y.P., Yu, C.T., and Lu, C.L. (2004). MuSiC: a tool for multiple sequence alignment with constraints. Bioinformatics 20, 2309-2311.

Tschaplinski, T.J., and Tuskan, G.A. (1994). Water-stress tolerance of black and eastern cottonwood clones and four hybrid progeny. II. Metabolites and inorganic ions that constitute osmotic adjustment. Can. J. For. Res. 24, 681687.

Tuskan, G.A., Gunter, L.E., Yang, Z.K., Yin, T., Sewell, M.M., and DiFazio, S.P. (2004). Characterization of microsatellites revealed by genomic sequencing of Populus trichocarpa. Can. J. For. Res. 34, 85-93.

Vaughn, M.W., Harrington, G.N., and Bush, D.R. (2002). Sucrose-mediated transcriptional regulation of sucrose symporter activity in the phloem. Proc. Natl. Acad. Sci. 99, 10876-10880.

Waara, S., and Glimelius, K. (1995). The potential of somatic hybridization in crop breeding. Euphytica 85, 217-233.

Weih, M. (2004). Intensive short rotation forestry in boreal climates: present and future perspectives. Can. J. For. Res. 34, 1369-1378. 
Weih, M., Hoeber, S., Beyer, F., and Fransson, P. (2014). Traits to ecosystems: the ecological sustainability challenge when developing future energy crops. Front. Energy Res. 2, 1-5.

Weiss, M.G., and Porter, K.B. (1948). Effect of polyploidy on soybeans. J. Am. Soc. Agron., 40, 710-724.

Wild, A., Schmitt, V., Strobel, P., Wilksch, W., and Wohlfahrt, S. (1996). Okulare und biochemische Schadensdiagnose bei Fichten und Weißtannen. Ein Vergleich beider Diagnoseverfahren an Dauerbeobachtungsflächen in BadenWürttemberg. Berichte Umweltforsch. Baden-Württ. PEF-Proj. Eur. Forschungszentrum für Maßnahmen zur Luftreinhalt. FZKA-PEF 149.

Willing, R.R., and Pryor, P.L.D. (1976). Interspecific hybridisation in poplar. Theor. Appl. Genet. 47, 141-151.

Wood, S.N. (2011). Fast stable restricted maximum likelihood and marginal likelihood estimation of semiparametric generalized linear models: estimation of semiparametric generalized linear models. J. R. Stat. Soc. Ser. B Stat. Methodol. 73, 3-36.

von Wühlisch, G. (2012). Poplars and willows in Germany: report of the national poplar commission. Available online at: http://www.bmel.de/SharedDocs/ Downloads/EN/Publications/PoplarsReport.pdf?__blob=publicationFile [Accessed October 16, 2014].

Xiong, Y.-C., Li, F.-M., and Zhang, T. (2006). Performance of wheat crops with different chromosome ploidy: root-sourced signals, drought tolerance, and yield performance. Planta 224, 710-718.

Xu, D., Duan, X., Wang, B., Hong, B., Ho, T.-H.D., and Wu, R. (1996). Expression of a late embryogenesis abundant protein gene, HVA1, from barley confers tolerance to water deficit and salt stress in transgenic rice. Plant Physiol. 110, 249-257.

Yancey, P.H. (2005). Organic osmolytes as compatible, metabolic and counteracting cytoprotectants in high osmolarity and other stresses. J. Exp. Biol. 208, 28192830. 
Yang, F., and Miao, L.-F. (2010). Adaptive responses to progressive drought stress in two poplar species originating from different altitudes. Silva Fenn. 44, 2337.

Yemm, E.W., and Willis, A.J. (1954). The estimation of carbohydrates in plant extracts by anthrone. Biochem. J. 57, 508-514.

Yu, H., Chen, X., Hong, Y.-Y., Wang, Y., Xu, P., Ke, S.-D., Liu, H.-Y., Zhu, J.-K., Oliver, D.J., and Xiang, C.-B. (2008). Activated expression of an Arabidopsis HD-START protein confers drought tolerance with improved root system and reduced stomatal density. Plant Cell Online 20, 1134-1151.

Yu, Q., Tigerstedt, P.M.A., and Haapanen, M. (2001). Growth and phenology of hybrid aspen clones (Populus tremula L. x Populus tremuloides Michx.). Silva Fenn. 35, 15-25. 


\section{Appendix}

\subsection{Declaration}

The following data shown in this thesis have been provided by colleagues.

The whole genome sequencing was conducted by the DNA Microarray and DeepSequencing Facility Göttingen, Department of Developmental Biochemistry, University of Göttingen.

Statistical analysis of the whole genome sequencing data including the mapping, the copy number variation analysis and the annotation was provided by Dr. Jochen Kruppa, Dr. Andreas Leha and Dr. Klaus Jung, Core Facility Medical Biometry and Statistical Bioinformatics, Department of Medical Statistics, University of Göttingen.

Modeling of the temperature and relative humidity data (section 2.3.1) was conducted by Sebastian Schoneberg, Büsgen-Institute, Department of Ecoinformatics, Biometrics and Forest Growth, University of Göttingen.

The carbohydrate analyses (section 3.1.2 and 3.2.2) were provided by Dr. Sonja Löffler, Department for Monitoring and Forest Development, Forest Research Institute Eberswalde. 


\subsection{Curriculum vitae}

\section{Personal data}

$\begin{array}{ll}\text { Name } & \text { Anne Hennig } \\ \text { Date of birth } & \text { October } 1^{\text {st }} 1983 \\ \text { Place of birth } & \text { Böblingen } \\ \text { Nationality } & \text { German }\end{array}$

\section{Education and scientific career}

12/2014 - 08/2015 Research associate, "Nordwestdeutsche Forstliche Versuchsanstalt”, Department Forest Genetic Resources, Hann. Münden

Section: Genetic analyses

03/2012 - 07/2015 PhD student, program "Molekulare Wissenschaften und Biotechnologie von Nutzpflanzen (BIONUTZ)”, University of Göttingen

Dissertation "Drought stress response of tetraploid hybrid aspen (Populus tremula x P. tremuloides) of protoplast fusion experiments”

09/2011 - 09/2014 Research associate, "Nordwestdeutsche Forstliche Versuchsanstalt”, Department Forest Genetic Resources, Hann. Münden

Project: “ZÜEND - Züchtung neuer Energiepappeln für Deutschland”

02/2011 - 04/2011 Graduate assistant, Physiological Ecology of Plants, University of Tübingen

10/2005 - 01/2011 Studies in biology, University of Tübingen Diploma thesis "Schwerkraftabhängige Genexpression in Zellkulturen von Arabisopsis thaliana"

04/2004 - 09/2005 Studies in dentistry, University of Tübingen

09/1994 - 07/2003 Otto-Hahn-Gymnasium Böblingen

09/1990 - 07/1994 Eduard-Mörike-Grundschule Böblingen 


\subsection{Publication}

\section{Water consumption and biomass production of protoplast fusion lines of poplar hybrids under drought stress}

Anne Hennig 1,2, Jörg R.G. Kleinschmit ${ }^{2}$, Sebastian Schoneberg ${ }^{3}$, Sonja Löffler ${ }^{4}$, Alwin Janßen $^{2}$, Andrea Polle ${ }^{1}$

${ }^{1}$ Büsgen-Institute, Department for Forest Botany and Tree Physiology, Georg-August University of Göttingen, Germany

${ }^{2}$ Northwest German Forest Research Institute, Department Forest Genetic Resources, Hann. Münden, Germany

${ }^{3}$ Büsgen-Institute, Department Ecoinformatics, Biometrics and Forest Growth, Georg-August University of Göttingen, Germany

${ }^{4}$ Forest Research Institute Eberswalde, Department for Monitoring and Forest Development, Eberswalde, Germany

Published in Frontiers Plant Science (2015) 6:330, doi: 10.3389/fpls.2015.00330 


\section{OPEN ACCESS}

Edited by:

Martin Weih,

Swedish University of Agricultural

Sciences, Sweden

Reviewed by:

Jennifer Cunniff,

Rothamsted Research, UK

Barb Thomas,

University of Alberta, Canada

*Correspondence:

Anne Hennig,

Department Forest Botany and Tree

Physiology, Büsgen-Institute, Georg-August University of Göttingen,

Büsgenweg 2, 37077 Göttingen,

Germany

anne.hennig@stud.uni-goettingen.de;

anne.hennig@nw-fva.de

Specialty section:

This article was submitted to

Plant Biotechnology,

a section of the journal

Frontiers in Plant Science

Received: 12 December 2014 Accepted: 27 April 2015

Published: 19 May 2015

Citation:

Hennig A, Kleinschmit JRG

Schoneberg S, Löffler S, Janßen A

and Polle $A$ (2015) Water

consumption and biomass production of protoplast fusion lines of poplar

hybrids under drought stress.

Front. Plant Sci. 6:330

doi: 10.3389/fp/s.2015.00330

\section{Water consumption and biomass production of protoplast fusion lines of poplar hybrids under drought stress}

\author{
Anne Hennig ${ }^{1,2 *}$, Jörg R. G. Kleinschmit ${ }^{2}$, Sebastian Schoneberg ${ }^{3}$, Sonja Löffler ${ }^{4}$, \\ Alwin Janßen ${ }^{2}$ and Andrea Polle ${ }^{1}$ \\ 1 Department for Forest Botany and Tree Physiology, Büsgen-Institute, Georg-August University of Göttingen, Göttingen, \\ Germany, ${ }^{2}$ Department Forest Genetic Resources, Northwest German Forest Research Institute, Hann. Münden, Germany, \\ ${ }^{3}$ Department Ecoinformatics, Biometrics and Forest Growth, Büsgen-Institute, Georg-August University of Göttingen, \\ Göttingen, Germany, ${ }^{4}$ Department for Monitoring and Forest Development, Forest Research Institute Eberswalde, \\ Eberswalde, Germany
}

Woody crops such as poplars (Populus) can contribute to meet the increasing energy demand of a growing human population and can therefore enhance the security of energy supply. Using energy from biomass increases ecological sustainability as biomass is considered to play a pivotal role in abating climate change. Because areas for establishing poplar plantations are often confined to marginal sites drought tolerance is one important trait for poplar genotypes cultivated in short rotation coppice. We tested 9-month-old plants of four tetraploid Populus tremula (L.) $\times$ P. tremuloides (Michx.) lines that were generated by protoplast fusion and their diploid counterpart for water consumption and drought stress responses in a greenhouse experiment. The fusion lines showed equivalent or decreased height growth, stem biomass and total leaf area compared to the diploid line. The relative height increment of the fusion lines was not reduced compared to the diploid line when the plants were exposed to drought. The fusion lines were distinguished from the diploid counterpart by stomatal characteristics such as increased size and lower density. The changes in the stomatal apparatus did not affect the stomatal conductance. When exposed to drought the carbohydrate concentrations increased more strongly in the fusion lines than in the diploid line. Two fusion lines consumed significantly less water with regard to height growth, producing equivalent or increased relative stem biomass under drought compared to their diploid relative. Therefore, these tetraploid fusion lines are interesting candidates for short rotation biomass plantation on dry sites.

\footnotetext{
Keywords: polyploidy, Populus, abiotic stress, short rotation coppice, stomatal morphology, carbohydrate concentration
}

\section{Introduction}

The world primary energy demand is increasing (Berndes et al., 2003; Asif and Muneer, 2007; Doman et al., 2014). About $11 \%$ of this demand was met by renewable sources as hydropower, biomass, biofuels, wind, geothermal and solar energy in 2008 (Chum et al., 2011). Biomass from 
bioenergy plants is expected to have a good potential to meet the increasing demand for global primary energy (Weih, 2004; Karp and Shield, 2008; Weih et al., 2014). Compared to fossil fuels, biomass contributes only marginally to the emission of greenhouse gasses (Weih, 2004), which reached their highest levels in history during the past decade and are main drivers of climate change (IPCC, 2014). Biomass is therefore considered to contribute substantially to the alleviation of climate change challenge (Weih, 2004; Karp and Shield, 2008). The establishment of short rotation coppice (SRC) is one possibility of generating biomass for energy purposes. SRC refers to plantations of fast growing trees and shrubs for biomass production with high initial growth and a rotation time of 3-5 years (Karp and Shield, 2008). The plantations of SRC show high biomass production and carbon dioxide fixation, subsequent use of wood chips has low carbon abatement costs (BMEL, 2007). In 2012, SRC covered an area of $5000-6000$ ha in Germany, i.e., only $0.0003 \%$ of the managed agricultural land (von Wühlisch, 2012; BMEL, 2014) indicating a high potential to increase the area of SRC-cultivated land.

It has been suggested that conflicts in land use for food or biomass production can be diminished by establishing SRC on marginal sites, that are affected by pollution, salinization or low water and mineral supply (Kuzovkina and Quigley, 2005; Karp and Shield, 2008; Polle et al., 2013). Therefore, species and varieties with high drought tolerance are required (Karp and Shield, 2008; Weih et al., 2014). Some species of the genus Populus can meet the objective of low water demand, i.e., Populus tremula (L.). Their growth is more tolerant to drought than that of silver birch, Scots pine or Norway spruce (Jarvis and Jarvis, 1963). Both P. tremula and P. tremuloides (Michx.) are naturally occurring in areas with dry continental climate (Jarvis and Jarvis, 1963; Viereck et al., 1986). Thus, it can be assumed that hybrid aspen $(P$. tremula $\times P$. tremuloides $)$ are also drought tolerant. However, biomass yield highly depends on the availability of water and drought tolerance can also be achieved at the expense of biomass (Araus et al., 2002; Bogeat-Triboulot et al., 2006; Cattivelli et al., 2008). Poplars are needed that combine enhanced drought tolerance and reasonable biomass production. As drought periods are likely to increase with climate change (Regier et al., 2009) drought tolerance and the maintenance of growth are important breeding objectives (McKendry, 2002; Cattivelli et al., 2008). Another important trait for poplar cultivated in SRC is the propagation via stem cuttings as this considerably reduces the investment costs (Stanturf et al., 2001). Poplar species of the section Tacamahaca and Aigeros, for example, $P$. nigra and $P$. trichocarpa $\times P$. deltoides show this specific trait in contrast to species of the section Populus (Stanturf et al., 2001). To combine the drought tolerance of $P$. tremula $\times$ $P$. tremuloides and the ability of propagation via stem cuttings of the species $P$. nigra and P. trichocarpa $\times P$. deltoides somatic hybridization via protoplast fusion appears to be a promising approach.

Genome duplication (polyploidization) has naturally occurred in the evolution of several plant species including crops like Gossypium hirsutum, Triticum aestivum, and Oryza sativa but also in tree species such as Populus (Finnegan, 2002; Blanc and
Wolfe, 2004; Rausher, 2007). Duplicated genes typically show a diversification in functions or subfunctionalization (Adams and Wendel, 2005). Several studies revealed that gene doubling influenced transcription levels by epigenetic alterations in the cytosine methylation or silencing of the ribosomal RNA resulting in a variation of morphology and phenotype (Finnegan, 2002; Liu and Wendel, 2003; Adams and Wendel, 2005). Silencing of polyploid genes can be organ-specific and was observed to occur even reciprocally (Adams et al., 2003).

Octaploid tobacco plants showed increased survival times over their tetraploid counterparts when exposed to stresses like cold, shade, water logging, nutrient deficiency and drought (Deng et al., 2012). Decreased susceptibility of polyploid varieties to drought was detected in crop species (Triticum), herbaceous species (Lonicera, Spathiphyllum, Nicotiana) as well as in tree species (Betula) (Li et al., 1996, 2009; Xiong et al., 2006; van Laere et al., 2010; Deng et al., 2012). Polyploidy can induce morphological changes in leaf characteristics that are associated with drought tolerance like an increased leaf thickness, a smaller total leaf area and an enhanced leaf mass per area (Kubiske and Abrams, 1992; Li et al., 2009). For instance, greater stomatal length and reductions in stomatal density, that are characteristics of plants in xeric habitats, were observed in polyploid Betula and Spathiphyllum (Abrams et al., 1994; Li et al., 1996; van Laere et al., 2010). Polyploidy can also influence the metabolic performance resulting in an induction of superoxide dismutase and catalase and consequently decreased accumulation of reactive oxygen species (ROS) (Deng et al., 2012). In Lonicera, photosynthesis, pre-dawn leaf water potential and stomatal conductance were less affected in drought-treated tetraploid variants compared to their diploid relatives (Li et al., 2009).

Plants cope with stresses like drought either by stress avoidance or stress tolerance where stress avoidance is referred to as the plants ability to minimize the adverse effect and tolerance as the capacity to endure unfavorable conditions (Puijalon et al., 2011). For example, osmotic adjustment with inorganic ions, carbohydrates and organic acids or changes in tissue elasticity can enhance plant's drought tolerance (Touchette et al., 2009). Osmotic adjustment plays a role in minimizing yield loss when drought occurs (Cattivelli et al., 2008). Therefore, analysis of osmotic adjustment under different drought conditions has been suggested as an effective selection criterion for drought tolerant genotypes (Cattivelli et al., 2008). Drought avoidance occurs when plants reduce their transpiration surface by leaf shedding for example (Gaur et al., 2008; Fischer and Polle, 2010). When facing water limiting conditions both drought tolerance and avoidance mechanisms are often combined to enhance physiological adjustments in plants (Touchette et al., 2009).

Because of the importance of poplars as bioenergy crops, the overarching goal of this study was to test polyploid species obtained by protoplast fusion for their performance under drought Here, diploid plant material of hybrid aspen (P. tremula $\times P$. tremuloides $)$, black poplar $(P$. nigra L.) and cottonwood hybrids (P. trichocarpa Torr. and Gray $\times$ P. deltoides Bartram ex Marsh.) were used to generate polyploid lines by protoplast fusion. We obtained four tetraploid lines of $P$. 
tremula $\times$ P. tremuloides and compared them to their diploid counterpart. To examine the suitability of the diploid and protoplast fusion lines for cultivation on dry sites, we investigated (i) morphological and physiological effects of polyploidization, (ii) water consumption, and (iii) drought stress performance in a greenhouse experiment.

\section{Materials and Methods}

\section{Plant Material}

Five-year-old trees of P. tremula $\times$ P. tremuloides ("Münden 2"), 20-old trees of $P$. nigra and 25-year-old trees of $P$. trichocarpa $\times$ $P$. deltoides were used for establishing in vitro cultures. Terminal and axillary winter buds of 1-year-old shoots were harvested and processed after a protocol modified according to Ahuja (1984). Buds were washed in tap water and sterilized in $70 \%$ ethanol (Carl Roth $\mathrm{GmbH}$ and Co. KG, Karlsruhe, Germany) with $0.1 \%$ L-ascorbic acid (Sigma Aldrich Laborchemikalien $\mathrm{GmbH}$, Hannover, Germany) for $20 \mathrm{~s}$ and in sodium hypochlorite (Carl Roth GmbH and Co. KG, Karlsruhe, Germany) (supplemented with 2 drops of Tween 20 (Carl Roth GmbH and Co. KG, Karlsruhe, Germany) for $20 \mathrm{~min}$. Material was then washed three times for $5 \mathrm{~min}$ in sterilized tap water. After shoot development plantlets were subcultured every 4 weeks on MSMedium (Murashige and Skoog, 1962) supplemented with 0.2 ppm 6-benzylaminopurine (Fluka Chemie $\mathrm{GmbH}$, Steinheim, Germany), 2\% sucrose (Carl Roth GmbH and Co. KG, Karlsruhe, Germany) and $2.9 \mathrm{~g} / \mathrm{L}$ Gelrite (Duchefa Biochemie, Haarlem, Netherlands). Protoplast fusion of the in vitro poplar clones was established according to modified protocols of Sasamoto et al. (2006) and Guo and Deng (1998) by the company Phytowelt GreenTechnologies $\mathrm{GmbH}$ as described previously (Lührs et al., 2010, 2012; Efremova et al., 2013). Shoot cultures from fusion products were regenerated as separate lines. Three lines of three protoplast fusion experiments between $P$. tremula $\times$ P. tremuloides ("Münden 2") and P. trichocarpa $\times$ P. deltoides (B19) and one line out of one protoplast fusion between $P$. tremula $\times$ P. tremuloides ("Münden 2") and P. nigra were used. The lines were micropropagated and rooted ex vitro by directly transferring them to substrate (nursery substrate (N: $250 \mathrm{mg} / \mathrm{L}$ P: $140 \mathrm{mg} / \mathrm{L}, \mathrm{K}: 250 \mathrm{mg} / \mathrm{L}$ ), Kleeschulte Erden $\mathrm{GmbH}$, Rüthen, Germany) under a foil tunnel equipped with a fog system. Plantlets were hardened by reducing air humidity gradually during 4 weeks. Rooted plants were transferred into 1.3-L pots on October 2012 (substrate composition as above blended with one gram long-term fertilizer Osmocote Exact lo start 8-9 M ( $1 \mathrm{~g} / \mathrm{L}$, $\mathrm{N}: \mathrm{P}: \mathrm{K}=15: 8: 10+3 \mathrm{MgO}$ ), The Scotts Company LLC, Heerlen, Netherlands per liter soil) and cultured in the greenhouse. For hibernation temperature was decreased according to ambient conditions but did not drop below $5^{\circ} \mathrm{C}$. In April 2013, plants were transferred to three-liter pots (substrate composition above) with long-term fertilizer $(1 \mathrm{~g} / \mathrm{L}$, Osmocote Exact Standard 5-6 M (1 g/L, N:P:K = 15:9:12 + 2 MgO), The Scotts Company LLC, Heerlen, Netherlands). Plants were cultured in the greenhouse and watered to pot capacity until the start of the drought treatment on July 11th, 2013, when the plants were 9 month old.

\section{Experimental Design}

Four lines from protoplast fusion and the original diploid hybrid aspen ("Münden 2") were used in a greenhouse experiment. Ten plants of each clone were randomly chosen as control and ten as treatment plants. Two plants each of four lines, still planted in three-liter pots, were placed into one box (eight plants) according to a scheme applying maximal space to the plants of one line. The plants positions were changed in each box in order to let all lines pass all positions of the boxes (four different distributions, one was repeated). In total, 12 lines (240 plants) were tested, but we focus in this analysis on the four fusion lines of the phenotype P. tremula $\times$ P. tremuloides. During the experiment the boxes were rotated daily to avoid position effects. No artificial light was supplemented. Temperature and relative air humidity during experimental time ranged from $16^{\circ} \mathrm{C}$ to $37^{\circ} \mathrm{C} / 37 \%$ to $60 \%$ (day) and from $11^{\circ} \mathrm{C}$ to $15^{\circ} \mathrm{C} / 80 \%$ to 99\% (night), respectively (Figures 1 A,B). Because of data logger failure inside the greenhouse during 8 days (day 11 to day 19), we used hourly data of existing data pairs for inner and outer temperature to generate a linear regression model (Equation 1) with the outer temperature $\left(x_{1}\right)$ as predictor variable.

$$
y=\beta_{0}+x_{1} \beta_{1}+\varepsilon
$$

The modeled and measured temperatures showed a high correlation $\left(R^{2}=0.92\right.$, Figure $\left.1 \mathrm{~A}\right)$. The relative humidity was modeled using a generalized linear regression approach as the target variable ranged between 0 and $100 \%$. Therefore, a logit function was applied (Equation 2) with the predicted temperature inside the greenhouse $\left(x_{1}\right)$ and the hour of the day $\left(x_{2}\right)$ as predictor variables.

$$
\hat{y}=\frac{\exp \left(\beta_{0}+\beta_{1} x_{1}+\beta_{2} x_{2}\right)}{1+\exp \left(\beta_{0}+\beta_{1} x_{1}+\beta_{2} x_{2}\right)}
$$

For more flexibility of the model (Equation 2) was extended by flexible splines according to Wood (2011). The predicted

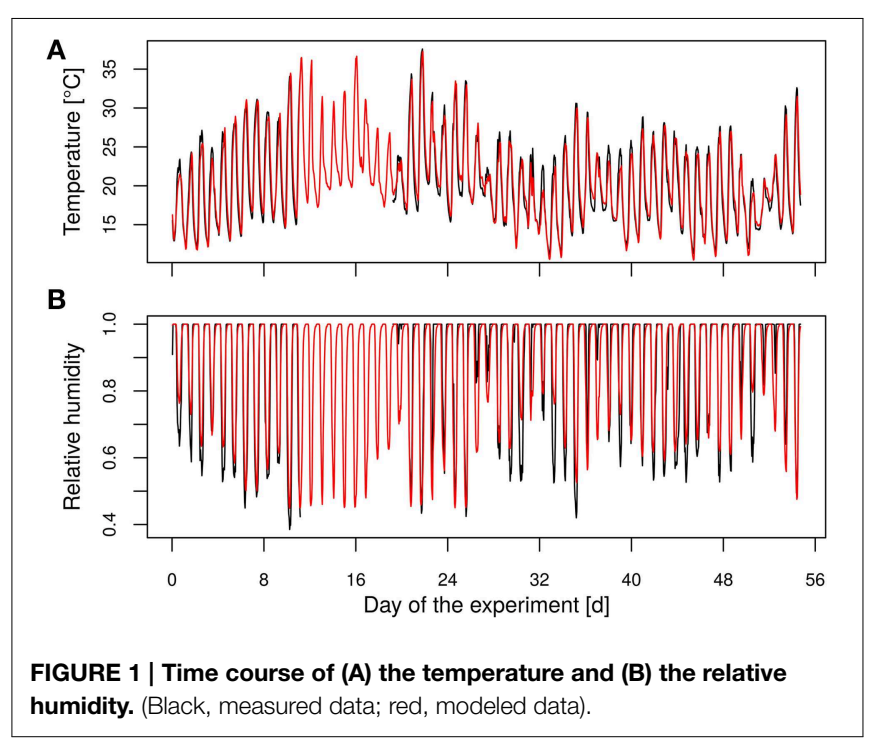


values of the relative humidity were highly correlated with the measured values $\left(R^{2}=0.79\right.$, Figure $\left.1 B\right)$. The vapor pressure deficit (vpd) was determined using the predicted temperature and relative humidity data with the Clausius-Clapeyron relationship according to Hartmann (1994).

All plants were watered twice up to saturation before starting the experiment. Then, control plants were watered daily to pot capacity and treatment plants were gradually dried until a soil water content of 10 vol.- $\%$ was reached and kept at the 10 vol.$\%$-level for 1 week. To enable uniform drying of plants within one line volumetric soil water content was measured daily using a soil moisture sensor (TRIME PICO32; Imko GmbH, Ettlingen, Germany). Two measurements were performed per pot and the mean soil moisture per line was calculated for all plants per line. Plants, whose soil moisture dropped below the average level of their line were watered to reach the mean volumetric soil moisture level. This procedure ensured that all plants of one line reached the 10 vol.- $\%$ soil moisture target level at the same time point. The 10 vol.- $\%$ periods for the different lines were staggered and first occurred in the diploid line at day six after starting the experiment and appeared last for fusion line 27-09 at day 47 (Figure 4A). After culturing the plants at this level for 1 week, treatment plants were not watered anymore but still investigated. The experiment ended at day 56, when all plants were harvested for biomass analysis.

\section{Morphology and Basic Characterization Leaf and Stomatal Morphology}

Leaf morphology of in vitro plants of the fusion lines and the original diploid clones were compared and the fusion lines were associated to one of the original clones phenotypically. The stomatal density and stomatal size were analyzed by leaf impressions from abaxial and adaxial leaf surfaces. Impressions were taken on the fifth fully expanded leaf of five plants per line before starting the experiment using clear nail polish. The stomatal density was determined by counting the stomata on three randomly chosen sections $(0.303 \mathrm{~mm} * 0.303 \mathrm{~mm})$ of every preparation using a microscope (400 X magnification, Zeiss Axio Observer Z1, Zeiss, Oberkochen, Germany). Subsequently, the number of stomata per square millimeter was calculated. For determining the stomatal size, length of three guard cells was measured in each section. The stomatal area index (SAI) was calculated as a mean of stomatal size of three stomata of each leaf section on abaxial surface and multiplied with the stomatal density of this section (Ashton and Berlyn, 1994).

\section{Height and Stem Biomass}

The height of all plants was measured at the beginning of the experiment (H_d0). For basic characterization height growth is shown for the data of the control group before starting the experiment (H_d0).At the end of the experiment all plants were separated into stem and root segments and dried at $103^{\circ} \mathrm{C}$ for 5 days. Dry weight of the stem (DW_end) was determined without the leaves. Stem biomass is displayed for the data of the control group.

\section{Total Leaf Area and Leaf Mass Per Area}

For determining total leaf area and calculating a ratio between leaf mass and total leaf area all leaves of six control plants from each line were harvested, weighed (Sartorius Basic BA 210, Sartorius Weighing Technology GmbH, Göttingen, Germany) and scanned with a standard scanner at the end of the experiment. Leaf area was calculated from the scans using the program Histo Version 1.0.1.2. (Datinf, Tübingen, Germany).

\section{Genetic Analyses \\ Ploidy Level}

Relative DNA content was analyzed by flow cytometry from leaves of in vitro cultures (Plant Cytometry Services, Netherlands).

\section{DNA Extraction}

The protocol of Dumolin et al. (1995) was used for total DNA isolation from leaves of in vitro cultures. Differing from the protocol the pellet was eluted in $75 \mu 11 \times$ TE Rnase.

\section{nSSR Analysis}

Eleven primers (ORPM0023, ORPM1031, ORPM1249, ORPM1261, PMGC0433, PMGC2163, WPMS05, WPMS09, WPMS12, WPMS14, GCPM2768) that were located on nine linkage groups were selected for analysis of nuclear simple sequence repeats (nSSR; web.ornl.gov/sci/ipgc/ ssr_resources.htm; van der Schoot et al., 2000; Smulders et al., 2001; Tuskan et al., 2004). Polymerase chain reaction was performed as described by van der Schoot et al. (2000), Smulders et al. (2001), Eusemann et al. (2009). nSSR fragment length analysis was carried out using a LI-COR sequencer (4300 DNA analyzer, LI-COR Biosciences, Bad Homburg, Germany). For genotype analysis the software Saga v3.0 (LI-COR Biosciences, Bad Homburg, Germany) was used.

\section{Drought-Related Parameters Water Consumption and Plant Vitality}

All water volumes that were added to the treatment plants within the 10 vol.- $\%$ soil moisture level for the 7 day period were recorded. The wilting and the desiccation of the leaves were determined for plant vitality analysis for treatment and control plants. A leaf was regarded as wilted, when its blade was in a parallel position to the shoot, i.e., the angle between shoot and leaf blade was $0^{\circ}-10^{\circ}$. Leaves that showed an angle of more than $10^{\circ}$ were considered as not wilted. Desiccation was observed as the percentage of dried leaves. Both parameters were observed daily during the drought period for all plants and were classified into five categories $(0,25,50,75,100 \%)$ according to Table 1. Then, a mean was calculated for each line and normalized to the last irrigation event.

\section{Stomatal Conductance and Carbohydrate Concentration}

The stomatal conductance was determined after 7 days exposure to 10 vol.-\% soil moisture with a porometer (AP4, Delta-T Devices, Cambridge, Great Britain) on the eighth fully expanded leaf of control and treatment plants in the morning between $8: 30 \mathrm{~h}$ and 11:30 h. That was on the following days of the 
TABLE 1 | Classification of vitality.

\begin{tabular}{lcc}
\hline Scale & $\begin{array}{c}\text { Wilting percentage of wilted } \\
\text { leaves [\%] }\end{array}$ & $\begin{array}{c}\text { Desiccation percentage of } \\
\text { dried leaves [\%] }\end{array}$ \\
\hline 0 & 0 & 0 \\
1 & 25 & 25 \\
2 & 50 & 50 \\
3 & 75 & 75 \\
4 & 100 & 100 \\
\hline
\end{tabular}

experiment: 27-01: day 13, 27-09, day 54, 27-10: day 18, 27-11: day 15, 27-12: day 15. For analysis of carbohydrate concentration leaf samples were taken from the upper fourth fully expanded leaf in five repetitions for control and treatment plants. Sampling was conducted after 7 days of exposure to 10 vol.- $\%$ soil moisture level during the morning $(10-12 \mathrm{~h})$. The material was immediately stored at $-20^{\circ} \mathrm{C}$ until further preparation. For total soluble carbohydrates the protocol of Yemm and Willis (1954) was modified as follows: Samples were extracted in 50\% ethanol, incubated with anthrone for $10 \mathrm{~min}$ at $98^{\circ} \mathrm{C}$ and afterwards immediately cooled down in iced water. Absorbance was then measured at $620 \mathrm{~nm}$ against a blank that included pure methanol instead of the methanol-extracted sample.

\section{Relative Height and Stem Increment}

The height of all plants was measured for control and treatment plants after culturing at 10 vol.-\% soil moisture (H_10\%) for 7 days and final height was observed at the end of the experiment (H_end). Relative height increment was calculated by dividing height increment (H_10\% - H_d0) by initial height (H_d0). As the period until the 10 vol.- $\%$ soil moisture level was reached differed for the tested lines, the height increment was divided by the number of cultured ( $\equiv$ days when plants were irrigated) days, i.e., for the lines 27-01, 27-09. 27-10, 27-11, and 2712 as follows: $13,54,18,22,15$. Relative stem increment was calculated for control and treatment plants as follows: First, a model between final stem dry mass (DW_end) and final height (H_end) was calculated using a logarithmic function. Then, the model was applied to initial height (H_d0) estimating initial stem biomass (DW_d0). Finally, the stem increment was calculated (DW_end-DW_d0), divided by the initial stem biomass (DW_d0) and then normalized to the number of days when plants were irrigated.

\section{Statistical Analysis}

All data were analyzed using the statistical software R ( $\mathrm{R}$ Core Team, 2013). The parameters height, stem biomass, total leaf area, leaf mass per area, stomatal length and density, the stomatal area index and the vpd during the 10 vol.- $\%$ soil moisture periods were analyzed by an One-Way analysis of variance (ANOVA, Supplementary Table 1 ). The hypothesis $\mathrm{H}_{0}$ describing that no differences between the genotypes exist was rejected if $p<$ 0.05. A post-hoc test (TukeyHSD) was used for determining significant differences between the genotypes (Supplementary Table 2). Two-Way ANOVA with independent factors genotype and treatment was conducted to test genotype, treatment and interaction effects on carbohydrate concentration, relative height increment and relative stem increment (Supplementary Table 1). For stomatal conductance the factor light was tested in addition (Supplementary Table 1). Using a post-hoc test (TukeyHSD) the dataset of control and treatment were analyzed together for determining significant differences for the parameters carbohydrate concentration, relative height and stem increment (Supplementary Table 2). For stomatal conductance the control and treatment were analyzed separately (Supplementary Table 2). Leaf wilting and desiccation was analyzed using a Wilcoxon signed-rank test. Here, a pairwise comparison was conducted for the genotypes (Supplementary Table 3). Differences between the lines were considered to be significant when $p<0.05$. For determining the water consumption at 10 vol.- $\%$ soil moisture we calculated the sum of added water volumes per plant and week. The linear models according to Equations (3) and (4) were tested.

$$
\begin{array}{r}
y=\beta_{0}+x_{1} \beta_{1}+\varepsilon \\
y=\beta_{0}+x_{1} \beta_{1}+x_{2} \beta_{2}+\varepsilon
\end{array}
$$

where $x_{1}$ indicates the genotype and $x_{2}$ the stem height.

When significant differences between the models were found the one with the lowest residual sums of squares was applied. For testing if a model with enhanced parameters is equal to a model with reduced parameters $\left(H_{0}\right)$ the test statistic is calculated by Equation (5):

$$
F=\frac{\frac{1}{p-k}\left(S S_{\text {reduced }}-S S_{\text {full }}\right)}{\frac{1}{n-p-1} S S_{\text {full }}}
$$

with $p$ number of parameter of the full model, $k$ number of parameters of the reduced model and $n$ number of observations. Equation (4) fitted the data better than Equation (3) (Supplementary Table 4). Differences among the genotypes were detected using Equation (4) by estimating the shift of the intercepts from a reference. Afterwards, this shift was tested for being equal to zero $\left(\mathrm{H}_{0}\right)$ using the exact $F$-Test. $\mathrm{H}_{0}$ was rejected if $p<0.05$. Each genotype served as reference using the $\mathrm{R}$ function "lm." Thereby, all treatments were tested against each other.

\section{Results}

\section{Morphological and Genetic Characterization}

We investigated four hybrid aspen lines that were obtained after three protoplast fusion experiments between $P$. tremula $\times P$. tremuloides and $P$. trichocarpa $\times P$. deltoides and one protoplast fusion experiment between $P$. tremula $\times P$. tremuloides and $P$. nigra in comparison to the original diploid clone of P. tremula $\times$ P. tremuloides.

In the tested putative heterofusion lines no DNA from $P$. nigra or $P$. trichocarpa $\times P$. deltoides was detected by nSSR analysis using $11 \mathrm{nSSR}$ markers that were located on nine linkage groups (Table 2). This result suggested that only DNA of $P$. tremula $\times P$. tremuloides was present. To get further insight into the genetic composition of the hybrid aspen lines flow cytometry was conducted. According to this analysis, the 
TABLE 2 | Morphological and genetic characterization of the diploid and the tetraploid hybrid aspen lines under optimal water supply (stem height was measured at the beginning of the experiment after 9 month in soil, other parameters were measured at the end of the experiment.

\begin{tabular}{|c|c|c|c|c|c|c|c|c|}
\hline Line & $\begin{array}{l}\text { Fusion } \\
\text { partners }\end{array}$ & $\begin{array}{c}\text { Leaf } \\
\text { morphology }\end{array}$ & $\begin{array}{c}\text { Stem } \\
\text { height }\left[\mathrm{m} * 10^{-2}\right]\end{array}$ & $\begin{array}{c}\text { Stem } \\
\text { biomass [g plant }{ }^{-1} \text { ] }\end{array}$ & $\begin{array}{c}\text { Total leaf } \\
\text { area }\left[\mathrm{m}^{2} \star 10^{-2} \text { plant }^{-1}\right]\end{array}$ & $\begin{array}{c}\text { Leaf mass } \\
\text { per area }\left[\mathrm{g} \mathrm{m}^{-2} \star 10\right]\end{array}$ & $\begin{array}{l}\text { Ploidy } \\
\text { level }\end{array}$ & nSSR \\
\hline 27-01 & - & P3 & $105.1 \pm 17.6^{c}$ & $17.5 \pm 8.3^{b}$ & $30.4 \pm 7.7^{\mathrm{b}, \mathrm{c}}$ & $1.38 \pm 0.15^{a}$ & $2 n$ & P3 \\
\hline $27-09$ & $\mathrm{P} 3 \times \mathrm{P} 9$ & P3 & $39.6 \pm 17.3^{a}$ & $1.9 \pm 1.2^{\mathrm{a}}$ & $6.5 \pm 1.7^{a}$ & $2.26 \pm 1.98^{C}$ & $4 n$ & P3 \\
\hline $27-10$ & $\mathrm{P} 3 \times \mathrm{P} 9$ & P3 & $80.3 \pm 16.7^{b}$ & $16.3 \pm 10.0^{b}$ & $23.9 \pm 12.7^{\mathrm{b}, \mathrm{c}}$ & $1.59 \pm 0.23^{b}$ & $4 n$ & P3 \\
\hline $27-11$ & $\mathrm{P} 3 \times \mathrm{P} 9$ & P3 & $49.8 \pm 11.8^{a}$ & $4.9 \pm 3.5^{a}$ & $15.4 \pm 7.8^{a, b}$ & $1.53 \pm 0.26^{a, b}$ & $4 n$ & P3 \\
\hline $27-12$ & $\mathrm{P} 3 \times \mathrm{P} 7$ & P3 & $92.8 \pm 18.4^{b, c}$ & $22.1 \pm 7.3^{b}$ & $34.2 \pm 6.0^{c}$ & $1.69 \pm 0.21^{b}$ & $4 n$ & P3 \\
\hline
\end{tabular}

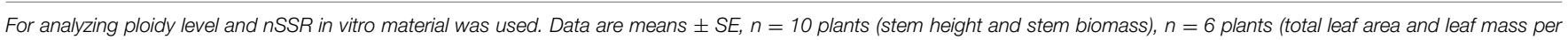
area), superscripted letters indicate differences between the lines (Tukey HSD test, $p<0.05$ ), P3: P. tremula $\times$ P. tremuloides, P7: P.nigra, P9: P. trichocarpa $\times$ P. deltoides).

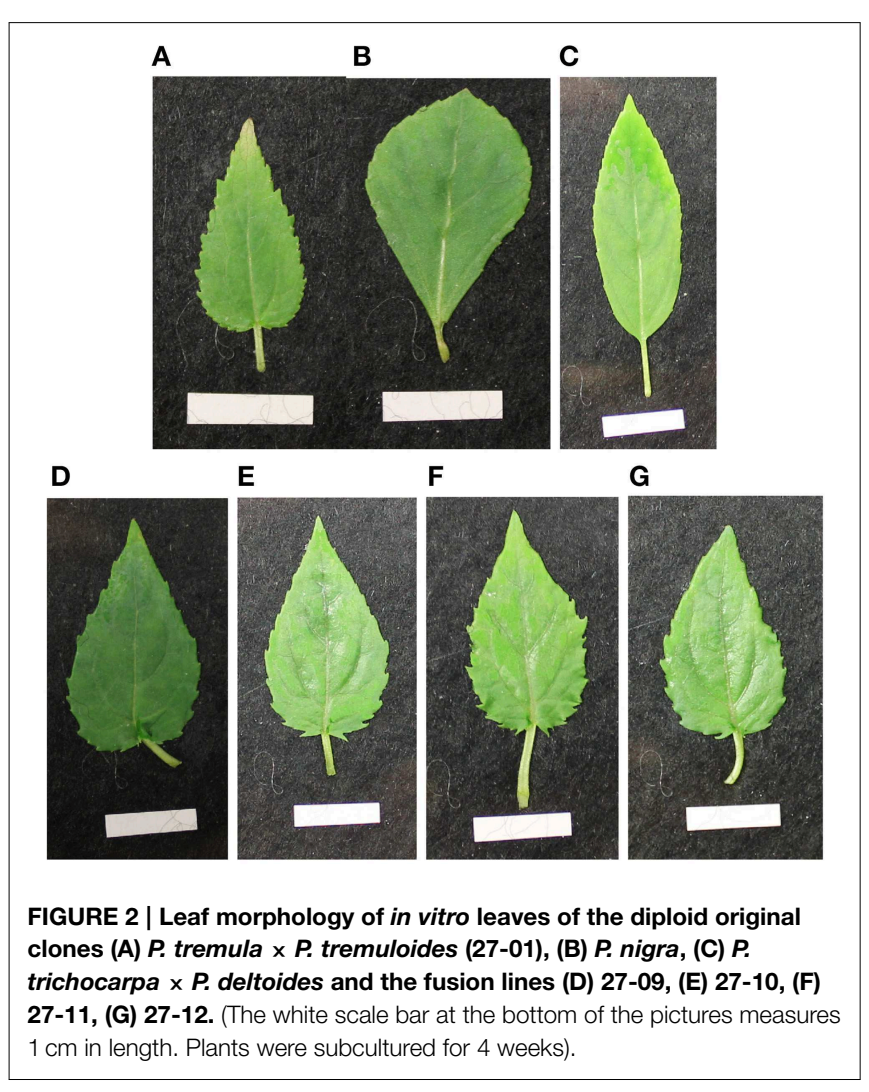

hybrid aspen lines showed a tetraploid set of chromosomes (Table 2). Our analyses, therefore, support that homofusion lines of hybrid aspen $(P$. tremula $\times P$. tremuloides $)$ were obtained, but no heterofusion lines with other poplar genotypes. This finding was also supported by the leaf morphology of the fusion lines that exhibited the $P$. tremula $\times P$. tremuloides phenotype (Figure 2). In the following text, the putative hybrid aspen clones that originated from the protoplast fusion experiments are therefore named fusion lines. The original diploid P. tremula $\times$ $P$. tremuloides clone is referred to as the diploid line.

For basic characterization of the fusion lines height at the beginning of the experiment after 9 month of soil culture and total leaf area, leaf mass per area and stem biomass production at the end of the experiment were compared to the diploid line under optimal water supply (Table 2). Plants heights were lower for the fusion lines 27-09, 27-10, and 27-11 than for the diploid line. Stem biomass of the fusion lines 27-09 and 27-11 was reduced. Furthermore, for the fusion line 27-09 the total leaf area was decreased compared to the diploid line. The leaf mass per area was increased in the fusion lines except for 27-11 suggesting enhanced leaf thickness for the fusion lines.

Microscopy of leaf impressions that were taken of the abaxial leaf surface before starting the experiment revealed that the stomatal lengths were higher but the stomatal densities were reduced for all fusion lines in comparison to the diploid line (Figures 3A,B). Among the fusion lines stomatal lengths and densities differed. Fusion line 27-11, which showed the lowest stomatal density on lower leaf surface, exhibited stomata on the leaf adaxial surface. But the stomatal density on the adaxial leaf surface was only 10 stomata $\mathrm{mm}^{-2}$ compared to 75 stomata $\mathrm{mm}^{-2}$ on the abaxial leaf side, thus was significantly lower. None of the other lines, including the diploid line, developed stomata on the adaxial leaf surface. The stomatal area index was reduced for the fusion lines 27-11 and 27-12 compared to the diploid line (Figure 3C).

\section{Performance of the Diploid and the Fusion Lines Under Drought Water Consumption and Leaf Vitality}

The plants were exposed to drought by gradually drying until soil moisture levels of 10 vol-\% were reached (Figure 4A). Each line attained the target soil moisture at a different time point and was kept at this level for a period of 7 days (Figure 4A). Subsequently, the lines were not watered anymore. The water consumption was determined during the 7 -day period at the 10 vol.- $\%$ soil moisture level. The diploid consumed more water than the fusion lines (Figure 4B). This was not only observed for fusion lines that were smaller than the diploid line, but was also detected for the fusion lines 27-10 and 27-12 when height was respected (Table 2, Figures 4B, 5). A further factor that may influence water consumption is a variation in the vpd. Although the periods when the plants experienced 10 vol-\% soil moisture occurred at different time points, vpd levels did not differ except for the fusion line 27-09 (Figure 4C). Here, the vpd was lower compared to all other lines. Relative to the height this line consumed as much water as the diploid line and even more than the fusion lines 27-10 and 27-12 (Figure 5) that experienced higher vpd. Therefore, variation in vpd among the lines was not the reason for differences in the water consumption. 

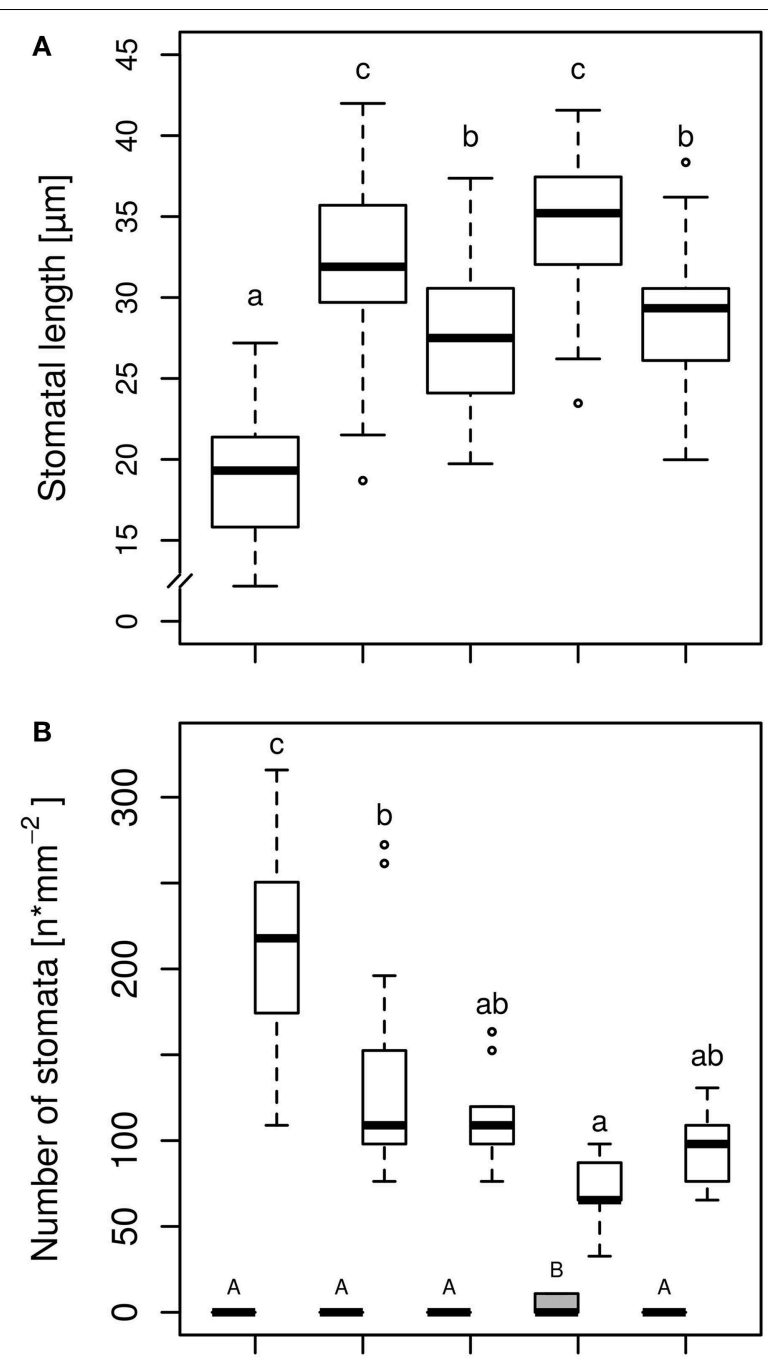

C

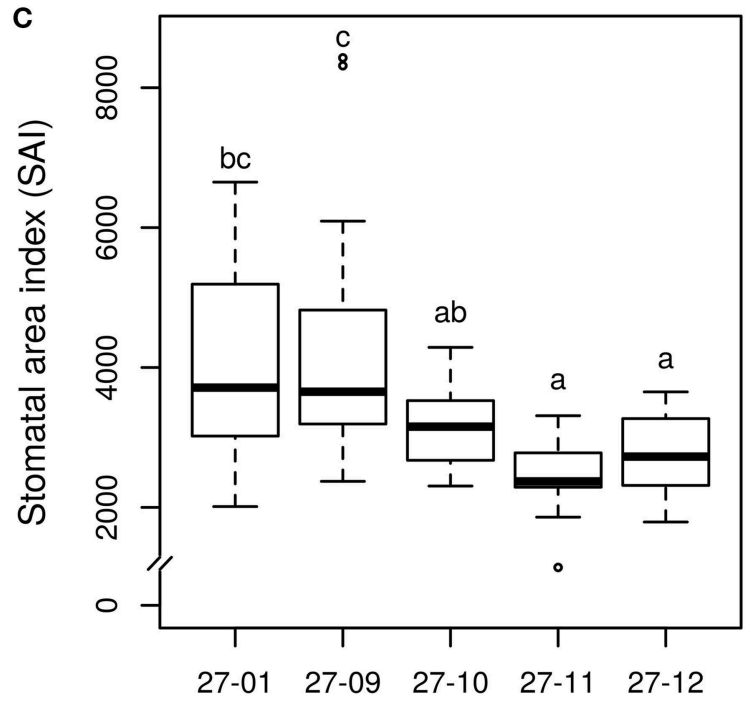

FIGURE 3 | (A) Stomatal length on abaxial surface, (B) Stomatal density on adaxial and abaxial surface, and (C) Stomatal area index (SAI) on abaxial

(Continued)

\section{FIGURE 3 | Continued}

surface [samples were taken of the upper fifth fully expanded leaf of the diploid line and the tetraploid fusion lines before starting the experiment, stomatal length: $n=45$ stomata per line, stomatal density: $n=15$ leaf sections per line and leaf side (gray box, adaxial side; white boxes, abaxial side), SAl: mean stomatal length of three stomata of one leaf section multiplied by stomatal density of this leaf section, $n=15$ leaf sections per line; 27-01: diploid, other lines: tetraploid. Boxplot definition: Outer transversal bars of the boxplots include $95 \%$ of the data, $50 \%$ of the data are defined by the boxes themselves, the median is shown by the highlighted line within the box. Outliers are represented by open circles. Different letters at the top of the boxes indicate significant differences between the lines (TukeyHSD test, $p<0.05$ ). Capitals are used for the adaxial side, lowercase letters for the abaxial side].

The linear regression analysis showed that the fusion lines 27 10 and 27-12 consumed significantly less water with regard to height than the diploid line (Figure 5).

Leaf wilting and desiccation were determined as indicators for plant vitality (Figures 6A,B). The wilting process of the diploid plants occurred more rapidly with a steeper increment than in the fusion lines. Average leaf wilting of about $85 \%$ already appeared at the third day after the final irrigation of the diploid line. Similarly strong wilting occurred in the fusion line 27-12 at day nine after the last watering, whereas this threshold was not observed for the fusion lines 27-10 and 27-11 during the whole experiment. Instead, desiccation of leaves was first visible in two fusion lines. The lines 27-10 and 27-12 showed a proportional leaf wilting of about 25 and 50\%, respectively, already at the end of the 10 vol.-\% soil moisture phase. Early leaf desiccation might have had an influence on leaf wilting because leaf desiccation reduces the transpiration surface. Maximum desiccation of $100 \%$ was reached for the diploid and the fusion line 27-12 20 days after last irrigation whereas this event did not occur for the fusion lines 27 10 and 27-11. This analysis could not be conducted for the fusion line 27-09, which was the smallest line with the lowest leaf area (Table 2) and consequently consumed little water. Therefore, this line reached the target date for stopping irrigation (i.e., after 7 days at 10 vol.-\% soil moisture) only 2 days before the end of the whole experimental time period, when leaves of other lines were already $100 \%$ wilted.

\section{Stomatal Conductance and Carbohydrate Concentration}

Under well-watered conditions, no differences were observed among the stomatal conductance of the diploid line and the fusion lines (Figure 7A). All tested lines responded to dry conditions with a reduction in the stomatal conductance (Figures 7A,B) whereas this did not differ among the droughtexposed lines (Figure 7B). Here, stomatal conductance was not correlated with stomatal density (Figures 3B, 7A,B).

All fusion lines increased their foliar carbohydrate concentrations in response to drought (Figure 8). In the diploid line, the increase was not significant (Figure 8). Overall, the carbohydrate concentrations of the fusion lines were similar to that of the diploid line (Figure 8). Genotype and treatment interactions were not found for the parameters carbohydrate concentration and stomatal conductance (Table 3). 


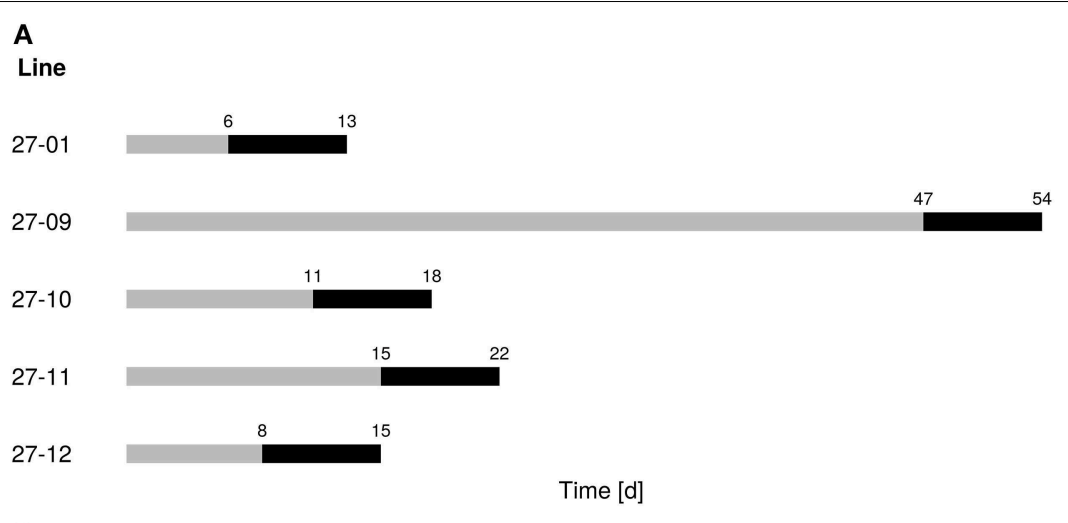

B

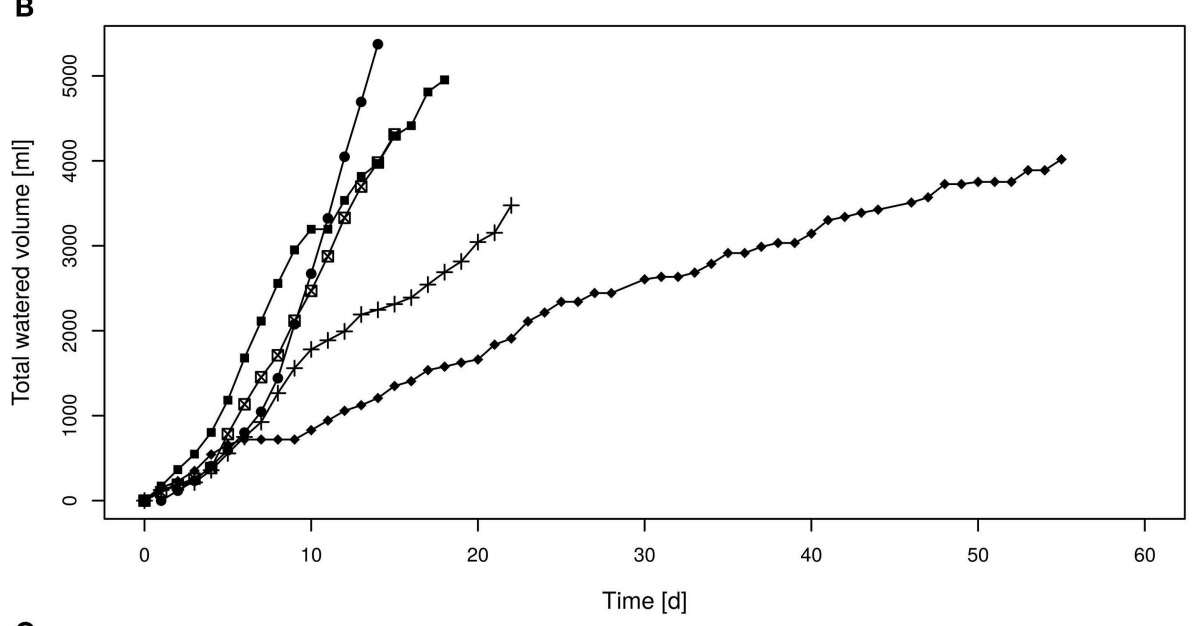

C

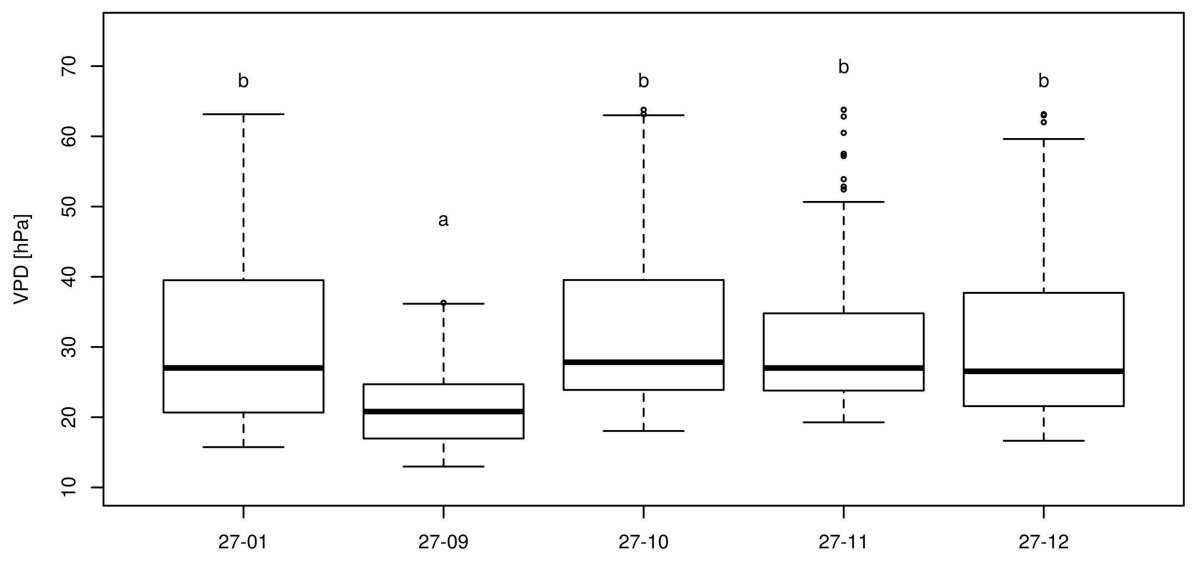

FIGURE 4 | (A) Scheme of the drought periods, (B) cumulative water volumes applied to each line, (C) vapor pressure deficit during the 10 vol.-\% levels [gray line: drying period until the 10 vol.- $\%$ soil moisture level was reached for all plants of one line, black line: 10 vol.. \% soil moisture period;
27-01: circles, 27-10: squares, 27-11: crosses, 27-12: crossed squares. Boxplots are defined as explained in Figure 3. Different letters at the top of the boxes indicate significant differences between the lines (TukeyHSD test, $p<0.05)$.

\section{Biomass Production}

Among the fusion lines the relative height increment was reduced under drought in the lines 27-10, 27-11, and 27-12, but not in the line 27-09. This line probably suffered only from mild drought because this fusion line was smaller than the other lines (Figure 9A). Instead, the diploid line experienced severe drought stress but showed no reduction in relative height increment (Figure 9A). Under optimally watered conditions the relative height growth of the fusion lines 27-10, 27-11, and 27-12 was equivalent to that of the diploid line, while that of the fusion line 27-09 was significantly lower (Figure 9A). Interactions between the genotype and the treatment 


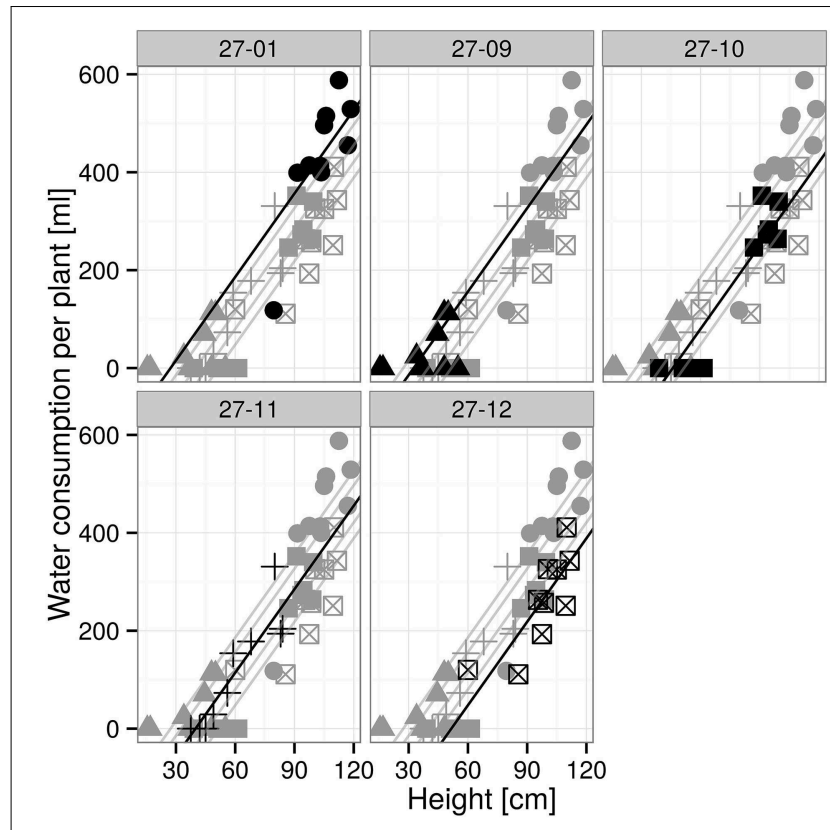

FIGURE 5 | Water consumption for $\mathbf{7}$ days at $\mathbf{1 0}$ vol.- $\%$ soil moisture level depending on height. $[n=10$ plants, data and the regression line of the respective plot are in black, others are visualized in gray; groups with different letters indicate significant differences between the lines (exact $F$-Test, $p<0.05): 27-01^{\mathrm{a}}, 27-09^{\mathrm{a}}, 27-10^{\mathrm{b}}, 27-11^{\mathrm{ab}}, 27-12^{\mathrm{b}}$ (Supplementary Table 5)].

were detected for both relative height and stem increment (Table 3).

Dry matter of the stem is an important parameter for biomass production in short rotation coppice. We analyzed the shoot dry matter without the leaves. The relative stem increment was not decreased in the fusion lines but enhanced for the fusion line 27-12 compared to the diploid line under optimally watered conditions (Figure 9B). Under the drought treatment, relative shoot increment was equivalent to the diploid line in all fusion lines except for the fusion line 27-11 that showed an increased relative shoot increment (Figure 9B).

\section{Discussion}

\section{Morphological and Genetic Characterization}

nSSR analysis did not reveal the presence of DNA of $P$. nigra or $P$. trichocarpa $\times P$. deltoides in any fusion line. Because all fusion lines were tetraploid, our results suggest that homofusions of two $P$. tremula $\times$ P. tremuloides protoplasts occurred.

Polyploidy often induces morphological and phenotypic variation (Liu and Wendel, 2003). A reduction in height growth, as observed here for some fusion lines, has been reported in other polyploid plants before (Porter and Weiss, 1948; Sharma and Datta, 1957; Riddle and Birchler, 2008; Deng et al., 2012). Because poplars of dry habitats were smaller than those of wet habitats (Regier et al., 2009; Yang and Miao, 2010), the observed height reduction with lower total leaf area in the tetraploid than in the diploid line might be advantageous for drought
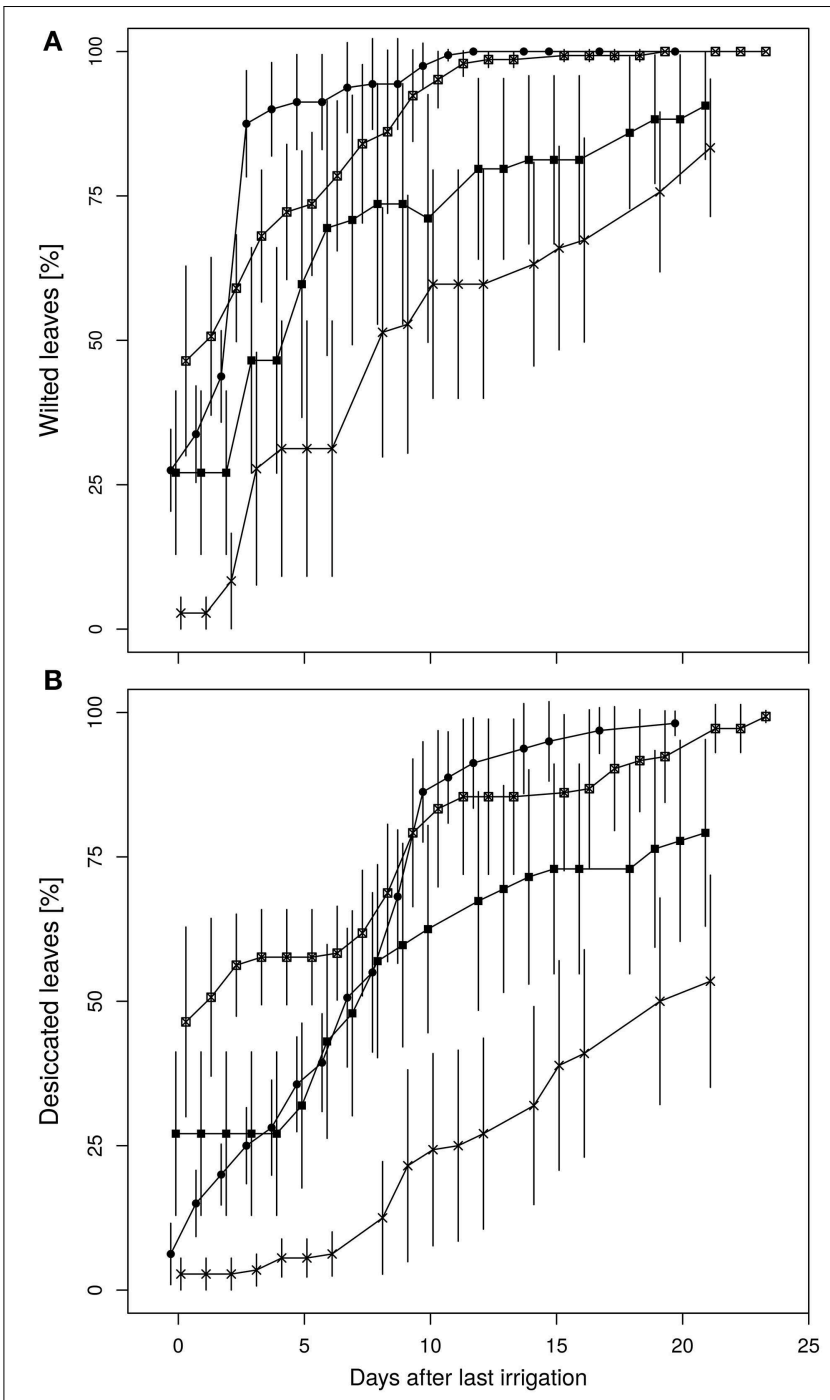

FIGURE 6 | Time course of (A) leaf wilting, (B) desiccation of leaves. (Data are normalized to last irrigation event and are means \pm standard errors, $n=10$ plants. 27-01: circles, 27-10: squares, 27-11: crosses, 27-12: crossed squares).

threatened habitats. We have shown here that these fusion lines also consumed less water than the diploid line.

The stomatal density is correlated with the maximum stomatal conductance in Mediterranean herbs, shrubs and woody species (Galmés et al., 2007). Decreased stomata density as observed in the fusion lines might therefore lead to enhanced drought tolerance as the stomatal conductance is reduced. However, in the fusion lines stomata lengths were enhanced. This modification of the stomatal apparatus has also been observed in other tetraploid species like Spathiphyllum (van Laere et al., 2010), Platanus (Liu et al., 2007) or Betula (Li et al., 1996). Hodgson et al. (2010) detected that stomatal length is positively correlated with genome size within the eudicots, Poaceae and other monocots without providing a causal link. The correlation of stomatal length with habitat humidity is discussed controversially (Abrams et al., 1994; Hodgson et al., 2010). For example, Hodgson et al. 


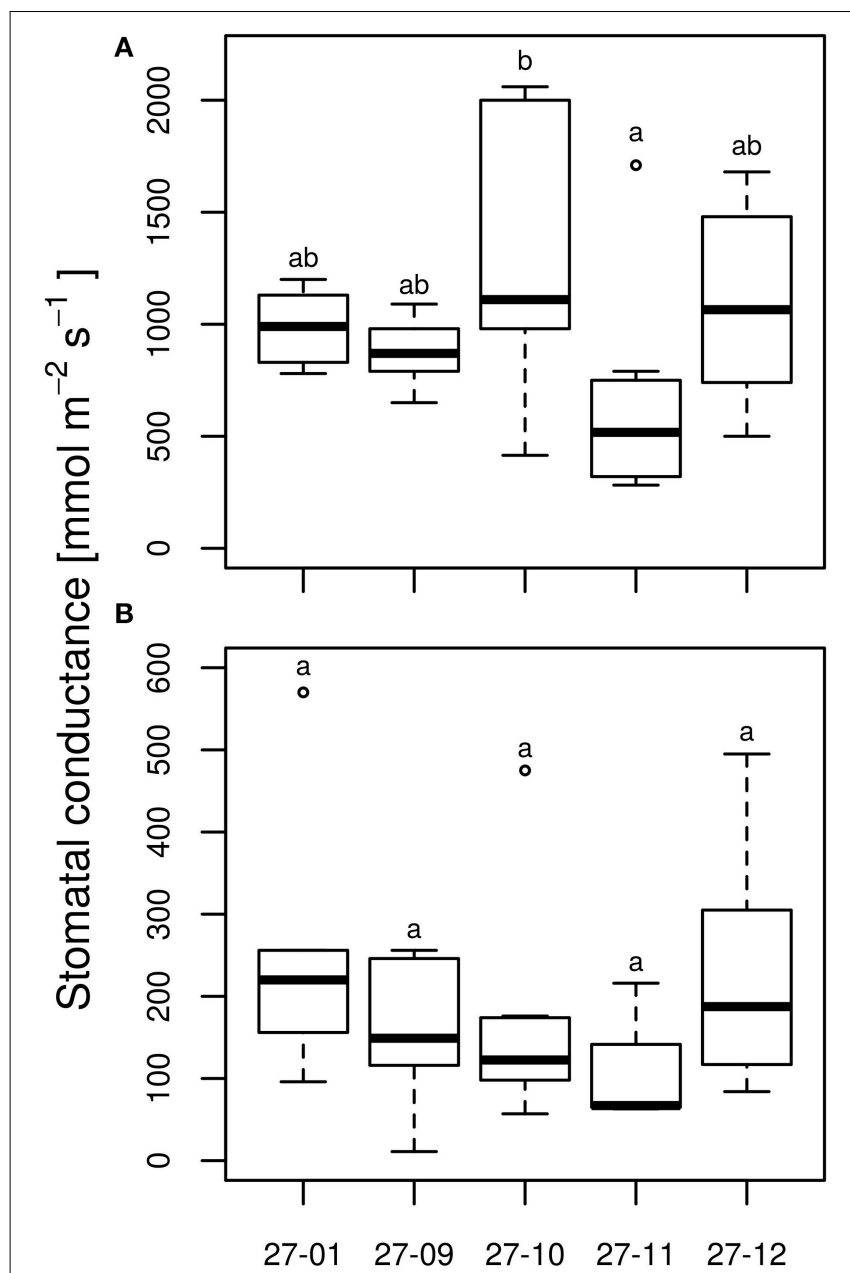

FIGURE 7 | Stomatal conductance at the end of 10 vol.-\% soil moisture level (A) watered plants, (B) drought-exposed plants. [ $n=10$ plants. Boxplots are defined as explained in Figure 3. Different letters at the top of the boxes indicate significant differences between the lines (TukeyHSD test, $p<0.05)]$.

(2010) stated that stomatal length is correlated with habitats of high humidity. Abrams et al. (1994), in contrast, reported increasing stomatal size from wet-mesic to mesic and xeric sites in deciduous tree species. Regier et al. (2009) observed that the stomatal length was increased in one $P$. nigra genotype under water limited conditions while abaxial stomatal density was reduced. In drought tolerant tomato cultivars stomatal density was decreased, but stomatal size increased compared to drought sensitive genotypes (Kulkarni and Deshpande, 2006). These stomatal traits that have also occurred in the fusion lines might be the reason for lower water consumption as observed here. Furthermore, Ashton and Berlyn (1994) observed a reduction in the SAI from wet to xeric habitats in Quercus species and suggested this parameter to predict drought tolerance. More, recently QTLs for this trait have been identified and were also linked with drought tolerance (Gailing et al., 2008). Here, SAI was reduced in two fusion lines (Figure 3C) only one out of these lines consumed significantly less water related to height

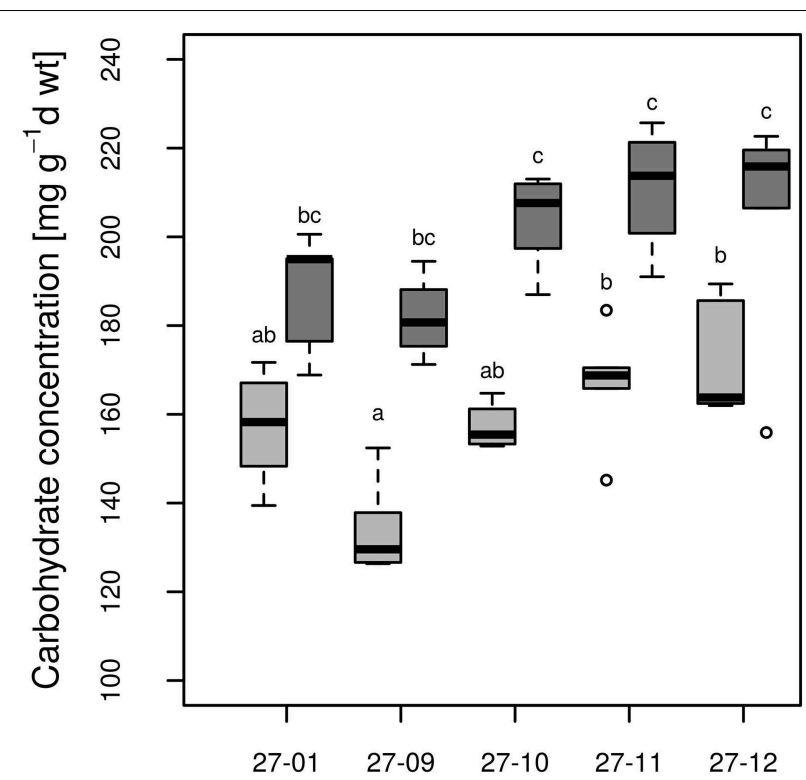

FIGURE 8 | Carbohydrate concentration at the end of $\mathbf{1 0}$ vol.-\% soil moisture level. [Watered plants: light gray, drought-exposed plants: dark gray, $n=6$ plants. Boxplots are defined as explained in Figure 3. Different letters at the top of the boxes indicate significant differences between the lines (TukeyHSD test, $p<0.05)$ ].

TABLE 3 | Significance of the parameters genotype (G), treatment (T), light (L) and their interaction effects on the stomatal conductance, the carbohydrate concentration, the relative height and stem increment ( ${ }^{\star} p<0.05,{ }^{* \star} p<0.01,{ }^{\star \star \star} p<0.001$; ns, not significant; - , not analyzed).

\begin{tabular}{lcccccc}
\hline Parameter & G & T & L & G:T & G:L & L:T \\
\hline Stomatal conductance & ns & $* *$ & ns & ns & ns & ns \\
Carbohydrate concentration & $* \star *$ & $* * *$ & - & ns & - & - \\
Relative height increment & $* * *$ & $* * *$ & - & $* * *$ & - & - \\
Relative stem increment & $* * *$ & $* * *$ & - & $*$ & - & -
\end{tabular}

indicating that SAI might be a relevant parameter associated with water consumption. However, the links between this trait and DNA dosage remain obscure.

\section{Performance of the Diploid Line and the Fusion Lines Under Drought Water Consumption and Leaf Vitality}

Polyploid plants often possess superior characteristics in comparison to their diploid counterparts with regard to morphological and physiological changes and their tolerance to environmental stresses (Xiong et al., 2006). In this study, we observed that all fusion lines consumed less water relative to height than the diploid line. Reduced water consumption was significant for the fusion lines 27-10 and 27-12, which both showed a total leaf area similar to the diploid line. Furthermore, there were other cases where severe height and leaf area reductions decreased water consumption of the fusion lines. The altered stomatal morphology (decreased stomatal density and 


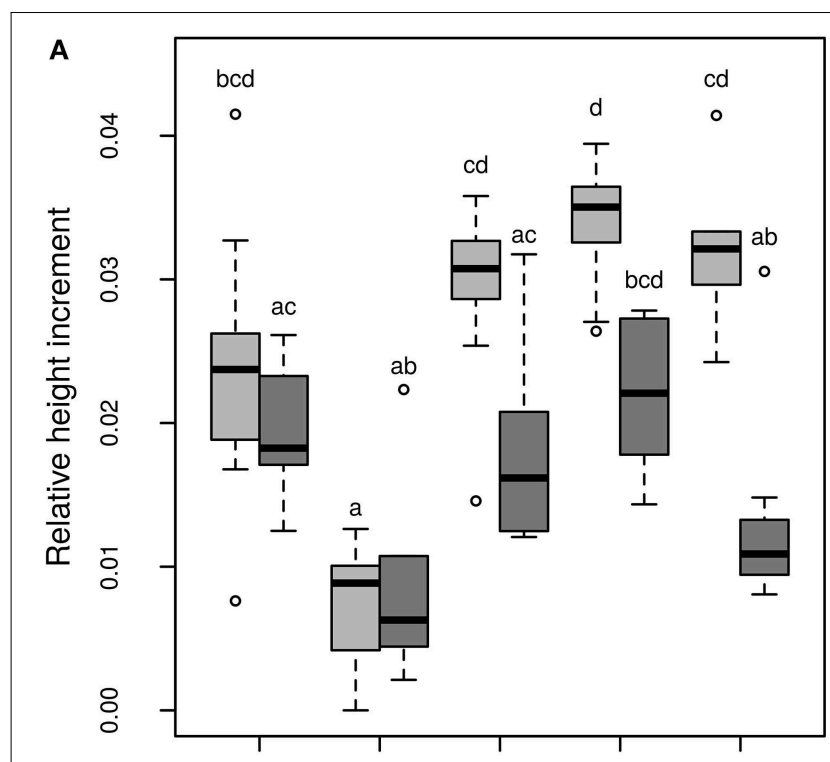

B

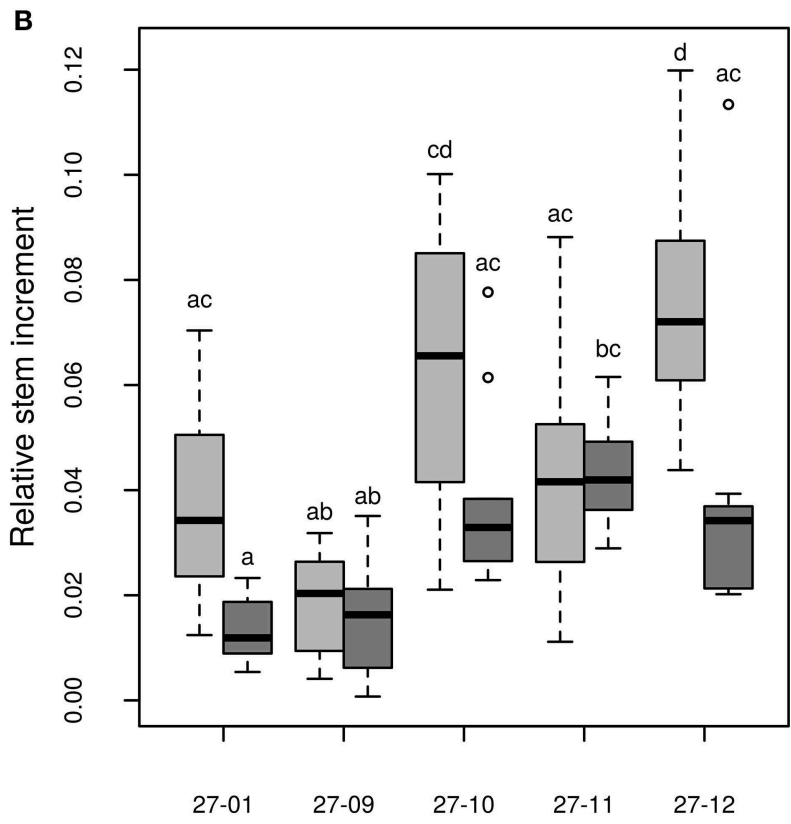

FIGURE 9 | (A) Relative height increment, (B) Relative stem increment [stem without leaves, relative stem increment data are normalized to the number of days when plants were irrigated, data of the relative height increment are normalized to the number of cultured days (三 days when plants were irrigated); watered plants: light gray, drought-exposed plants: dark gray, $n=10$ plants. Boxplots are defined as explained in Figure 3. Different letters at the top of the boxes indicate significant differences between the lines (TukeyHSD test, $p<0.05)$ ].

increased stomatal size) and the increased leaf mass per area (a low surface to volume ratio) that is linked to dry habitats (Poorter et al., 2009) in the fusion lines 27-10 and 27-12 might have reduced the transpiration and thereby enabled the plants to use water more efficiently.

The leaf wilting was more severe for the diploid line than for the fusion lines, but two of the fusion lines showed early leaf desiccation which increased to about $50 \%$ at the end of the drought. In the genus Populus, leaf shedding occurs to avoid desiccation of the remaining tissue (Fischer and Polle, 2010). Blake and Tschaplinski (1992) noted that leaf shedding and the related reduction of the transpiration surface led to an increase of the water potential in the remaining tissue. In analogy to this, our finding suggests that the early-wilting fusion lines were better adapted to drought than the diploid line because they reduced the transpiration surface rapidly by desiccating a part of the leaves and thereby might have been able to delay wilting of the remaining foliage.

\section{Stomatal Conductance and Carbohydrate Concentration}

The positive correlation between stomatal density and stomatal conductance as described for herbs and trees in literature (Abrams et al., 1994; Galmés et al., 2007) was not found here. Despite the variation in stomatal morphology, significant differences in the stomatal conductance between the different ploidy levels were not discovered under well-watered conditions. In polyploid Betula and Lonicera plants, stomatal conductance was less affected by drought compared to the diploid variants ( $\mathrm{Li}$ et al., 1996, 2009), whereas the poplar fusion lines in our study exhibited the same response to drought as the diploid line.

Carbohydrates play important roles for osmotic adjustment of poplar tissues to drought stress (Danielsen and Polle, 2014). Notably, in the fusion lines the carbohydrate concentrations were more strongly increased under drought conditions than in the diploid line (Figure 8). For instance, Deng et al. (2012) also observed enhanced carbohydrate levels and increased survival of octaploid tobacco compared to its tetraploid variant under stress conditions. Accumulation of carbohydrates leads to osmotic adjustment by decreasing the osmotic potential in the cell and contributes to the stress tolerance (Touchette et al., 2009). Carbohydrates also function in osmoprotection by stabilizing proteins and membranes (Crowe et al., 1992). The stronger increase in carbohydrate concentration in the fusion lines might have enabled them to cope with dry conditions better than the diploid line because of improved osmotic adjustment and cellular protection.

\section{Biomass Production}

Although the initial height was reduced for the fusion lines 27-09, 27-10, and 27-11 (Table 2) the relative height increment of the fusion lines 27-10,27-11, and 27-12 was equivalent to that of the diploid line under well-watered conditions indicating no growth constraints (Figure 9A). Height growth of Populus is sensitive to drought at an early stage (Bogeat-Triboulot et al., 2006). McDowell et al. (2008) suggested that plants under drought conditions suffer mainly from carbon starvation because of stomatal closure. Consequently, growth is reduced. In the context of the present study, this theory implies that the fusion lines 27 $10,27-11$, and 27-12 closed their stomata to reduce water loss, as a consequence their height increment decreased. Additionally, they avoided further increase in stress because they reduced the area of growing tissue that had to be supplied with water. This can also be a part of the stress avoidance response. Eventually, these 
measures may have led to reduced water demand, apparent as the lower water consumption of the fusion lines. In contrast, the diploid line did not respond to drought by early diminishment of height growth and thus, did not save resources. These suggestions are in line with the resource requirement hypothesis pertaining that polyploid plants grow slower and therefore, have a decreased resource demand compared to their diploid counterparts (Deng et al., 2012). In practical terms, it is obvious that in plantations for woody biomass production, genotypes are needed that represent a compromise of biomass production and drought tolerance.

In SRC stem biomass production is the most important parameter to be optimized because the woody parts are used for energy production (Karp and Shield, 2008; Polle et al., 2013). In our study, an enhancement in the relative shoot increment was detected for the fusion line 27-11 under drought and for 27-12 under control conditions, respectively compared to the diploid line. Because two of these fusion lines also showed total biomass production similar to that of the diploid line, the new genotypes appear to be reasonable alternatives for plantation in dry areas.

\section{Conclusion}

Overall, the tetraploid lines that were generated by protoplast fusion varied significantly in morphological characteristics such as height, total leaf area and stomatal characteristics as well as in physiological traits such as carbohydrate production under drought and water consumption. The phenotypic diversity might be due to mutations in the chromosomes caused during the protoplast fusion process (Prange et al., 2012). This diversity renders the fusion lines predestined for breeding. Moreover, we could show that the fusion lines 27-10 and 27-12 desiccated a part of their foliage at an early stage of drought and were more water saving than the diploid line. All fusion lines showed a higher increase in carbohydrate concentration and a decrease in relative height increment when suffered from severe drought suggesting better drought adaptation by stress tolerance and avoidance mechanisms. Adaptability to low water supply is favorable for the SRC plantation, because it is expected that biomass plantations will be established on marginal sites with low

\section{References}

Abrams, M. D., Kubiske, M. E., and Mostoller, S. A. (1994). Relating wet and dry year ecophysiology to leaf structure temperate tree species. Ecology 75, 123-133. doi: $10.2307 / 1939389$

Adams, K. L., Cronn, R., Percifield, R., and Wendel, J. F. (2003). Genes duplicated by polyploidy show unequal contributions to the transcriptome and organspecific reciprocal silencing. Proc. Natl. Acad. Sci. U.S.A. 100, 4649-4654. doi: $10.1073 /$ pnas.0630618100

Adams, K. L., and Wendel, J. F. (2005). Polyploidy and genome evolution in plants. Curr. Opin. Plant Biol. 8, 135-141. doi: 10.1016/j.pbi.2005.01.001

Ahuja, M. R. (1984). A commercially feasible micropropagation method for aspen. Silvae Genet. 33, 174-176.

Araus, J. L., Slafer, G. A., Reynolds, M. P., and Royo, C. (2002). Plant breeding and drought in C3 cereals: what should we breed for? Ann. Bot. 89, 925-940. doi: 10.1093/aob/mcf049

Ashton, P. M. S., and Berlyn, G. P. (1994). A comparison of leaf physiology and anatomy of Quercus (section Erythrobalanus-Fagaceae) species in water and mineral supply to avoid competition with agricultural land (von Wühlisch, 2012). Furthermore, a decrease in soil moisture of $5 \%$ up to $12 \%$ in the upper $10 \mathrm{~cm}$ deep soil is predicted for large parts of Europe in the long term (year 20802099) (Dai, 2012). Thus, it is likely that even production on currently moist sites will have to cope with water limitations in the future. Eventually, a sufficient supply of water is a decisive factor that determines the success of establishing SRC plantations (Helbig and Müller, 2009). Therefore, the fusion lines represent interesting candidates for the cultivation on SRC.

\section{Acknowledgments}

Research was funded by the "Fachagentur Nachwachsende Rohstoffe e.V." (Agency for Renewable Resources) within the project "ZÜEND-Züchtung neuer Energiepappeln für Deutschland" (FKZ 22005010) and partly by funding from the European Community's Seventh Framework Programme (FP7/2007-2013) under the grant agreement $n^{\circ}$ FP7-311929 to AP. The authors thank Dr. Renate Lührs, Dr. Nadja Efremova, and Angelika Krull from the company Phytowelt GreenTechnologies $\mathrm{GmbH}$ (Cologne, Germany) for protoplast fusion of in vitro plantlets and kindly providing the fusion lines [project "Innovative Hybridpappeln" (FKZ 22006307)]. Plant material was provided within the project "ZÜEND." Optimal culturing of the in vitro plants by Silvia Köhler and Tina Wetzel and technical assistance provided by Dagmar Leisten is highly appreciated. Assistance with the graphical representation was kindly provided by Johannes Signer. The publication fund of the University of Göttingen and the Deutsche Forschungsgemeinschaft supported open access publication of this article.

\section{Supplementary Material}

The Supplementary Material for this article can be found online at: http://journal.frontiersin.org/article/10.3389/fpls.2015. 00330/abstract different light environments. Am. J. Bot. 81, 589-597. doi: 10.2307/24 45734

Asif, M., and Muneer, T. (2007). Energy supply, its demand and security issues for developed and emerging economies. Renew. Sustain. Energy Rev. 11, 1388-1413. doi: 10.1016/j.rser.2005.12.004

Berndes, G., Hoogwijk, M., and van den Broek, R. (2003). The contribution of biomass in the future global energy supply: a review of 17 studies. Biomass Bioenergy 25, 1-28. doi: 10.1016/S0961-9534(02) 00185-X

Blake, T. J., and Tschaplinski, T. J. (1992). "Water relations," in Ecophysiology of Short Rotation Forest Crops, eds C. P. Mitchell, J. B. Ford-Robertson, T. Hinckley, and L. Sennerby-Forsse (Barking: Elsevier Science Publishers LTD), 66-94.

Blanc, G., and Wolfe, K. H. (2004). Widespread paleopolyploidy in model plant species inferred from age distributions of duplicate genes. Plant Cell Online 16, 1667-1678. doi: 10.1105/tpc.021345

BMEL. (2007). Nutzungen von Biomasse zur Energiegewinnung_Empfehlungen an die Politik. Wissenschaftlicher Beirat beim Bundesministerium für Ernährung, 
Landwirtschaft und Verbraucherschutz, 242 S. Available online at: www.bmelv. de/cae/servlet/contentblob/382594/publicationFile/23017/GutachtenWBA.pdf BMEL. (2014). Starke Landwirtschaft. Available online at: http://www.bmel.de/DE/ Landwirtschaft/landwirtschaft_node.html [Accessed October 29, 2014].

Bogeat-Triboulot, M.-B., Brosche, M., Renaut, J., Jouve, L., Le Thiec, D., Fayyaz, P., et al. (2006). Gradual soil water depletion results in reversible changes of gene expression, protein profiles, ecophysiology, and growth performance in Populus euphratica, a poplar growing in arid regions. Plant Physiol. 143, 876-892. doi: 10.1104/pp.106.088708

Cattivelli, L., Rizza, F., Badeck, F.-W., Mazzucotelli, E., Mastrangelo, A. M., Francia, E., et al. (2008). Drought tolerance improvement in crop plants: an integrated view from breeding to genomics. Field Crops Res. 105, 1-14. doi: 10.1016/j.fcr.2007.07.004

Chum, H., Faaij, A., Moreira, J., Berndes, G., Dhamija, P., Dong, H., et al. (2011). "Bioenergy," in IPCC Special Report on Renewable Energy Sources and Climate Change Mitigation, eds O. Edenhofer, R. Pichs-Madruga, Y. Sokona, K. Seyboth, P. Matschoss, S. Kadner, et al. (Cambridge; New York, NY: Cambridge University Press), 1-26.

Crowe, J. H., Hoekstra, F. A., and Crowe, L. M. (1992). Anhydrobiosis. Annu. Rev. Physiol. 54, 579-599. doi: 10.1146/annurev.ph.54.030192.003051

Dai, A. (2012). Increasing drought under global warming in observations and models. Nat. Clim. Change 3, 52-58. doi: 10.1038/nclimate1633

Danielsen, L., and Polle, A. (2014). Poplar nutrition under drought as affected by ectomycorrhizal colonization. Environ. Exp. Bot. 108, 89-98. doi: 10.1016/j.envexpbot.2014.01.006

Deng, B., Du, W., Liu, C., Sun, W., Tian, S., and Dong, H. (2012). Antioxidant response to drought, cold and nutrient stress in two ploidy levels of tobacco plants: low resource requirement confers polytolerance in polyploids? Plant Growth Regul. 66, 37-47. doi: 10.1007/s10725-011-9626-6

Doman, L., Singer, L., and Arora, V. (2014). International Energy Outlook 2014. U.S. Energy Information Administration (EIA). Available online at: http://www. eia.gov/forecasts/ieo/pdf/0484(2014).pdf [Accessed October 23, 2014].

Dumolin, S., Demesure, B., and Petit, R. J. (1995). Inheritance of chloroplast and mitochondrial genomes in pedunculate oak investigated with an efficient PCR method. Theor. Appl. Genet. 91, 1253-1256. doi: 10.1007/BF00220937

Efremova, N., Lührs, R., Welters, P., Voß, M., Fladung, M., Hennig, A., et al. (2013). Züchtung neuer Energiepappeln. Conference Manuscript, "Agrarholz 2013", International Conference 19.-20.02.2013 in Berlin.

Eusemann, P., Fehrenz, S., and Schnittler, M. (2009). Development of two microsatellite multiplex PCR systems for high throughput genotyping in Populus euphratica. J. For. Res. 20, 195-198. doi: 10.1007/s11676-009-0038-7

Finnegan, E. J. (2002). Epialleles-a source of random variation in times of stress. Curr. Opin. Plant Biol. 5, 101-106. doi: 10.1016/S1369-5266(02) 00233-9

Fischer, U., and Polle, A. (2010). "Populus responses to abiotic stress," in Genetics and Genomics of Populus, eds S. Jansson, R. Bhalerao, and A. Groover (Berlin: Springer Verlag), 225-247.

Gailing, O., Langenfeld-Heyser, R., Polle, A., and Finkeldey, R. (2008). Quantitative trait loci affecting stomatal density and growth in a Quercus robur progeny: implications for the adaptation to changing environments. Glob. Change Biol. 14, 1934-1946. doi: 10.1111/j.1365-2486.2008.01621.x

Galmés, J., Flexas, J., Savé, R., and Medrano, H. (2007). Water relations and stomatal characteristics of Mediterranean plants with different growth forms and leaf habits: responses to water stress and recovery. Plant Soil 290, 139-155. doi: 10.1007/s11104-006-9148-6

Gaur, P. M., Krishnamurthy, L., and Kashiwagi, J. (2008). Improving droughtavoidance root traits in Chickpea (Cicer arietinum L.)-current status of research at ICRISAT. Plant Prod. Sci. 11, 3-11. doi: 10.1626/pps.11.3

Guo, W. W., and Deng, X. X. (1998). Somatic hybrid plantlets regeneration between Citrus and its wild relative, Murraya paniculata via protoplast electrofusion. Plant Cell Rep. 18, 297-300. doi: 10.1007/s0029900 50575

Hartmann, D. L. (1994). Global Physical Climatology. San Diego, CA: Academic Press. 350-351.

Helbig, C., and Müller, M. (2009). "Biotische und abiotische Risikofaktoren," in Anbau und Nutzung von Bäumen auflandwirtschaftlichen Flächen, eds T. Reeg, A. Bemman, W. Konold, D. Murach, and H. Spieker (Weinheim: Wiley-VCH), 83-97.
Hodgson, J. G., Sharafi, M., Jalili, A., Diaz, S., Montserrat-Marti, G., Palmer, C., et al. (2010). Stomatal vs. genome size in angiosperms: the somatic tail wagging the genomic dog? Ann. Bot. 105, 573-584. doi: 10.1093/aob/mcq011

IPCC. (2014). "Climate change 2014: mitigation of climate change," in Contribution of Working Group III to the Fifth Assessment Report of the Intergovernmental Panel on Climate Change, eds O. Edenhofer, R. Pichs-Madruga, Y. Sokona, E. Farahani, S. Kadner, K. Seyboth, et al. (Cambridge; New York, NY: Cambridge University Press), 1-139.

Jarvis, P. G., and Jarvis, M. S. (1963). The water relations of tree seedlings.: IV. Some aspects of the tissue water relations and drought resistance. Physiol. Plant. 16, 501-516. doi: 10.1111/j.1399-3054.1963.tb08327.x

Karp, A., and Shield, I. (2008). Bioenergy from plants and the sustainable yield challenge. New Phytol. 179, 15-32. doi: 10.1111/j.1469-8137.2008.02432.x

Kubiske, M. E., and Abrams, M. D. (1992). Photosynthesis, water relations, and leaf morphology of xeric versus mesic Quercus rubra ecotypes in central Pennsylvania in relation to moisture stress. Can. J. For. Res. 22, 1402-1407. doi: $10.1139 / \mathrm{x} 92-186$

Kulkarni, M., and Deshpande, U. (2006). Anatomical breeding for altered leaf parameters in tomato genotypes imparting drought resistance using leaf strength index. Asian J. Plant Sci. 5, 414-420. doi: 10.3923/ajps.2006.414.420

Kuzovkina, Y. A., and Quigley, M. F. (2005). Willows beyond wet lands: uses of Salix L. species for environmental projects. Water Air Soil Pollut. 162, 183-204. doi: 10.1007/s11270-005-6272-5

Li, W.-D., Biswas, D. K., Xu, H., Xu, C.-Q., Wang, X.-Z., Liu, J.-K., et al. (2009). Photosynthetic responses to chromosome doubling in relation to leaf anatomy in Lonicera japonica subjected to water stress. Funct. Plant Biol. 36, 783-792. doi: 10.1071/FP09022

Li, W.-L., Berlyn, G. P., and Ashton, P. M. S. (1996). Polyploids and their structural and physiological characteristics relative to water deficit in Betula papyrifera (Betulaceae). Am. J. Bot. 83, 15-20. doi: 10.2307/2445949

Liu, B., and Wendel, J. F. (2003). Epigenetic phenomena and the evolution of plant allopolyploids. Mol. Phylogenet. Evol. 29, 365-379. doi: 10.1016/S10557903(03)00213-6

Liu, G., Li, Z., and Bao, M. (2007). Colchicine-induced chromosome doubling in Platanus acerifolia and its effect on plant morphology. Euphytica 157, 145-154. doi: 10.1007/s10681-007-9406-6

Lührs, R., Efremova, N., Krull, A., Löfke, C., Ning, D., Müller, A., et al. (2010). Innovative Hybridpappeln-Schnelles Wachstum für Deutschland. Conference manuscript, "Agrarholz 2010", International Conference 18.-19.05.2010 in Berlin. Available online at: http://veranstaltungen.fnr.de/fileadmin/allgemein/ pdf/veranstaltungen/Agrarholz2010/12_2_Beitrag_Luehrs.pdf [Accessed November 13, 2014].

Lührs, R., Efremova, N., Welters, P., Meier-Dinkel, A., Janßen, A., Voß, M.-M., et al. (2012). "ZÜEND-Züchtung neuer energiepappeln für deutschland," in Züchtung und Ertragsleistung schnellwachsender Baumarten im Kurzumtrieb, Conference Manuscript, "FastWOOD Symposium", National Conference 21.22.09.2011 in Hann. Muenden. 388-389.

McDowell, N., Pockman, W. T., Allen, C. D., Breshears, D. D., Cobb, N., Kolb, T., et al. (2008). Mechanisms of plant survival and mortality during drought: why do some plants survive while others succumb to drought? New Phytol. 178, 719-739. doi: 10.1111/j.1469-8137.2008.02436.x

McKendry, P. (2002). Energy production from biomass (part 1): overview of biomass. Bioresour. Technol. 83, 37-46. doi: 10.1016/S0960-8524(01)00118-3

Murashige, T., and Skoog, F. (1962). A revised medium for rapid growth and bioassays with tobacco tissue cultures. Physiol. Plant 15, 473-497. doi: 10.1111/j.1399-3054.1962.tb08052.x

Polle, A., Janz, D., Teichmann, T., and Lipka, V. (2013). Poplar genetic engineering: promoting desirable wood characteristics and pest resistance. Appl. Microbiol. Biotechnol. 97, 5669-5679. doi: 10.1007/s00253-013-4940-8

Poorter, H., Niinemets, Ü., Poorter, L., Wright, I. J., and Villar, R. (2009). Causes and consequences of variation in leaf mass per area (LMA): a meta-analysis. New Phyt. 182, 565-585, doi: 10.1111/j.1469-8137.2009.02830.x

Porter, K. B., and Weiss, M. G. (1948). The effect of polyploidy on soybeans. J. Am. Soc. of Agron. 40, 710-724.

Prange, A. N. S., Bartsch, M., Meiners, J., Serek, M., and Winkelmann, T. (2012). Interspecific somatic hybrids between Cyclamen persicum and C. coum, two sexually incompatible species. Plant Cell Rep. 31, 723-735. doi: 10.1007/s00299011-1190-z 
Puijalon, S., Bouma, T. J., Douady, C. J., van Groenendael, J., Anten, N. P. R., Martel, E., et al. (2011). Plant resistance to mechanical stress: evidence of an avoidance-tolerance trade-off. New Phyt. 191, 1141-1149. doi: 10.1111/j.14698137.2011.03763. $\mathrm{x}$

Rausher, M. D. (2007). New Phytologist on plant evolution. New Phytol. 174, 705-707. doi: 10.1111/j.1469-8137.2007.02100.x

R Core Team. (2013). R: A Language and Environment for Statistical Computing. Vienna: R Foundation for statistical Computing. Available online at: http:// www.R-project.org.

Regier, N., Streb, S., Cocozza, C., Schaub, M., Cherubini, P., Zeeman, S. C., et al. (2009). Drought tolerance of two black poplar (Populus nigra L.) clones: contribution of carbohydrates and oxidative stress defence. Plant Cell Environ. 32, 1724-1736. doi: 10.1111/j.1365-3040.2009.02030.x

Riddle, N. C., and Birchler, J. A. (2008). Comparative analysis of inbred and hybrid maize at the diploid and tetraploid levels. Theor. Appl. Genet. 116, 563-576. doi: 10.1007/s00122-007-0691-1

Sasamoto, H., Wakita, Y., Yokota, S., Yoshizawa, N., Katsuki, T., Nishiyama, Y., et al. (2006). Effects of electric cell fusion treatment among leaf protoplasts of Populus alba and Alnus firma on growth, leaf morphology, and RAPD pattern of eleven acclimatized plants. Vitro Cell. Dev. Biol. Plant 42, 174-178. doi: 10.1079/IVP2005732

Sharma, A. K., and Datta, P. C. (1957). Artificial polyploidy in coriander (Coriandrum sativum L.). Caryologia 10, 152-158. doi: 10.1080/00087114.1957.10797618

Smulders, M. J. M., van Der Schoot, J., Arens, P., and Vosman, B. (2001). Trinucleotide repeat microsatellite markers for black poplar (Populus nigra L.). Mol. Ecol. Notes 1, 188-190. doi: 10.1046/j.1471-8278.2001.00071.x

Stanturf, J. A., van Oosten, C., Netzer, D. A., Coleman, M. D., and Portwood, C. J. (2001). "Ecology and silviculture of poplar plantations," in Poplar Culture in North America, eds D. I. Dickmann, J. G. Isebrands, J. E. Eckenwalder, and J. Richardson. doi: 10.1139/9780660181455

Touchette, B. W., Smith, G. A., Rhodes, K. L., and Poole, M. (2009). Tolerance and avoidance: two contrasting physiological responses to salt stress in mature marsh halophytes Juncus roemerianus Scheele and Spartina alterniflora Loisel. J. Exp. Marine Biol. Ecol. 380, 106-112. doi: 10.1016/j.jembe.2009.08.015

Tuskan, G. A., Gunter, L. E., Yang, Z. K., Yin, T. M., Sewell, M. M., and DiFazio, S. P. (2004). Characterization of microsatellites revealed by genomic sequencing of trichocarpa. Can. J. For. Res. 34, 85-93. doi: 10.1139/x03-283

van der Schoot, J., Pospíšková, M., Vosman, B., and Smulders, M. J. M. (2000). Development and characterization of microsatellite markers in black poplar (Populus nigra L.). Theor. Appl. Genet. 101, 317-322. doi: $10.1007 / \mathrm{s} 001220051485$ van Laere, K., França, S. C., Vansteenkiste, H., Huylenbroeck, J., Steppe, K., and Labeke, M.-C. (2010). Influence of ploidy level on morphology, growth and drought susceptibility in Spathiphyllum wallisii. Acta Physiol. Plant. 33, 1149-1156. doi: 10.1007/s11738-010-0643-2

Viereck, L. A., Cleve, K. V., and Dyrness, C. T. (1986). "Forest ecosystem distribution in the taiga environment," in Forest Ecosystems in the Alaskan Taiga. Ecological Studies, eds K. V. Cleve, F. S. C. III, P. W. Flanagan, L. A. Viereck, and C. T. Dyrness (New York, NY: Springer), 22-43. Available online at: http://link.springer.com/chapter/10.1007/978-1-4612-4902-3_3 [Accessed November 26, 2014].

von Wühlisch, G. (2012). Poplars and Willows in Germany: Report of the National Poplar Commission. Available online at: http://www.bmel.de/SharedDocs/ Downloads/EN/Publications/PoplarsReport.pdf?_blob=publicationFile [Accessed October 16, 2014].

Weih, M. (2004). Intensive short rotation forestry in boreal climates: present and future perspectives. Can. J. For. Res. 34, 1369-1378. doi: 10.1139/x04-090

Weih, M., Hoeber, S., Beyer, F., and Fransson, P. (2014). Traits to ecosystems: the ecological sustainability challenge when developing future energy crops. Front. Energy Res. 2:17. doi: 10.3389/fenrg.2014.00017

Wood, S. N. (2011). Fast stable restricted maximum likelihood and marginal likelihood estimation of semiparametric generalized linear models. J. R. Statis. Soc. 73, 3-36. doi: 10.1111/j.1467-9868.2010.00749.x

Xiong, Y.-C., Li, F.-M., and Zhang, T. (2006). Performance of wheat crops with different chromosome ploidy: root-sourced signals, drought tolerance, and yield performance. Planta 224, 710-718. doi: 10.1007/s00425-006-0252-x

Yang, F., and Miao, L.-F. (2010). Adaptive responses to progressive drought stress in two poplar species originating from different altitudes. Silva Fennica 44, 23-37. doi: 10.14214/sf.160

Yemm, E. W., and Willis, A. J. (1954). The estimation of carbohydrates in plant extracts by anthrone. Biochem. J. 57, 508-514.

Conflict of Interest Statement: The authors declare that the research was conducted in the absence of any commercial or financial relationships that could be construed as a potential conflict of interest.

Copyright (C) 2015 Hennig, Kleinschmit, Schoneberg, Löfler, Janßen and Polle. This is an open-access article distributed under the terms of the Creative Commons Attribution License (CC BY). The use, distribution or reproduction in other forums is permitted, provided the original author(s) or licensor are credited and that the original publication in this journal is cited, in accordance with accepted academic practice. No use, distribution or reproduction is permitted which does not comply with these terms. 